\title{
Intensive and home hemodialysis : acute effects and long-term outcomes
}

Citation for published version (APA):

Cornelis, T. (2015). Intensive and home hemodialysis : acute effects and long-term outcomes. [Doctoral Thesis, Maastricht University]. Datawyse / Universitaire Pers Maastricht. https://doi.org/10.26481/dis.20150610tc

Document status and date:

Published: 01/01/2015

DOI:

$10.26481 /$ dis.20150610tc

Document Version:

Publisher's PDF, also known as Version of record

\section{Please check the document version of this publication:}

- A submitted manuscript is the version of the article upon submission and before peer-review. There can be important differences between the submitted version and the official published version of record.

People interested in the research are advised to contact the author for the final version of the publication, or visit the DOI to the publisher's website.

- The final author version and the galley proof are versions of the publication after peer review.

- The final published version features the final layout of the paper including the volume, issue and page numbers.

Link to publication

\footnotetext{
General rights rights.

- You may freely distribute the URL identifying the publication in the public portal. please follow below link for the End User Agreement:

www.umlib.nl/taverne-license

Take down policy

If you believe that this document breaches copyright please contact us at:

repository@maastrichtuniversity.nl

providing details and we will investigate your claim.
}

Copyright and moral rights for the publications made accessible in the public portal are retained by the authors and/or other copyright owners and it is a condition of accessing publications that users recognise and abide by the legal requirements associated with these

- Users may download and print one copy of any publication from the public portal for the purpose of private study or research.

- You may not further distribute the material or use it for any profit-making activity or commercial gain

If the publication is distributed under the terms of Article $25 \mathrm{fa}$ of the Dutch Copyright Act, indicated by the "Taverne" license above, 


\section{INTENSIVE and HOME HEMODIALYSIS}

Acute Effects and Long-Term Outcomes

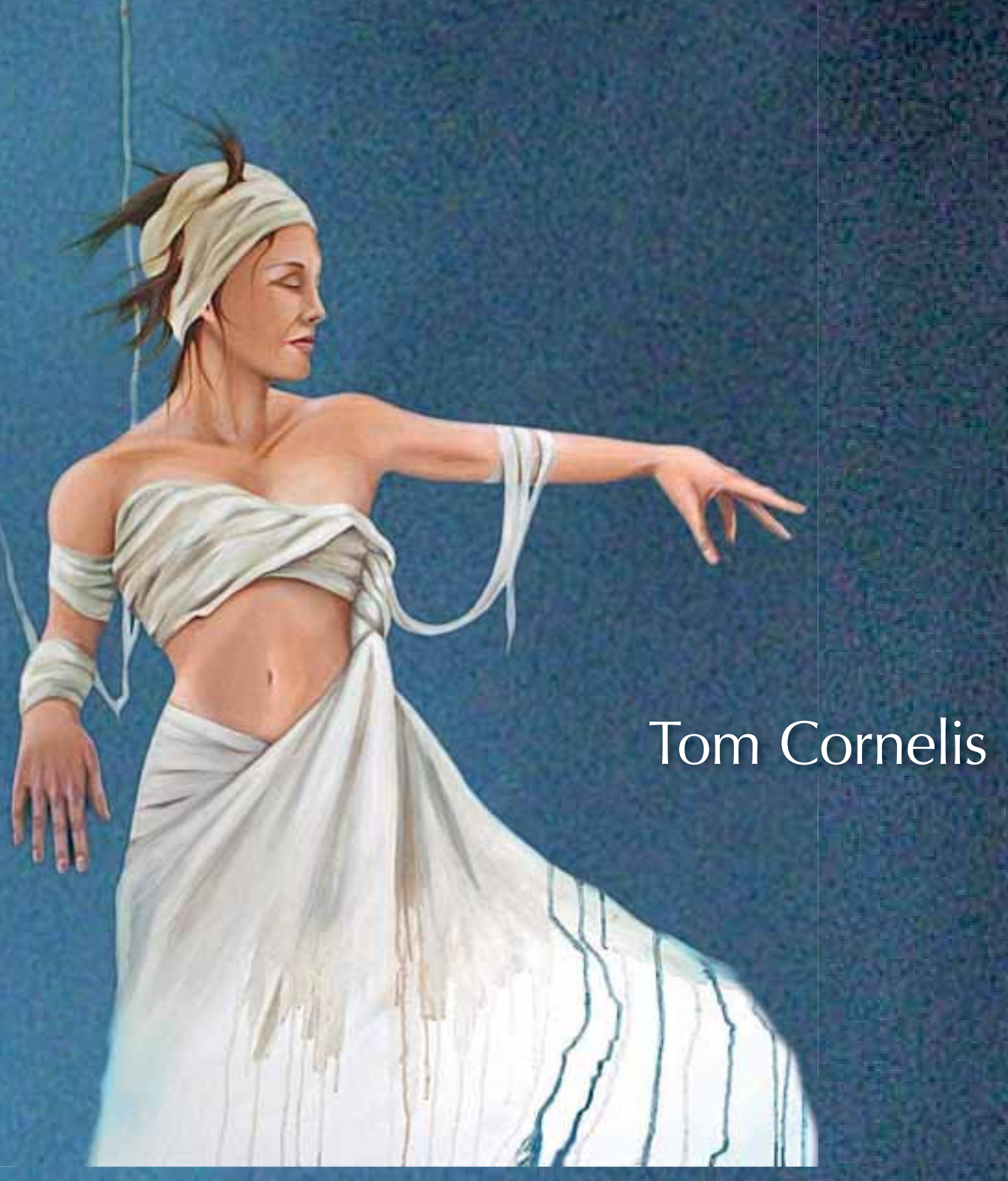


${ }^{\circ}$ Copyright Tom Cornelis, Maastricht 2015

Layout: Tiny Wouters

Cover: Fabiano Peltrera ("Freedom")

Printed by: Datawyse B.V.

ISBN: 9789461594402

The first part of the acute INTHEM 0 study (chapter 2) was funded by an unrestricted grant from Fresenius Medical Care. The second part of the acute INTHEMO study (chapter 3) was supported by research grants from Fresenius Medical Care, Baxter Healthcare, Bellco, and Nipro. The study presented in chapter 6.3 was financially supported by Baxter Healthcare.

Printing of the thesis was financially supported by an unrestricted grant from Fresenius Medical Care. 


\section{INTENSIVE and HOME}

\section{HEM ODIALYSIS}

\section{Acute Effects and Long-Term Outcomes}

\section{ACADEMISCH PROEFSCHRIFT}

ter verkrijging van de graad van doctor aan de Universiteit M aastricht, op gezag van de Rector Magnificus, Prof. dr. L.L.G. Soete volgens het besluit van het College van Decanen,

in het openbaar te verdedigen op woensdag 10 juni 2015, om 12:00 uur.

door

Tom Cornelis

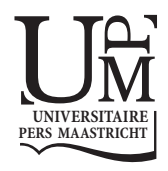




\section{Promotores}

Prof. dr. J.P. Kooman

Prof. dr. K.M . Leunissen

\section{Copromotores}

Prof. dr. C.T. Chan (University of Toronto, Canada)

Dr. F.M. van der Sande

\section{Beoordelingscommissie}

Prof. dr. H. ten Cate (voorzitter)

Prof. dr. W. Van Biesen

Dr. C.J. Konings

Prof. dr. J.M.G.A. Schols

Prof. dr. C.D.A. Stehouwer 




\section{Table of contents}

Chapter 1 General introduction and outline of the thesis 9

PART I ACUTE EFFECTS OF INTENSIVE HEM ODIALYSIS 31

Chapter 2 Acute hemodynamic response and uremic toxin removal in 33 conventional and extended hemodialysis and hemodiafiltration: a randomized crossover study

Chapter 3 Protein-bound uremic toxins, dicarbonyl stress and AGEs in conventional and extended hemodialysis and hemodiafiltration

Part II LONG-TERM OUTCOMES OF INTENSIVE AND HOME HEMODIALYSIS

Chapter 4 Home dialysis is a successful strategy in nonrenal solid organ 69 transplant recipients with end-stage renal disease

Chapter 5 Effects of intensive and home hemodialysis on fertility and pregnancy

5.1 Intensive hemodialysis associates with improved pregnancy outcomes: a Canadian and United States cohort comparison

5.2 Fertility and obstetrical follow-up in intensive home 99 hemodialysis

5.3 Antiangiogenic factors and maternal hemodynamics during 109 intensive hemodialysis in pregnancy

Chapter 6 The role of intensive and home hemodialysis in geriatric ESRD

6.1 Can intensive hemodialysis prevent loss of functionality in the elderly ESRD patient?

6.2 Intensive hemodialysis in the (nursing) home: the bright side of geriatric ESRD care?

6.3 An international feasibility study of home hemodialysis in older patients

Chapter 7 Vascular access vulnerability in intensive hemodialysis: a significant Achilles' heel?

Chapter 8 Summary, conclusions and future perspectives

Samenvatting

List of abbreviations

Valorisation

Dankwoord

Curriculum Vitae 



\section{Chapter 1}

General introduction and outline of the thesis 



\section{General characteristics}

The final stages of kidney failure [known as end-stage renal disease (ESRD)] reduce survival and quality of life, but can be treated with renal replacement therapy (RRT). Kidney transplantation, especially living donation, offers the best outcomes but is not always possible, and even suitable transplantation candidates often have to wait a long time before kidney transplantation may take place. The alternative to kidney transplantation is dialysis. Currently, most dialysis patients are treated with hemodialysis (HD), whereby blood from the patient is cleaned by an artificial kidney. As illustrated in Figure 1.1, blood is drawn from the vascular access (which may be an arteriovenous fistula, graft or dialysis catheter), and subsequently pumped through the extracorporeal system including dialysis lines and the dialysis membrane, and finally given back to the vascular access of the patient.

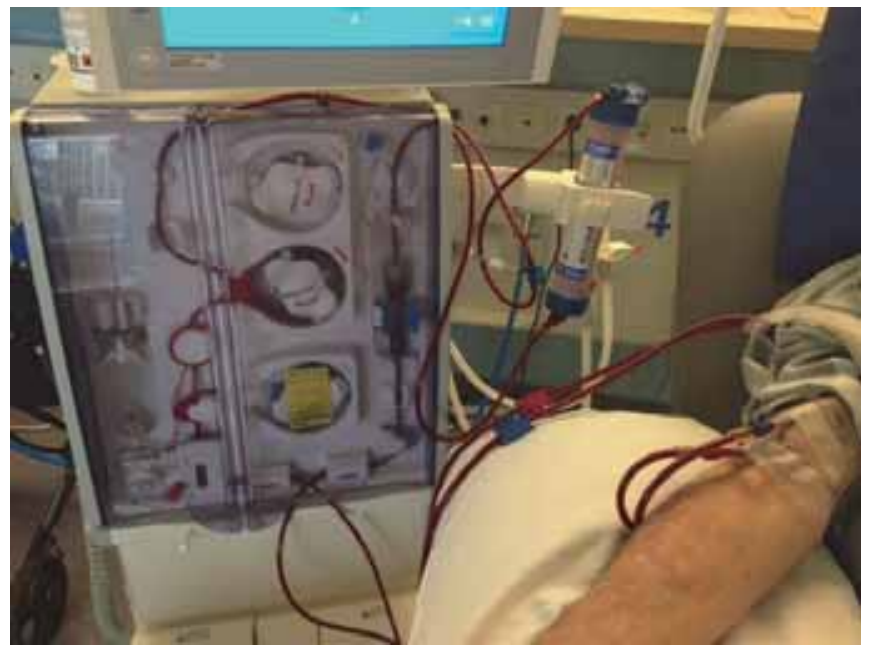

Figure 1.1 In hemodialysis, blood is drawn from the vascular access, and subsequently pumped through the extracorporeal system for cleaning and ultrafiltration, and finally given back to the vascular access of the patient.

Cleansing of the blood occurs in HD via diffusion of uremic toxins from the blood (high concentration of uremic toxins) to the dialysate (low concentration of uremic toxins) flowing countercurrently of the blood through a semi-permeable dialysis membrane (Figure 1.2). Removal of excess fluid occurs by applying a positive pressure gradient between the blood and dialysate compartment. Additionally, cleansing may take place via convection whereby toxins are displaced from blood to dialysate via the mechanism of solvent drag, a dialysis technique which is called hemofiltration (Figure 1.3). If HD is 
combined with hemofiltration, this dialysis technique is called hemodiafiltration (HDF). Another, less frequently used, dialysis modality is peritoneal dialysis (PD), whereby removal of toxic waste products and excess fluid occurs across the peritoneal membrane after instillation of PD solution into the peritoneal cavity (Figure 1.4). The instillation of PD fluid into the abdomen may be performed manually by a four or five long-term rinsing scheme divided over the whole day [continuous ambulatory PD (CAPD)]. The second PD modality is automated PD (APD), whereby a cycler automatically performs the instillation and exchanges during the night with a last fill for the day dwell of the PD solution.

\section{Diffusion}

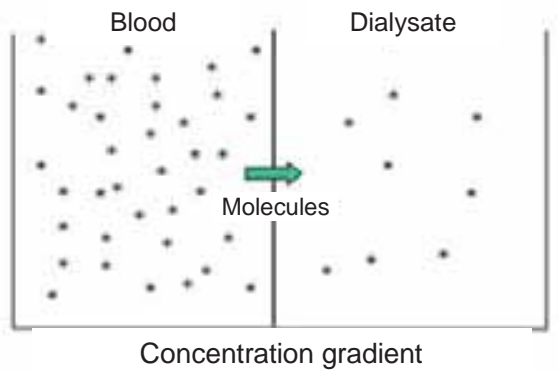

Figure 1.2 The solute transport principle on which hemodialysis is based is dittusion, which corresponds to a passive transfer of solutes through a semipermeable membrane, from blood to dialysate along each molecule's (solute's) concentration gradient.

\section{Convection}

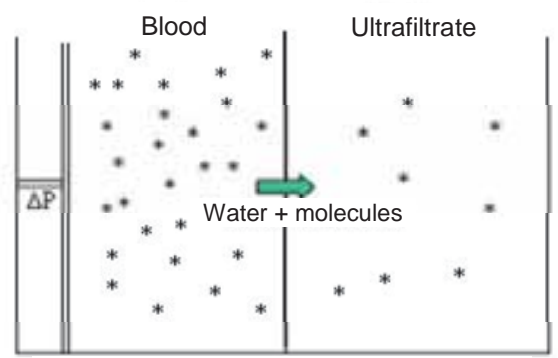

Hydrostatic pressure gradient

Figure 1.3 The transmembrane pressure ( $\Delta \mathrm{P}=$ hydrostatic pressure gradient) existing from one side of the hemofilter to the other leads to the passage of solvent (plasma water), bringing with it the passive flow of solutes it contains (solvent drag). 

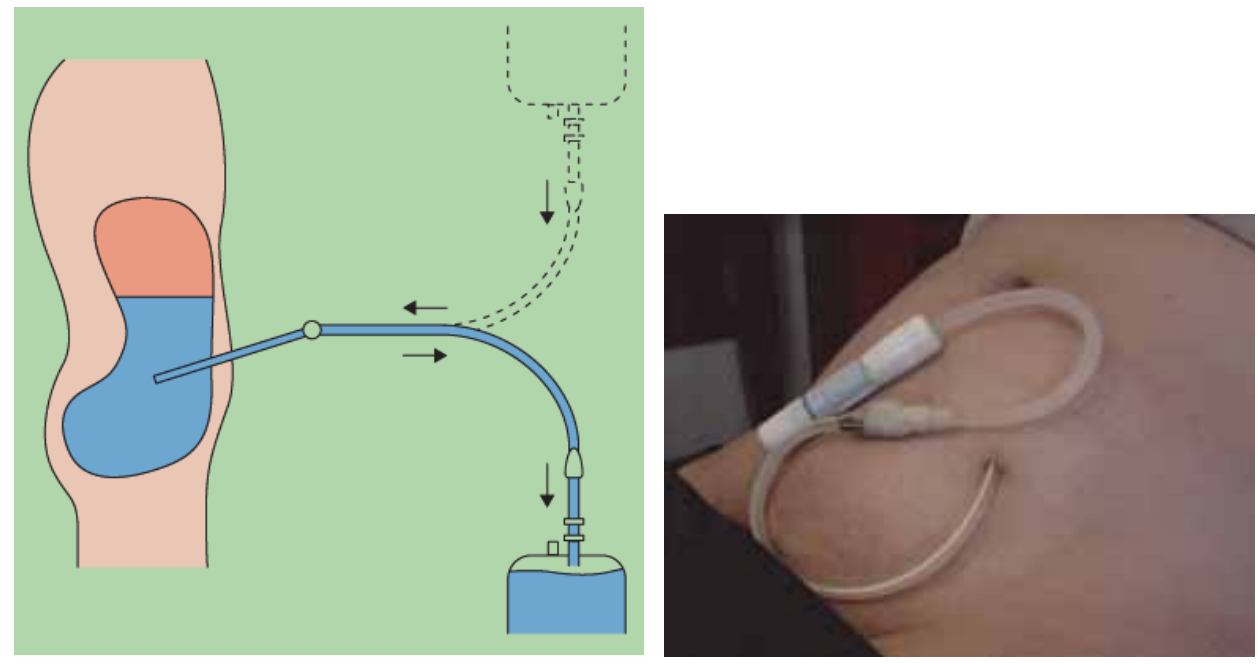

Figure 1.4 Peritoneal dialysis (PD) uses the patient's peritoneum in the abdomen as a membrane across which fluids and dissolved substances are exchanged from the blood. Dialysate fluid is introduced through a permanent tube in the abdominal cavity and flushed out either every night while the patient sleeps [automated peritoneal dialysis (APD)] or via regular exchanges throughout the day [continuous ambulatory peritoneal dialysis (CAPD)].

Available for 70 years, globally, more than 2 million people receive dialysis for chronic kidney disease (CKD). Nevertheless, albeit life sustaining, HD performed in the traditional, thrice-weekly regime, which is worldwide the most commonly used dialysis technique, is unsatisfactory with a 7 -fold increase in mortality compared to the general population, suboptimal quality of life (QoL), and high economic burden to society ${ }^{1,2}$. In contrast to the native kidneys, $\mathrm{HD}$ is performed on an intermittent basis, which leads to unphysiologic fluctuations in the internal milieu of the patient. Furthermore, dialysis techniques are less efficient than the native kidneys for the clearance of larger uremic toxins. The increased mortality in the dialysis population is mainly due to an increased risk of cardiovascular events, although infectious complications also play a significant role 3,4

The increased cardiovascular risk of dialysis patients at short term is mainly based on the occurrence of intra-dialytic hypotension, acute cardiac events including myocardial infarction and arrhythmias, as well as myocardial stunning ${ }^{5-7}$. Hypotension is the most common acute complication during HD. The pathophysiology of intra-dialytic hemodynamic instability is multifactorial, and includes underlying ischemic and valvular heart disease, left ventricular hypertrophy (LVH) and diastolic dysfunction, autonomic 
nervous system and baroreceptor sensitivity impairment, and impaired vascular refilling from the interstitial compartment due to arterial stiffness and hypoalbuminemia ${ }^{8-10}$. Also, the reduced neuro-vegetative reactivity blunts the peripheral venous constriction and hence lowers the amount of venous blood returning to the heart ${ }^{9}$, and it also blunts the heart rate response to acute hypotension and bradycardia may develop as hypovolemia ensues (Bezold-Jarisch reflex) ${ }^{10}$. Last, impaired vascular reactivity due to increased core temperature secondary to HD may play a role in intra-dialytic hemodynamic instability ${ }^{11}$. Especially in patients with pre-existing cardiac and/or cerebrovascular disease, hypotension may even ensue in serious complications such as myocardial or cerebral ischemia.

At the long term, dialysis patients suffer from LVH, cardiovascular calcifications, global systolic dysfunction due to repetitive myocardial stunning, as well as arterial hypertension ${ }^{7,12,13}$. The presence of LVH is important clinically because it is associated with heart failure, cardiac arrhythmias, fatal myocardial infarction, decreased left ventricular ejection fraction, sudden cardiac death, and cerebrovascular events. In general, the development of heart failure with LVH results from depressed left ventricular systolic function and/or diastolic dysfunction. Risk factors for the development of LVH in CKD patients include anemia, hypertension, ischemic heart disease, and aging. Furthermore, dialysis patients are often confronted with fluid overload especially when they are anuric. Also, it has been elegantly demonstrated that the long inter-dialytic interval (between the HD session on Friday and Monday or between the HD session on Saturday and Tuesday for the thrice-weekly HD regimens) is associated with an increased risk of cardiovascular mortality ${ }^{14}$.

Data are conflicting regarding the effects on morbidity and mortality of HDF versus HD in dialysis patients. Some studies suggested that conventional hemofiltration and HDF represent the best intermittent RRT for cardiovascular stability, resulting in a reduction of intra-dialytic hypotension compared to $H D^{15,16}$. Others have shown that in low temperature HD the same hemodynamic stability can be achieved as in hemofiltration and $\mathrm{HDF}^{11,17}$. Also, at the long term, HDF may reduce cardiovascular morbidity and mortality by reducing the levels of uremic toxins and by decreasing the incidence of intra-dialytic hypotension and the severity of LVH, but data from different studies show discordant results on this topic ${ }^{16,18}$.

\section{What is intensive (home) hemodialysis?}

Most HD patients are dialyzed these days in the hospital 3 times a week for 4 hours per session (conventional HD). Although its origins go back to the sixties of the previous 
century, home HD is undergoing a significant revival over the last 20 years ${ }^{19}$. This resurgence is related to a bunch of observational data showing several benefits of home HD compared to conventional HD, including improved patient survival, better QoL and reduced costs ${ }^{20-22}$. Also, home HD increases the flexibility of the patient, and it allows patient exposure to different treatment regimens.

If $\mathrm{HD}$ is performed in an intensive setting (intensive HD), benefits on uremia control, survival and QoL may even further increase. Charra et al. in Tassin reported dramatically improved survival of dialysis patients by extending the duration of thriceweekly in-centre $H D^{23}$. Intensive HD refers to $H D$ with an increase in dialysis frequency (number of days per week) and/or session length above a standard conventional regimen of thrice-weekly 4-hour HD. There are 3 predominant intensive HD schedules that are commonly identified; 1 . Short-daily HD (SDHD) is performed 5 to 6 days per week with shorter HD duration (2 to 3 hours) as in conventional HD; 2. Long HD refers to an increased duration of the dialysis session; and 3. Long-frequent HD involves an increase in both frequency and length of the session. Both long and long-frequent HD can be provided overnight while the patient sleeps [nocturnal HD (NHD)]. SDHD and NHD can be delivered in the hospital, but preferably patients on intensive HD are dialyzed in the home setting (intensive home HD) in order to avoid frequent transport to the hospital or dialysis centre. A summary of typical dialysis frequencies, session duration and blood and dialysate flows for conventional and intensive HD is presented in Table $1.1^{24}$.

Table 1.1 Intensive HD regimens (adopted from reference 24)

\begin{tabular}{lcccc}
\hline & Conventional HD & SDHD & Long HD & Long-frequent HD \\
\hline Frequency & 3 & $5-6$ & $3-4$ & $5-6$ \\
Duration & 4 & $2-3.5$ & $>5.5$ & $>5.5$ \\
Dialysate Flow & $500-800$ & $500-800$ & $300-500$ & $300-500$ \\
Blood Flow & $300-400$ & 400 & $200-400$ & $200-300$ \\
Std Kt/V & 2.5 (12hea $/$ week) & 3.75 (13.5h/week) & $3.75(26.8 \mathrm{~h} /$ week $)$ & 5.82 (40.2h/week) \\
\hline
\end{tabular}

HD: hemodialysis; SDHD: short daily HD; Std Kt/V: standardized Kt/V. Frequency in sessions per week; duration in hours per session; dialysate and blood flow in $\mathrm{ml} / \mathrm{min}$.

\section{Clinical benefits of intensive HD}

As described above, the complications of conventional intermittent HD may be related to the often dramatic changes in the internal milieu associated with thrice-weekly HD treatments. More frequent and/or longer HD sessions may reduce the severity of internal environment disturbance by more physiologic correction of the internal mileu, 
by optimization of fluid and uremic toxin removal, and by avoidance of the long interdialytic interval. A summary of the ample benefits of intensive HD is presented in Table $1.2^{25}$.

Table 1.2 Clinical benefits of intensive HD (Adopted from reference 25).

\begin{tabular}{lcc}
\hline & NHD & SDHD \\
\hline Blood pressure & $H+$ (PVR reduction) & + (ECV reduction) \\
LVH & $H$ (afterload reduction) & + (preload reduction) \\
LV systolic function & $+H$ & $?$ \\
Arterial compliance & $+H$ & $?$ \\
Sleep apnea & ++ & $?$ \\
Autonomic nervous system & + & f (dialysis duration) \\
Phosphate & + & + \\
Anemia & + & + \\
Malnutrition & $+(\mathrm{CRP}, \mathrm{IL}-6)$ & $+(\mathrm{CRP})$ \\
Inflammation & + & $?$ \\
Cognition & + & $?$ \\
Fertility & + & + \\
Quality of life & & + \\
\hline
\end{tabular}

NHD: nocturnal HD; SDHD: short daily HD; PVR: peripheral vascular resistance; ECV: effective circulating volume; LVH: left ventricular hypertrophy; f: function; CRP: C-reactive protein; IL-6: interleukin-6

Several studies have evaluated survival in SDHD and NHD. However, no well-powered randomized controlled trial (RCT) has been performed so far. Observational data show better patient survival rates for SDHD and NHD patients as compared to conventional $\mathrm{HD}^{26-33}$. In addition, SDHD and NHD cohorts have equal survival rates as compared to deceased donor transplant recipients ${ }^{34,35}$, although in the most recent retrospective cohort study of intensive home HD patients and kidney transplant recipients, kidney transplantation was associated with superior treatment and patient surviva $\left.\right|^{36}$.

Blood pressure (BP) reduction is one of the most consistent benefits of intensive HD in randomized and non-randomized studies ${ }^{37-43}$. One of the first reports of improved BP control by means of intensive HD came from Tassin in France where an inverse correlation between mean BP measured by ambulatory BP monitoring and duration of dialysis session was found ${ }^{44}$. The Frequent Hemodialysis Network (FHN) study showed a significant reduction in systolic BP among the NHD cohort after 12 months of -9.7 $(-16.9,-2.5) \mathrm{mmHg}$ with a significant decrease in antihypertensive agents. No difference was seen in the patients on conventional $H D$ at the home setting, illustrating the importance of intensive HD (and not only of location) for BP control ${ }^{40}$. NHD reduces BP by lowering total peripheral resistance and plasma norepinephrine levels ${ }^{42,43}$. SDHD also improves BP control, but the speculated mechanism is here via reduction in fluid overload $^{39}$. 
Observational studies of $\mathrm{SDHD}^{39,45}$ and $\mathrm{NHD}^{37,39}$ cohorts as well as one RCT of NHD ${ }^{46}$ have reported improvement in left ventricular mass index as a marker of LVH, which is associated with infaust cardiovascular outcomes in CKD and dialysis patients. A recent meta-analysis of observational studies and data from RCT's looking at the effects of both frequent and extended HD on left ventricular geometry, reported improvement in left ventricular mass index in both groups ${ }^{47}$. Furthermore, Jefferies et al. demonstrated, in a cross-sectional study, that more frequent HD regimens were associated with lower ultrafiltration volumes and rates compared with conventional in-centre HD. Intradialytic fall in systolic BP was reduced in SDHD groups and abolished in the NHD group. Frequent HD regimes were associated with less dialysis-induced myocardial stunning compared with conventional $\mathrm{HD}^{48}$.

Optimization of phosphate and mineral metabolism control, which is also associated with LVH, vascular calcifications and cardiovascular outcomes in dialysis patients, is described with extended $\mathrm{HD}$ and, to a minor extent, with $\mathrm{SDHD}^{40,46,50}$. Long-frequent $\mathrm{HD}$ patients can most often be taken off phosphate binding drugs, and frequently require phosphate supplementation through the dialysate. In the long term, improved control of hyperphosphatemia and secondary hyperparathyroidism by intensive HD may result in reduced risk of LVH and vascular calcifications.

The impact of intensive HD on QoL has been the subject of multiple studies, and overall results show an increase in kidney-specific domains of QoL-parameters ${ }^{38,46,51-53}$. QoL in intensive HD may increase due to increased autonomy and functionality, reduced pill burden, liberalisation of diet and fluid intake, elimination of transport time (in casu home HD), continuation of employment, and reduction of uremic symptoms. In addition to QoL, mood improvement can be seen with intensive HD at the home setting ${ }^{46}$.

Both SDHD and NHD have demonstrated improved sleep quality. The FREEDOM study showed a decreased prevalence of restless legs syndrome from 35 to $26 \%$ after 12 months of SDHD $(P=0.05)^{54}$. NHD has been associated with a reduction in the frequency of sleep apnea episodes ${ }^{55}$.

Conception rates and outcomes of pregnancies are poor in patients on dialysis. Observational data show better outcomes in patients dialyzing more than 12 hours per week and in patients with lower urea levels ${ }^{56,57}$. In this context, intensive HD seems associated with the best pregnancy outcomes in patients requiring dialysis ${ }^{58}$. It is postulated that intensive HD may partially restore the pituitary-hypothalamic axis by increasing toxin clearance. Also, a better control of fluid status and BP could have beneficial effects on pregnancy. In men, intensive HD could improve fertility by increasing testosterone level and decreasing hyperprolactinemia ${ }^{59}$. 


\section{Risks of intensive hemodialysis}

Frequent HD may potentially lead to more vascular access complications due to more frequent cannulation. In the FHN trial, patients on SDHD had a shorter time to first vascular access event compared with the conventional HD group ${ }^{60,61}$. Most of these events were vascular access repairs as opposed to losses. A similar trend was found in the nocturnal arm of the FHN study ${ }^{40,61}$.

The rope-ladder technique is the predominant cannulation method of arteriovenous fistulas and grafts (Figure 1.5). For every HD, two new sites are chosen for needle placement to allow good healing of the puncture wound. Buttonhole (constant-site) cannulation is an alternative technique whereby needles are inserted each time at exactly the same spot using the same insertion angle and the same depth of penetration for each consecutive dialysis session (Figure 1.5). Buttonhole cannulation is commonly used in frequent HD because it may result in decreased pain, faster cannulation and lower risk of hematoma ${ }^{51,62,63}$. However, concerns have been raised recently regarding the safety of this method, especially at the level of infections. Several studies have indeed highlighted the increased risk of local and systemic buttonhole infections in patients on intensive $H D^{51,64,65}$.

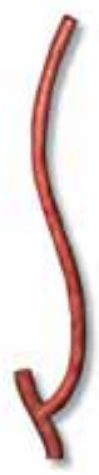

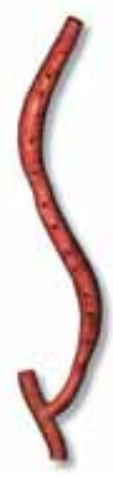

A

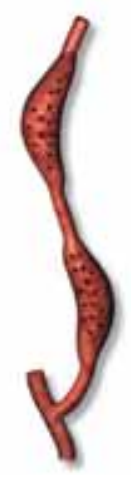

B

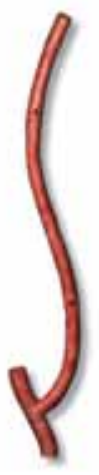

C

Figure 1.5 A. Rope ladder technique B. Area technique C. Butttonhole technique. (Copyright Eric Lemmens - D\&L graphics)

Residual kidney function (RKF) in dialysis patients is associated with clinical benefits ${ }^{66}$. A significant decline in RKF is observed in the first year after dialysis initiation, especially in conventional HD patients ${ }^{67}$. Recently, the nocturnal FHN study showed a faster reduction in RKF in patients on NHD as compared to conventional $\mathrm{HD}^{68}$. This may be 
related to increased changes in BP and fluid state, reduction in osmotic load and possible increased inflammatory response and platelet activation ${ }^{69}$. More studies are required to confirm the finding of faster RKF loss in intensive HD, and also to elucidate the potential underlying mechanisms for this observation.

\section{Who is eligible for intensive and home hemodialysis?}

Patient motivation is essential for the feasibility of intensive home HD. In this setting, there are few absolute contraindications for this treatment such as lack of suitable vascular access (in casu intensive HD), uncontrolled psychosis and lack of caregiver (if the patient is dependent and if there is no availability of dialysis nurses) (in casu home $\mathrm{HD})^{70}$.

Lack of motivation/interest, unwillingness to change, learned helplessness, fear of isolation, perceived burden on caregivers and fear of cannulation, are known barriers to home $\mathrm{HD}^{71-73}$. However, these barriers can often be overcome by adequate pre-dialysis education, motivational training of patient and caregiver, nurse-assisted cannulation, nurse-led home visits, a well-defined nursing/technical support system for patients, and provision of respite care ${ }^{74-76}$.

\section{Target populations for intensive (home) hemodialysis}

In a recent overview article, Tennankore et al. classified target populations for intensive home HD in established, suggested and emerging indications for this modality (Figure 1.6 $)^{77}$. Patients who present with persistent extracellular fluid overload, severe hypertension and/or LVH, and resistant hyperphosphatemia are established candidates for intensive HD. Sleep apnoea, reduced QoL, uremic symptoms, and also (desire for) pregnancy should also trigger the initiation of intensive HD in the dialysis patient (suggested target populations). In addition to these potential target populations, there are emerging patient populations for whom intensive home HD may also be considered. Emerging patient populations range from caregiver-dependent patients because patients and caregivers generally prefer a home-based dialysis therapy ${ }^{78,79}$, crash starters ${ }^{80}$, employed patients ${ }^{81}$, transplant and PD failures ${ }^{82}$, and morbid obesity $^{83}$. Also, one case with severe hyperoxaluria who benefitted from frequent NHD has been described in the literature ${ }^{84}$. 


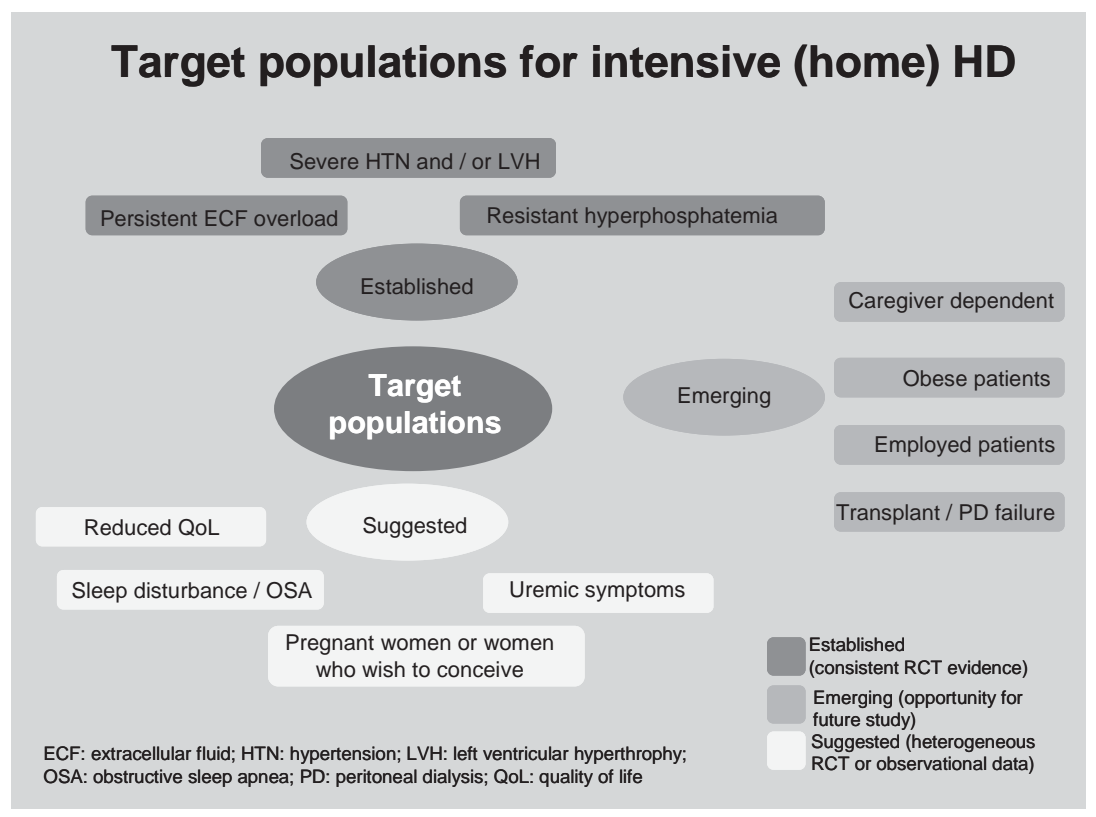

Figure 1.6 Target populations for intensive (home) HD (adapted from ref. 77)

\section{Outline of the thesis}

As described above, intensive home HD has a number of important clinical benefits as compared to in-centre conventional HD. However, intensive HD also associates with risks and barriers. Both clinical benefits and risks-barriers of intensive (home) HD represent an opportunity for ongoing research and quality improvement initiatives to further stimulate the adoption of intensive home HD in the general dialysis population as well as in specific patient groups. In this context, we decided to study both acute effects and long-term outcomes of intensive and home HD.

For the first part of this thesis comparing the acute effects of conventional and extended dialysis, we decided to look at two major changes which happen during dialysis. The first important effect of HD on dialysis patients is the hemodynamic effect. Conventional HD often results in hemodynamic changes such as intra-dialytic hypotension, intravascular volume depletion due to impaired refilling of the intravascular compartment out of the extravascular compartment, and myocardial stunning resulting in global systolic dysfunction at the long-term ${ }^{6,85,86}$. From previous studies, it is unclear whether HDF may have a protective effect on cardiovascular 
complications compared to HD. Recent studies suggest that cool HD has similar effects as HDF on hemodynamic stability. We decided to perform a detailed hemodynamic evaluation during 4 different dialysis modalities including conventional HD, conventional HDF, extended HD, and extended HDF. We assessed intra-dialytic changes of peripheral and central systolic and diastolic BP, cardiac output (CO), peripheral vascular resistance, peripheral microcirculation, as well as relative blood volume (RBV) and energy balance.

The second important effect of HD on dialysis patients is the removal and clearance of uremic toxins. Accumulation of uremic toxins is associated with morbidity and mortality in ESRD patients. Uremic toxins are divided into three classes; the small molecular weight (MW) ( $<500 \mathrm{Da})$ toxins (such as urea, creatinine, phosphate) with no known protein binding, the middle molecules such as beta2-microglobulin (B2M) and Fibroblast Growth Factor-23 (FGF-23) ( $>500 \mathrm{Da}$ ), and toxins with known protein binding $^{87}$. Among the uremic toxins in the middle molecule range, B2M is certainly one of the most frequently studied compounds ${ }^{88}$. Another novel middle molecule is FGF-23, an emerging uremic toxin with possible relevance for cardiovascular morbidity and mortality ${ }^{89,90}$.

Protein-bound uremic toxins (PBUT) contain a wide variety of toxins, but evidence regarding toxicity, as well as relation with outcome, is predominantly available for the indole and phenol-type toxins, such as indoxyl sulphate (IS), p-cresylsulphate (PCS) and $p$-cresylglucuronide $(P C G)^{91-97}$. These toxins are derived from intestinal fermentation products of tryptophane and tyrosine, respectively. In vitro studies showed diversity in toxic effects of these substances, especially in relation to inflammation, oxidative stress, endothelial damage and renal fibrosis ${ }^{91-93,98,99}$. Other members of this class, with somewhat less evidence regarding their toxicity, are indole-3-acetic acid (IAA), 3-carboxyl-4-methyl-5-propyl-2-furanpropionic acid (CM PF) and hippuric acid (HA) $)^{100}$. Increased levels of Advanced glycation end-products (AGEs) have also been reported to accelerate atherosclerosis, cardiovascular morbidity and mortality as well as dysregulation of the immune system ${ }^{101-103}$. AGEs, such as N-carboxymethyl-lysine $(\mathrm{CML})$, pentosidine, and methylglyoxal (MG) derivatives, are produced by nonenzymatic reactions of sugars with free amino groups on proteins, peptides, or amino acids $^{104}$. They may also originate from other pathways such as oxidation of sugars, lipids and amino acids to create reactive aldehydes. AGEs cause tissue damage by protein cross-linking and altered protein structure and function, but they also activate AGEspecific receptors which triggers pro-inflammatory and oxidative stress pathways. Dialysis patients, even if they are not diabetic, have an increased level of AGEs; this is not only due to decreased clearance of AGEs, but increased endogenous AGE formation caused by oxidative stress may also contribute. Furthermore, reactive dicarbonyl 
compounds play a role in the generation of pentosidine in uremic patients ${ }^{105}$. Several reviews have elucidated the detrimental role of AGEs in end-organ damage in dialysis patients $^{106,107}$.

Whereas conventional HD is effective in removing small MW uremic toxins, it is less efficient in removing middle molecules and protein-bound toxins ${ }^{91,92}$. Some studies suggested improved removal of middle molecules and PBUT with HDF. Improved removal of uremic toxins such as the middle molecules B2M and FGF-23 but also of PBUT, AGEs, and dicarbonyl stress compounds, may partially explain why patients on intensive HD have improved outcomes compared to patients on conventional HD.

In the second part of the thesis, we opted to study long-term outcomes of intensive and home HD. We decided to study three vulnerable dialysis populations. The first group are patients who developed ESRD after non-renal solid organ transplantation (NRSOT). These patients often have multiple co-morbidities such as arterial hypertension, diabetes mellitus, and coronary artery disease, which are all risk factors for cardiovascular mortality. Heterogeneous results favoring different dialysis modalities provide no uniform recommendation for this vulnerable patient population, and no study had evaluated the possibility of home HD in patients who develop ESRD after NRSOT.

The second patient group of dialysis patients we studied, are women with ESRD who want to become pregnant or who are pregnant. The first successful pregnancy reported in a patient on chronic HD occurred in 1970, and was considered an overwhelming success ${ }^{108}$. Initial enthusiasm was tempered with subsequent studies noting pregnancy in women with ESRD to be uncommon due to decreased fertility, and often associated with poor outcomes including decreased live birth rate, low birth weight, and preeclampsia ${ }^{109,110}$. However, recent data showed that frequent NHD, as an intensive dialysis modality, resulted in reduced maternal and fetal complications in pregnant ESRD patients ${ }^{111}$.

The third and last group of vulnerable ESRD patients studied in this thesis, are older patients on dialysis. The number of elderly patients with ESRD requiring dialysis initiation is steadily increasing ${ }^{112,113}$. ESRD and dialysis initiation in elderly are often accompanied by loss of independence ${ }^{114,115}$. This suggests that elderly patients are less likely to overcome events occurring around the time of dialysis initiation as compared to younger patients. The events leading to functional decline may include dialysisrelated hypotension, cerebral and cardiac events, as well as malnutrition and increased infection risk. 
In the last chapter of the second part of the thesis, we opted to study one of the potential barriers of intensive HD, and we reviewed available studies assessing vascular access complications in comparison with conventional HD.

These considerations gave rise to the formulation of the following investigational aims of the thesis:

\section{PART I: ACUTE EFFECTS OF INTENSIVE HEM ODIALYSIS}

a. To study and compare acute hemodynamic effects (BP, cardiac output, relative blood volume, microcirculation, thermal balance) and uremic toxin (small solutes and middle molecules) removal in conventional and extended dialysis techniques (CHAPTER 2)

b. To investigate the removal and clearance of protein-bound uremic toxins, dicarbonyl stress compounds and advanced glycation endproducts in conventional and extended dialysis (CHAPTER 3)

PART II: LONG-TERM OUTCOM ES OF INTENSIVE AND HOM E HEM ODIALYSIS

a. To report the outcomes of home dialysis in patients with ESRD after non-renal solid organ transplantation (CHAPTER 4)

b. To explore the implications of intensive (home) HD on fertility and pregnancy (CHAPTER 5)

c. To hypothesize on the potential beneficial effects and to study the feasibility of intensive and home HD in elderly ESRD patients (CHAPTER 6)

d. To analyze the results of studies looking at the effects of intensive HD on vascular access complications (CHAPTER 7) 


\section{References}

1. Collins AJ, Foley RN, Chavers B, Gilbertson D, Herzog C, Ishani A, Johansen K, Kasiske BL, Kutner N, Liu J, St Peter W, Guo H, Hu Y, Kats A, Li S, Li S, M aloney J, Roberts T, Skeans M, Snyder J, Solid C, Thompson $B$, Weinhandl $E$, Xiong $H$, Yusuf A, Zaun D, Arko C, Chen SC, Daniels F, Ebben J, Frazier E, Johnson R, Sheets D, Wang X, Forrest B, Berrini D, Constantini E, Everson S, Eggers P, Agodoa L. US Renal Data System 2012 annual data report. Am J Kidney Dis 2013;61(Suppl 1):el-e480.

2. Gabbay E, M eyer KB, Griffith JL, Richardson M M , M iskulin DC. Temporal trends in health-related quality of life among hemodialysis patients in the United States. Clin J Am Soc Nephrol 2010;5:261-7.

3. Baigent $\mathrm{C}$, Burbury $\mathrm{K}$, Wheeler D. Premature cardiovascular disease in chronic renal failure. Lancet 2000;356:147-52.

4. Dalrymple LS, Johansen KL, Chertow GM, Cheng SC, Grimes B, Gold EB, Kaysen GA. Infection-related hospitalizations in older patients with ESRD. Am J Kidney Dis 2010;56:522-30.

5. Shoji T, Tsubakihara Y, Fuji M, Imai E. Hemodialysis-associated hypotension as an independent risk factor for two-year mortality in hemodialysis patients. Kidney Int 2004;66:1212-20.

6. Burton JO, Jefferies HJ, Selby NM, M clntyre CW. Hemodialysis-induced cardiac injury: determinants and associated outcomes. Clin J Am Soc Nephrol 2009;4:914-20.

7. Burton J0, Jefferies HJ, Selby NM, M clntyre CW. Hemodialysis-induced repetitive myocardial injury results in global and segmental reduction in systolic cardiac function. Clin J Am Soc Nephrol 2009;4:1925-31.

8. Schneditz D, Roob J, Oswald M, Pogglitsch H, Moser M, Kenner T, Binswanger U. Nature and rate of vascular refilling during dialysis. Kidney Int 1992;42:1425-33.

9. Kooman JP, Gladziwa U, Bocker G, van Bortel LM, van Hooff JP, Leunissen KM. Role of the venous system in hemodynamics during ultrafiltration and bicarbonate dialysis. Kidney Int 1992;42:718-26.

10. Santoro A, Mancini E, Spongano M, Rossi M, Paolini F, Zucchelli P. A haemodynamic study of hypotension during hemodialysis using electrical bioimpedance cardiography. Nephrol Dial Transplant 1990;5(Suppl 1):147-53.

11. van der Sande FM, Kooman JP, Konings CJ, Leunissen KM. Thermal effects and blood pressure response during postdilution hemodiafiltration and hemodialysis: the effect of amount of replacement fluid and dialysate temperature. J Am Soc Nephrol 2001;12:1916-20.

12. Glassock RJ, Pecoits-Filho R, Barberato SH. Left ventricular mass in chronic kidney disease and ESRD. Clin J Am Soc Nephrol 2009;4:S79-91.

13. Bhan I, Thadhani R. Vascular calcification and ESRD: a hard target. Clin J Am Soc Nephrol 2009;4:S102-5.

14. Foley RN, Gilbertson DT, Murray T, Collins AJ. Long interdialytic interval and mortality among patients receiving hemodialysis. New Engl J Med 2011;365:1099-107.

15. Locatelli F, Altieri P, Andrulli S, Bolasco P, Sau G, Pedrini LA, Basile C, David S, Feriani M, M ontagna G, Di Iorio BR, Memoli B, Cravero R, Battaglia G, Zoccali C. Hemofiltration and hemodiafiltration reduce intradialytic hypotension in ESRD. J Am Soc Nephrol 2010;21:1798-807.

16. Maduell F, Moreso F, Pons M, Ramos R, Mora-Macià J, Carreras J, Soler J, Torres F, Campistol JM, Martinez-Castelao A; ESHOL study group. High-efficiency postdilution online hemodiafiltration reduced all-cause mortality in hemodialysis patients. J Am Soc Nephrol 2013;24:487-97.

17. Donauer J, Schweiger C, Rumberger B, Krumme B, Böhler J. Reduction of hypotensive side effects during online-haemodiafiltration and low temperature haemodialysis. Nephrol Dial Transplant 2003;18:1616-22.

18. Grooteman MP, van den Dorpel MA, Bots ML, Penne EL, van der Weerd NC, M azairac AH, den Hoedt $\mathrm{CH}$, van der Tweel I, Lévesque R, Nubé MJ, ter Wee PM, Blankestijn PJ; CONTRAST Investigators. Effect of online hemodiafiltration on all-cause mortality and cardiovascular outcomes. J Am Soc Nephrol. 2012;23:1087-96.

19. George CR. History of home haemodialysis in Australia. Nephrology (Carlton) 2005;10:215-21.

20. Woods JD, Port FK, Stannard D, Blagg CR, Held PJ. Comparison of mortality with home hemodialysis and center hemodialysis: a national study. Kidney Int 1996;49:1464-70. 
21. Bremer BA, McCauley CR, Wrona RM, Johnson JP. Quality of life in end-stage renal disease: a reexamination. Am J Kidney Dis 1989;13:200-9.

22. Lee H, Manns B, Taub K, Ghali WA, Dean S, Johnson D, Donaldson C. Cost analysis of ongoing care of patients with end-stage renal disease: the impact of dialysis modality and dialysis access. Am J Kidney Dis 2002;40:611-22.

23. Charra B, Calemard E, Ruffet M, Chazot C, Terrat JC, Vanel T, Laurent G. Survival as an index of adequacy of dialysis. Kidney Int 1992;41:1286-91.

24. Chan CT, Covic A, Craig JC, Davenport A, Kasiske BL, Kuhlmann MK, Levin NW, Li PK, Locatelli F, Rocco MV, Wheeler DC. Novel techniques and innovation in blood purification: a clinical update from kidney disease: improving global outcomes. Kidney Int 2013;83:359-71.

25. Perl J, Chan CT. Home hemodialysis, daily hemodialysis, and nocturnal hemodialysis: Core Curriculum 2009. Am J Kidney Dis 2009;54:1171-84.

26. Kjellstrand C, Buoncristiani U, Ting G, Traeger J, Piccoli GB, Sibai-Galland R, Young BA, Blagg CR. Survival with short-daily hemodialysis: assocation of time, site, and dose of dialysis. Hemodial Int 2010;14:46470.

27. Jun M, Jardine MJ, Gray N, M asterson R, Kerr PG, Agar JW, Hawley CM, van Eps C, Cass A, Gallagher M, Perkovic V. Outcomes of extended-hours hemodialysis performed predominantly at home. Am J Kidney Dis 2013;61:247-53.

28. Pauly RP, Maximova K, Coppens J, Asad RA, Pierratos A, Komenda P, Copland M, Nesrallah GE, Levin A, Chery A, Chan CT. Patient and technique survival among a Canadian multicenter nocturnal home hemodialysis cohort. Clin J Am Soc Nephrol 2010;5:1815-20.

29. Blagg CR, Kjellstrand CM, Ting GO, Young BA. Comparison of survival between short-daily hemodialysis and conventional hemodialysis using the standardized mortality ratio. Hemodial int 2006;10:371-4.

30. Weinhandl ED, Liu J, Gilbertson DT, Arenson TJ, Collins AJ. Survival in daily home hemodialysis and matched thrice-weekly in-center hemodialysis patients. J Am Soc Nephrol 2012;23:895-904.

31. Nesrallah GE, Lindsay RM, Cuerden MS, Garg AX, Port F, Austin PC, M oist LM, Pierratos A, Chan CT, Zimmerman D, Lockridge RS, Couchoud C, Chazot C, Ofsthun N, Levin A, Copland M, Courtney M, Steele A, McFarlane PA, Geary DF, Pauly RP, Komenda P, Suri RS. Intensive hemodialysis associates with improved survival as compared with conventional hemodialysis. J Am Soc Nephrol 2012;23:696-705.

32. Johansen KL, Zhang R, Huang Y, Chen SC, Blagg CR, Goldfarb-Rumyantzev AS, Hoy CD, Lockridge RS Jr, Miller BW, Eggers PW, Kutner NG. Survival and hospitalization among patients using nocturnal and short daily compared to conventional hemodialysis: a USRDS study. Kidney Int 2009;76:984-90.

33. Lockridge RS, Kjellstrand CM. Nightly home hemodialysis: outcome and factors associated with survival. Hemodial Int 2011;15:211-28.

34. Kjellstrand CM, Buoncristiani U, Ting G, Traeger J, Piccoli GB, Sibai-Galland R, Young BA, Blagg CR. Short daily haemodialysis: survival in 415 patients treated for 1006 patient-years. Nephrol Dial Transplant 2008;23:3283-9.

35. Pauly RP, Gill JS, Rose CL, Asad RA, Chery A, Pierratos A, Chan CT. Survival among nocturnal home haemodialysis patients compared to kidney transplant recipients. Nephrol Dial Transplant 2009;24:2915-9.

36. Tennankore KK, Kim SJ, Baer HJ, Chan CT. Survival and hospitalization for intensive home hemodialysis compared with kidney transplantation. J Am Soc Nephrol 2014;25:2113-20.

37. Chan CT, Floras JS, Miller JA, Richardson RM, Pierratos A. Regression of left ventricular hypertrophy after conversion to nocturnal hemodialysis. Kidney Int 2002;61:2235-9.

38. Lockridge RS, Jr, Spencer M, Craft V, Pipkin M, Campbell D, M CPhatter L, Albert J, Anderson H, Jennings F, Barger T. Nightly home hemodialysis: five and one-half years of experience in Lynchburg, Virginia. Hemodial Int 2004;8:61-9.

39. Nesrallah G, Suri R, Moist L, Kortas C, Lindsay R. Volume control and blood pressure management in patients undergoing quotidian hemodialysis. Am J Kidney Dis 2003;42:13-7. 
40. Rocco MV, Lockridge RS, Jr, Beck GJ, Eggers PW, Gassman JJ, Greene T, Larive B, Chan CT, Chertow GM, Copland M, Hoy CD, Lindsay RM, Levin NW, Ornt DB, Pierratos A, Pipkin MF, Rajagopalan S, Stokes JB, Unruh ML, Star RA, Kliger AS; Frequent Hemodialysis Network (FHN) Trial Group. The effects of frequent nocturnal home hemodialysis: the frequent hemodialysis network nocturnal trial. Kidney Int 2011;80:1080-91.

41. Kraus M, Burkart J, Hegeman R, Solomon R, Coplon N, M oran J. A comparison of centerbased vs. homebased daily hemodialysis for patients with endstage renal disease. Hemodial Int 2007;11:468-77.

42. M cGregor DO, Buttimore AL, Lynn KL, Nicholls MG, Jardine DL. A comparative study of blood pressure control with short in-center versus long home hemodialysis. Blood Purif 2001;19:293-300.

43. Chan CT, Harvey PJ, Picton P, Pierratos A, Miller JA, Floras JS. Short-term blood pressure, noradrenergic, and vascular effects of nocturnal home hemodialysis. Hypertension 2003;42:925-31.

44. Chazot C, Charra B, Laurent G, Didier C, Vo Van C, Terrat JC, Calemard E, Vanel T, Ruffet M. Interdialysis blood pressure control by long haemodialysis sessions. Nephrol Dial Transplant 1995;10:831-7.

45. Fagugli RM, Reboldi G, Quintaliani G, Pasini P, Ciao G, Cicconi B, Pasticci F, Kaufman JM, Buoncristiani U. Short daily hemodialysis: blood pressure control and left ventricular mass reduction in hypertensive hemodialysis patients. Am J Kidney Dis 2001;38:371-6.

46. Culleton BF, Walsh M, Klarenbach SW, Mortis G, Scott-Douglas N, Quinn RR, Tonelli M, Donnelly S, Friedrich MG, Kumar A, Mahallati $H$, Hemmelgarn BR, Manns BJ. Effect of frequent nocturnal hemodialysis vs conventional hemodialysis on left ventricular mass and quality of life: a randomized controlled trial. JAM A 2007; 98:1291-9.

47. Susantitaphong P, Koulouridis I, Balk EM, Madias NE, Jaber BL. Effect of frequent or extended hemodialysis on cardiovascular parameters: a metaanalysis. Am J Kidney Dis 2012; 59:689-99.

48. Jefferies HJ, Virk B, Schiller B, M oran J, M cIntyre CW. Frequent hemodialysis schedules are associated with reduced levels of dialysis-induced cardiac injury (myocardial stunning). Clin J Am Soc Nephrol. 2011;6:1326-32.

49. Jaber BL, Lee Y, Collins AJ, Hull AR, Kraus M A, M cCarthy J, Miller BW, Spry L, Finkelstein FO; FREEDOM Study Group. Effect of daily hemodialysis on depressive symptoms and postdialysis recovery time: interim report from the FREEDOM (Following Rehabilitation, Economics And Everyday-Dialysis Outcome Measurements) Study. Am J Kidney Dis 2010;56: 531-9.

50. Walsh M, Manns BJ, Klarenbach S, Tonelli M, Hemmelgarn B, Culleton B. The effects of nocturnal compared with conventional hemodialysis on mineral metabolism: a randomized-controlled trial. Hemodial Int 2010;14:174-81.

51. van Eps CL, Jeffries JK, Johnson DW, Campbell SB, Isbel NM, M udge DW, Hawley CM. Quality of life and alternate nightly nocturnal home hemodialysis. Hemodial Int 2010;14:29-38

52. Vos PF, Zilch O, Jennekens-Schinkel A, Salden M, Nuyen J, Kooistra M MP, van Huffelen AC, Sitskoorn $M M$. Effect of short daily home haemodialysis on quality of life, cognitive functioning and the electroencephalogram. Nephrol Dial Transplant 2006;21:2529-35

53. Heidenheim AP, M uirhead N, M oist L, Lindsay RM. Patient quality of life on quotidian hemodialysis. Am J Kidney Dis 2003;42(1 Suppl):36-41.

54. Jaber BL, Schiller B, Burkart JM, Daoui R, Kraus MA, Lee Y, Miller BW, Teitelbaum I, Williams AW, Finkelstein FO; FREEDOM Study Group. Impact of short daily hemodialysis on restless legs symptoms and sleep disturbances. Clin J Am Soc Nephrol 2011;6:1049-56.

55. Hanly PJ, Pierratos A. Improvement of sleep apnea in patients with chronic renal failure who undergo nocturnal hemodialysis. N Engl J Med 2001;344:102-7.

56. Okundaye I, Abrinko P, Hou S. Registry of pregnancy in dialysis patients. Am J Kidney Dis 1998; 31:76673.

57. Asamiya Y, Otsubo S, Matsuda Y, Kimata N, Kikuchi K, M iwa N, Uchida K, M ineshima M, M itani M, Ohta $\mathrm{H}$, Nitta K, Akiba T. The importance of low blood urea nitrogen levels in pregnant patients undergoing hemodialysis to optimize birth weight and gestational age. Kidney Int 2009;75:1217-22.

58. Barua M, Hladunewich M, Keunen J, Pierratos A, M CFarlane P, Sood M, Chan CT. Successful pregnancies on nocturnal home hemodialysis. Clin J Am Soc Nephrol 2008;3:392-6. 
59. van Eps C, Hawley C, Jeffries J, Pierratos A, M CFarlane P, Sood M, Chan CT. Changes in serum prolactin, sex hormones and thyroid function with alternate nightly nocturnal home haemodialysis. Nephrology (Carlton) 2012;17:42-7.

60. FHN Trial Group, Chertow GM, Levin NW, Beck GJ, Depner TA, Eggers PW, Gassman JJ, Gorodetskaya I, Greene T, James S, Larive B, Lindsay RM, M ehta RL, Miller B, Ornt DB, Rajagopalan S, Rastogi A, Rocco MV, Schiller B, Sergeyeva O, Schulman G, Ting GO, Unruh M L, Star RA, Kliger AS. In-center hemodialysis six times per week versus three times per week. N Engl J M ed 2010;363:2287-300.

61. Suri RS, Larive B, Sherer S, Eggers P, Gassman J, James SH, Lindsay RM, Lockridge RS, Ornt DB, Rocco MV, Ting GO, Kliger AS; Frequent Hemodialysis Network Trial Group. Risk of vascular access complications with frequent hemodialysis. J Am Soc Nephrol 2013; 24: 498-505

62. Leitch R, Ouwendyk M, Ferguson E, Clement L, Peters K, Heidenheim AP, Lindsay RM. Nursing issues related to patient selection, vascular access, and education in quotidian hemodialysis. Am J Kidney Dis 2003; 42(1 Suppl): 56-60.

63. Verhallen AM, Kooistra M P, van Jaarsveld BC. Cannulating in haemodialysis: rope-ladder or buttonhole technique? Nephrol Dial Transplant 2007; 22: 2601-4.

64. MacRae JM, Ahmed SB, Atkar R, Hemmelgarn BR. A randomized trial comparing buttonhole with rope ladder needling in conventional hemodialysis patients. Clin J Am Soc Nephrol 2012; 7: 1632-8.

65. Nesrallah GE, Cuerden M, Wong JH, Pierratos A. Staphylococcus aureus bacteremia and buttonhole cannulation: long-term safety and efficacy of mupirocin prophylaxis. Clin J Am Soc Nephrol 2010; 5:1047-53.

66. Vilar E, Farrington K. Emerging importance of residual renal function in end-stage renal failure. Semin Dial 2011; 24: 487-94.

67. Jansen MA, Hart AA, Korevaar JC, Dekker FW, Boeschoten EW, Krediet RT; NECOSAD Study Group. Predictors of the rate of decline of residual renal function in incident dialysis patients. Kidney Int 2002; 62: 1046-53.

68. Daugirdas JT, Greene T, Rocco MV, Kaysen GA, Depner TA, Levin NW, Chertow GM, Ornt DB, Raimann JG, Larive B, Kliger AS; FHN Trial Group. Effect of frequent hemodialysis on residual kidney function. Kidney Int 2013; 83: 949-58.

69. Daugirdas JT, Bernardo AA. Hemodialysis effect on platelet count and function and hemodialysisassociated thrombocytopenia. Kidney Int 2012; 82: 147-57.

70. Rioux JP, Faratro R, Chan CT. Nocturnal home hemodialysis: implementation, quality assurance and future challenges. Minerva Urol Nefrol 2010; 62: 103-10.

71. M Laughlin K, Manns B, Mortis G, Hons R, Taub K. Why patients with ESRD do not select self-care dialysis as a treatment option. Am J Kidney Dis 2003; 41: 380-5.

72. Zhang AH, Bargman JM, Lok CE, Porter E, Mendez M, Oreopoulos DG, Chan CT. Dialysis modality choices among chronic kidney disease patients: identifying the gaps to support patients on home-based therapies. Int Urol Nephrol 2010;42: 759-64.

73. Cafazzo JA, Leonard K, Easty AC, Rossos PG, Chan CT. Patient-perceived barriers to the adoption of nocturnal home hemodialysis. Clin J Am Soc Nephrol 2009; 4: 784-9.

74. Pipkin M, Eggers PW, Larive B, Rocco MV, Stokes JB, Suri RS, Lockridge RS Jr; Frequent Hemodialysis Network Trial Group. Recruitment and training for home hemodialysis: experience and lessons from the nocturnal dialysis trial. Clin J Am Soc Nephrol 2010; 5: 1614-20.

75. Morton RL, Tong A, Webster AC, Snelling P, Howard K. Characteristics of dialysis important to patients and family caregivers: a mixed methods approach. Nephrol Dial Transplant 2011; 26: 4038-46.

76. Agar JW. Home hemodialysis in Australia and New Zealand: practical problems and solutions. Hemodial Int 2008; 12(Suppl 1): S26-S32.

77. Tennankore K, Nadeau-Fredette A-C, Chan CT. Intensified home hemodialysis: clinical benefits, risks and target populations. Nephrol Dial Transplant 2014;29:1342-9.

78. Morton RL, Snelling P, Webster AC, Rose J, Masterson R, Johnson DW, Howard K. Dialysis modality preference of patients with CKD and family caregivers: a discrete choice study. Am J Kidney Dis 2012; 60: 102-11.

79. Tennankore KK, Kim SJ, Chan CT. The feasibility of caregiver-assisted home nocturnal hemodialysis. Nephron Clin Pract 2012;122: 17-23. 
80. Rioux JP, Cheema H, Bargman JM, Watson D, Chan CT. Effect of an in-hospital chronic kidney disease education program among patients with unplanned urgent-start dialysis. Clin J Am Soc Nephrol 2011; 6:799-804.

81. Helantera I, Haapio M, Koskinen P, Grönhagen-Riska C, Finne P. Employment of patients receiving maintenance dialysis and after kidney transplant: a crosssectional study from Finland. Am J Kidney Dis 2012; 59:700-6.

82. Nadeau-Fredette AC, Bargman JM, Chan CT. Clinical outcome of home hemodialysis in patients with previous peritoneal dialysis exposure: evaluation of the integrated home dialysis model. Perit Dial Int $2014 \mathrm{M}$ ar 1. [Epub ahead of print]

83. Hoogeveen EK, Halbesma N, Rothman KJ, Stijnen T, van Dijk S, Dekker FW, Boeschoten EW, de Mutsert R; Netherlands Cooperative Study on the Adequacy of Dialysis-2 (NECOSAD) Study Group. Obesity and mortality risk among younger dialysis patients. Clin J Am Soc Nephrol 2012; 7:280-8.

84. Plumb TJ, Swee M L, Fillaus JA. Nocturnal home hemodialysis for a patient with type 1 hyperoxaluria. Am J Kidney Dis 2013;62:1155-9.

85. M cIntyre CW, Burton JO, Selby NM, Leccisotti L, Korsheed S, Baker CS, Camici PG. Hemodialysis-induced cardiac dysfunction is associated with an acute reduction in global and segmental myocardial blood flow. Clin J Am Soc Nephrol 2008;3:19-26.

86. Dasselaar JJ, Slart RH, Knip M, Pruim J, Tio RA, M clntyre CW, de Jong PE, Franssen CF: Haemodialysis is associated with a pronounced fall in myocardial perfusion. Nephrol Dial Transplant 2009;24:604-10

87. Vanholder R, De Smet R, Glorieux G, Argilés A, Baurmeister U, Brunet P, Clark W, Cohen G, De Deyn PP, Deppisch R, Descamps-Latscha B, Henle T, Jörres A, Lemke HD, M assy ZA, Passlick-Deetjen J, Rodriguez M, Stegmayr B, Stenvinkel P, Tetta C, Wanner C, Zidek W; European Uremic Toxin Work Group (EUTox). European Uremic Toxin Work Group (EUTox). Review on uremic toxins: classification, concentration, and interindividual variability. Kidney Int. 2003;63:1934-43.

88. Drüeke TB, M assy ZA. Beta2-microglobulin. Semin Dial 2009;22:378-80.

89. Kovesdy CP, Quarles LD. Fibroblast growth factor-23: what we know, what we don't know, and what we need to know. Nephrol Dial Transplant 2013;29:2228-36.

90. Knap B, Veceric-Haler Z, Benedik M, Buturovic-Ponikvar J, Ponikvar R, Bren AF. Fibroblast growth factor 23 and left ventricular mass index in maintenance hemodialysis patients: standard versus long nocturnal hemodialysis. Ther Apher Dial 2013;17:407-11.

91. Neirynck N, Glorieux G, Schepers E, Pletinck A, Dhondt A, Vanholder R. Review of protein bound toxins, possibility for blood purification therapy. Blood Purif 2013;35:45-50.

92. Niwa T. Removal of protein-bound uraemic toxins by haemodialysis. Blood Purif 2013;35:20-5.

93. Liabeuf S, Drüeke TB, Massy ZA. Protein-bound uremic toxins: new insight from clinical studies. Toxins (Basel) 2011;3:911-9.

94. Barreto FC, Barreto DV, Liabeuf S, M eert N, Glorieux G, Temmar M, Choukroun G, Vanholder R, Massy ZA. European Uremic Toxin Work Group (EUTox). Serum indoxyl sulfate is associated with vascular disease and mortality in chronic kidney disease patients. Clin J Am Soc Nephrol 2009;4:1551-8.

95. Liabeuf S, Barreto DV, Barreto FC, Meert N, Glorieux G, Schepers E, Temmar M, Choukroun G, Vanholder R, Massy ZA. European Uraemic Toxin Work Group (EUTox). Free p-cresylsulphate is a predictor of mortality in patients at different stages of chronic kidney disease. Nephrol Dial Transplant 2010;25:1183-91.

96. Liabeuf S, Glorieux G, Lenglet A, Diouf M, Schepers E, Desjardins L, Choukroun G, Vanholder R, Massy ZA. European Uremic Toxin (EUTox) Work Group. Does p-cresylglucuronide have the same impact on mortality as other protein-bound uremic toxins? PLoS One 2013;8:e67168.

97. Vanholder R, Schepers E, Pletinck A, Nagler EV, Glorieux G. The uremic toxicity of indoxyl sulfate and pcresyl sulfate: a systematic review. J Am Soc Nephrol 2014;25:1897-907.

98. Ito S, Yoshida M. Protein-bound uremic toxins: new culprits of cardiovascular events in chronic kidney disease patients. Toxins (Basel) 2014;6:665-78.

99. Meijers BK, Evenepoel P. The gut-kidney axis: indoxyl sulfate, p-cresyl sulfate and CKD progression. Nephrol Dial Transplant 2011;26:759-61.

100. Watanabe $H$, Miyamoto $Y$, Otagiri M, Maruyama $T$. Update on the pharmacokinetics and redox properties of protein-bound uremic toxins. J Pharm Sci 2011;100:3682-95. 
101. Zoccali C, Benedetto FA, Mallamaci F, Tripepi G, Fermo I, Focà A, Paroni R, M alatino LS. Inflammation is associated with carotid atherosclerosis in dialysis patients. Creed investigators. Cardiovascular Risk Extended Evaluation in Dialysis patients. J Hypertens 2000;18:1207-13.

102. Wagner Z, M olnar M, M olnar GA, Tamaskó M, Laczy B, Wagner L, Csiky B, Heidland A, Nagy J, Wittmann I. Serum carboxymethyllysine predicts mortality in hemodialysis patients. Am J Kidney Dis 2006;47:294300.

103. Friedlander MA, Wu YC, Elgawish A, Monnier VM. Early and advanced glycosylation end products. Kinetics of formation and clearance in peritoneal dialysis. J Clin Invest 1996:97:728-35.

104. Mallipattu SA, He JC, Uribarri J. Role of advanced glycation endproducts and potential therapeutic interventions in dialysis patients. Semin Dial 2012;25:529-38.

105. M iyata T, Ueda Y, Yamada Y, Izuhara Y, Wada T, Jadoul M, Saito A, Kurokawa K, van Ypersele de Strihou C. Accumulation of carbonyls accelerates the formation of pentosidine, an advanced glycation end product: carbonyl stress in uremia. J Am Soc Nephrol 1998;9;69-77.

106. Raj DS, Choudhury D, Welbourne TC, Levi M. Advanced glycation end products: a Nephrologist's perspective. Am J Kidney Dis 2000;35:365-30.

107. Bohlender JM, Franke S, Stein G, Wolf G. Advanced glycation end products and the kidney. Am J Phsyiol renal Physiol 2005;289:F645-F59.

108. Confortini P, Galanti G, Ancona G, Giongo A, Bruschi E, Lorenzini E. Full term pregnancy and successful delivery in a patient on chronic hemodialysis. Proc Eur Dial Transplant Assoc 1971;8:74-80.

109. Hou SH, Grossman S, Molitch ME. Hyperprolactinemia in patients with renal insufficiency and chronic renal failure requiring hemodialysis or chronic ambulatory peritoneal dialysis. Am J Kidney Dis 1985; 6:245-9.

110. Bagon JA, Vernaeve H, De M uylder X, Lafontaine JJ, Martens J, Van Roost G. Pregnancy and dialysis. Am J Kidney Dis 1998; 31:756-65.

111. Barua M, Hladunewich M, Keunen J, Pierratos A, M CFarlane P, Sood M, Chan CT. Successful pregnancies on nocturnal home hemodialysis. Clin J Am Soc Nephrol 2008; 3:392-6.

112. Stengel B, Billon S, Van Dijk PC, Jager KJ, Dekker FW, Simpson K, Briggs JD. Trends in the incidence of renal replacement therapy for end-stage renal disease in Europe, 1990-1999. Nephrol Dial Transplant 2003;18:1824-33.

113. Santoro A and Mancini E. Hemodialysis and the elderly patient: complications and concerns. J Nephrol 2010;23:80-9.

114. Kurella Tamura M, Covinsky KE, Chertow GM, Yaffe K, Landefeld CS, M cCulloch CE. Functional status of elderly adults before and after initiation of dialysis. N Engl J M ed 2009;361:1539-47.

115. Jassal SV, Chiu E, Hladunewich M. Loss of independence in patients starting dialysis at 80 years of age or older. N Engl J M ed 2009;361:1612-3. 



\section{PART I}

\section{AOUTEQTECTSOFINIENSVE HEMODIALYSIS}





\section{Chapter 2}

Acute hemodynamic response and uremic toxin removal in conventional and extended hemodialysis and hemodiafiltration: a randomized crossover study

Cornelis T, van der Sande FM, Eloot S, Cardinaels E, Bekers O, DamoiseauX J, Leunissen KM , Kooman JP Am J Kidney Dis 2014;64:247-56 


\section{ABSTRACT}

Background: Intensive hemodialysis has significant benefits. Recently, the role of extended hemodiafiltration gained interest. Aim of this study was to evaluate the acute effects of extended hemodialysis and hemodiafiltration on hemodynamic response and solute removal.

Study Design: Randomized crossover trial.

Settings and Participants: Stable end-stage renal disease patients undergoing conventional hemodialysis.

Intervention: Thirteen patients randomly completed, a single study of 4-hour HD (HD4), 4-hour HDF (HDF4), 8-hour HD (HD8) and 8-hour HDF (HDF8), with a 2-week interval between the study sessions. Between the study sessions, the patient received routine conventional HD treatments.

Outcomes: Acute hemodynamic effects and uremic toxin clearance.

M easurements: Blood pressure and heart rate, pulse wave analysis, cardiac output, microvascular density by sublingual capillaroscopy, as well as relative blood volume and thermal variables were measured. Clearance and removal of uremic toxins were also studied.

Results: Long treatments showed more stability of peripheral systolic blood pressure $(\mathrm{mmHg})$ (change during HD4 -21.7 \pm 15.6 ; HDF4 -23.3 \pm 20.8 ; HD8 $-6.7 \pm 15.2, P=0.04$ versus HD4 and $P=0.08$ versus HDF4; HDF8 $-0.5 \pm 14.4 ; \mathrm{P}=0.004$ versus $\mathrm{HD} 4$ and $\mathrm{P}=0.008$ versus HDF4). A similar observation was found for peripheral diastolic and central blood pressure. Cardiac output (1/min)

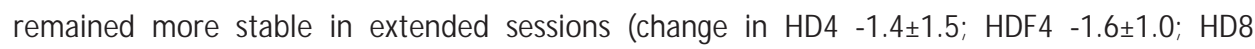
$-0.4 \pm 0.9, P=0.02$ versus HDF4; HDF8 $-0.5 \pm 0.8 ; P=0.06$ versus HD4 and $P=0.03$ versus HDF4), in line with decreased relative blood volume slope in long dialysis. No differences in microvascular density were found. Energy transfer rates (W) were comparable (HD4 13.3 \pm 4.7 , HDF4 16.2 \pm 5.6 , HD8 14.2 \pm 6.0 , HDF8 14.5 \pm 4.3 ). Small molecule and phosphate removal were superior during long treatments. Beta2 microglobulin and FGF23 reduction ratios were highest in HDF8.

Limitations: small sample size, only acute effects were studied

Conclusion: Treatment time, and not modality was the determinant for the hemodynamic response. Hemodiafiltration significantly improved removal of middle molecules, with superior results in extended hemodiafiltration. 


\section{Introduction}

Intensive hemodialysis (HD) [short-daily HD (SDHD), in-centre nocturnal HD (NHD) and home NHD] is associated with significant improvement of several clinical, biochemical and biological parameters ${ }^{1}$. A potential explanation for these observed results is the increased removal of uremic toxins due to the increased duration and/or frequency of $H D^{2-7}$.

Long HD also results in better hemodynamic stability likely due to more physiologic fluid removal ${ }^{8,9}$. It may reduce myocardial stunning which is associated with cardiovascular morbidity and mortality ${ }^{10-13}$. Furthermore, beneficial effects of long HD on the autonomic nervous system might be involved ${ }^{14}$.

There is evidence that hemodiafiltration (HDF) has advantageous effects on hemodynamic stability ${ }^{15,16}$. This may be due to autonomous nervous system protection by $\mathrm{HDF}^{17}$. Online HDF may also provide an additional extracorporeal cooling effect by thermal energy loss ${ }^{18,19}$. However, it is still not proven that HDF provides hemodynamic benefits if extracorporeal energy balance is comparable ${ }^{19,20}$. Also, the effects of modality versus time have not been directly compared using detailed hemodynamic measurements.

The removal of uremic toxins can also be influenced by modality, also depending on molecular size and compartmental kinetics ${ }^{2}$. Studies have shown optimized beta2microglobulin (B2M) and Fibroblast Growth Factor 23 (FGF23) clearance with HDF ${ }^{21-23}$. However, only one study so far has assessed the effect of extended HDF on uremic toxin removal ${ }^{22}$, and none so far has compared this modality with extended HD.

The aims of the present study were, firstly to perform a detailed hemodynamic analysis comparing conventional and extended high-flux HD and HDF, and secondly, to compare the effects of these modalities on the removal of selected uremic toxins.

\section{Methods}

\section{Design of the study}

Prevalent conventional HD patients underwent, in random order (consecutive blind selection of one of the 24 closed envelopes each enclosing one of the 24 possible study orders), a mid-week 4-hour HD (HD4) session, a mid-week 4-hour online HDF (HDF4) session, a mid-week 8-hour HD (HD8) session, and a mid-week 8-hour online HDF (HDF8) session with a 2-week interval between the study sessions. Between the study sessions, these patients received routine conventional HD treatments. 
Patients were recruited from the prevalent conventional HD population of the Maastricht University Medical Centre. Inclusion criteria were: prevalent conventional HD patients without significant residual urine production, arteriovenous fistula (AVF) enabling double-needle vascular access with blood flow rate of $300 \mathrm{ml} / \mathrm{min}$, written informed consent and age more than 18 years. Exclusion criteria were: withdrawal of consent and any acute illness such as infection or cardiovascular event.

All treatments were performed with the Fresenius 5008 Therapy System (Fresenius Medical Care, Bad Homburg, Germany). FX80 $®$ dialyzers were used for HD, and FX800 $®$ dialyzers were used for HDF. Blood flow was $300 \mathrm{ml} / \mathrm{min}$ and dialysate flow $600 \mathrm{ml} / \mathrm{min}$ in all study sessions. Substitution flow was $83.3 \mathrm{ml} / \mathrm{min}$ to achieve a total substitution volume of $15 \mathrm{I}$ for HDF4 and $30 \mathrm{I}$ for HDF8. Online HDF was performed in post-dilution mode. Dialysate composition was: $\mathrm{Ca}^{2+} 1.5 \mathrm{mmol} / \mathrm{l}, \mathrm{K}^{+} 2 \mathrm{mmol} / \mathrm{l}, \mathrm{Na}^{+} 136-138 \mathrm{mmol} / \mathrm{l}$, bicarbonate $35-38 \mathrm{mmol} / \mathrm{l}$. Dialysate temperature varied among the patients from 35.5 to $36.5^{\circ} \mathrm{C}$. Dialysate composition and temperature remained unchanged during the study period. Potassium supplementation was provided if necessary. Total ultrafiltration volume was calculated based on target weight and intake during dialysis. Target weight was set on the basis of clinical assessment of volume status in combination with bio-impedance results.

This study was approved by the local ethics committee at the Maastricht University Medical Centre under number NL34908.068.10/MEC10-2-098, and was registered under clinicaltrials.gov number NCT01328119.

\section{Hemodynamic measurements}

All measurements were performed before the start of the study session, and subsequently at time points $30,60,120$ and 240 minutes. In the 8-hour sessions, a measurement was also done at times 360 and 480 minutes. Intermittent blood pressure (BP) and heart rate (HR) were measured with the Task Force M onitor (TFM , CN Systems, Austria) ${ }^{24}$. Relative blood volume (RBV) was monitored continuously with the Fresenius Blood Volume Monitor (BVM) system (Fresenius Medical Care) ${ }^{25}$. Sublingual microcirculation assessing microvascular density and red blood cell (RBC) filling percentage was measured with the Sidestream Dark Field (SDF) camera (MicroVision Medical Inc., Wallingford, PA) and the Glycocheck software (Glycocheck BV, M aastricht, Netherlands) ${ }^{26}$. Pulse Wave Analysis (PWA) including central systolic and diastolic BP, augmentation index (Aix), subendocardial viability ratio (SEVR) and ejection duration (ED), was measured with Sphygmocor ${ }^{\circledR}$ (AtCor M edical, Sydney, Australia) ${ }^{27,28}$. Cardiac output (CO) was measured with the Transonic System (TRS, Transonic Systems, Ithaca, 
NY, USA $)^{24,29}$. Bio-impedance was performed with the Body Composition Monitor (BCM $®$, Fresenius Medical Care) to assess pre- and post-dialysis overhydration ${ }^{30,31}$.

\section{Thermal balance and energy expenditure}

Venous and arterial blood temperatures were measured continuously with the Blood Temperature Monitor (BTM) system (Fresenius Medical Care) ${ }^{32}$. The BTM calculates extracorporeal arterio-venous temperature gradients $\left(\Delta \mathrm{T}_{\mathrm{av}}\right)$ and energy transfer (ET) rates. $\mathrm{ET}$ (in $\mathrm{kJ} / \mathrm{h}$ ) is calculated using the following formula: $\mathrm{c} \times \varrho \times \mathrm{Q}_{\mathrm{b}} \times\left(\mathrm{T}_{\text {art }}-\mathrm{T}_{\text {ven }}\right.$ ), where

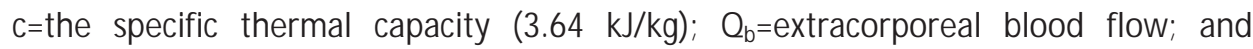
$\mathrm{e}=$ density of the blood $\left(1052 \mathrm{~kg} / \mathrm{m}^{3}\right)$.

\section{Blood and dialysate sampling and measurements}

Serum samples were taken from the inlet bloodlines immediately before the onset of dialysis and at 15, 30, 60, 120 and 240 minutes during the 4- and 8-hour sessions. Additional samples were taken at 360 and 480 minutes during the long sessions. Samples were always obtained after decreasing the blood flow to $50 \mathrm{ml} / \mathrm{min}$ for at least one minute. A mixture of dialysate and ultrafiltrate was continuously collected in a fractionated fashion in a bag. At the end of the treatment and after thorough mixing, a $10 \mathrm{ml}$ sample was drawn from the collection bag in order to quantify solute concentration. All samples were stored at $-80^{\circ} \mathrm{C}$ until analysis.

Urea, creatinine, uric acid and phosphorus were measured using routine assays on a Cobas 6000 analyzer (Roche Diagnostics, Mannheim, Germany). B2M was detected in serum and dialysate using a two-site chemoluminescent immunometric assay (Immulite 2000 System, Diagnostic Products Corporation, Los Angeles, CA). C-terminal FGF23 concentrations were measured in stored serum samples using a two-site second generation ELISA kit (Immutopics, San Clemente, CA), with antibodies directed against two epitopes within the C-terminal region of the FGF23 molecule.

\section{Calculations}

Total solute removal (TSR) was calculated by multiplying the dialysate concentration of the solute by the sum of dialysate volume, the ultrafiltration volume and (in the HDF sessions) the substitution volume. Dialytic clearances (Cls) were calculated as total solute removal divided by the dialysis duration and by the log mean of the pre- and post-dialysis blood concentration of the solute. Reduction ratio (RR) of solutes was defined as a function of pre-dialysis (Cpre) and post-dialysis (Cpost) concentration $(\mathrm{RR}=[1-($ Cpost/Cpre) $] \times 100)$. For B2M and FGF-23, concentration at the dialysis end 
(Cpost) was corrected for hemoconcentration based on total protein concentration at start versus end of the dialysis session.

\section{Statistical analyses}

Data are expressed as mean $\pm \mathrm{SD}$. For hemodynamic measurements, this study combined repeated measurements during a treatment modality with a comparison of different treatment modalities using the patient as his/her own control. The Kolmogorov-Smirnov test was used to assess the normal distribution of the data. As no non-normally distributed variables of the data were observed, repeated measurements ANOVA and paired t-tests were used to assess differences among the treatments. The tests were considered significant if the P-value was below 0.05 . The IBM SPSS Statistics 20 program was used for statistical analyses.

Changes in hemodynamic parameters were expressed as the slope of the regression line constructed from the measurements at the consecutive measurement points (corresponding to a change per period of time), multiplied by the time of the treatment. This method allowed for interpolation in case of a missing value between the start and the end of the treatment. Hence, slopes could be calculated for $\mathrm{CO}$ with $80 \%$ availability of planned measurements.

The slope in BP was the primary outcome parameter. In the study by Basile et al., a difference of $15.5 \pm 15.6 \mathrm{mmHg}$ was found between long and short treatments ${ }^{9}$. In a power analysis, a sample size of 8 is needed to show a significant difference in BP decline between two paired treatments with a power of 0.8 and an alpha of 0.05 . In order to allow for multiple comparisons and for drop-out, it was chosen to include 16 patients in the study.

\section{Results}

\section{Patient and treatment characteristics}

Of the sixteen included patients, only thirteen completed the study (1 drop-out for intestinal ischemia, 1 for recurrent infections and hospitalization, and 1 because of patient decision). Complications were unrelated to the study. Ten of the 13 patients were men. M ean age was $53.6 \pm 20.4$ years. Patients were on conventional HD therapy for $49 \pm 29$ months. Mean body mass index (BMI) was $26.7 \pm 4.3 \mathrm{~kg} / \mathrm{m}^{2}$. Three patients had mean residual diuresis of $420 \pm 96 \mathrm{ml}$ per 24 hours; the remaining 10 patients were anuric. Ten patients had a history of arterial hypertension, and cardiovascular disease was present in 9 patients. Cardiovascular drugs were used in 12 patients (beta blockers 
in 11 , calcium channel blockers in 5, ACE inhibitors in 2, and angiotensin receptor blockers in 4 patients), and their prescription was unaltered during the whole study. Causes of end-stage renal disease (ESRD) were diabetic nephropathy $(n=4)$, hypertensive nephropathy $(n=3)$, glomerulonephritis $(n=1)$, polycystic kidney disease $(n=1)$, renal hypoplasia $(n=1)$, multiple myeloma $(n=1)$, Alport syndrome $(n=1)$, and reflux nephropathy $(n=1)$. Baseline results of all measured variables were comparable among the 4 groups, except for a trend to lower overhydration in the HDF8 group (Table 2.1). Also, mean pre-dialysis B2M levels were significantly higher before the HDF8 studies than before the HD4 and HD8 sessions.

Table 2.1 Pretreatment hemodynamic indices and serum levels.

\begin{tabular}{lcccc}
\hline & HD4 & HDF4 & HD8 & HDF8 \\
\hline Peripheral SBP (mmHg) & $142.8 \pm 19.5$ & $138.6 \pm 26.2$ & $145.4 \pm 28.7$ & $137.9 \pm 26.0$ \\
Peripheral DBP (mmHg) & $77.5 \pm 16.0$ & $81.5 \pm 17.0$ & $75.8 \pm 18.2$ & $73.4 \pm 19.6$ \\
Central SBP (mmHg) & $129.3 \pm 18.5$ & $127.1 \pm 21.4$ & $128.8 \pm 27.9$ & $124.5 \pm 28.0$ \\
Central DBP (mmHg) & $80.2 \pm 16.2$ & $83.9 \pm 18.2$ & $77.9 \pm 18.6$ & $74.8 \pm 21.0$ \\
HR (bpm) & $73.5 \pm 8.6$ & $73.2 \pm 10.2$ & $75.1 \pm 4.8$ & $71.5 \pm 9.3$ \\
$\mathrm{CO}(\mathrm{l} / \mathrm{min})$ & $6.35 \pm 1.92$ & $6.50 \pm 1.53$ & $6.35 \pm 1.25$ & $6.28 \pm 2.07$ \\
Weight $_{\text {pre-post }}(\mathrm{kg})$ & $1.17 \pm 0.66$ & $1.53 \pm 1.29$ & $1.31 \pm 0.78$ & $1.10 \pm 0.55$ \\
$\left(\mathrm{OH}_{\text {pre }}+\mathrm{OH}_{\text {post }} / 2\right.$ (l) & $0.90 \pm 1.18$ & $0.68 \pm 1.41$ & $0.48 \pm 1.41$ & $0.04 \pm 1.20$ \\
Urea $(\mathrm{mg} / \mathrm{dl})$ & $112.8 \pm 24.6$ & $115.2 \pm 19.8$ & $114.6 \pm 24.0$ & $114.0 \pm 22.8$ \\
Creatinine $(\mathrm{mg} / \mathrm{dl})$ & $10.2 \pm 3.3$ & $10.4 \pm 2.8$ & $10.2 \pm 3.1$ & $10.4 \pm 2.9$ \\
Uric acid $(\mathrm{mg} / \mathrm{dl})$ & $6.0 \pm 1.0$ & $6.2 \pm 0.8$ & $5.9 \pm 0.7$ & $6.2 \pm 0.5$ \\
Phosphorus $(\mathrm{mg} / \mathrm{dl})$ & $4.5 \pm 1.6$ & $4.9 \pm 1.9$ & $5.0 \pm 1.8$ & $4.9 \pm 1.6$ \\
B2M (mg/l) & $21.0 \pm 4.9$ & $23.7 \pm 4$ & $22.4 \pm 6.4$ & $24.4 \pm 6.1 * \pm$ \\
FGF23 (RU/ml) & $779(404-4203)$ & $914(488-3958)$ & $908(436-4307)$ & $1019(545-6606)$ \\
\hline
\end{tabular}

Data in mean \pm SD, except for FGF23 in median (IQR). SBP: Systolic BP; DBP: Diastolic BP; HR: heart rate; bpm:

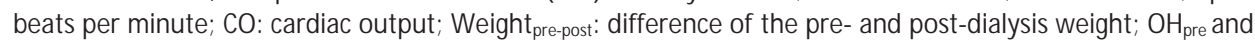
$\mathrm{OH}_{\text {post: }}$ overhydration pre- and post-dialysis as assessed by BCM ; B2M : Beta2 M icroglobulin; FGF23: Fibroblast Growth Factor 23. Conversion factors for units: creatinine in $\mathrm{mg} / \mathrm{dl}$ to $\mu \mathrm{mol} / \mathrm{l}, \mathrm{x} 88.4$; uric acid in $\mathrm{mg} / \mathrm{dl}$ to $\mathrm{mmol} / \mathrm{l}, \mathrm{x} 0.06$; serum urea in $\mathrm{mg} / \mathrm{dl}$ to $\mathrm{mmol} / \mathrm{l}, \mathrm{x} 0.167$; serum phosphorus in $\mathrm{mg} / \mathrm{dl}$ to $\mathrm{mmol} / \mathrm{l}, \mathrm{x} 0.32$. $* \mathrm{P} \varangle 0.05$ versus $H D 4 ; \ddagger \mathrm{P} \varangle 0.05$ versus $H D 8$.

Treatment characteristics of the different dialysis modalities are listed in Table 2.2. The ultrafiltration rates refer to the amount of fluid taken off per patient dry weight and fluid intake during the dialysis session, and hence do not take the extra ultrafiltration into account for the HDF sessions. 
Table 2.2 Treatment characteristics.

\begin{tabular}{lcccc}
\hline Parameter & HD4 & HDF4 & HD8 & HDF8 \\
\hline Effective dialysis time $(\mathrm{min})$ & $246 \pm 4$ & $245 \pm 3$ & $486 \pm 2^{*} \dagger$ & $487 \pm 6^{*} \dagger$ \\
Blood volume (I) & $67.9 \pm 1.6$ & $68.5 \pm 1.1$ & $134.9 \pm 2.0^{*} \dagger$ & $135.3 \pm 1.5^{*} \dagger$ \\
Blood flow (ml/min) & $283 \pm 7$ & $286 \pm 5$ & $287 \pm 4$ & $288 \pm 3$ \\
Dialysate flow $(\mathrm{ml} / \mathrm{min})$ & $569 \pm 24$ & $578 \pm 7$ & $576 \pm 8$ & $572 \pm 11$ \\
Total ultrafiltration (I) & $1.98 \pm 0.76$ & $1.77 \pm 0.63$ & $2.31 \pm 0.82$ & $2.21 \pm 0.81$ \\
Ultrafiltration rate $(\mathrm{ml} / \mathrm{h})$ & $500 \pm 193$ & $449 \pm 160$ & $295 \pm 111^{*} \dagger$ & $265 \pm 83^{*} \dagger$ \\
Substitution volume $(\mathrm{I})$ & - & $14.6 \pm 1.1$ & - & $29.7 \pm 0.4 \dagger$ \\
Dialysate sodium $(\mathrm{mmol} / \mathrm{l})$ & $137.2 \pm 1.4$ & $137.2 \pm 1.4$ & $136.9 \pm 1.6$ & $137.2 \pm 1.1$ \\
Dialysate temperature $\left({ }^{\circ} \mathrm{C}\right)$ & $35.9 \pm 0.4$ & $35.9 \pm 0.4$ & $35.8 \pm 0.4$ & $36.0 \pm 0.4$ \\
spKt/V & $1.49 \pm 0.21$ & $1.60 \pm 0.30$ & $3.30 \pm 0.54^{*} \dagger$ & $3.34 \pm 1.05^{*} \dagger$ \\
eKt/V & $1.36 \pm 0.26$ & $1.41 \pm 0.26$ & $3.09 \pm 0.51^{*} \dagger$ & $3.14 \pm 0.99^{*} \dagger$ \\
\hline
\end{tabular}

Data in mean \pm SD. spKt/V: single pool Kt/V; eKt/V: equilibrated Kt/V. $* P<0.05$ versus $H D 4 ; \dagger P \varangle 0.05$ versus HDF4.

\section{Changes in relative blood volume, cardiac and hemodynamic parameters}

Changes in cardiac and hemodynamic parameters are summarized in Table 2.3 and in Figures 2.1 and 2.2. Peripheral systolic BP $(\mathrm{mmHg})$ appeared to be better preserved over the whole session in the long-hour dialysis treatments (change during HD4 $-21.7 \pm 15.6$; HDF4 $-23.3 \pm 20.8$; HD8 $-6.7 \pm 15.2, P=0.04$ versus $H D 4$ and $P=0.08$ versus HDF4; HDF8 $-0.5 \pm 14.4 ; P=0.004$ versus $H D 4$ and $P=0.008$ versus HDF4), without significant differences between HD and HDF. A similar trend was found for peripheral diastolic $\mathrm{BP}$ and central $\mathrm{BP}$, as well as for $\mathrm{CO}(\mathrm{I} / \mathrm{min}$ ) (change during HD4 $-1.4 \pm 1.5$; HDF4 $-1.6 \pm 1.0$; HD8 $-0.4 \pm 0.9, P=0.02$ versus HDF4; HDF8 $-0.5 \pm 0.8 ; P=0.06$ versus HD4 and $P=0.03$ versus HDF4) and RBV. Changes in HR, other PWA indices, microvascular density and RBC filling did not differ significantly between the 4 treatments.

Table 2.3 Changes in hemodynamic parameters and thermal balance.

\begin{tabular}{lcclc}
\hline Parameter & HD4 & HDF4 & HD8 & HDF8 \\
\hline Peripheral SBP $(\mathrm{mmHg})$ & $-21.7 \pm 15.6$ & $-23.3 \pm 20.8$ & $-6.7 \pm 15.2^{*}$ & $-0.5 \pm 14.4^{*} \dagger$ \\
Peripheral DBP $(\mathrm{mmHg})$ & $-5.0 \pm 10.2$ & $-11.5 \pm 12.9$ & $-1.1 \pm 7.2 \dagger$ & $-1.2 \pm 10.1 \dagger$ \\
Central SBP $(\mathrm{mmHg})$ & $-19.2 \pm 19.8$ & $-24.2 \pm 14.8$ & $-7.1 \pm 11.3$ & $-3.8 \pm 14.4 \dagger$ \\
Central DBP $(\mathrm{mmHg})$ & $-5.0 \pm 11.6$ & $-12.1 \pm 13.1^{*}$ & $-2.6 \pm 5.3$ & $+3.5 \pm 8.6 \dagger$ \\
HR $(\mathrm{bpm})$ & $-1.0 \pm 7.9$ & $-0.9 \pm 10.6$ & $-0.7 \pm 11.9$ & $+0.9 \pm 8.3$ \\
CO $(\mathrm{l} / \mathrm{min})$ & $-1.4 \pm 1.5$ & $-1.6 \pm 1.0$ & $-0.4 \pm 0.9 \dagger$ & $-0.5 \pm 0.8 \dagger$ \\
RBV $(\%)$ & $-8.1 \pm 5.4$ & $-9.1 \pm 5.4$ & $-4.4 \pm 6.5 \dagger$ & $-3.3 \pm 4.7^{*} \dagger$ \\
Total ET (k) & $-191.2 \pm 68.5$ & $-230.3 \pm 79.8^{*}$ & $-410.0 \pm 170.4^{*} \dagger$ & $-413.3 \pm 122.9^{*} \dagger$ \\
ET Rate $(\mathrm{W})$ & $-13.3 \pm 4.7$ & $-16.2 \pm 5.6$ & $-14.2 \pm 6.0$ & $-14.5 \pm 4.3$ \\
\hline
\end{tabular}

Data in mean \pm SD. SBP: systolic BP; DBP: diastolic BP; HR: heart rate; bpm: beats per minute; CO: cardiac output: RBV: relative blood volume; ET: energy transfer. $* \mathrm{P} \varangle 0.05$ versus HD4; $\uparrow \mathrm{P} \varangle$ 0.05 versus HDF4. 
Figure 2.3 shows the mean peripheral systolic BP values at the respective time points for the 4 different study sessions. After an initial drop after 30 minutes in all treatments, an absence in further decrease in peripheral systolic BP was noted in the long treatment sessions after 120 minutes.

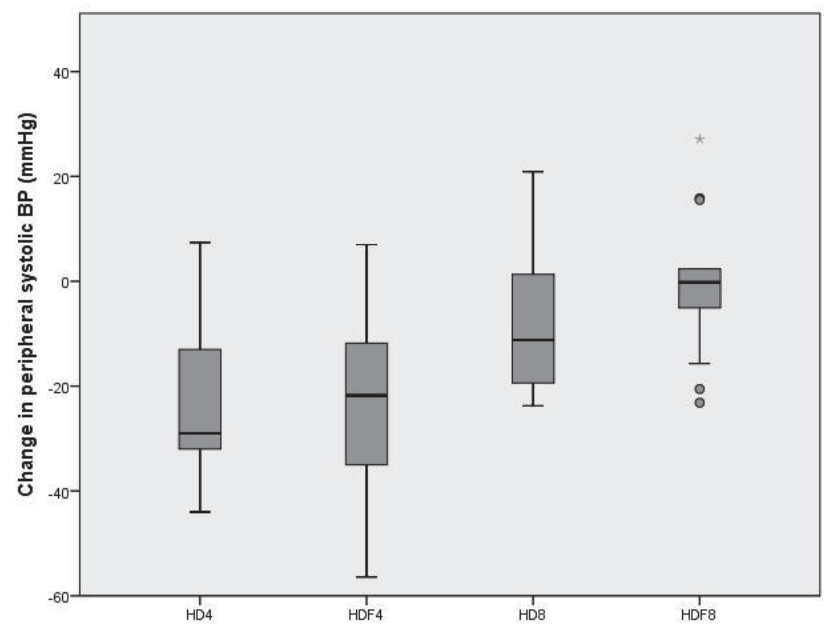

Figure 2.1 Change in peripheral systolic BP.

Data in median (horizontal black line) and interquartile range (box). Whisker bars extend to 1.5 times the height of the box and generally indicate the 5th and 95th percentile. Points are outliers. The asterisk is an extreme outlier.

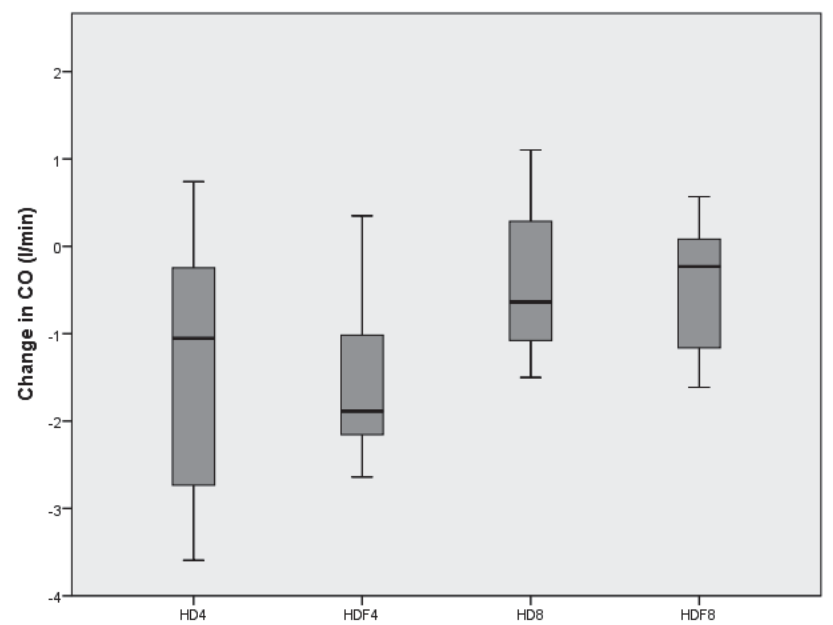

Figure 2.2 Change in cardiac output.

Data in median (horizontal black line), interquartile range (box), and minimal and maximal values (whiskers). 


\section{Thermal balance and energy expenditure}

Total energy transfer per treatment $(\mathrm{kJ})$ was significantly higher in the 8-hour dialysis sessions (HD4 -191.2 \pm 68.5 , HDF4 $-230.3 \pm 79.8 ; P=0.008$ versus HD4, HD8 $-410.0 \pm 170.4$; $\mathrm{P} \varangle 0.001$ versus HD4 and HDF4, HDF8 $-413.3 \pm 122.9 ; \mathrm{P} \varangle \mathrm{0} .001$ versus HD4 and HDF4). Energy transfer rate (W) however was not significantly different between treatments

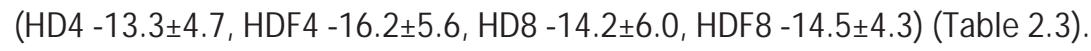

\section{Clearance of urea, creatinine, uric acid, phosphate, B2M and FGF23}

As shown in Figure 2.4, reduction ratios (RRs) of B2M and FGF23 were superior for extended HDF. No differences in total solute removal (TSR) for urea, creatinine, uric acid and phosphate were found between HD and HDF, but longer treatments resulted in the highest values. Total removal of B2M was superior in the extended HDF sessions (Table 2.4 and Figure 2.5). Dialytic clearance of small molecules was similar between the study sessions, but dialytic clearance of B2M was higher in HDF than in HD (Table 2.4).

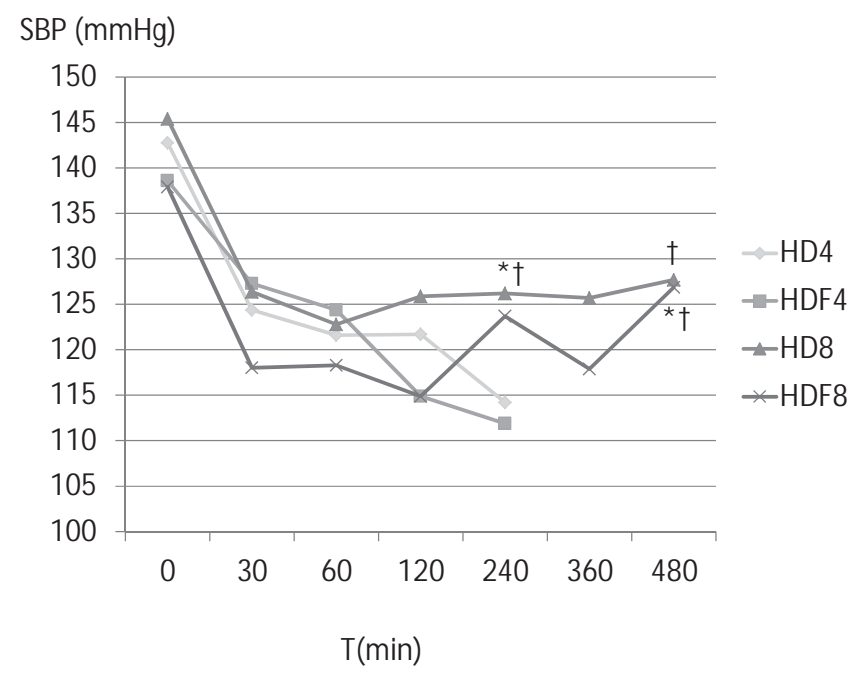

Figure 2.3 M ean SBP values at the respective time points for the 4 different study sessions.

Data in mean. Treatments were compared by paired t-test at the corresponding time points, and at the end of the treatments. $* P<0.05$ versus HD4; $\uparrow \mathrm{P} \measuredangle 0.05$ versus HDF4 
Table 2.4 Total solute removals (TSR) and dialytic clearances (Cls).

\begin{tabular}{lccccc}
\hline & Urea $(60 \mathrm{Da})$ & $\mathrm{Cr}(113 \mathrm{Da})$ & $\mathrm{UA}(168 \mathrm{Da})$ & $\mathrm{P}(95 \mathrm{Da})$ & $\mathrm{B} 2 \mathrm{M}(11.8 \mathrm{kDa})$ \\
\hline TSR $_{\text {HD4 }}$ & $31.8 \pm 10.8$ & $2.2 \pm 0.9$ & $1.0 \pm 0.2$ & $875 \pm 262$ & $99.5 \pm 39.3$ \\
TSR $_{\text {HDF4 }}$ & $31.8 \pm 8.3$ & $2.3 \pm 0.8$ & $1.1 \pm 0.2$ & $932 \pm 264$ & $135.0 \pm 49.4^{*}$ \\
TSR $_{\text {HD8 }}$ & $42.5 \pm 12.6^{*} \dagger$ & $3.1 \pm 1.1^{*} \dagger$ & $1.4 \pm 0.4^{*} \dagger$ & $1408 \pm 295^{*} \dagger$ & $143.3 \pm 49.6^{*}$ \\
TSR $_{\text {HDF8 }}$ & $42.0 \pm 13.9^{*} \dagger$ & $3.4 \pm 1.3^{*} \dagger$ & $1.3 \pm 0.4$ & $1490 \pm 283^{*} \dagger$ & $188.6 \pm 60.2^{*} \dagger \neq$ \\
$\mathrm{Cl}_{\text {HD4 }}$ & $214.0 \pm 24.3$ & $147.0 \pm 19.8$ & $145.9 \pm 22.3$ & $108.0 \pm 18.1$ & $31.4 \pm 11.9$ \\
$\mathrm{Cl}_{\text {HDF4 }}$ & $222.8 \pm 28.9$ & $153.9 \pm 22.0$ & $156.7 \pm 38.0$ & $110.1 \pm 10.3$ & $48.9 \pm 11.7^{*}$ \\
$\mathrm{Cl}_{\text {HD8 }}$ & $242.6 \pm 36.8$ & $146.2 \pm 2.5$ & $147.9 \pm 40.7$ & $99.5 \pm 17.8$ & $28.5 \pm 8.2 \dagger$ \\
$\mathrm{Cl}_{\text {HDF8 }}$ & $229.5 \pm 28.0$ & $144.1 \pm 17.9$ & $131.7 \pm 26.6$ & $102.9 \pm 13.2$ & $40.9 \pm 7.8^{*} \ddagger$ \\
\hline
\end{tabular}

Data in mean \pm SD. TSR for Urea, Cr: creatinine in g; UA: uric acid in g; TSR for B2M: beta2-microglobulin in mg; $\mathrm{P}$ : phosphorus in $\mathrm{mg} ; \mathrm{Cl}$ in $\mathrm{ml} / \mathrm{min}$. $* \mathrm{P} \varangle 0.05$ versus HD4; $\uparrow \mathrm{P} \varangle 0.05$ versus HDF4; $¥ \mathrm{P} \varangle .05$ versus HD8

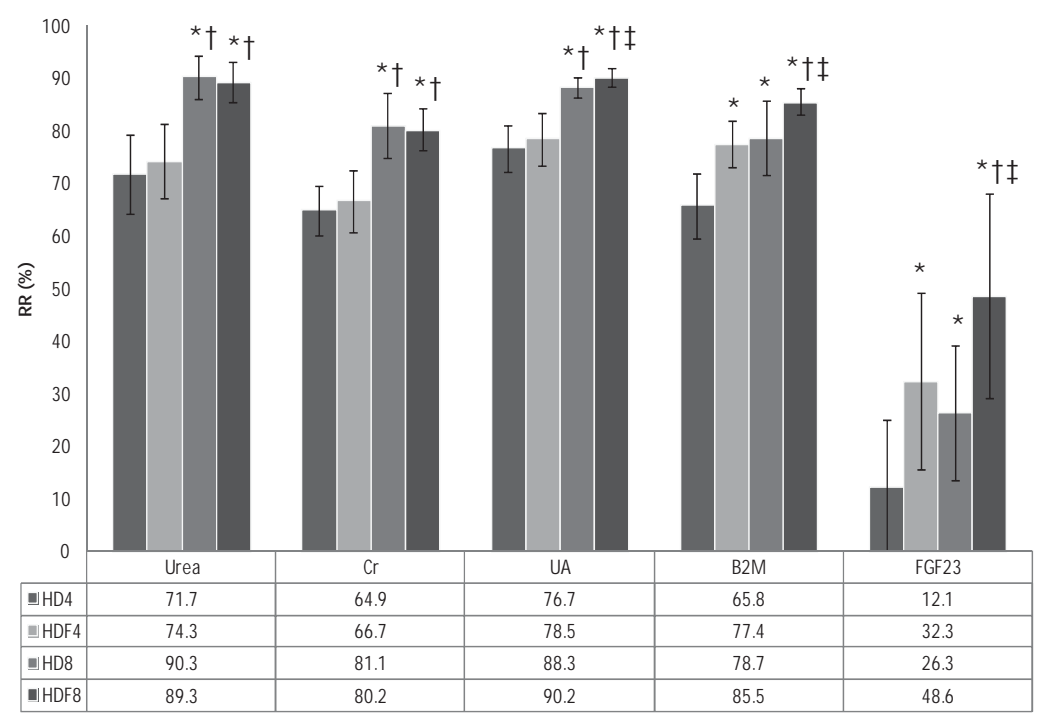

Figure 2.4 Reduction ratios.

Data in mean \pm SD. Cr: creatinine; UA: uric ucid; B2M: Beta2 microglobulin; FGF23: Fibroblast Growth Factor 23. $* P \triangleleft 0.05$ versus HD4; $\uparrow P \varangle 0.05$ versus HDF4; $\ddagger P \varangle 0.05$ versus HD8. 


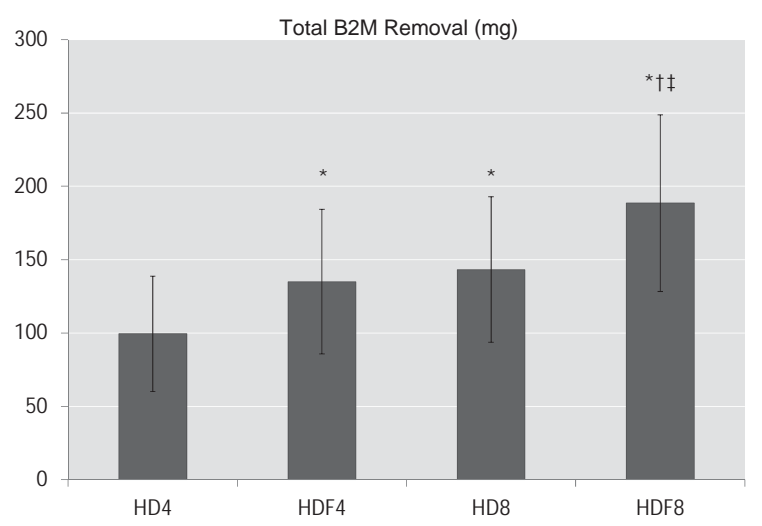

Figure 2.5 Total B2M removal.

Data in mean \pm SD. $* P \varangle 0.05$ versus HD4; $\uparrow \mathrm{P} \varangle 0.05$ versus HDF4; $\ddagger \mathrm{P} \varangle 0.05$ versus HD8.

\section{Discussion}

This randomized crossover study shows superiority of long-hour dialysis treatments over conventional treatments at the level of hemodynamic stability, but no apparent differences were found between HD and HDF. However, the addition of convection had beneficial effects on the removal of larger uremic toxins.

Improved hemodynamic control was likely related to better CO preservation in longhour dialysis, which seemed to result from slower RBV decline due to increased capillary refill. This latter finding is in line with the study from Basile et al. showing better plasma volume preservation with long-hour $\mathrm{HD}^{9}$. However, this was not yet linked before to $\mathrm{CO}$ stability, and no study before has looked at the effects of long-hour HDF on RBV and CO preservation and on intra-dialytic BP stability. Some studies suggested that conventional hemofiltration and HDF represent the best intermittent renal replacement therapy (RRT) for cardiovascular stability, resulting in a reduction of intradialytic hypotension compared to $\mathrm{HD}^{15,16}$. Others have shown that in low temperature HD the same hemodynamic stability can be achieved as in hemofiltration and $\mathrm{HDF}^{19,20}$.

We observed a drop in peripheral systolic BP after 30 minutes in all treatments (Figure 2.3). This may be due to overestimation of pre-dialytic BP or it may result from the release of vaso-active substances ${ }^{33-35}$. The reason for the absence of decrease in systolic 
BP after 120 minutes in the long sessions is likely due to lower ultrafiltration rates and better RBV and CO preservation.

Donauer and colleagues showed that online HDF had a more pronounced cooling effect due to additional energy loss through the infusion line ${ }^{20}$. In the present study, no difference in energy transfer rate was observed between the different treatments, including both HDF prescriptions. The lack of difference in our study between HD and HDF is most likely due to the usage of lower dialysate temperatures as compared to previous studies, in which the effect of additional energy loss through the infusion line may have been less pronounced. We found the total energy loss to be $13.3 \mathrm{~W}$ in HD4 as compared to $5.4 \mathrm{~W}$ during conventional HD and $16.6 \mathrm{~W}$ during online HDF in the study by Donauer ${ }^{20}$.

This study investigated intradialytic hemodynamic control in long-hour HDF. One previous study demonstrated that nocturnal HDF resulted in pre-dialysis systolic BP decrease, significant reduction in antihypertensive drugs, as well as significant rise in ejection fraction and decrease in left ventricular mass (LVM) and left ventricular mass index (LVMI ${ }^{22}$. Basile and colleagues observed that systolic BP decreased significantly during the 4-hour sessions, whereas it remained stable during the 8-hour sessions ${ }^{9}$. Interestingly, overhydration appeared in our patients to be slightly lower in the HDF8 group, likely due to reasons of chance since the treatment order was randomized. However, this did not appear to have an impact on the hemodynamic response during the study, given the fact that the hemodynamic control in HDF8 was comparable with HD8, and superior as compared to the shorter treatment sessions.

We performed comparative measurements of intravital microcirculation. In contrast to a previous study, we did not observe changes in microcirculatory indices during dialysis $^{36}$. Also, no differences between the different dialysis studies were found. Perhaps, ultrafiltration volumes were too low to result in differential microcirculation between 4-hour and 8-hour treatments. However, it should be acknowledged that we used a different analysis software as compared to the aforementioned study ${ }^{36}$.

In line with previous findings, we found higher phosphate removal in the extended dialysis sessions $s^{6,37-40}$. But in contrast to previous studies, we found similar phosphate removal in HD and HDF treatments ${ }^{41-43}$. A recent meta-analysis of randomized controlled trials on convective therapies versus low-flux HD revealed a net increase in the phosphate clearance in convective therapies by $20.8 \mathrm{ml} / \mathrm{min}(95 \% \mathrm{Cl} 12.3-29.2$, $\mathrm{P}<0.001$ ); there was also an $8.6 \%$ net increase in the phosphate reduction ratio in convective therapies $(95 \% \mathrm{Cl} 5.5-11.7, \mathrm{P} \varangle 0.001)^{44}$. The absence of difference in phosphate removal between HD and HDF in our report could be explained by the usage of high-flux membranes. Also, the use of relatively low convective volumes during HDF, which were due to blood flow rates uniformly set at $300 \mathrm{ml} / \mathrm{min}$ in order to comply 
with traditional blood flow prescriptions for long dialysis, may have played a role ${ }^{1}$. It should however be mentioned that the study by Minutolo et al. also used high-flux membranes for conventional $\mathrm{HD}$ and relatively low convective volumes during $\mathrm{HDF}^{41}$. In another study looking at phosphate removal in high-flux HD and HDF, phosphorus removal was higher $(1099 \pm 239$ in HDF versus $864 \pm 366 \mathrm{mg} / \mathrm{session}$ in $\mathrm{HD}, \mathrm{P} \varangle 0.05)$ and serum phosphorus levels were lower $(3.4 \pm 0.8$ in HDF versus $4.5 \pm 1.6 \mathrm{mg} / \mathrm{dl}$ in $\mathrm{HD}$, $P<0.05)$ in the HDF group at the end of 3 months follow-up, but this study did not use a randomized design ${ }^{45}$. The long-term effects of the different dialysis modalities on phosphate control were not assessed in our study.

In contrast to phosphate, B2M removal and dialytic clearance were found in our study to benefit both from increasing dialysis time and adding convection to the dialysis therapy. However, we have to acknowledge that mean pre-dialysis B2M levels were significantly higher before the HDF8 sessions as compared to the HD4 and HD8 sessions, which is likely due to chance given the randomization of the study. Raj et al. showed that B2M mass removal was significantly higher with low-flux nocturnal HD as compared to high-flux conventional HD $(585 \pm 309 \mathrm{mg}$ versus $127 \pm 48 \mathrm{mg}, \mathrm{P}<0.001)$ with a percentage reduction of $38.8 \pm 7.1 \%$ versus $20.5 \pm 5.8 \%$. Previous studies showed a reduction in pre-dialysis $B 2 \mathrm{M}$ levels after switching from low-flux-HD to online $\mathrm{HDF}^{43,46,47}$ and high-flux $\mathrm{HD}$ to online $\mathrm{HDF}^{48,49}$. The recent meta-analysis of randomized controlled trials on convective therapies versus low-flux HD by Susantitaphong et al. showed a $64.8 \mathrm{ml} / \mathrm{min}$ net increase in B2M clearance (95\% Cl 46.8-82.8, $\mathrm{P} \varangle 0.001)$, a $60.8 \%$ net increase in B2M RR ( $95 \% \mathrm{Cl} 51.1-70.5, \mathrm{P} \varangle \mathrm{0.001})$, and a $205 \mathrm{mg}$ net increase in total B2M removal per session in convective therapies (95\% Cl 154-256, $\mathrm{P} \varangle 0.001)^{44}$. Maduell et al. recently demonstrated in a prospective crossover study that in nocturnal alternate-night online HDF, B2M RR significantly increased after 6 months of the higher convective volume $(35-50 \mathrm{l}$ ) from $80.3 \pm 4.2 \%$ in conventional HDF to $84.2 \pm 4.3 \%$ at 6 months of nocturnal alternate-night HDF $(P \varangle 0.01)^{22}$. However, this study did not compare B2M removal with NHD.

Few comparative data exist on the removal of FGF23, a novel and emerging uremic toxin with possible relevance for cardiovascular morbidity and mortality ${ }^{50,51}$. In a crosssectional study, no significant differences in FGF23 levels were observed between patients treated with standard HD $(2677 \pm 4010 \mathrm{RU} / \mathrm{ml})$ or NHD $(4134 \pm 6310 \mathrm{RU} / \mathrm{ml})$, which is also possibly due to the high standard deviation and the relatively small groups $^{52}$. In contrast, Zaritsky found lower FGF23 levels in SDHD as compared to standard $\mathrm{HD}^{53}$, and Patrier et al. showed an increase in FGF23 RR with online HDF as compared to conventional high-flux $\mathrm{HD}^{23}$. In our study, FGF23 RR, although not as pronounced as for B2M, was highest during extended HDF. The overall lower RR values of FGF23 as compared to B2M , can be explained by its higher M W (32 kDa for FGF23 as 
compared to $11.8 \mathrm{kDa}$ for B2M). Total FGF23 removal could not be studied because the levels in dialysate were similar as in the negative control, i.e. dialysis fluid.

Limitations of this study are the relatively small number of patients. Patients were on average younger than the general dialysis patient. Moreover, average ultrafiltration volumes were low. However, previous studies have elucidated that myocardial stunning may even occur in the presence of limited ultrafiltration ${ }^{54}$. In addition, hemodynamic analysis was only performed during single treatment sessions. As the goal of the study was to analyse the detailed hemodynamic response, the long-term effects of the different treatments on hemodynamic response and specifically the incidence of intradialytic hypotension could not be assessed. The same limitation holds true for the analysis of uremic toxin removal where conclusions on the long-term effects of the different modalities on uremic toxin levels could not be made. Furthermore, convective volumes during HDF were relatively low, whereas recent trials showed a relation between convective volume and outcome ${ }^{16,42}$. However, as explained before, this prescription target was chosen in order to be compatible with uniform blood flow rates of $300 \mathrm{ml} / \mathrm{min}$ and not to compromise the comparison between the different treatments. Last, no post-dialysis blood samples were taken to assess rebound of uremic toxins.

This study has several strengths. First, it is a randomized crossover study. Next, hemodynamic effects were assessed under controlled conditions with multiple measurements. Also, direct dialysate quantification was performed to assess uremic toxin removal. Last, blood flow and dialysate flow were identical in HD and HDF treatments, thereby excluding a potential role of blood flow in thermal balance and hemodynamic stability and of dialysate flow in uremic toxin removal.

In conclusion, the hemodynamic response appeared significantly related to treatment time and not necessarily to the use of HDF as compared to HD, at least under circumstances of comparable thermal control. Furthermore, extending dialysis treatment significantly increased the removal of uremic toxins. Addition of convection augmented B2M removal and RR as well as FGF23 RR yielding comparable results between conventional HDF and extended HD but with superior results in extended HDF (Figures 2.4 and 2.5). More studies are required to assess the potential long-term benefits of nocturnal HDF. 


\section{References}

1. Perl J, Chan CT. Home hemodialysis, daily hemodialysis, and nocturnal hemodialysis. Am J Kidney Dis 2009;54:1171-84.

2. Leypoldt JK. Kinetics of beta2-microglobulin and phosphate during hemodialysis: effects of treatment frequency and duration. Semin Dial 2005;18:401-8.

3. Yuen D, Richardson RM, Chan CT. Improvements in phosphate control with short daily in-center hemodialysis. Clin Nephrol 2005;64:364-70.

4. Kohn OF, Coe FL, Ing TS. Solute kinetics with short daily home hemodialysis using slow dialysate flow rate. Hemodial Int 2010:14:39-46.

5. Raj DS, Ouwendyk M, Francoeur R, Pierratos A. Beta(2)-microglobulin kinetics in nocturnal haemodialysis. Nephrol Dial Transplant 2000;15:58-64.

6. Eloot S, Van Biesen W, Dhondt A, Van de Wynkele H, Glorieux G, Verdonck P, Vanholder R. Impact of hemodialysis duration on the removal of uremic retention solutes. Kidney Int 2008;73:765-70.

7. Basile C, Libutti P, Di Turo AL, Casino FG, Vernaglione L, Tundo S, Maselli P, De Nicolò EV, Ceci E, Teutonico A, Lomonte C. Removal of uraemic retention solutes in standard bicarbonate haemodialysis and long-hour slow-flow bicarbonate haemodialysis. Nephrol Dial Transplant 2011;26:1296-303.

8. Chan CT, Harvey PJ, Picton P, Pierratos A, Miller JA, Floras JS. Short-term blood pressure, noradrenergic, and vascular effects of nocturnal home hemodialysis. Hypertension 2003;42: 925-31.

9. Basile C, Libutti P, Di Turo AL, Tundo S, Maselli P, Casucci F, Losurdo N, Teutonico A, Vernaglione L, Lomonte C. Haemodynamic stability in standard bicarbonate haemodialysis and long-hour slow-flow bicarbonate haemodialysis. Nephrol Dial Transplant 2011;26:252-8.

10. Burton JO, Jefferies HJ, Selby NM, M clntyre CW. Hemodialysis-induced cardiac injury: determinants and associated outcomes. Clin J Am Soc Nephrol 2009;4: 914-20.

11. Burton JO, Jefferies HJ, Selby NM, M clntyre CW. Hemodialysis-induced repetitive myocardial injury results in global and segmental reduction in systolic cardiac function. Clin J Am Soc Nephrol 2009;4: 1925-31.

12. Jefferies HJ, Virk B, Schiller B, M oran J, M cIntyre CW. Frequent hemodialysis schedules are associated with reduced levels of dialysis-induced cardiac injury (myocardial stunning). Clin J Am Soc Nephrol 2011;6:1326-32.

13. Breidthardt T, Burton JO, Odudu A, Eldehni MT, Jefferies HJ, M clntyre CW. Troponin T for the detection of dialysis-induced myocardial stunning in hemodialysis patients. Clin J Am Soc Nephrol 2012;7: 1285-92.

14. Chan CT, Shen SX, Picton P, Floras J. Nocturnal home hemodialysis improves baroreflex effectiveness index of end-stage renal disease patients. J Hypertens 2008;26:1795-800.

15. Locatelli F, Altieri P, Andrulli S, Bolasco P, Sau G, Pedrini LA, Basile C, David S, Feriani M, M ontagna G, Di Iorio BR, Memoli B, Cravero R, Battaglia G, Zoccali C. Hemofiltration and hemodiafiltration reduce intradialytic hypotension in ESRD. J Am Soc Nephrol 2010;21:1798-807.

16. Maduell F, Moreso F, Pons M, Ramos R, Mora-Macià J, Carreras J, Soler J, Torres F, Campistol JM, Martinez-Castelao A; ESHOL Study Group. ESHOL study group. High-efficiency postdilution online hemodiafiltration reduced all-cause mortality in hemodialysis patients. J Am Soc Nephrol 2013;24: 487-97.

17. Genovesi S, Bracchi O, Fabbrini P, Luisetto E, Viganò MR, Lucini D, Malacarne M, Stella A, Pagani M. Differences in heart rate variability during haemodialysis and haemofiltration. Nephrol Dial Transplant 2007;22:2256-62.

18. Kooman J, Basci A, Pizzarelli F, Canaud B, Haage P, Fouque D, Konner K, Martin-Malo A, Pedrini L, Tattersall J, Tordoir J, Vennegoor M, Wanner C, ter Wee P, Vanholder R. EBPG guideline on haemodynamic instability. Nephrol Dial Transplant 2007;22 (Suppl 2):ii22-44.

19. van der Sande FM, Kooman JP, Konings C , Leunissen KM. Thermal effects and blood pressure response during postdilution hemodiafiltration and hemodialysis: the effect of amount of replacement fluid and dialysate temperature. J Am Soc Nephrol 2001;12:1916-20. 
20. Donauer J, Schweiger C, Rumberger B, Krumme B, Böhler J. Reduction of hypotensive side effects during online-haemodiafiltration and low temperature haemodialysis. Nephrol Dial Transplant 2003;18:1616-22.

21. Pedrini LA, De Cristofaro V, Comelli M, Casino FG, Prencipe M, Baroni A, Campolo G, Manzoni C, Colì L, Ruggiero P, Acquistapace I, Auriemma L. Long-term effects of high-efficiency on-line haemodiafiltration on uraemic toxicity. A multicentre prospective randomized study. Nephrol Dial Transplant 2011;26:2617-24.

22. Maduell $F$, Arias $M$, Durán $C E$, Vera $M$, Fontseré $N$, Azqueta $M$, Rico $N$, Pérez $N$, Sentis $A$, Elena $M$, Rodriguez N, Arcal C, Bergadá E, Cases A, Bedini JL, Campistol JM. Nocturnal, every-other-day, online haemodiafiltration: an effective therapeutic alternative. Nephrol Dial Transplant 2012;27:1619-31.

23. Patrier L, Dupuy AM, Granger Vallée A, Chalabi L, M orena M, Canaud B, Cristol JP. FGF-23 removal is improved by on-line high-efficiency hemodiafiltration compared to conventional high flux hemodialysis. J Nephrol 2013;26:342-9.

24. Kitzler TM, Sergeyeva O, M orris A, Kotanko P, Levin N. Noninvasive measurement of cardiac output in hemodialysis patients by Task Force Monitor: a comparison with Transonic system. ASAIO Journal 2007;53:561-5.

25. Schneditz D, Pogglitsch H, Horina J, Binswanger U. A blood protein monitor for the continuous measurement of blood volume changes during hemodialysis. Kidney Int 1990;38:342-6.

26. Vlahu CA, Lemkes BA, Struijk DG, Koopman MG, Krediet RT, Vink H. Damage of the endothelial glycocalyx in dialysis patients. J Am Soc Nephrol 2012;23:1900-8.

27. Frimodt-M øller M, Nielsen AH, Kamper A-L, Strandgaard S. Reproducibility of pulse-wave analysis and pulse-wave velocity determination in chronic kidney disease. Nephrol Dial Transplant 2008;23:594-600.

28. O'Rourke M F, Gallagher DE. Pulse wave analysis. J Hypertens Suppl 1996;14:S147-7.

29. Schneditz D, Wang E, Levin NW. Validation of haemodialysis recirculation and access blood flow measured by thermodilution. Nephrol Dial Transplant 1999;14:376-83.

30. M oissI UM, Wabel P, Chamney PW, Bosaeus I, Levin NW, Bosy-Westphal A, Korth O, M üller MJ, Ellegård L, M almros V, Kaitwatcharachai C, Kuhlmann M K, Zhu F, Fuller NJ. Body fluid volume determination via body composition spectroscopy in health and disease. Physiol M eas 2006;27:921-33.

31. Wizemann V, Rode C, Wabel P. Whole-body spectroscopy (BCM) in the assessment of normovolemia in hemodialysis patients. Contrib Nephrol 2008;161:115-8.

32. Krämer M, Polaschegg HD. Control of blood temperature and thermal energy balance during hemodialysis. Proc IEEE EM BS 1992;14:2299-300.

33. Kooman JP, Gladziwa U, Böcker G, Wijnen JA, Bortel L, Luik AJ, de Leeuw PW, van Hoff JP, Leunissen $\mathrm{KM}$. Blood pressure during the interdialytic period in haemodialysis patients: estimation of representative blood pressure values. Nephrol Dial Transplant 1992;7:917-23.

34. Agarwal R, M etiku T, Tegegne GG, Light RP, Bunaye Z, Bekele DM, Kelley K. Diagnosing hypertension by intradialytic blood pressure recordings. Clin J Am Soc Nephrol 2008;3:1364-72.

35. Beerenhout CH, Noris M, Kooman JP, Porrati F, Binda E, Morigi M, Bekers O, van der Sande FM, Todeschini M, Macconi D, Leunissen KM, Remuzzi G. Nitric oxide synthetic capacity in relation to dialysate temperature. Blood Purif 2004;22:203-9.

36. Bemelmans RHH, Boerma EC, Barendregt J, Ince C, Rommes JH, Spronk PE. Changes in the volume status of haemodialysis patients are reflected in sublingual microvascular perfusion. Nephrol Dial Transplant 2009;24:3487-92.

37. Mucsi I, Hercz G, Uldall R, Ouwendyk M, Francoeur R, Pierratos A. Control of serum phosphate without any phosphate binders in patients treated with nocturnal hemodialysis. Kidney Int 1998;53:1399-404.

38. Alloatti S, M olino A, M anes M, Bonfant G, Pellu V. Long nocturnal dialysis. Blood Purif 2002;20:525-30.

39. Sampaio MS, Ruzany F, Dorigo DM, Suassuna JH. Phosphate mass removal during hemodialysis: a comparison between eKT/V-matched conventional and extended hemodialysis. Am J Nephrol 2012;36:121-6.

40. Toussaint N, Boddington J, Simmonds R, Waldron C, Sommerville C, Agar J. Calcium phosphate metabolism and bone mineral density with nocturnal hemodialysis. Hemodial Int 2006;10:280-6. 
41. M inutolo R, Bellizzi V, Cioffi M, lodice C, Giannattasio P, Andreucci M, Terracciano V, Di lorio BR, Conte G, De Nicola L. Postdialytic rebound of serum phosphorus: pathogenetic and clinical insights. J Am Soc Nephrol 2002;13:1046-54.

42. Penne EL, van der Weerd NC, van den Dorpel MA, Grooteman MP, Lévesque R, Nubé MJ, Bots ML, Blankestijn PJ, ter Wee PM; CONTRAST Investigators. CONTRAST Investigators. Short-term effects of online hemodiafiltration on phosphate control: a result from the randomized controlled Convective Transport Study (CONTRAST). Am J Kidney Dis 2010;55:77-87.

43. Pedrini LA, De Cristofaro V, Comelli M, Casino FG, Prencipe M, Baroni A, Campolo G, Manzoni C, Colì L, Ruggiero $P$, Acquistapace I, Auriemma L. Long-term effects of high-efficiency on-line haemodiafiltration on uraemic toxicity. A multicenter prospective randomized study. Nephrol Dial Transplant 2011;26:2617-24.

44. Susantitaphong P, Siribamrungwong M, Jaber BL. Convective therapies versus low-flux hemodialysis for chronic kidney failure: a meta-analysis of randomized controlled trials. Nephrol Dial Transplant 2013;28:2859-74.

45. Francisco RC, Aloha M, Ramon PS. Effects of high-efficiency postdilution online haemodiafiltration and high-flux hemodialysis on serum phosphorus and cardiac structure and function in patients with endstage renal disease. Int Urol Nephrol 2013;45:1373-8.

46. Wizemann V, Lotz C, Techert F, Uthoff S. On-line haemodiafiltration versus low-flux hemodialysis. A prospective randomized study. Nephrol Dial Transplant 2000;15:S43-8.

47. Moon SJ, Kim DK, Chang JH, Kim CH, Kim HW, Park SY, Han SH, Lee JE, Yoo TH, Han DS, Kang SW. The impact of dialysis modality on skin hyperpigmentation in hemodialysis patients. Nephrol Dial Transplant 2009;24:2803-9.

48. Maduell F, del Pozo C, Garcia H, Sanchez L, Hdez-Jaras J, Albero M D, Calvo C, Torregrosa I, Navarro V. Change from conventional haemodiafiltration to on-line haemodiafiltration. Nephrol Dial Transplant 1999;14:1202-7.

49. Tiranathanagul K, Praditpornsilpa K, Katavetin P, Srisawat N, Townamchai N, Susantitaphong P, Tungsanga K, Eiam-Ong S. On-line hemodiafiltration in Southeast Asia: a three years prospective study of a single center. Ther Apher Dial 2009;13:56-62.

50. Gutiérrez OM, Mannstadt M, Isakova T, Rauh-Hain JA, Tamez H, Shah A, Smith K, Lee H, Thadhani R, Jüppner $\mathrm{H}$, Wolf $\mathrm{M}$. Fibroblast growth factor 23 and mortality among patients undergoing hemodialysis. N Engl J Med 2008;359:584-92.

51. Kovesdy CP, Quarles LD. Fibroblast growth factor-23: what we know, what we don't know, and what we need to know. Nephrol Dial Transplant 2013;29:2228-36.

52. Knap B, Veceric-Haler Z, Benedik M, Buturovic-Ponikvar J, Ponikvar R, Bren AF. Fibroblast growth factor 23 and left ventricular mass index in maintenance hemodialysis patients: standard versus long nocturnal hemodialysis. Ther Apher Dial 2013;17:407-11.

53. Zaritsky J, Rastogi A, Fischmann G, Yan J, Kleinman K, Chow G, Gales B, Salusky IB, Wesseling-Perry K. Short daily hemodialysis is associated with lower plasma FGF23 levels when compared with conventional hemodialysis. Nephrol Dial Transplant 2014;29:437-41.

54. Assa S, Hummel YM , Voors AA, Kuipers J, Westerhuis R, de Jong PE, Franssen CF. Hemodialysis-induced regional left ventricular systolic dysfunction: prevalence, patient and dialysis treatment-related factors, and prognostic significance. Clin J Am Soc Nephrol 2012;7:1615-23. 


\section{Chapter}

Protein-bound uremic toxins, dicarbonyl stress and AGEs in conventional and extended hemodialysis and hemodiafiltration

Cornelis T, Eloot S, Vanholder R, Glorieux G, van der Sande FM, Scheijen JL, Leunissen KM, Kooman JP, Schalkwijk CG Nephrol Dial Transplant 2015 Apr 9 [Epub ahead of print] 


\section{ABSTRACT}

Background: Protein-bound uremic toxins (PBUT), dicarbonyl stress and advanced glycation endproducts (AGEs) associate with cardiovascular disease in dialysis. Intensive hemodialysis (HD) may have significant clinical benefits. Aim of this study was to evaluate the acute effects of conventional and extended HD and hemodiafiltration (HDF) on reduction ratio (RR) and total solute removal (TSR) of PBUT, dicarbonyl stress compounds and AGEs.

Methods: Thirteen stable conventional HD patients randomly completed a single study of 4-hour HD (HD4), 4h HDF (HDF4), 8h HD (HD8), and 8h HDF (HDF8), with a 2-week interval between the study sessions. RR and TSR of PBUT [indoxyl sulfate (IS), p-cresyl sulfate (PCS), p-cresyl glucuronide (PCG), 3-carboxyl-4-methyl-5-propyl-2-furanpropionic acid (CMPF), indole-3 acetic acid (IAA), and hippuric acid (HA)], of free and protein-bound AGEs [N $\mathrm{N}^{\epsilon}$-(Carboxymethyl)lysine $(\mathrm{CML}), \mathrm{N}^{\epsilon}$-(Carboxyethyl)lysine (CEL), $\mathrm{N}_{\delta}$-(5-hydro-5-methyl-4-imidazolon-2-yl)-ornithine (M G-H1), pentosidine], as well as of dicarbonyl compounds [glyoxal (GO), methylglyoxal (MG), 3-deoxyglucosone (3-DG)] were determined.

Results: Compared to HD4, HDF4 resulted in increased RR of total and/or free fractions of IAA and IS as well as increased RR of free CML and CEL. HD8 and HDF8 showed a further increase of TSR and RR of PBUT (except CM PF), as well as of dicarbonyl stress and free AGEs compared to HD4 and HDF4. Compared to HD8, HDF8 only significantly increased RR of total and free IAA and free PCS, as well as RR of free CEL.

Conclusions: Dialysis time extension (HD8 and HDF8) optimized TSR and RR of PBUT, dicarbonyl stress and AGEs, whereas HDF8 was superior to HD8 for only a few compounds. 


\section{Introduction}

Accumulation of uremic toxins is associated with morbidity and mortality in patients with end-stage renal disease (ESRD). Whereas conventional hemodialysis (HD) is effective in removing small molecular weight (MW) uremic toxins, it is less efficient in removing middle $M W$ and protein-bound toxins ${ }^{1-3}$. Evidence regarding toxicity of protein-bound uremic toxins (PBUT) is predominantly available for the indole and phenol-type toxins ${ }^{2-11}$. The addition of convection and the use of protein-leaking membranes have resulted in improvement in reduction ratio (RR) and/or a reduction in plasma levels of PBUT ${ }^{12,13}$, although data are conflicting ${ }^{14}$. Extended slow-flow dialysis techniques showed no or limited additive effect on the removal of PBUT ${ }^{15,16}$. However, no study compared the removal between short and long dialysis timeframes while maintaining blood and dialysis flow rates the same, and there are no data on the effect of extended HDF.

Other types of toxins are dicarbonyl compounds, such as methylglyoxal (MG), glyoxal (GO) and 3-deoxyglucosone (3-DG). Dicarbonyl stress may be involved in vascular damage, either directly or through the formation of advanced glycation end-products $(A G E S)^{17-19}$. The formation of $\mathrm{N}^{\epsilon}$-(carboxymethyl)lysine $(\mathrm{CML}$ ) may be mediated by $\mathrm{GO}$ and 3-DG ${ }^{20,21} \cdot \mathrm{N}^{\epsilon}$-(carboxyethyl)lysine (CEL) can be formed by a non-enzymatic reaction between MG and lysine, whereas the formation of pentosidine is likely mediated through the Amadori pathway ${ }^{20,22} \cdot \mathrm{N}_{\delta}$-(5-hydro-5-methyl-4-imidazolon-2-yl)-ornithine (M G-H1) is a major AGE, and is formed by the reaction of MG with arginine. Tissue damage by AGEs results from protein cross-linking and from activation of AGE-specific receptors $(R A G E s)^{20,23}$. Plasma levels of $C M L$ are related to mortality in dialysis patients $^{24}$. Few studies have assessed the effect of dialysis on dicarbonyl stress compounds and $\mathrm{AGEs}^{25-28}$.

Intensive (short daily and nocturnal) HD is associated with significant improvement of several clinical and laboratory markers ${ }^{29}$. This could be partially explained by the optimized removal of uremic solutes ${ }^{29-31}$. Given the scarcity of comparative studies differentiating between the respective effects of time and convection on nonconventional uremic toxins, the aim of the present study was to compare the reduction in concentration, removal and clearance of PBUT, dicarbonyl stress compounds and AGEs between conventional and extended HD and HDF sessions. 


\section{M aterials and methods}

\section{Design of the study}

Details of the study and of the cohort have been described previously ${ }^{31}$. FX80®dialyzers were used for HD, and FX800 ®dialyzers were used for HDF. Blood flow was $300 \mathrm{ml} / \mathrm{min}$ and dialysate flow $600 \mathrm{ml} / \mathrm{min}$ in all study sessions. Total substitution volume was $15 \mathrm{~L}$ for HDF4 and 30L for HDF8. Online HDF was performed in post-dilution mode. The study was approved by the local ethics committee at the M aastricht University Medical Centre under number NL34908.068.10/MEC10-2-098, and was registered under clinicaltrials.gov number NCT01328119. Included patients gave written informed consent.

\section{Blood and dialysate sampling and measurements}

Serum samples were taken from the inlet bloodlines immediately before the onset of dialysis and at the end of the study session. A mixture of spent dialysate and ultrafiltrate was continuously collected in a fractionated fashion in a bag. At the end of the treatment and after thorough mixing, a $10 \mathrm{ml}$ sample was drawn from the collection bag in order to quantify solute concentration. All samples were stored at $-80^{\circ} \mathrm{C}$ until analysis.

To establish the total concentration of hippuric acid (HA) [79 Da, protein binding (PB) $\sim 40-50 \%$ ], indole-3-acetic acid (IAA) (175 Da, PB 75-95\%), indoxyl sulfate (IS) (212 Da, PB $200-95 \%$ ), p-cresyl sulfate (PCS) (187 Da, PB -95\%), p-cresyl glucuronide (PCG) (284 Da, PB 10-30\%) and 3-carboxyl-4-methyl-5-propyl-2-furanpropionic acid (CMPF) (240 Da, PB $\sim 100 \%)^{1,3}$, serum and dialysate samples were deproteinized by heat denaturation and were analyzed by reversed-phase high-performance liquid chromatography (RP-HPLC) ${ }^{32}$. IS and IAA (excitation $\lambda_{\text {ex }}: 280 \mathrm{~nm}$; emission $\lambda_{\text {em }}: 340 \mathrm{~nm}$ ), as well as PCS and PCG ( $\left.\lambda_{\text {ex }}: 265 \mathrm{~nm} ; \lambda_{\mathrm{em}}: 290 \mathrm{~nm}\right)$ were determined by fluorescence analysis. HA and CMPF were analyzed by UV detection at $254 \mathrm{~nm}^{34}$. Due to technical problems, dialysate concentrations of PCS could not be measured. Serum total protein (TP) was analyzed according to standard methods.

The following dicarbonyl compounds ( $\alpha$-oxaldehydes) were measured: glyoxal (GO, $58 \mathrm{Da}$ ), methylglyoxal (MG, 72 Da, PB 99\%) and 3-deoxyglucosone (3-DG, $162 \mathrm{Da}$ ). As representatives of $A G E s, N^{\epsilon}$-(Carboxyethyl)lysine (CEL, $\left.\pm 200 \mathrm{Da}\right), \mathrm{N}^{\epsilon}$-(Carboxymethyl)lysine (CML, $204 \mathrm{Da}, \mathrm{PB}>95 \%), \quad \mathrm{N}_{\delta^{-}}$(5-hydro-5-methyl-4-imidazolon-2-yl)ornithine (MG-H1), and pentosidine (342 Da, $\mathrm{PB}>95 \%)^{20,32}$ were measured in its free form as well as protein-bound. Ultraperformance liquid chromatography-tandem mass spectrometry (UPLC-MS) was used to determine protein-bound and free CML, CEL and 
MG-H1, as well as to analyze the dicarbonyl compounds GO, MG and 3-DG ${ }^{34,35}$. Pentosidine was detected in plasma protein hydrolysates by one-column RP-HPLC method $^{36}$.

\section{Calculations}

Total solute removal (TSR) was calculated by multiplying the dialysate solute concentration of the $10 \mathrm{ml}$ representative spent dialysate sample by the sum of dialysate volume, the ultrafiltration volume and (in the HDF sessions) the substitution volume. To calculate TSR of dicarbonyl stress compounds, we subtracted the concentration of fresh dialysate from the concentration of dialysate collected at the end of the study session. Dialytic clearances (Cls) were calculated as total solute removal divided by the dialysis duration and by the log mean of the average of pre- and post-dialysis solute blood concentration. Reduction ratio (RR) of solutes was defined as a function of pre-dialysis $\left(C_{\text {pre }}\right)$ and post-dialysis $\left(C_{\text {post }}\right)$ concentration $\left(R R=\left[1-\left(C_{\text {post }} / C_{\text {pre }}\right)\right]\right.$ $x 100)$. For all protein-bound compounds, concentration at the dialysis end $\left(C_{\text {post }}\right)$ was corrected for hemoconcentration based on TP concentration at start versus end of the dialysis session.

\section{Statistical analyses}

Data are expressed as mean $\pm S \mathrm{D}$. The Kolmogorov-Smirnov test was used to assess the normal distribution of the data. Comparison of mean values among groups was done using repeated measures ANOVA, and, if significant, followed by Fisher's Least Significant Difference (LSD) test to assess differences between individual time points. The tests were considered significant if the P-value was below 0.05 . P-values are presented in the Results section if the value was between 0.01 and 0.05 . The IBM SPSS Statistics 20 program was used for statistical analyses.

For paired comparison of 2 groups, 11 patients would be needed to observe significant differences in RR of $10 \%$ between 2 groups with a power of 0.8 and an alpha of 0.05 . The RR of PBUT was used as the primary outcome parameter. In a recent study by Meert et al, RR of PCS was $38 \pm 10 \%$ for conventional HD as compared to $50 \pm 8 \%$ for $\mathrm{HDF}^{13}$. 


\section{Results}

\section{Patient and treatment characteristics}

Thirteen prevalent conventional HD patients underwent, in random order, at midweek, a 4-hour HD (HD4) session, a 4-hour post-dilution online HDF (HDF4) session, an 8-hour HD (HD8) session, and an 8-hour post-dilution online HDF (HDF8) session, with a 2-week interval between the study sessions. Ten of the 13 patients were men. Mean age was $53.6 \pm 20.4$ years. Patients were on conventional HD therapy for $49 \pm 29$ months. Three patients had mean residual diuresis of $420 \pm 96 \mathrm{ml}$ per 24 hours. Treatment characteristics of the different dialysis modalities were described previously ${ }^{31}$. Baseline pre-dialysis serum levels of PBUT, AGEs, and dicarbonyl stress were comparable among the 4 strategies, except for higher baseline protein-bound CEL levels in HD8 compared to HDF4 and higher baseline protein-bound MG-H1 levels in HDF8 compared to HD8 (Table 3.1).

Table 3.1 Pretreatment serum levels of protein-bound uremic toxins, AGEs and dicarbonyl stress compounds.

\begin{tabular}{|c|c|c|c|c|}
\hline & HD4 & HDF4 & HD8 & HDF8 \\
\hline $\mathrm{PCG}_{\text {total }}$ & $0.60 \pm 0.73$ & $0.76 \pm 1.04$ & $0.63 \pm 0.67$ & $0.88 \pm 1.15$ \\
\hline$P C G_{\text {free }}$ & $0.54 \pm 0.66$ & $0.68 \pm 0.96$ & $0.58 \pm 0.63$ & $0.80 \pm 1.08$ \\
\hline$H A_{\text {total }}$ & $3.81 \pm 2.20$ & $4.12 \pm 2.82$ & $4.19 \pm 2.53$ & $4.37 \pm 2.67$ \\
\hline$H A_{\text {free }}$ & $2.15 \pm 1.41$ & $2.26 \pm 1.66$ & $2.43 \pm 1.81$ & $2.58 \pm 1.87$ \\
\hline IAA total & $0.21 \pm 0.23$ & $0.21 \pm 0.16$ & $0.19 \pm 0.17$ & $0.20 \pm 0.17$ \\
\hline IAA free & $0.063 \pm 0.082$ & $0.061 \pm 0.057$ & $0.055 \pm 0.056$ & $0.057 \pm 0.052$ \\
\hline $\mid \mathrm{S}_{\text {total }}$ & $2.95 \pm 1.37$ & $3.08 \pm 1.73$ & $3.02 \pm 1.28$ & $2.99 \pm 1.47$ \\
\hline$I S_{\text {free }}$ & $0.18 \pm 0.11$ & $0.18 \pm 0.12$ & $0.18 \pm 0.10$ & $0.19 \pm 0.13$ \\
\hline PCS total & $2.79 \pm 1.53$ & $2.64 \pm 2.04$ & $2.79 \pm 1.37$ & $2.85 \pm 1.80$ \\
\hline$P C S_{\text {free }}$ & $0.34 \pm 0.37$ & $0.16 \pm 0.15$ & $0.24 \pm 0.28$ & $0.19 \pm 0.15$ \\
\hline CM PF & $0.22 \pm 0.26$ & $0.22 \pm 0.30$ & $0.21 \pm 0.25$ & $0.22 \pm 0.27$ \\
\hline$C M L_{\text {protein-bound }}$ & $10493 \pm 3283$ & $10553 \pm 3050$ & $10690 \pm 3331$ & $10743 \pm 3194$ \\
\hline CM L free & $1733 \pm 604$ & $1854 \pm 492$ & $1839 \pm 626$ & $1783 \pm 430$ \\
\hline $\mathrm{CEL}_{\text {protein-bound }}$ & $1897 \pm 465$ & $1869 \pm 261$ & $2065 \pm 403 \dagger$ & $2061 \pm 468$ \\
\hline $\mathrm{CEL}_{\text {free }}$ & $986 \pm 376$ & $1061 \pm 299$ & $987 \pm 358$ & $1082 \pm 423$ \\
\hline M G-H $1_{\text {protein-bound }}$ & $3758 \pm 77$ & $3724 \pm 883$ & $3662 \pm 996$ & $4091 \pm 841 \ddagger$ \\
\hline$M G-H 1_{\text {free }}$ & $4786 \pm 2416$ & $5215 \pm 1994$ & $4981 \pm 2330$ & $6119 \pm 5082$ \\
\hline Pentosidine $_{\text {protein-bound }}$ & $272 \pm 149$ & $280 \pm 160$ & $277 \pm 157$ & $279 \pm 149$ \\
\hline MG & $1839 \pm 852$ & $1815 \pm 481$ & $2079 \pm 821$ & $1794 \pm 489$ \\
\hline GO & $1878 \pm 439$ & $1991 \pm 371$ & $1939 \pm 462$ & $1918 \pm 289$ \\
\hline 3-DG & $1740 \pm 666$ & $1675 \pm 392$ & $1829 \pm 580$ & $1528 \pm 226$ \\
\hline
\end{tabular}

Data in mean $\pm S D$. IS: indoxyl sulfate; PCS: p-cresyl sulphate; PCG: p-cresyl glucuronide; IAA: indole-3-acetic acid; CMPF: 3-carboxyl-4-methyl-5-propyl-2-furanpropionic acid; HA: hippuric acid in $\mathrm{mg} / \mathrm{dl}$. CML: $\mathrm{N}$-carboxymethyl-lysine;, CEL: N-carboxyethyl-lysine; MG-H1: N-hydromethyl-imidazolon-ornithine; MG: methylglyoxal;, GO: glyoxal; , 3-DG: 3-deoxyglucosone in nmol/l. † $\mathrm{P} \varangle 0.05$ versus HDF4; $¥ \mathrm{P} \varangle 0.05$ versus HD8. 
Since the patients underwent only one respective study session followed by a 2-week interval of conventional routine HD (for wash-out reasons), we did not see any differences in pre-dialysis uremic toxin levels at the end of each study period (Table 3.2).

Table 3.2 Pre-dialysis concentrations of studied uremic toxins 2 weeks after one single study session of the respective dialysis modalities (single study sessions were separated by a 2-week interval of routine conventional hemodialysis).

\begin{tabular}{|c|c|c|c|c|}
\hline & 2 weeks post-HD4 & 2 weeks post-HDF4 & 2 weeks post-HD8 & 2 weeks post-HDF8 \\
\hline PCG total & $1.03 \pm 1.09$ & $0.42 \pm 0.41$ & $0.97 \pm 1.30$ & $0.63 \pm 0.85$ \\
\hline$P C G_{\text {free }}$ & $0.94 \pm 1.02$ & $0.37 \pm 0.37$ & $0.89 \pm 1.21$ & $0.57 \pm 0.77$ \\
\hline$H A_{\text {total }}$ & $4.81 \pm 2.67$ & $3.33 \pm 2.30$ & $4.12 \pm 2.57$ & $3.97 \pm 2.56$ \\
\hline$H A_{\text {free }}$ & $2.84 \pm 2.03$ & $1.87 \pm 1.47$ & $2.38 \pm 1.67$ & $2.31 \pm 1.79$ \\
\hline IAA total & $0.17 \pm 0.10$ & $0.18 \pm 0.18$ & $0.22 \pm 0.16$ & $0.22 \pm 0.26$ \\
\hline $\mid A A_{\text {free }}$ & $0.054 \pm 0.042$ & $0.048 \pm 0.050$ & $0.065 \pm 0.059$ & $0.066 \pm 0.089$ \\
\hline $\mathrm{IS}_{\text {total }}$ & $3.16 \pm 1.12$ & $3.00 \pm 1.61$ & $3.03 \pm 1.53$ & $2.72 \pm 1.56$ \\
\hline IS $S_{\text {free }}$ & $0.20 \pm 0.12$ & $0.18 \pm 0.13$ & $0.20 \pm 0.12$ & $0.17 \pm 0.12$ \\
\hline $\mathrm{PCS}_{\text {total }}$ & $3.10 \pm 1.90$ & $2.31 \pm 1.19$ & $3.02 \pm 1.93$ & $2.88 \pm 1.88$ \\
\hline$P C S_{\text {free }}$ & $0.21 \pm 0.16$ & $0.26 \pm 0.34$ & $0.20 \pm 0.16$ & $0.28 \pm 0.39$ \\
\hline CMPF & $0.26 \pm 0.37$ & $0.23 \pm 0.29$ & $0.23 \pm 0.29$ & $0.16 \pm 0.12$ \\
\hline CM Lprotein-bound & $9965 \pm 2292$ & $10273 \pm 3784$ & $10388 \pm 2987$ & $10751 \pm 3630$ \\
\hline$C M L_{\text {free }}$ & $1910 \pm 419$ & $1747 \pm 526$ & $1843 \pm 489$ & $1649 \pm 801$ \\
\hline CEL protein-bound & $2036 \pm 229$ & $1878 \pm 593$ & $1886 \pm 289$ & $2028 \pm 463$ \\
\hline CEL free & $1130 \pm 272$ & $1023 \pm 377$ & $1028 \pm 420$ & $909 \pm 449$ \\
\hline M G-H1 $1_{\text {protein-bound }}$ & $3878 \pm 879$ & $3960 \pm 787$ & $3670 \pm 808 \dagger$ & $3790 \pm 1024$ \\
\hline$M G-H 1_{\text {free }}$ & $5394 \pm 1975$ & $5802 \pm 5377$ & $5211 \pm 2869$ & $4884 \pm 3111$ \\
\hline Pentosidine $_{\text {protein-bound }}$ & $263 \pm 116$ & $254 \pm 149$ & $267 \pm 161$ & $291 \pm 172$ \\
\hline MG & $1803 \pm 644$ & $1859 \pm 786$ & $1750 \pm 539$ & $2046 \pm 955$ \\
\hline GO & $2029 \pm 271$ & $1788 \pm 488$ & $1893 \pm 311$ & $1849 \pm 418$ \\
\hline 3-DG & $1787 \pm 427$ & $1630 \pm 541$ & $1606 \pm 496$ & $1537 \pm 392$ \\
\hline
\end{tabular}

Data in mean $\pm S D$. IS (indoxyl sulfate), PCS: p-cresyl sulphate: PCG: $p$-cresyl glucuronide: IAA: indole-3-acetic acid; CMPF: 3-carboxyl-4-methyl-5-propyl-2-furanpropionic acid in $\mathrm{mg} / \mathrm{dl}$; HA: hippuric acid in $\mathrm{mg} / \mathrm{dl}$ : CM L: $\mathrm{N}$-carboxymethyl-Iysine; CEL: N-carboxyethyl-lysine; MG-H1: N-hydromethyl-imidazolon-ornithine; MG: methylglyoxal; GO: glyoxal; 3-DG: 3-deoxyglucosone in $\mathrm{nmol} / \mathrm{l}$. $\dagger \mathrm{P} \varangle 0.05$ versus HDF4 (paired t-tests were performed; LSD was not valid because of the missing data for every patient, since no blood samples were taken 2 weeks after the last study session)

\section{Reduction ratio (RR), total solute removal (TSR) and dialytic clearance (Cl) of protein-bound uremic toxins}

RR of total and free fractions of PCG, HA, IAA, IS and PCS for the 4 different modalities are displayed in Figures 3.1 and 3.2, respectively. No free fraction of CM PF could be measured. Also, no reduction of CM PF was observed for any of the 4 modalities. For the total PBUT concentrations, HDF4 resulted in higher RR of IAA $(P=0.014)$ and IS $(P=0.035)$ compared to HD4. HD8 increased RR of total HA, IAA, IS and PCS compared to 
HD4 and HDF4 (Figure 3.1). HDF8 also resulted in significantly increased RR of total HA, IS and PCS compared to HD4 and HDF4, as well as in higher RR of total IAA compared to HD4, HDF4 and HD8 ( $P=0.043)$. For the free PBUT fractions, HDF4 showed a significant increase in RR of IAA compared to HD4 (Figure 3.2). HD8 showed higher RR of free IAA and IS compared to HD4 and HDF4. HDF8 resulted in higher RR of free PCG, HA, IS and PCS $(P=0.046)$ compared to HD4 and HDF4; as well as higher RR of free IAA and free PCS $(\mathrm{P}=0.045)$ compared to HD4, HDF4 and HD8.

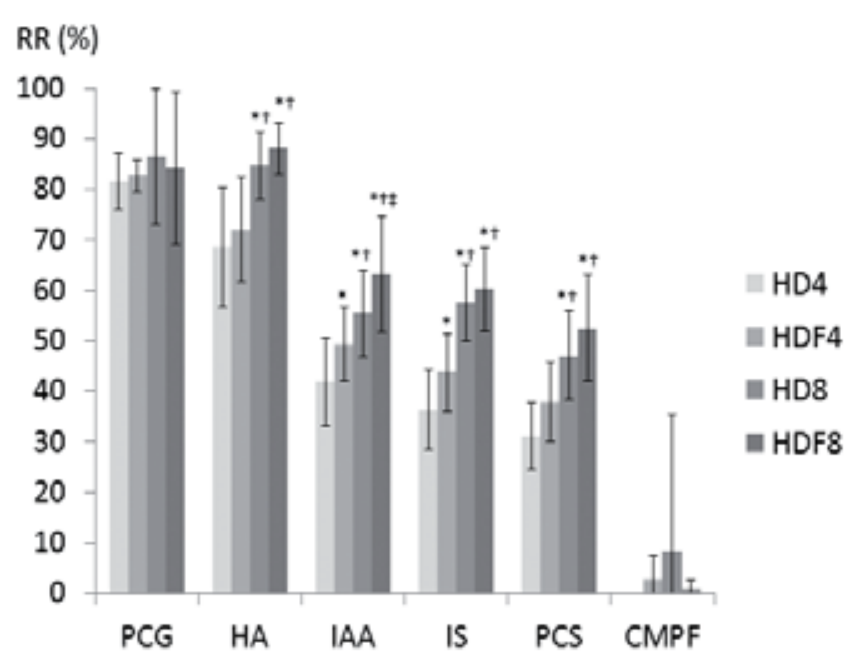

Figure 3.1 Reduction ratios (RR) of total protein-bound uremic toxins. PCG: p-cresyl glucuronide; HA: hippuric acid; IAA: indole-3-acetic acid; IS: indoxyl sulfate; PCS: p-cresyl sulfate; CMPF: 3carboxyl-4-methyl-5-propyl-2-furanpropionic acid; HD4: 4-hour hemodialysis; HDF4: 4-hour hemodiafiltration; HD8: 8-hour hemodialysis; HDF8: 8-hour hemodiafiltration. ${ }^{*} \mathrm{P} \triangleleft 0.05$ versus $H D 4 ; \dagger P \varangle 0.05$ versus HDF4; $¥ \mathrm{P} \varangle 0.05$ versus HD8

TSR and Cl of PBUT (except for PCS which could not be traced as such in the dialysate) are shown in Table 3.3. HDF4 did not result in a significant increase of TSR of PBUT compared to HD4. HD8 and HDF8 showed increased TSR of all PBUT compared to HD4 (PCG HDF8-HD4, $\mathrm{P}=0.017$; HA HD8-HD4, $\mathrm{P}=0.023$; HA HDF8-HD4, $\mathrm{P}=0.040$ ) except for TSR of IAA in HDF8 (HDF8-HD4, $P=0.058$ ). HD8 and HDF8 increased TSR of HA compared to HDF4. No significant differences in TSR of PBUT between HD and HDF were found for the same length of dialysis, either conventional of extended. $\mathrm{Cl}$ of the different PBUT was similar among groups. 


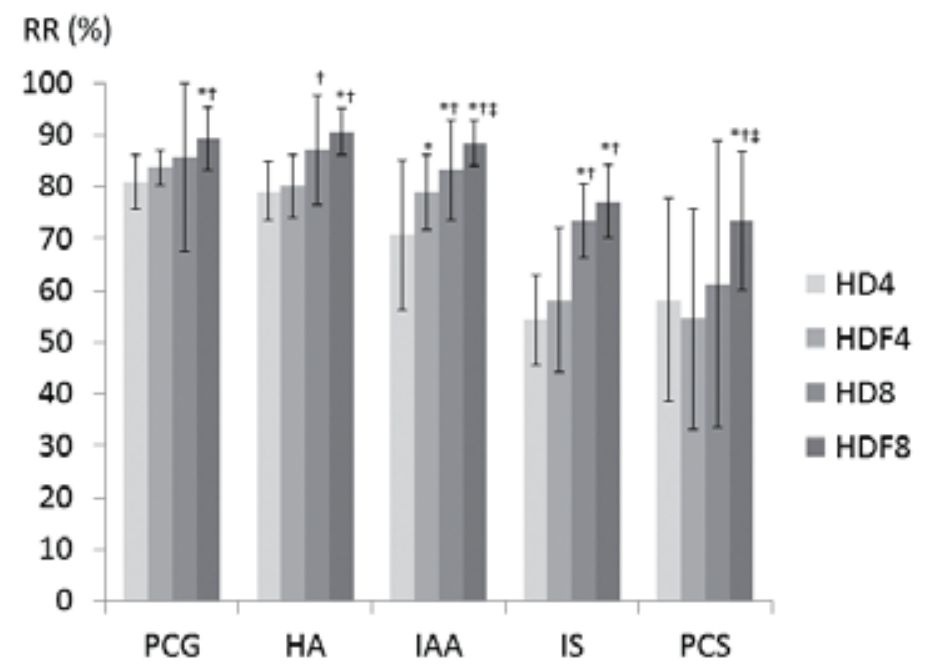

Figure 3.2 Reduction ratios (RR) of free protein-bound uremic toxins. PCG: $\mathrm{p}$-cresyl glucuronide; HA: hippuric acid; IAA: indole-3-acetic acid; IS: indoxyl sulfate; PCS: p-cresyl sulfate; HD4: 4-hour hemodialysis; HDF4: 4-hour hemodiafiltration; HD8: 8-hour hemodialysis; HDF8: 8-hour hemodiafiltration. $* \mathrm{P} \varangle 0.05$ versus $H D 4 ; \uparrow P \varangle 0.05$ versus HDF4; $\ddagger \mathrm{P} \varangle 0.05$ versus HD8

Table 3.3 Total solute removals (TSR) and dialytic clearances (Cls) of PBUT.

\begin{tabular}{lllll}
\hline & \multicolumn{1}{c}{ PCG } & \multicolumn{1}{c}{ HA } & \multicolumn{1}{c}{ IAA } & IS \\
\hline TSR $_{\text {HD4 }}$ & $108.0 \pm 139.0$ & $622.7 \pm 411.4$ & $14.6 \pm 10.9$ & $148.2 \pm 80.3$ \\
TSR $_{\text {HDF4 }}$ & $133.5 \pm 183.5$ & $657.7 \pm 450.3$ & $16.5 \pm 10.0$ & $176.5 \pm 91.2$ \\
TSR $_{\text {HD8 }}$ & $169.0 \pm 182.5^{*}$ & $965.0 \pm 802.2^{*} \dagger$ & $22.4 \pm 13.9^{*}$ & $239.5 \pm 128.4^{*}$ \\
TSR $_{\text {HDF8 }}$ & $180.7 \pm 235.1^{*}$ & $945.5 \pm 615.7^{* \dagger}$ & $19.6 \pm 11.9$ & $249.1 \pm 130.0^{*}$ \\
& & & & \\
$\mathrm{Cl}_{\text {HD4 }}$ & $158.8 \pm 42.3$ & $118.7 \pm 35.6$ & $41.5 \pm 18.0$ & $25.5 \pm 8.1$ \\
$\mathrm{Cl}_{\text {HDF4 }}$ & $151.1 \pm 35.2$ & $123.0 \pm 20.1$ & $40.4 \pm 15.8$ & $27.6 \pm 7.2$ \\
$\mathrm{Cl}_{\text {HD8 }}$ & $143.3 \pm 40.7$ & $114.0 \pm 26.9$ & $38.6 \pm 14.2$ & $25.0 \pm 6.5$ \\
$\mathrm{Cl}_{\text {HDF8 }}$ & $133.5 \pm 41.6$ & $114.7 \pm 26.9$ & $38.2 \pm 17.6$ & $28.0 \pm 9.9$ \\
\hline
\end{tabular}

Data in mean \pm SD. TSR for PCG: $p$-cresyl glucuronide; HA: hippuric acid; IAA: indole-3-acetic acid in mg; IS: indoxyl sulfate in $\mathrm{mg}$. $\mathrm{Cl}$ in $\mathrm{ml} / \mathrm{min}$. $* \mathrm{P} \varangle 0.05$ versus $\mathrm{HD} 4 ; \dagger \mathrm{P} \varangle 0.05$ versus HDF4

Reduction ratio (RR), total solute removal (TSR) and dialytic clearance (Cl) of dicarbonyl stress and RR of AGEs

HDF4 did not increase RR of dicarbonyl stress compounds compared to HD4 (Figure 3.3). HD8 increased RR of MG and GO compared to HD4 and HDF4 (GO HD8-HDF4, $\mathrm{P}=0.036)$ HDF8 increased RR of MG and GO compared to HD4. RR of 3-DG was not increased by HD8 and HDF8 compared to HD4 and HDF4 (RR 19.1+27.2\% in HD4, 
$12.7 \pm 17.4 \%$ in HDF4, $11.1 \pm 19.0 \%$ in $\mathrm{HD} 8$, and $12.0 \pm 17.3 \%$ in HDF8 sessions) (Figure 3.3).

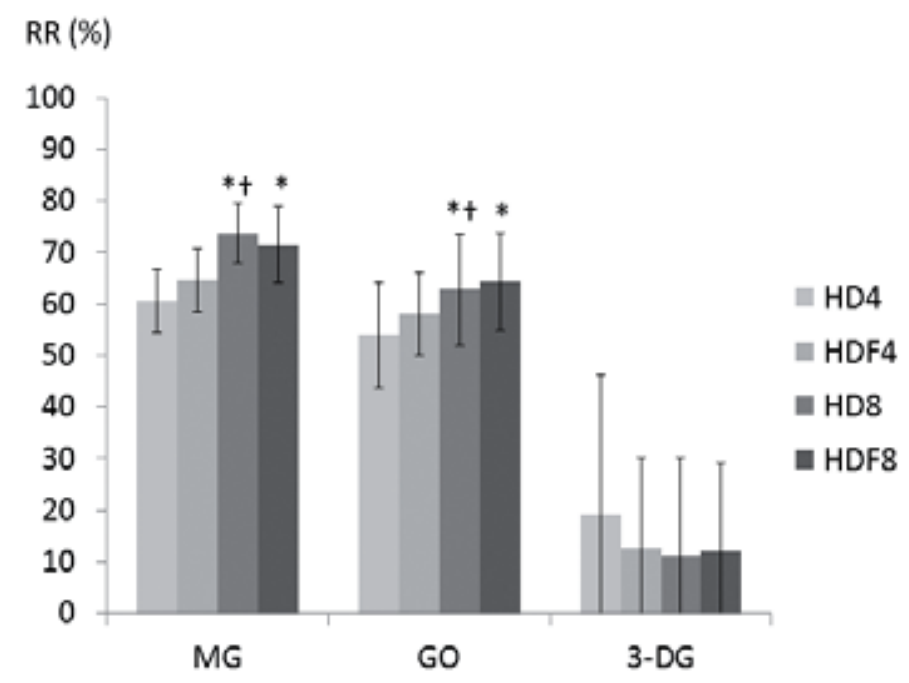

Figure 3.3 Reduction ratios (RR) of dicarbonyl stress. MG: methylglyoxal; GO: glyoxal; HD4: 4-hour hemodialysis; HDF4: 4-hour hemodiafiltration; HD8: 8-hour hemodialysis; HDF8: 8-hour hemodiafiltration. $* \mathrm{P} \varangle 0.05$ versus HD4; $\uparrow \mathrm{P} \varangle 0.05$ versus HDF4.

TSR and $\mathrm{Cl}$ of dicarbonyl stress compounds are shown in Table 3.4. HDF4 did not increase TSR of GO, MG or 3-DG compared to HD4. HD8 increased TSR of GO compared to HD4 ( $P=0.035$ ) as well as TSR of 3-DG compared to HD4 and HDF4. Similarly to HD8, HDF8 resulted in increased TSR of GO compared to HD4 ( $P=0.041)$ as well as increased TSR of 3-DG compared to HD4 and HDF4. There was also a trend to higher TSR for M G in HD8 and HDF8 compared to HD4 and HDF4. Cl of the different dicarbonyl stress compounds was similar among groups except for higher $\mathrm{Cl}$ of GO in HDF8 compared to HD4 ( $P=0.017)$.

HDF4 showed a significant increase in RR of free CML $(P=0.016)$ and CEL $(P=0.034)$ compared to HD4 (Figure 3.4). HD8 resulted in higher RR of free CM L, CEL and M G-H1 compared to HD4 and HDF4. HDF8 increased RR of free MG-H1 compared to HD4 and HDF4, as well as increased RR of free CEL compared to HD4, HDF4 and HD8 (free CEL HDF8-HD8, $P=0.016$ ). No reduction in the protein-bound AGEs (CML, CEL, M G-H1 and pentosidine) was found in the 4 different dialysis modalities. 
Table 3.4 Total solute removals (TSR) and dialytic clearances (Cls) of dicarbonyl stress compounds.

\begin{tabular}{llcc}
\hline & GO & M G & 3-DG \\
\hline TSR $_{\text {HD4 }}$ & $14.9 \pm 4.5$ & $39.5 \pm 13.2$ & $51.6 \pm 23.5$ \\
TSR $_{\text {HDF4 }}$ & $15.9 \pm 5.7$ & $46.2 \pm 15.9$ & $48.8 \pm 21.8$ \\
TSR $_{\text {HD8 }}$ & $21.2 \pm 10.0^{*}$ & $62.0 \pm 29.7$ & $94.8 \pm 25.3^{*} \dagger$ \\
TSR $_{\text {HDF8 }}$ & $21.9 \pm 7.7^{*}$ & $57.9 \pm 24.0$ & $102.7 \pm 34.8^{*} \dagger$ \\
& & & \\
$\mathrm{Cl}_{\text {HD4 }}$ & $47.8 \pm 12.1$ & $163.2 \pm 46.7$ & $122.1 \pm 55.9$ \\
$\mathrm{Cl}_{\text {HDF }}$ & $54.0 \pm 24.6$ & $184.7 \pm 63.8$ & $124.2 \pm 22.8$ \\
$\mathrm{Cl}_{\text {HD8 }}$ & $37.9 \pm 15.4$ & $124.4 \pm 45.9$ & $107.5 \pm 37.4$ \\
$\mathrm{Cl}_{\text {HDF8 }}$ & $39.0 \pm 13.7^{*}$ & $128.0 \pm 51.1$ & $116.5 \pm 29.4$ \\
\hline
\end{tabular}

Data in mean \pm SD. TSR for GO: glyoxal; MG: methylglyoxal in $\mu$ mol;3-DG: 3-deoxyglucosone in $\mu \mathrm{mol}$. $\mathrm{Cl}$ in $\mathrm{ml} / \mathrm{min}$. * $\mathrm{P} \varangle 0.05$ versus HD4; $\uparrow \mathrm{P} \varangle 0.05$ versus HDF4.

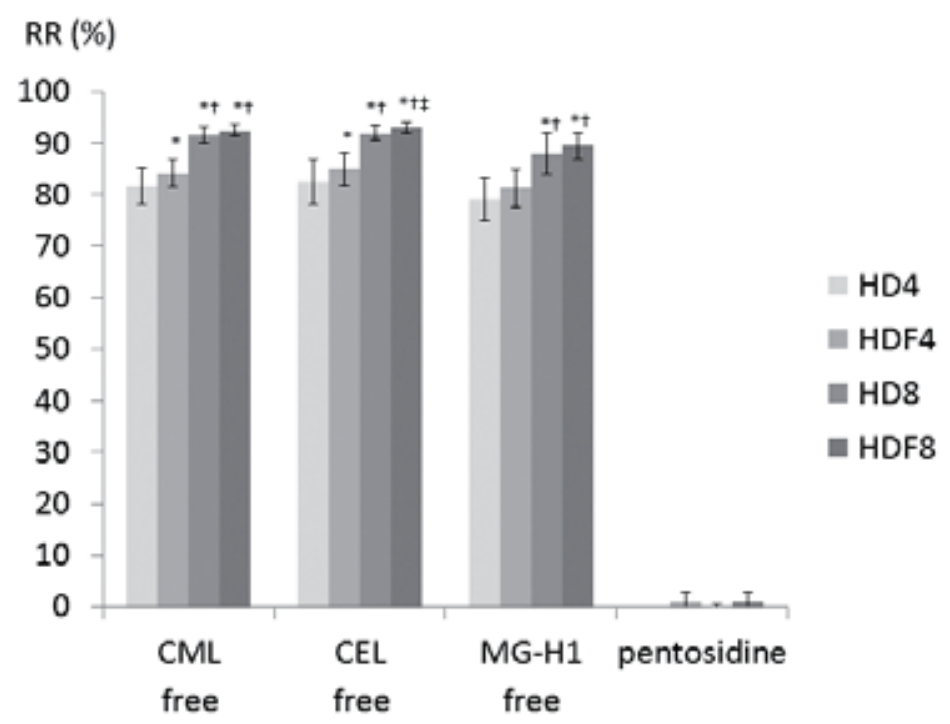

Figure 3.4 Reduction ratios (RR) of AGEs. CM L: $N^{€}-\left(\right.$ carboxymethyl)lysine; CEL: $N^{€}-($ carboxyethyl)lysine; M G-H1:N ${ }_{8}$-(5-hydro-5-methyl-4-imidazolon-2-yl)-ornithine; HD4: 4-hour hemodialysis; HDF4: 4-hour hemodiafiltration; HD8: 8-hour hemodialysis; HDF8: 8-hour hemodiafiltration. * $\mathrm{P} \varangle 0.05$ versus $H D 4 ; \uparrow P \varangle 0.05$ versus $H D F 4 ; ~ \ddagger P \varangle 0,05$ versus $H D 8$.

\section{Discussion}

This randomized crossover study shows, for the first time, markedly increased TSR and RR of PBUT, dicarbonyl stress compounds and AGEs by prolonging dialysis treatment time. HD8 and HDF8 increased RR and TSR of most PBUT, dicarbonyl stress and free AGEs compared to HD4 and HDF4. HDF8 resulted in highest RR of total and free IAA, free PCS and free CEL compared to HD4, HDF4 and HD8. The effects of time and 
convection on the reduction and removal of uremic toxins could be optimally disentangled by comparing conventional and extended sessions of HD and HDF using identical prescriptions of blood and dialysate flow among the four groups.

The most important finding of this study is an increased removal of PBUT during long dialysis, if blood and dialysate flow are kept at 300 and $600 \mathrm{ml} / \mathrm{min}$ respectively. This is in contrast with findings from Basile et al. who observed no increased removal of IAA, IS, HA and homocysteine during 8 hours of slow-flow dialysis while using blood and dialysate flows of only $190 \mathrm{ml} / \mathrm{min}^{15}$. Since time added more than convection to their removal, it seems that the clearance of hippuric, indolic and phenolic PBUT is predominantly diffusive, and thus dependent upon blood and dialysate flows. It also suggests that their clearance is mainly achieved by removal of their free fraction. Increasing dialysis time will progressively lower free PBUT levels, facilitating dissociation of bound toxins from albumin resulting in continued availability of these toxins for diffusion to the dialysate, but with protein binding as a refraining factor. Moreover, a multi-compartmental behavior of PBUT, by which increasing dialysis time could allow refilling of PBUT from secondary compartments, was also suggested by Meijers et al. who found lower RR than in our study with nocturnal HD but with lower blood and dialysate flows ${ }^{16}$. The importance of diffusion on removal of PBUT during extended dialysis was also highlighted by Sirich et al, who showed better clearance if a high dialyzer surface was combined to high dialysate flow ${ }^{37}$. Luo et al. demonstrated an increase in dialytic clearance of PBUT by increasing dialysate flow through the use of two high-flux dialyzers in series ${ }^{38}$. Also in a study of short daily HD, in which blood flows of $250 \mathrm{ml} / \mathrm{min}$ and dialysate flows of $500 \mathrm{ml} / \mathrm{min}$ were applied, a reduction in predialytic levels of $\mathrm{p}$-cresol, IS and IAA was observed ${ }^{33}$.

The limited additive effect of convection on PBUT could be explained by the fact that HDF mainly contributes to optimized removal of middle molecules whereas the additive effect on small molecules (such as the free fraction of PBUT) is limited. RR of total IS and RR of total and free IAA in our study was higher with HDF4 compared to HD4, without a significant increase in TSR. Interestingly, whereas no effect of HDF4 on the RR of PCS was observed compared to HD4, RR of free PCS was higher for HDF8 compared to HD4 HDF4 and HD8 In the literature, divergent results of the effects of convective techniques on RR and/or TSR of PBUT are reported, but even if a positive effect was found, the difference was never spectacular ${ }^{12-14,39,40}$.

RR and TSR of dicarbonyl products and free AGEs were also significantly enhanced by increasing treatment time. Convection had an additional effect on RR of free CML and CEL. MG, GO and 3-DG are relatively small substances with high protein binding reversibility $^{41}$. Protein binding reversibility however does not appear to apply for the 
AGES CM L, CEL and pentosidine, whose total fractions actually increased during dialysis, likely as a result of hemoconcentration. A recent meta-analysis showed a significant reduction in pre-dialytic plasma levels of pentosidine, but not in the RR of pentosidine and AGEs with high-flux HD or HDF as compared to low-flux $\mathrm{HD}^{40}$, suggesting that other mechanisms (e.g. a decrease in inflammation) might lead to beneficial effects of these treatments on AGE levels. Lin et al. observed increased RR and clearance of AGEs with online HDF as compared to high-flux HD ${ }^{28}$. Beck et al. also found a reduction in plasma AGEs after a session with online $\mathrm{HDF}^{42}$. Among the scanty studies addressing the removal of dicarbonyl compounds, Agalou et al. found that a single 4-hour HD session with a polysulfone dialyzer reduced levels of free $\mathrm{CM} L$, CEL, pentosidine but also of free GO and MG, in a way fairly similar to the findings in our study with standard 4-hour $H D^{25}$. However, our results were markedly more impressive during the extended sessions.

Of note, we observed for a number of molecules divergent effects on RR versus TSR in the comparison of HD versus HDF as well as of extended versus short treatment time sessions. In general, significant differences in RR without differences in TSR between $\mathrm{HD}$ and HDF are to be explained by a more efficient removal during HDF from the plasmatic compartment by highly efficient dialysis which is not matched by a corresponding solute shift from the extraplasmatic to the intraplasmatic compartment. With an increase in treatment time, the dissociation of inter-compartmental transport becomes less pronounced as there is more opportunity for equilibration between compartments. An additional explanation for divergent effects on RR and TSR may be the differential generation and reactivity of studied molecules, which may especially apply for the dicarbonyl stress compounds.

Our study has some limitations. First, patient sample size was small. Also, long-term effects of the different treatments on these non-traditional uremic toxin levels could not be assessed. Convective volumes during HDF were relatively low, especially for 4-hour $\mathrm{HDF}^{43,44}$. Dialysate concentrations of free AGEs were not measured. No postdialysis blood samples were taken to assess rebound of uremic toxins, but this bias was obviated by also assessing TSR.

This study has several strengths. First, it is a randomized crossover study of multiple dialysis modalities analyzing a multitude of non-traditional uremic toxins which have been related to outcome as well as end-organ complications in clinical and experimental studies. Direct dialysate quantification was performed to assess uremic toxin removal. Last, blood flow and dialysate flow were identical in HD and HDF treatments allowing the strict separation of the time and convection component. 
In conclusion, in this randomized crossover study, extended HD and HDF, using comparable blood flows as in standard dialysis sessions, enhanced RR and removal of PBUT, dicarbonyl stress and free AGEs. Conventional HDF had an additive effect on the RR of some PBUT and free AGEs, but not on dicarbonyl compounds. Optimal RR was obtained with extended HDF, especially for RR of total and free IAA and free PCS, as well as RR of free CEL. The clinical relevance of these findings needs to be addressed in controlled prospective trials. 


\section{References}

1. Vanholder R, De Smet R, Glorieux G, et al: European Uremic Toxin Work Group (EUTox). Review on uremic toxins: classification, concentration, and interindividual variability. Kidney Int 2003;63:1934-43.

2. Neirynck N, Glorieux G, Schepers E, Pletinck A, Dhondt A, Vanholder R. Review of protein-bound toxins, possibility for blood purification therapy. Blood Purif 2013;35 Suppl 1:45-50.

3. Niwa T. Removal of protein-bound uraemic toxins by haemodialysis. Blood Purif 2013;35 Suppl 2:20-5.

4. Liabeuf S, Drüeke TB, Massy ZA. Protein-bound uremic toxins: new insight from clinical studies. Toxins (Basel) 2011;3:911-9.

5. Barreto FC, Barreto DV, Liabeuf S, et al. European Uremic Toxin Work Group (EUTox). Serum indoxyl sulfate is associated with vascular disease and mortality in chronic kidney disease patients. Clin J Am Soc Nephrol 2009;4:1551-8.

6. Liabeuf S, Barreto DV, Barreto FC, et al. European Uraemic Toxin Work Group (EUTox). Free pcresylsulphate is a predictor of mortality in patients at different stages of chronic kidney disease. Nephrol Dial Transplant 2010;25:1183-91.

7. Liabeuf S, Glorieux G, Lenglet A, et al. European Uremic Toxin (EUTox) Work Group. Does pcresylglucuronide have the same impact on mortality as other protein-bound uremic toxins? PLoS One 2013;24;8:e67168.

8. Vanholder R, Schepers E, Pletinck A, Nagler EV, Glorieux G. The uremic toxicity of indoxyl sulfate and pcresyl sulfate: a systematic review. J Am Soc Nephrol 2014;25:1897-907.

9. Ito S, Yoshida M. Protein-bound uremic toxins: new culprits of cardiovascular events in chronic kidney disease patients. Toxins (Basel) 2014;6:665-78.

10. Meijers BK, Evenepoel P. The gut-kidney axis: indoxyl sulfate, p-cresyl sulfate and CKD progression. Nephrol Dial Transplant 2011;26:759-61.

11. Watanabe $\mathrm{H}$, Miyamoto $\mathrm{Y}$, Otagiri $\mathrm{M}, \mathrm{M}$ aruyama $\mathrm{T}$. Update on the pharmacokinetics and redox properties of protein-bound uremic toxins. J Pharm Sci 2011;100:3682-95.

12. Meert N, Waterloos MA, Van Landschoot M, et al. Prospective evaluation of the change of predialysis protein-bound uremic solute concentration with postdilution online hemodiafiltration. Artif Organs 2010;34:580-5.

13. Meert N, Eloot S, Schepers $\mathrm{E}$, et al. Comparison of removal capacity of two consecutive generations of high-flux dialysers during different treatment modalities. Nephrol Dial Transplant 2011;26:2624-30.

14. Krieter DH, Hackl A, Rodriguez A, et al. Protein-bound uremic toxin removal in haemodialysis and postdilution haemodiafiltration. Nephrol Dial Transplant 2010;25:212-8.

15. Basile C, Libutti P, Di Turo AL, et al. Removal of uraemic retention solutes in standard bicarbonate haemodialysis and long-hour slow-flow bicarbonate haemodialysis. Nephrol Dial Transplant 2011;26:1296-303.

16. Meijers B, Toussaint ND, M eyer T, et al. Reduction in protein-bound solutes unacceptable as marker of dialysis efficacy during alternate-night nocturnal hemodialysis. Am J Nephrol 2011;34:226-32.

17. Thornalley PJ. Glycation free adduct accumulation in renal disease: the new AGE. Pediatr Nephrol 2005;20:1515-22.

18. Thornalley PJ, Rabbani N. Highlights and hotspots of protein glycation in end-stage renal disease. Semin Dial 2009;22:400-4.

19. Rabbani N, Thornalley PJ. Methylglyoxal, glyoxalase 1 and the dicarbonyl proteome. Amino Acids 2012;42:1133-42.

20. Weiss MF, Erhard P, Kader-Attia FA, et al. Mechanisms for the formation of glycoxidation products in end-stage renal disease. Kidney Int 2000;57:2571-85.

21. van de Kerkhof J, Schalkwijk CG, Konings CJ, et al. Nepsilon-(carboxymethyl)lysine, Nepsilon(carboxyethyl)lysine and vascular cell adhesion molecule-1 (VCAM-1) in relation to peritoneal glucose prescription and residual renal function; a study in peritoneal dialysis patients. Nephrol Dial Transplant 2004;19:910-6.

22. M iyata T, Ueda Y, Yamada Y, et al. Accumulation of carbonyls accelerates the formation of pentosidine, an advanced glycation end product: carbonyl stress in uremia. J Am Soc Nephrol 1998;9;69-77. 
23. Gaens KH, Stehouwer CD, Schalkwijk CG. Advanced glycation end products and its receptor for advanced glycation endproducts in obesity. Curr Opin Lipidol 2013;24:4-11.

24. Wagner Z, Molnár M, M olnár GA, et al. Serum carboxymethyllysine predicts mortality in hemodialysis patients. Am J Kidney Dis 2006;47:294-300.

25. Agalou S, Ahmed N, Thornalley PJ, Dawnay A. Advanced glycation end product free adducts are cleared by dialysis. Ann N Y Acad Sci 2005;1043:734-9.

26. Fagugli RM, Vanholder R, De Smet R, et al. Advanced glycation end products: specific fluorescence changes of pentosidine-like compounds during short daily hemodialysis. Int J Artif Organs 2001;24: 256-62.

27. Gerdemann A, Wagner Z, Solf A, et al. Plasma levels of advanced glycation end products during haemodialysis, haemodiafiltration and haemofiltration: potential importance of dialysate quality. Nephrol Dial Transplant 2002;17:1045-49.

28. Lin CL, Huang CC, Yu CC, Yang HY, Chuang FR, Yang CW. Reduction of advanced glycation end product levels by on-line haemodiafiltration in long-term haemodialysis patients. Am J Kidney Dis 2003;42: 524-31.

29. Perl J, Chan CT. Home hemodialysis, daily hemodialysis, and nocturnal hemodialysis. Am J Kidney Dis 2009;54:1171-84.

30. Eloot S, Van Biesen W, Dhondt A, Van de Wynkele H, Glorieux G, Verdonck P, Vanholder R. Impact of hemodialysis duration on the removal of uremic retention solutes. Kidney Int 2008;73:765-70.

31. Cornelis T, van der Sande FM, Eloot S, et al. Acute hemodynamic effects and uremic toxin removal in conventional and extended hemodialysis and hemodiafiltration: a randomized crossover study. Am J Kidney Dis 2014;64:247-56.

32. Vanholder R, Hoefliger N, De Smet R, Ringoir S. Extraction of protein bound ligands from azotemic sera: comparison of 12 deproteinization methods. Kidney Int 1992;41:1707-12.

33. Fagugli RM, De Smet R, Buoncristiani U, Lameire N, Vanholder R. Behavior of non-protein-bound and protein-bound uremic solutes during daily hemodialysis. Am J Kidney Dis 2002;40:339-47.

34. Hanssen NM, Engelen L, Ferreira I, et al. Plasma levels of advanced glycation endproducts $\mathrm{N} \varepsilon$ (carboxymethyl)lysine, $\mathrm{N} \varepsilon$-(carboxyethyl)lysine, and pentosidine are not independently associated with cardiovascular disease in individuals with or without type 2 diabetes: the Hoorn and CODAM studies. J Clin Endocrinol M etab 2013;98:E1369-73.

35. Scheijen JL, Schalkwijk CG. Quantification of glyoxal, methylglyoxal and 3-deoxyglucosone in blood and plasma by ultra performance liquid chromatography tandem mass spectrometry: evaluation of blood specimen. Clin Chem Lab M ed 2014;52:85-91.

36. Scheijen JL, van de Waarenburg MP, Stehouwer CD, Schalkwijk CG. Measurement of pentosidine in human plasma protein by a single-column high-performance liquid chromatography method with fluorescence detection. J Chromatogr B Analyt Technol Biomed Life Sci 2009;877:610-4.

37. Sirich TL, Luo FJ, Plummer NS, Hostetter TH, M eyer TW. Selectively increasing the clearance of proteinbound uremic solutes. Nephrol Dial Transplant 2012;27:1574-9.

38. Luo FJ, Patel KP, Marquez IO, Plummer NS, Hostetter TH, M eyer TW: Effect of increasing dialyzer mass transfer area coefficient and dialysate flow on clearance of protein bound solutes: a pilot crossover trial. Am J Kidney Dis 2009;43: 1042-9.

39. Bammens B, Evenepoel P, Verbeke K, Vanrenterghem Y. Removal of the protein-bound solute p-cresol by convective transport: a randomized cross-over study. Am J Kidney Dis 2004;44:278-85.

40. Susantitaphong P, Siribamrungwong M, Jaber BL. Convective therapies versus low-flux hemodialysis for chronic kidney failure: a meta-analysis of randomized controlled trials. Nephrol Dial Transplant 2013;28:2859-74.

41. Lo TW, Westwood ME, M cLellan AC, Selwood T, Thornalley PJ. Binding and modification of proteins by methylglyoxal under physiological conditions. A kinetic and mechanistic study with $\mathrm{N}$ alphaacetylarginine, $\mathrm{N}$ alpha-acetylcysteine, and $\mathrm{N}$ alpha-acetyllysine, and bovine serum albumin. J Biol Chem 1994;269:32299-305.

42. Beck $W$, Techert $F$, Lebsanft $H$, et al. Treatment frequency and efficiency in hemodiafiltration. Blood Purif 2013;35:224-9. 
43. Maduell $F$, Moreso $F$, Pons $M$, et al: ESHOL study group. High-efficiency postdilution online hemodiafiltration reduced all-cause mortality in hemodialysis patients. J Am Soc Nephrol 2013;24: 487-97.

44. Penne EL, van der Weerd NC, van den Dorpel MA, et al; CONTRAST Investigators. Short-term effects of online hemodiafiltration on phosphate control: a result from the randomized controlled Convective Transport Study (CONTRAST). Am J Kidney Dis 2010;55:77-87. 



\section{PART I}

\section{LONG-TERM OUTCOMESOFINIENSVEAND}

\section{HOME HEMODIALYSS}





\section{Chapter 4}

Home dialysis is a successful strategy in nonrenal solid organ transplant recipients with end-stage renal disease

Cornelis T, Rioux JP, Bargman JM , Chan CT Nephrol Dial Transpl 2010;25:3425-9 


\section{ABSTRACT}

Background: Chronic kidney disease (CKD) is a common complication of solid organ transplantation with a substantial risk of progression to end-stage renal disease (ESRD). The impact of dialysis modality on morbidity and mortality is unknown in these patients. The aim of the present analysis was to describe our experience with home dialysis [peritoneal dialysis (PD) and home hemodialysis (home HD)] to assess the feasibility of this modality in patients who developed ESRD after nonrenal solid organ transplant (NRSOT).

M ethods: A retrospective observational cohort study with consecutive patients initiated on home dialysis after NRSOT from 2000 to 2009 was conducted. We collected data on patient demographics, laboratory parameters and blood pressure as well as clinical adverse events using our electronic clinical database.

Results: Between 2000 and 2009, 25 patients [median age 56 years; interquartile range (IQR), 43-65] initiated home dialysis. Ten patients started home HD and 15 patients initiated PD. The types of NRSOT were liver $(n=11)$, heart $(n=8)$, lung $(n=5)$ and heart-lung $(n=1)$. The median vintage of NRSOT at time of dialysis initiation was 8.7 years (IQR, 6.3-11.4). The median home dialysis follow-up was 24 months (IQR, 15-53). The median values of blood pressure, phosphate, calcium, parathyroid hormone and hemoglobin were within the $\mathrm{K} / \mathrm{DOQ}$ targets. The hospitalization and infection rates were 1 episode every 22 and 29 patient-months respectively. Three patients switched to in-centre conventional hemodialysis during follow-up and eight patients died.

Conclusion: Home dialysis (PD and home HD) is a feasible and sustainable modality for patients with ESRD after NRSOT. Home dialysis offers several potential benefits, such as improved hemodynamic and metabolic control, which may be important in the NRSOT population. Home dialysis in patients who develop ESRD after NRSOT should be actively considered for this cohort. 


\section{Introduction}

Nonrenal solid organ transplantation (NRSOT) is often complicated by the development of chronic kidney disease (CKD) ${ }^{1-4}$ with calcineurin-inhibitor (CNI) nephrotoxicity being primarily responsible ${ }^{5,6}$. After reaching CKD stage IV, these patients have a $29 \%$ risk of requiring renal replacement therapy (RRT) and they constitute 3 to $5 \%$ of the prevalent chronic hemodialysis (HD) population in the United States ${ }^{7}$.

The impact of the choice of the dialysis modality in NRSOT patient is unknown. Renal registry data suggest that peritoneal dialysis (PD) is underused in the setting of $\mathrm{NRSOT}^{8-10}$, potentially because of perceptions of infectious complications and poor technique survival. Heterogeneous results favouring both $\mathrm{PD}^{11}$ or $\mathrm{HD}^{12}$ provide no uniform recommendation for this vulnerable patient population. Home HD is a renal replacement modality that has received renewed interest. However, no study has evaluated the possibility of this modality in patients who develop ESRD after NRSOT.

The aim of the present study was to describe our experience in performing home dialysis (PD and home HD) in patients who developed ESRD after NRSOT to assess the feasibility of both modalities.

\section{Methods}

\section{Design and definition}

This is a retrospective observational cohort study. Institutional research ethics board approval was obtained. Information obtained was validated with electronic and paper charts. Subjects included all consecutive incident ESRD patients initiating home dialysis therapy (PD and home HD) at the Toronto General Hospital, University Health Network, from January $1^{\text {st }} 2000$ to December $31^{\text {st }} 2009$. Demographic variables included age, gender, etiology of ESRD and comorbid conditions. Other collected data consisted of the type of NRSOT, primary disease necessitating NRSOT, vintage of NRSOT at the start of home dialysis, home dialysis follow-up and disposition (transfer to in-centre HD, kidney transplant or death) until December $31^{\text {st }} 2009$. Estimated GFR at time of home dialysis initiation using the 4 variables MDRD formula ${ }^{13}$, blood pressure (BP) and standard laboratory parameters (calcium, phosphorus, parathyroid hormone, hemoglobin and albumin) were collected at time of home dialysis initiation and every six months until termination of home dialysis. All data in home HD patients were collected prior to their dialysis session. Data from PD patients were obtained from their 
routine clinic blood work. We assessed clinical adverse events including infection, hospitalization, development of cancer, and death.

\section{Dialysis prescription}

Our home HD patients dialyzed 4 to 7 days a week for 5 to 8 hours overnight using a conventional dialysis platform and a high flux biocompatible dialyzer. A dialysate flow rate of $200-350 \mathrm{ml} / \mathrm{min}$ and a blood flow rate of $250-300 \mathrm{ml} / \mathrm{min}$ were used. Unfractionated heparin was used during treatments. Our PD patients were on either continuous ambulatory peritoneal dialysis (CAPD) or continuous cycling peritoneal dialysis (CCPD). The prescriptions were adjusted according to their treating physician, fluid status and laboratory results.

\section{Statistical analysis}

Continuous variables were expressed as median and interquartile range. Categorical variables were expressed as number. Continuous data were compared using the MannWhitney test while dichotomous data were compared by Pearson's chi-square analysis. All P-values were two-tailed, and values less than 0.05 were considered significant. All analyses were performed using SPSS-16 (SPSS, Chicago, IL).

\section{Results}

During the study period, 25 patients initiated home dialysis (15 in PD and 10 in home HD) after NRSOT at the Toronto General Hospital. Baseline characteristics are summarized in Table 4.1. The median age of our cohort was 54 years (IQR, 43-65). Sixteen patients were male. The types of NRSOT were liver (11 patients), heart (8 patients), lung (5 patients) and heart-lung (1 patient). The median duration of NRSOT at time of home dialysis initiation was 8.7 years (IQR, 6.3-11.4). The most frequent cause of ESRD was CNI nephrotoxicity. The estimated GFR at the time of initiation of home dialysis ranged from 5 to $15 \mathrm{ml} / \mathrm{min}$. Six patients had another renal replacement modality (five conventional $\mathrm{HD}$ and one renal transplant) before initiating home dialysis. The median home dialysis follow-up was 24 months (IQR, 15-53). Six patients had a kidney transplant during follow-up.

Laboratory parameters and BP after home dialysis initiation are outlined in Table 4.2. All median values of laboratory parameters and BP were within the K/DOQI targets ${ }^{14-16}$. There was no statistically significant difference in laboratory values or BP control between PD and home HD patients. 


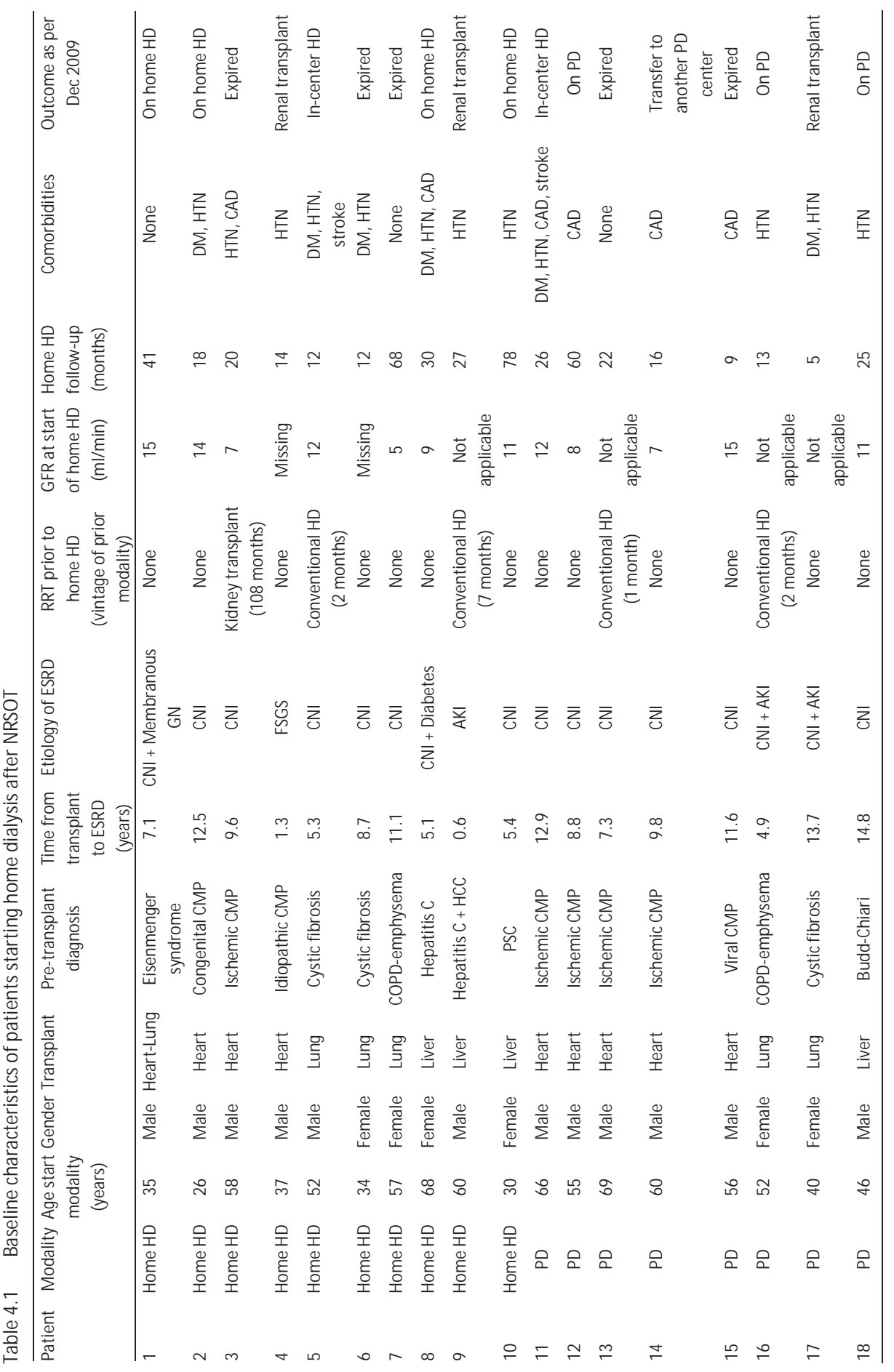




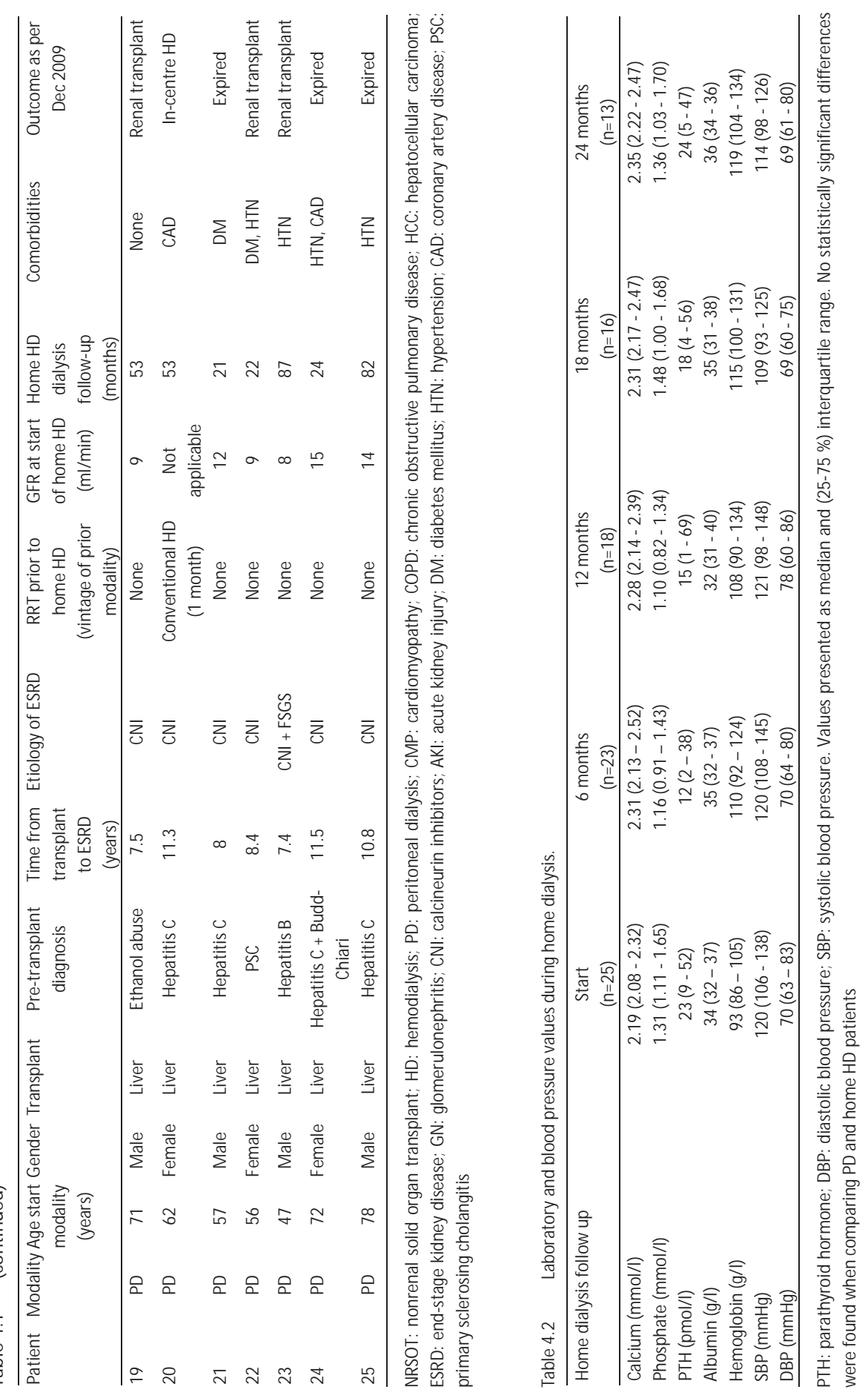


The clinical adverse events are summarized in Table 4.3. A total of 18 peritonitis and three line sepsis were document during the follow-up. The peritonitis rate was 1 for every 29 patient-months among the 15 PD patients. This rate was 1 for every 32 patient-months among the liver transplant recipients on PD. Three patients were converted to in-centre HD; one home HD patient after 12 months because of hepatic encephalopathy, one PD patient after 26 months because of PD catheter removal for Pseudomonas peritonitis and another PD patient decided to change modality after one episode of peritonitis. Eight patients (three in home HD and five in PD) expired during follow-up. The causes of death were cancer $(n=3)$, myocardial infarction $(n=1)$, fatal arrhythmia following a myocardial infarction $(n=1)$, ischemic bowel $(n=1)$ and septic shock following PD peritonitis $(n=1)$ and pneumonia $(n=1)$.

Table 4.3 Clinical adverse events of patients on home dialysis.

\begin{tabular}{lccc}
\hline & $\begin{array}{c}\text { Home HD } \\
(\mathrm{n}=10)\end{array}$ & $\begin{array}{c}\text { PD } \\
(\mathrm{n}=15)\end{array}$ & $\begin{array}{c}\text { All patients } \\
(\mathrm{n}=25)\end{array}$ \\
\hline Infections & & & \\
$\quad$ Total episodes & 5 & 24 & 29 \\
$\quad$ Total rate (episode / patient-months) & $1 / 64$ & $1 / 22$ & $1 / 29$ \\
$\quad$ Peritonitis rate (episode / patient-months) & $\mathrm{N} / \mathrm{A}$ & $1 / 29$ & $\mathrm{~N} / \mathrm{A}$ \\
$\quad \begin{array}{l}\text { Hospitalizations } \\
\quad \text { Total episodes }\end{array}$ & 9 & 29 & 38 \\
$\quad$ Total rate (episode / patient-months) & $1 / 36$ & $1 / 18$ & $1 / 22$ \\
$\quad$ Reason for hospitalization & & & \\
$\quad$ Infection & 4 & 9 & 13 \\
$\quad$ Vancer & 2 & 0 & 2 \\
$\quad$ Vascular events & 0 & 3 & 3 \\
$\quad$ Oolume overload & 0 & 4 & 4 \\
Conversion to in-centre HD & $3 *$ & $13^{* *}$ & 16 \\
Cancer during home dialysis & 1 & 2 & 3 \\
Myocardial infarction & 3 & 5 & 8 \\
Death & 1 & 1 & 2 \\
\hline
\end{tabular}

HD: hemodialysis; PD: peritoneal dialysis. All values represented as number unless otherwise specified. No statistically significant differences were found when comparing PD and home HD patients * diarrhea $(n=1)$, hepatic encephalopathy $(n=1)$ and non cardiac chest pain $(n=1) ; * *$ hemoperitoneum $(n=1)$, parathyroidectomy $(n=1)$, diarrhea $(n=1)$, failure to cope $(n=3)$, seizure $(n=2)$, upper gastrointestinal bleeding $(n=1)$, gout attack $(n=1)$, encephalopathy $(n=2)$, warfarin overdose $(n=1)$.

\section{Discussion}

In the present study, we describe our experience with home dialysis (PD and home HD) for patients who developed ESRD after NRSOT. This study is the first to assess both PD and home HD as potential renal replacement modalities after NRSOT. To our 
knowledge, this study provides the longest follow-up (median 24 months) of home dialysis in NRSOT recipients. Our results illustrate that 1 ) home dialysis is a feasible and sustainable modality in patients who develop ESRD after NRSOT and 2) home dialysis might provide specific benefits for this particular patient population.

The peritonitis rate in our cohort of transplant patients (1 episode per 29 patientmonths) was higher compared to the rate of our program as a whole (1 episode per 39 patient-months). This may be a simple variation based on a small number of patients included in the study or may be explained in part by the fact that PD patients on immunosuppressive therapy are at greater risk for peritonitis ${ }^{17}$. However, the peritonitis rate in our cohort of patients was lower compared to the published literature in heart and heart-lung transplant recipients on PD ( 1 episode per 15 patientmonths) ${ }^{18}$. To date, no comparable data are available in the home HD literature.

The hospitalization rate in our cohort of patients ( 1 episode per 22 patient-months) was higher compared to our dialysis population overall ( 1 episode per 30 patient-months; unpublished data). In the majority of cases, the reasons for hospitalization were not directly related to complications of dialysis (Table 4.3). It is reasonable to postulate that NRSOT patients are more likely to be hospitalized because of their co-morbidities. The trend toward a lower hospitalization rate among home HD patients may be explained by selection bias since our home HD patients tend to be younger with less co-morbid burden ${ }^{19}$.

Potential advantages of PD in NRSOT were recently summarized ${ }^{20}$. They include reduction of the risk for viral transmission of hepatitis to non-infected dialysis patients ${ }^{21,22}$, optimization of hemodynamic stability during dialysis in the context of slow continuous ultrafiltration ${ }^{23}$, avoidance of bacteremia related to dialysis catheter and the potential preservation of residual renal function ${ }^{24}$. Nocturnal home HD is also associated with several potential benefits including improved BP control ${ }^{25}$, regression of left ventricular hypertrophy and improved left ventricular ejection fraction ${ }^{26,27}$, optimization of phosphate control ${ }^{28}$ and improved survival compared to conventional $\mathrm{HD}^{29}$. Our home dialysis cohort had BP and laboratory parameters within the K/DOQI targets for the first two years of follow-up ${ }^{14-16}$. These advantages of home dialysis, both $\mathrm{PD}$ and home HD, are crucial in the management of NRSOT patients who might benefit from 1) optimized hemodynamic stability and 2) improved metabolic control which is essential in the context of CNI's metabolic side effects.

It is also worth noting that eight liver transplant patients successfully used PD as their dialysis modality. Furthermore, the rate of peritonitis was not higher among liver transplant recipients on PD. This extends previous observation that PD should not be withheld from liver transplant patients ${ }^{30,31}$. 
Based on our results, home dialysis should be considered as a first line therapy for NRSOT patients developing ESRD. Patients should be educated about home dialysis to provide the RRT best suited to their lifestyle and medical conditions ${ }^{32,33}$. The promotion of home dialysis in this vulnerable population may help to preserve their quality of life, which should be examined in future studies.

Our study is limited by its retrospective nature. We were unable to compare our cohort of patients on home dialysis with in-centre conventional HD patients because of selection bias. Furthermore, due to our small sample size, we might not be able to identify modest differences between PD and home HD patients. Finally, the outcomes of our cohort of patients could be in part explained by a selection bias since healthier and younger patients might be more prone to choose home dialysis.

In conclusion, home dialysis is a feasible and sustainable alternative to in-centre conventional HD to treat ESRD in NRSOT. However, larger multicentre studies are needed to compare home dialysis versus in-centre HD among NRSOT patients. Studies focusing on home dialysis outcomes and selection criteria merit further investigation. 


\section{References}

1. Pattison JM, Petersen J, Kuo P, Valantine V, Robbins RC, Theodore J. The incidence of renal failure in one hundred consecutive heart-lung transplant recipients. Am J Kidney Dis 1995;26:643-8.

2. van Gelder T, Balk AH, Zietse R, Hesse C, Mochtar B, Weimar W. Renal insufficiency after heart transplantation: a case-control study. Nephrol Dial Transplant 1998;13:2322-6.

3. Zaltzman JS, Pei Y, Maurer J, Patterson A, Cattran DC. Cyclosporine nephrotoxicity in lung transplant recipients. Transplantation 1992;54:875-8.

4. Fisher NC, Nightingale PG, Gunson BK, Lipkin GW, Neuberger JM. Chronic renal failure following liver transplantation: a retrospective analysis. Transplantation 1998;66:59-66.

5. Bennett WM , DeM attos A, M eyer M M , Andoh T, Barry JM. Chronic cyclosporine nephropathy in renal transplantation. Transplant Proc 1996;28:2100-3.

6. Naesens M, Kuypers DR, Sarwal M. Calcineurin inhibitor nephrotoxicity. Clin J Am Soc Nephrol 2009;4: 481-508.

7. Ojo AO, Held PJ, Port FK, Wolfe RA, Leichtman AB, Young EW, Arndorfer J, Christensen L, Merion RM. Chronic renal failure after transplantation of a nonrenal organ. N Engl J M ed 2003;349:931-40.

8. Alam A, Badovinac K, Ivis F, Trpeski L, Cantarovich M. The outcome of heart transplant recipients following the development of end-stage renal disease: analysis of the Canadian Organ Replacement Register (CORR). Am J Transplant 2007;7:461-5.

9. Al Riyami D, Alam A, Badovinac K, Ivis F, Trpeski L, Cantarovich M. Decreased survival in liver transplant patients requiring chronic dialysis: a Canadian experience. Transplantation 2008;85:1277-80.

10. Gill JS, Abichandani R, Khan S, Kausz AT, Pereira BJ. Opportunities to improve the care of patients with kidney transplant failure. Kidney Int 2002;61:2193-200.

11. Ahmad M, Robert R, Bargman JM, Oreopoulos D. Advantages of peritoneal dialysis in comparison to hemodialysis, in cardiac allograft recipients with end stage renal disease. Int Urol Nephrol 2008;40: 1083-7.

12. Bernardini J, Piraino B, Kormos RL. Patient survival with renal replacement therapy in heart transplantation patients. ASAIO J 1998;44:M 546-8.

13. Levey AS, Bosch JP, Lewis JB, Greene T, Rogers N, Roth D. A more accurate method to estimate glomerular filtration rate from serum creatinine: a new prediction equation. Modification of Diet in Renal Disease Study Group. Ann Intern Med 1999;130:461-70.

14. KDOQI Clinical Practice Guideline and Clinical Practice Recommendations for anemia in chronic kidney disease: 2007 update of hemoglobin target. Am J Kidney Dis 2007;50:471-530.

15. K/DOQI clinical practice guidelines for bone metabolism and disease in chronic kidney disease. Am J Kidney Dis 2003;42:S1-201.

16. K/DOQI clinical practice guidelines for cardiovascular disease in dialysis patients. Am J Kidney Dis 2005; 45:S1-153.

17. Andrews PA, Warr KJ, Hicks JA, Cameron JS. Impaired outcome of continuous ambulatory peritoneal dialysis in immunosuppressed patients. Nephrol Dial Transplant 1996;11:1104-8.

18. Jayasena SD, Riaz A, Lewis CM, Neild GH, Thompson FD, Woolfson RG. Outcome in patients with endstage renal disease following heart or heart--lung transplantation receiving peritoneal dialysis. Nephrol Dial Transplant 2001;16:1681-5.

19. Rioux JP, Bargman JM, Chan CT. Systematic differences among patients initiated on home haemodialysis and peritoneal dialysis: the fallacy of potential competition. Nephrol Dial Transplant 2010;25:2364-7.

20. Perl J, Bargman JM, Jassal SV. Peritoneal dialysis after nonrenal solid organ transplantation: clinical outcomes and practical considerations. Perit Dial Int 2010;30:7-12.

21. Cusumano AM, Poratto F, del Pino N, Fernández JL, Vilches A. Identification of hepatitis $C$ virus RNA in peritoneal dialysis fluid of patients with viremia. Perit Dial Int 2005;25:478-82.

22. Blake PG. Integrated end-stage renal disease care: the role of peritoneal dialysis. Nephrol Dial Transplant 2001;16 Suppl 5:61-6. 
23. Jansen MA, Hart AA, Korevaar JC, Dekker FW, Boeschoten EW, Krediet RT; NECOSAD Study Group. Predictors of the rate of decline of residual renal function in incident dialysis patients. Kidney Int 2002;62:1046-53.

24. Rottembourg J, Issad B, Allouache M, Jacobs C. Recovery of renal function in patients treated by CAPD. Adv Perit Dial 1989;5:63-6.

25. Chan CT, Harvey PJ, Picton P, Pierratos A, Miller JA, Floras JS. Short-term blood pressure, noradrenergic, and vascular effects of nocturnal home hemodialysis. Hypertension 2003;42:925-31.

26. Chan C, Floras JS, M iller JA, Pierratos A. Improvement in ejection fraction by nocturnal haemodialysis in end-stage renal failure patients with coexisting heart failure. Nephrol Dial Transplant 2002;17:1518-21.

27. Culleton BF, Walsh M, Klarenbach SW, Mortis G, Scott-Douglas N, Quinn RR, Tonelli M, Donnelly S, Friedrich MG, Kumar A, Mahallati H, Hemmelgarn BR, Manns BJ. Effect of frequent nocturnal hemodialysis vs conventional hemodialysis on left ventricular mass and quality of life: a randomized controlled trial. JAM A 2007;298:1291-9.

28. Mucsi I, Hercz G, Uldall R, Ouwendyk M, Francoeur R, Pierratos A. Control of serum phosphate without any phosphate binders in patients treated with nocturnal hemodialysis. Kidney Int 1998;53:1399-404.

29. Johansen KL, Zhang R, Huang Y, Chen SC, Blagg CR, Goldfarb-Rumyantzev AS, Hoy CD, Lockridge RS Jr, Miller BW, Eggers PW, Kutner NG. Survival and hospitalization among patients using nocturnal and short daily compared to conventional hemodialysis: a USRDS study. Kidney Int 2009;76: 984-90.

30. Shukla AM, Lobbedez T, Chu M, Izatt S, Bargman JM, Oreopoulos DG. Peritoneal dialysis in end-stage renal disease after liver transplantation. Adv Perit Dial 2004;20:93-7.

31. Apiratpracha W, Chung HV, Ali JA, Bashir K, Yoshida EM, Singh RS. Peritoneal dialysis after orthotopic liver transplant surgery. Perit Dial Int 2007;27:99-100.

32. Manns BJ, Taub K, Vanderstraeten C, Jones H, Mills C, Visser M, M cLaughlin K. The impact of education on chronic kidney disease patients' plans to initiate dialysis with self-care dialysis: a randomized trial. Kidney Int 2005;68:1777-83.

33. M CLaughlin $\mathrm{K}$, Jones $\mathrm{H}$, VanderStraeten $\mathrm{C}$, Mills $\mathrm{C}$, Visser $\mathrm{M}$, Taub K, Manns B. Why do patients choose self-care dialysis? Nephrol Dial Transplant 2008;23:3972-6. 



\section{Chapter 5}

Effects of intensive and home hemodialysis on

fertility and pregnancy 



\section{Chapter}

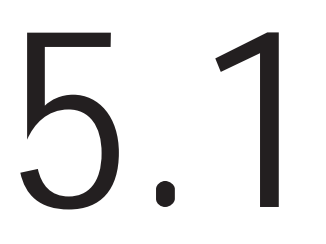

\section{Intensive hemodialysis associates with improved pregnancy outcomes: a Canadian and United States cohort comparison}




\section{ABSTRACT}

Pregnancy is rare in women with end-stage renal disease (ESRD), and when it occurs, it is often accompanied by significant maternal and fetal morbidity, and even mortality. Preliminary data from the Toronto nocturnal dialysis program suggested that increased clearance of uremic toxins by the provision of intensified hemodialysis improves pregnancy outcomes, but small numbers and the absence of a comparator group limited widespread applicability of these findings. We compared pregnancy outcomes from 22 pregnancies in the Toronto Pregnancy and Kidney Disease Clinic and Registry (2000-2013) with outcomes from 70 pregnancies in the American Registry for Pregnancy in Dialysis Patients (1990-2011). The primary outcome was the live birth rate and secondary outcomes included gestational age and birth weight. The live birth rate in the Canadian cohort (86.4\%) was significantly higher than the rate in the American cohort $(61.4 \%$; $\mathrm{P}=0.03$ ). Among patients with established $\mathrm{ESRD}$, the median duration of pregnancy in the more intensively dialyzed Toronto cohort was 36 weeks (interquartile range, 32-37) compared with 27 weeks (interquartile range, 21-35) in the American cohort ( $P=0.002)$. Furthermore, a dose response between dialysis intensity and pregnancy outcomes emerged, with live birth rates of $48 \%$ in women dialyzed $\leq 20$ hours per week and $85 \%$ in women dialyzed $>36$ hours per week $(P=0.02)$, with longer gestational age and greater infant birth weight for women dialyzed more intensively. Pregnancy complications were few and manageable. We conclude that pregnancy may be safe and feasible in women with ESRD receiving intensive hemodialysis. 


\section{Introduction}

The first successful pregnancy reported in a patient on chronic hemodialysis (HD) occurred in 1970, and was considered an overwhelming success ${ }^{1}$. Initial enthusiasm was tempered with subsequent studies noting pregnancy in women with end stage renal disease (ESRD) to be uncommon due to decreased fertility ${ }^{2-6}$, and often associated with poor outcomes ${ }^{7,8}$. However, recent data suggest that pregnancy while on intensive HD may result in better outcomes ${ }^{9}$, providing a viable option for young women whose reproductive years are lost to ESRD.

Our group previously demonstrated that nocturnal HD (NHD), as an intensive dialysis modality, resulted in reduced maternal and fetal complications in pregnant ESRD patients $^{9,10}$. In this report, we present our expanding clinical series of all pregnant patients supported by intensive dialysis in Toronto from 2000 to 2013, and compare the outcomes from this prospective cohort to the American Registry for Pregnancy in Dialysis Patients (ARPD). We hypothesized that intensive HD with enhanced multidisciplinary follow-up would be associated with improved pregnancy outcomes as compared with conventional dialysis regimens.

\section{Results}

\section{Cohort characteristics}

The Toronto Pregnancy and Kidney Disease (PreKid) Clinic and Registry included 22 pregnancies in 17 patients. Characteristics of this cohort are detailed in Table 5.1.1. Eighteen pregnancies occurred after the start of chronic dialysis, whereas HD was initiated during pregnancy in four women. The comparison group included 70 pregnancies from the ARPD (57 occurred in women already on HD and 13 occurred in women approaching ESRD). The two cohorts were comparable with respect to the causes of ESRD. However, the Toronto group was significantly older than the American patients ( $34 \pm 4$ versus $27 \pm 6$ years; $P<0.001$ ). The PreKid cohort was $59 \%$ Caucasian (10 Caucasians, 3 African Canadians, 3 Asians, and 1 South Asian); however, we do not have data on race for patients in the ARPD cohort. In the established chronic dialysis patients, there was no significant difference in dialysis vintage at the time of pregnancy, with a median of 41 months [interquartile range (IQR), 16-72)] and 18 months (IQR, 7-48) months in the PreKid and ARPD cohorts, respectively. However in women approaching ESRD, Canadian patients were started on dialysis at an earlier gestational age ( $14 \pm 7$ versus $24 \pm 7$ weeks, $P=0.03)$. 


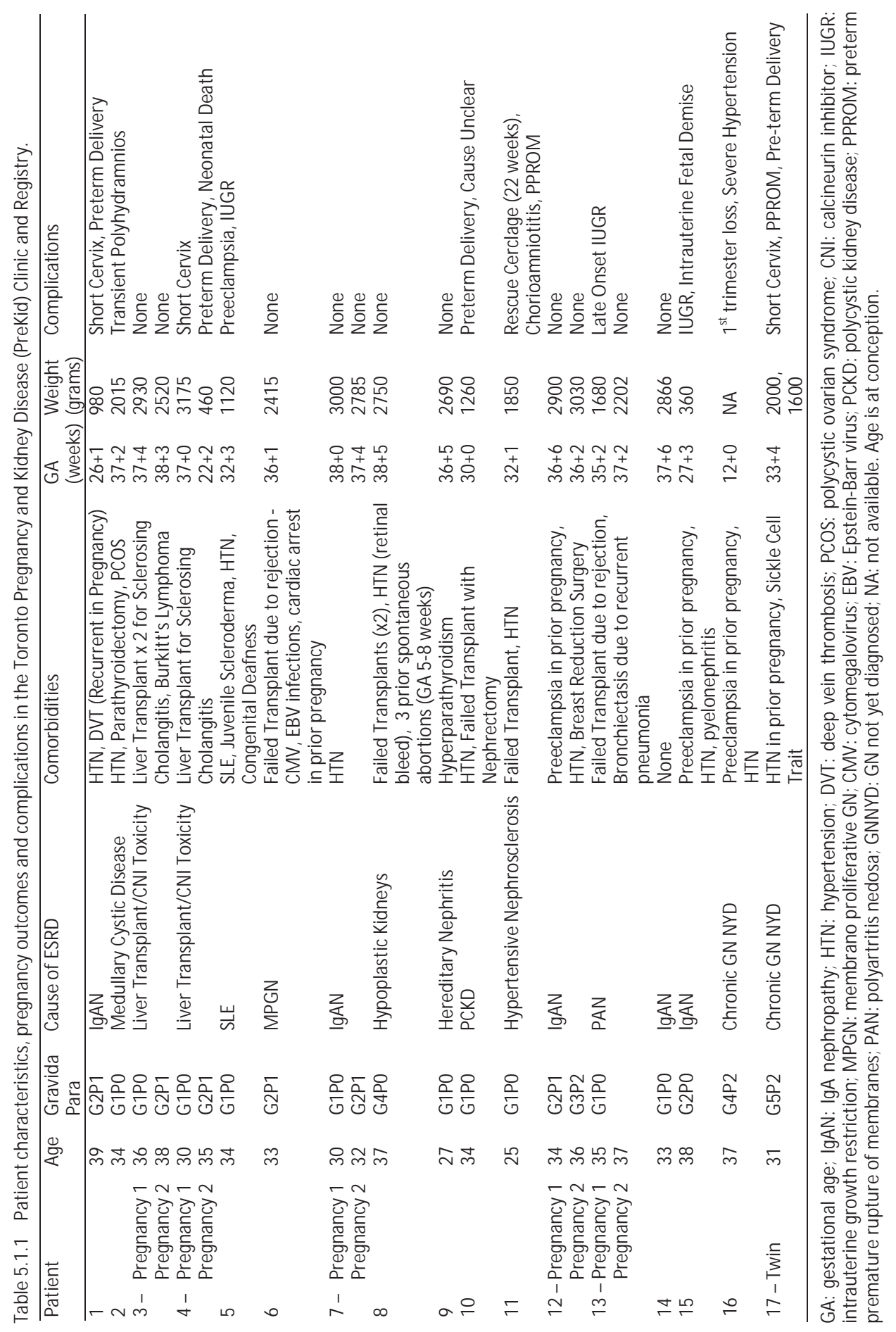




\section{Pregnancy outcomes}

Of the 22 pregnancies followed in the Toronto PreKid Clinic, 19 (86.4\%) resulted in a live birth, which was significantly higher than the live birth rate of $61.4 \%$ reported to the ARPD ( $P=0.03$; see Table 5.1.2). In the Toronto Cohort, there was one first-trimester loss, intrauterine fetal demise and neonatal death resulting in a poor outcome in $14 \%$ of pregnancies compared with $39 \%$ in the United States registry. All poor pregnancy outcomes occurred in women with established ESRD, whereas the women who initiated dialysis during pregnancy all had live births in both cohorts. In patients with established ESRD, the live birth rate, however, was significantly higher in the PreKid cohort (83.3\%) compared with the ARPD cohort (52.6\%; $P=0.02$ ).

Table 5.1.2 Cohort-specific pregnancy outcomes.

\begin{tabular}{lccc}
\hline Pregnancy Outcomes & Toronto & USA & P Value \\
\hline Live birth rate (Entire Cohort) & $19(86.4)$ & $43(61.4)$ & 0.03 \\
Spontaneous abortion, $1^{\text {st }}$ trimester & $1(4.5)$ & $5(7.1)$ & \\
Spontaneous abortion, 2 ${ }^{\text {nd }}$ trimester & $0(0)$ & $14(20.0)$ & \\
Neonatal death & $1(4.5)$ & $5(7.1)$ & \\
$\quad$ Still birth & $1(4.5)$ & $3(4.3)$ & \\
Live birth rate (ESRD patients only) & $15(83.3)$ & $30(52.6)$ & 0.02 \\
Among patients with establishd ESRD & & & \\
$\quad$ Dialysis time (hours/ week) & $43 \pm 6$ & $17 \pm 5$ & $\varangle .001$ \\
$\quad$ Gestational age (weeks) & $36(32-37)$ & $27(21-35)$ & 0.002 \\
Among patients with renal failure during pregnancy & & & \\
$\quad$ Dialysis time (hours/week) & $33 \pm 6$ & $15 \pm 4$ & $\varangle .001$ \\
$\quad$ Gestational age (weeks) & $34(29-37)$ & $33(31-37)$ & $\mathrm{NS}$ \\
All pregnancies (except $1^{\text {st }}$ and $2^{\text {nd }}$ trimester spontaneous abortions) & & \\
$\quad$ Dialysis time (hours/week) & $42 \pm 7$ & $17 \pm 5$ & $\varangle .001$ \\
$\quad$ Birth weight (grams) & $2118 \pm 857$ & $1748 \pm 949$ & $\mathrm{NS}$ \\
Among surviving infants in established ESRD patients & & & \\
$\quad$ Normal birth weight & $8(50.0)$ & $10(32.3)$ & $\mathrm{NS}$ \\
Low birth weight $(<2500 \mathrm{~g})$ & $7(43.8)$ & $12(38.7)$ & \\
Very low birth weight $(<1500 \mathrm{~g})$ & $1(6.3)$ & $9(29.0)$ & \\
\hline
\end{tabular}

Values are presented as $\mathrm{n}(\%)$, mean $\pm \mathrm{SD}$, or median (interquartile range). Values for gestational age are rounded to the nearest week. ESRD: end-stage renal disease.

Among women with established ESRD, the duration of pregnancy was longer in the PreKid cohort at 36 weeks (IQR, 32-37) compared with 27 weeks (IQR, 21-35) in the ARPD cohort $(P=0.002)$. The Canadian ESRD patients received $43 \pm 6$ hours of dialysis compared with the $17 \pm 5$ hours provided in the United States $(P \varangle 0001)$. Of interest, there was no difference in the duration of pregnancy in women who started dialysis during pregnancy [34 weeks (IQR, 29-37) versus 33 weeks (IQR, 31-37); P=NS] despite earlier initiation of dialysis ( $14 \pm 7$ versus $24 \pm 7$ weeks; $P=0.03$ ) and the provision of more 
dialysis ( $33 \pm 6$ versus $15 \pm 4$ hours; $\mathrm{P} \varangle .001$ ) in the Canadian cohort. After excluding firstand second-trimester losses wherein birth weight was not available, gestational weight tended to be higher in the PreKid cohort compared with the ARPD cohort (2118 \pm 857 and $1748 \pm 949 \mathrm{~g}$, respectively). Among surviving infants of established ESRD patients, $6 \%$ of infants in the Canadian cohort were classified as very low birth weight compared with $29 \%$ of infants in the US cohort (Table 5.1.1).

With respect to the assessment of dialysis intensity on pregnancy outcomes in women with ESRD, there was a dose-response relationship. The live birth rate improved in each successive tertile of hours of $\mathrm{HD}$ provided, improving from $48 \%$ in women receiving $\leq 20$ hours to $85 \%$ in women receiving $\geq 37$ hours of $H D$ weekly ( $P=0.02$; Figure 5.1.1). This relationship between dialysis intensity and outcome was confirmed by a time-toevent analysis $(P=0.01$; Figure 5.1.2). Furthermore, gestational age increased significantly with higher levels of $\mathrm{HD}(\mathrm{P}=0.002$; Figure 5.1.3A) along with a trend toward larger babies (Figure 5.1.3B). As such, correlations between dialysis intensity and gestational age $\left(R^{2}=0.15 ; P \varangle 0.001\right)$ as well as birth weight $\left(R^{2}=0.08 ; P=0.04\right)$ were observed.

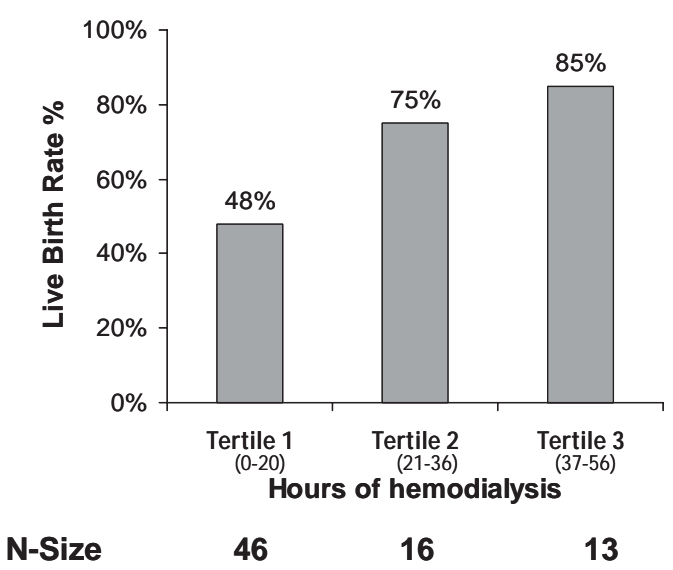

Figure 5.1.1 Live birth rates by dialysis intensity.

In women with established ESRD, there is a significant dose-response relationship between hemodialysis intensity and the live birth rate $(\mathrm{P}=0.02)$, improving from $48 \%$ in women receiving $\leq 20$ hours to $75 \%$ in women receiving between 21 and 36 hours to $85 \%$ in women receiving $\geq 37$ hours of hemodialysis weekly. 


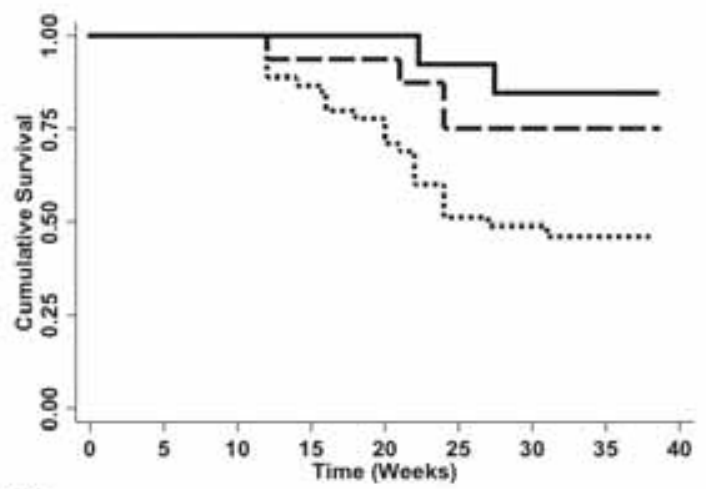

Number at risk

$0-20$ Hours $(\cdots \cdots) 45$

21.36 Hours $(--16$

$37-56$ Hours $\longrightarrow 13$

$\begin{array}{ll}45 & 35 \\ 16 & 15 \\ 13 & 13\end{array}$

$\begin{array}{ll}17 & 0 \\ 11 & 0 \\ 11 & 0\end{array}$

Figure 5.1.2 Time-to-event analysis by dialysis intensity.

In women with established ESRD, there is a significant pregnancy survival advantage among women with high delivered doses of dialysis (log-rank test; $\mathrm{P}=0.01$ ).

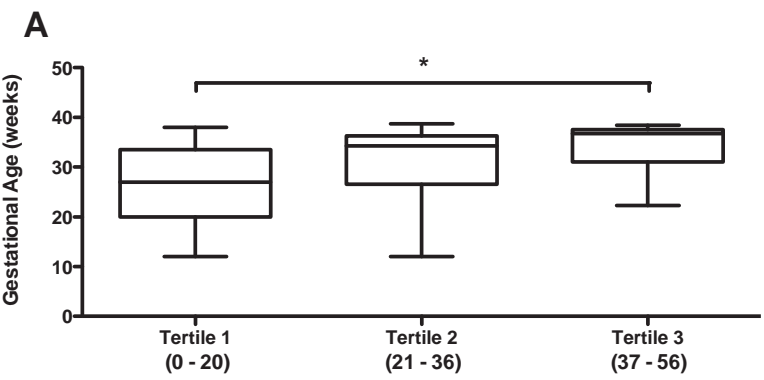

B

Hours of Hemodialysis

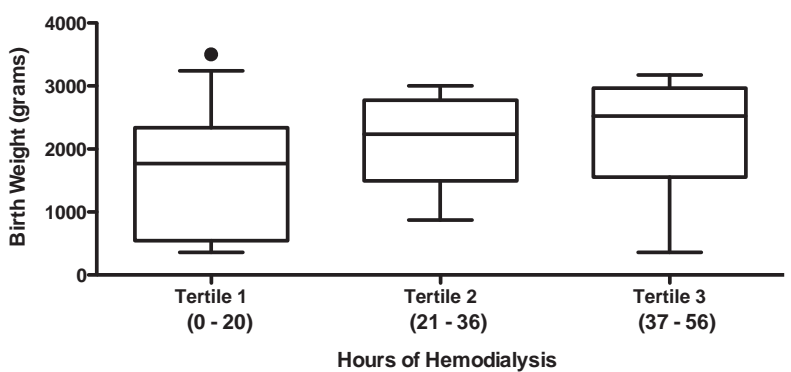

Figure 5.1.3 Gestational age and birth weight by dialysis intensity.

In women with established ESRD, gestational age increased significantly with higher levels of hemodialysis (A) along with a trend toward larger babies (B). The circle represents an outlier. $* \mathrm{P}=0.002$. 


\section{Pregnancy complications in the Toronto PreKid Clinic and Registry Cohort}

Pregnancy complications for the PreKid cohort are also summarized in Table 5.1.1. The majority of the patients had unremarkable pregnancies or manageable complications. All but two women delivered vaginally. Four patients were noted to have short cervices. Patient 1 was diagnosed after 24 weeks gestation, delivering preterm at 26 weeks. Patient 4 (first pregnancy) was diagnosed after 20 weeks gestation, but her cervical length remained stable on bed rest. She subsequently delivered at 37 weeks gestation. In her second pregnancy, a normal cervical length was noted at her anatomy scan at 20 weeks gestation, but she delivered precipitously at a previable gestational age of 22 weeks. Patient 11 required a rescue cerclage at 22 weeks and delivered at 32 weeks due to preterm premature rupture of membranes. Finally, the twin pregnancy was also noted to have a shortened cervix and delivered at almost 34 weeks gestation. Only a single patient (Patient 2) had transient polyhydramnios. Evidence of placental insufficiency was noted in three pregnancies. The pregnancy in patient 5 was complicated presumably by preeclampsia (diagnosed on the basis of worsening hypertension, decreased fetal growth rate, and elevated umbilical artery pulsatility indices), requiring a caesarean section just beyond 32 weeks of gestation. Late-onset intrauterine growth restriction was noted in patient 13 during her first pregnancy, whereas early severe intrauterine growth restriction resulting in intrauterine demise was noted in patient 15 . Of note, this pregnancy was conceived with ovarian stimulation and intrauterine insemination. Patient 10 was admitted for preterm labor at 30 weeks of gestation. The only first-trimester loss occurred in a patient with difficult to manage hypertension due to noncompliance. Otherwise, the mean systolic and diastolic BP was maintained within normal physiological ranges during the full period of gestation, with only 4 patients requiring antihypertensive therapy.

\section{Discussion}

Our comparative analysis demonstrates that intensive HD is feasible and optimizes pregnancy outcomes in patients with ESRD. The proportion of living infants was higher in the Canadian cohort as compared to contemporary controls derived from the ARPD cohort. Furthermore, median gestational age was higher, and maternal and neonatal complications were few and manageable. Because a dose-response relationship between dialysis dose and pregnancy outcomes including survival, gestational age, and birth weight was noted, we speculate that an intensified dialysis dose may play an important role by providing a healthy maternal environment for normal placental development, a prerequisite for normal fetal growth and decreased pregnancy 
complications. In women with established ESRD, it would appear that more intensive $\mathrm{HD}$ is necessary to optimize outcome, because women receiving the highest amounts of HD had significantly better live birth rates, longer gestational ages, and thus bigger babies. However, our data again reiterated the importance of residual renal function in women who started dialysis after pregnancy, with all women in both cohorts having live births. In fact, dialysis intensity should likely be adjusted to account for the degree of residual renal function, because the intensive routine dialysis regimen in the Toronto patients may have been unnecessarily burdensome. Taken together, our growing experience of intensively dialysed pregnant patients may allow us to titrate the optimal dialysis dose in women with ESRD both with and without residual renal function.

Pregnancy in women with ESRD is typically complicated by increased maternal and fetal morbidity and mortality. In the 1970 s, only $23 \%$ of pregnancies in women on dialysis resulted in live infants ${ }^{7}$. One might presume that the high rates of termination in this early study influenced the poor live birth rate, but subsequent data from the United States and Saudi Arabian Registry, wherein termination was unlikely, did not reflect a much better outcome, with a live birth rate of only $37 \%^{11,12}$. Even in these early data the importance of the relationship between time on dialysis and outcome began to emerge as those cases that progressed beyond 28 weeks had their dialysis time increased from an average of $9.4 \pm 2.3$ to $12.0 \pm 2.6$ hours $^{8}$.

More recently, live birth rates have improved, as it has become standard practice to increase the dose of delivered dialysis after conception. In the largest series to date, 52 pregnancies with an $87 \%$ overall successful birth rate was described wherein the standard practice was to increase dialysis time to 12-18 hours per week ${ }^{13}$. Despite remarkably better live birth rates, the mean gestational age was noted to be only $32.7 \pm 3.1$ weeks with a mean gestational weight of $1554 \pm 663$ grams. Furthermore, significant rates of complications including preeclampsia (19\%), polyhydramnios (40\%), transfusions (25\%), and hypertension (70\%) were reported. In our study, the amount of delivered dialysis was significantly higher in the Toronto cohort, and although the live birth rate was similar (86.4\%), gestation was prolonged considerably compared to both the reported literature as well as our ARPD comparator cohort. Complications were few, transfusions were unnecessary, and hypertension was either absent or easily managed with only three women manifesting evidence of placental dysfunction. Only one patient had transient polyhydramnios, which was managed by lowering the dry weight. Four patients developed a short cervix detected on the level II ultrasound with untoward outcomes, and the exact reason for the high incidence of short cervix in our cohort remains unknown.

There are a number of other potential mechanisms wherein intensive dialysis regimens might improve pregnancy outcome. Studies in NHD patients have revealed beneficial 
effects, including clinical (BP, left ventricular hypertrophy), biochemical (urea and phosphate clearance, anemia) and biological parameters (endothelial function, inflammation $)^{14}$, which may all contribute to improved pregnancy outcomes. However, the success of intensified regimens appears to be directly related to enhanced clearance of urea and likely other solutes. In a series of 28 pregnant women receiving HD with 18 surviving infants, a significant negative relationship was noted between BUN and birth weight $(r=0.53, P=0.02)$ as well as gestational age $(r=0.50, P=0.02)^{15}$. A birth weight of at least $1500 \mathrm{~g}$ was achieved at a blood urea nitrogen $(B U N)<49 \mathrm{mg} / \mathrm{dl}$ (urea $17.9 \mathrm{mmol} / \mathrm{l}$ ) and a gestational age of at least 32 weeks was achieved at a BUN<48 mg/dl (urea $17.1 \mathrm{mmol} / \mathrm{l}$ ). Furthermore, residual renal function has been demonstrated to improve pregnancy outcomes, with significant discrepancies in live birth rates that favored women who conceived before the initiation of dialysis compared with established dialysis patients ${ }^{8,16}$. Our study confirmed the importance of enhanced clearance with improved live birth rates among women with residual renal function and intensified dialysis regimens. Taken together, dialysis dose should be titrated to maintain a normal metabolic state, with women with more residual kidney function requiring less intensive dialysis.

Our study has a number of important limitations. Data for the Canadian cohort were collected prospectively, whereas the survey data from the American cohort were retrospectively reported. The difficulty in finding a control population necessitated including patients from 1990 onward in the American cohort, but this cutoff was chosen because it reflects widespread availability of erythropoietin-stimulating agents and biocompatible membranes. Furthermore, recently published data from the Australia and New Zealand Dialysis and Transplant (ANZDATA) Registry, which included 49 pregnancies spanning 1966-2008, failed to demonstrate an effect of era on the live birth rate ${ }^{17}$. Although the Canadian patients also had extensive comorbidities, diabetes, which in itself can result in very poor pregnancy outcomes, was notably absent. The maternal mortality ratio and the infant mortality rate are established markers of the overall quality of obstetric care, and both are consistently higher in the United States than in Canada by a small fraction ${ }^{18}$. All patients in the Greater Toronto Area were managed in one of the two obstetrics centres wherein the two designated obstetricians are experienced with respect to the management of this high-risk patient population. We lacked data on potentially important characteristics that could have factored towards pregnancy outcomes including race and access to health care, which was known and standardized only in the PreKid high-risk obstetrics clinic. Finally, there were missing data in the ARPD, but every effort was made to ensure that our imputation strategies provided the most conservative effect size estimates. 
In conclusion, intensive HD is associated with a higher proportion of live births compared with standard care in pregnant ESRD patients. In addition, maternal and neonatal complications tended to be few and manageable. We propose that intensive HD should be considered as a viable and feasible option for dialysis patients of childbearing age who want to become pregnant or who are pregnant. However, given that maternal and neonatal complications are still more frequent in pregnant ESRD patients than in the pregnant non-ESRD population, these patients deserve meticulous follow-up by a dedicated high-risk obstetrician in close collaboration with a nephrology team. Ongoing international collaborative research remains necessary to continue to improve pregnancy outcomes in women with ESRD.

\section{Concise methods}

The research ethics boards at both the University of Toronto and Loyola University Medical Centre approved the collection of data for study purposes as per the Declaration of Helsinki for Medical Research Involving Human Subjects. Both registries meet the criteria for privacy compliance per the Health Services Research and the Health Insurance Portability and Accountability Act Privacy Rules.

\section{Toronto PreKid Clinic and Registry Patients}

The Toronto PreKid Clinic was established in 2000 capturing all young women with ESRD who conceived on HD or required HD during pregnancy for CKD progressing to ESRD. Therapeutic terminations were excluded, as were women with peripartum AKI who recovered enough function to come off HD in the postpartum period. Data for the Toronto PreKid Clinic Registry were collected prospectively, including information on the dialysis prescription, laboratory data, as well as pregnancy follow-up and outcome data. In all cases, antenatal care was performed in the PreKid Clinic by an obstetrician specializing in high-risk pregnancy (J.K. or D.H.) and supported by a designated nephrologist (M.H.). Both the dialysis prescription and the obstetric follow-up were standardized in all patients, as previously described in detail ${ }^{19}$.

In stable HD patients, the dialysis intensity was increased to 6-8 hours for 6 to 7 days per week either before or immediately after conception. Patients who were not on dialysis before pregnancy initiated this same intensive dialysis regimen. As previously described $^{9}$, the intensified dialysis regimen resulted in normalization of predialysis and postdialysis urea levels. No dietary restrictions were required and phosphate supplementation was required for all patients. Ultrafiltration was determined by clinical assessment of BP and volume status. The degree of anemia and iron deficiency 
increased during the pregnancy with increasing needs for erythropoietin-stimulating agents and intravenous iron administration, typically administered weekly to maintain a target hemoglobin of $100-110 \mathrm{~g} / \mathrm{l}$.

With respect to the obstetric care, a first-trimester screen that included nuchal translucency was offered between 11 and 14 weeks of gestation to detect fetal aneuploidy. The maternal serum screen or the quadruple test was done between 15 and 20 weeks of gestation. Between 18 and 20 weeks of gestation, a level II ultrasound was performed to exclude fetal anomalies and to measure cervical length. Between 22 and 24 weeks of gestation, a placental ultrasound was performed to assess placental dimensions along with uterine and umbilical artery Doppler waveforms to detect impending placental insufficiency ${ }^{20}$. From 26 weeks of gestation onward, ultrasounds were scheduled every 2 weeks to follow measurements of fetal well-being, biometry, amniotic fluid index, cervical length, and umbilical artery pulsatility indices, which occurred weekly as the patient neared term or when pregnancy complications were encountered. Routinely, induction of labor was booked prior to 39 weeks of gestation mainly for logistical reasons to coordinate in-centre HD and nephrology care.

\section{ARPD patients}

The ARPD collects retrospective data through physician surveys. Data include maternal characteristics (age, the cause of ESRD where available, and dialysis vintage), the hours of HD provided during pregnancy, as well as pregnancy outcomes (gestational age and birth weight). Eligible controls were selected from 394 pregnancies reported to the ARPD. All cases before 1990 were excluded in an attempt to provide contemporaneous controls. Pregnancies in which the woman was treated with peritoneal dialysis and pregnancies that were electively terminated were also excluded. From the remaining pregnancies, we selected those in which the number of hours of dialysis per week and the pregnancy outcome were known. We used only pregnancies in which we had information either on gestational age or birth weight. In 10 cases, the precise gestational age was missing for patients losing their infants in the first or second trimester. To provide the most conservative estimate possible, a gestational age of 12 weeks was assigned for a first-trimester loss and 24 weeks for a second-trimester loss. Birth weight was not reported in four patients with either a stillbirth or a neonatal death, along with an additional four patients with surviving infants, birth weight was not reported. Hence, the mean birth weight for the particular gestational age was imputed to again provide the most conservative estimate. 


\section{Compared outcomes}

Outcomes were ascertained by review of the relevant medical records and defined as follows: surviving infants, infants who were alive at discharge from the hospital; neonatal death, death before discharge from hospital or within the first month of life; intrauterine fetal demise, intrauterine fetal death after the first trimester before the onset of labor; and spontaneous abortion, spontaneous loss of pregnancy prior to viability or 24 weeks of gestation. Spontaneous abortions were further classified into first- and second-trimester losses. Low birth weight was defined as neonatal weight $<2500 \mathrm{~g}$, whereas very low birth weight was defined as neonatal weight $<1500 \mathrm{~g}$. Pregnancy outcomes were analyzed separately in established HD patients and those who required dialysis initiation during pregnancy. Only women who conceived after dialysis initiation were included in the analysis of dialysis intensity on pregnancy outcomes due to the potential confounding effects of residual kidney function. Dialysis intensity was assessed continuously as well as categorically after dividing the hours of dialysis into clinically relevant tertiles $(0-20,21-36$, and $37-56$ hours) to capture the typically prescribed dialysis regimens in the two countries.

\section{Statistical analyses}

Descriptive statistics were calculated for all variables of interest. Continuous variables were assessed for normality both visually (normal probability plot) and by inferential statistics (Shapiro-Wilk and Kolmogorov-Smirnov tests). Normally distributed variables were expressed as the mean $\pm \mathrm{SD}$ and nonparametric variables were expressed as the median and interquartile range. Categorical measures were summarized using counts and percentages. The $t$ test or the $M$ ann-Whitney $\mathrm{U}$ test was used to compare the two groups. Proportions were compared using the chi-squared test statistic. The time to event (neonatal death, intrauterine fetal demise, or spontaneous abortion) was analyzed using the Kaplan-Meier product limit method. Survival functions were compared using the log-rank test. The Kruskal-Wallis test with a pairwise MannWhitney $\mathrm{U}$ test and a Bonferroni correction for between-group differences was used to compare gestational age by dialysis dose, whereas an ANOVA was used t compare birth weigth by dialysis dose along with a linear test for trend. Correlation was used to assess the relationship between dialysis intensity and gestational age as well as birth weight. A $P$ value $\varangle$.05 was deemed statistically significant. All analyses were carried out or supervised by M.H. using Stata Version 13 software (Stata Press). 


\section{References}

1. Confortini P, Galanti G, Ancona G, et al. Full term pregnancy and successful delivery in a patient on chronic hemodialysis. Proc Eur Dial Transplant Assoc 1971;8:74-80.

2. Holley JL, Schmidt RJ, Bender FH, Dumler F, Schiff M. Gynecologic and reproductive issues in women on dialysis. Am J Kidney Dis 1997;29:685-90.

3. Lim VS, Henriquez C, Sievertsen G, Frohman LA. Ovarian function in chronic renal failure: evidence suggesting hypothalamic anovulation. Ann Intern Med 1980;93:21-7.

4. Mantouvalos H, Metallinos C, Makrygiannakis A, Gouskos A. Sex hormones in women on hemodialysis. Int J Gynaecol Obstet 1984;22:367-70.

5. Gómez F, de la Cueva R, Wauters JP, Lemarchand-Béraud T. Endocrine abnormalities in patients undergoing long-term hemodialysis. The role of prolactin. Am J Med 1980;68:522-30.

6. Hou SH, Grossman S, Molitch ME. Hyperprolactinemia in patients with renal insufficiency and chronic renal failure requiring hemodialysis or chronic ambulatory peritoneal dialysis. Am J Kidney Dis 1985;6: 245-9.

7. Report from the Registration Committee of the European Dialysis and Transplant Association: Successful pregnancies in women treated by dialysis and kidney transplantation. Br J Obstet Gynaecol 1980;87:839-45.

8. Bagon JA, Vernaeve H, De M uylder X, et al. Pregnancy and dialysis. Am J Kidney Dis 1998;31:756-65.

9. Barua $M$, Hladunewich $M$, Keunen J, et al. Successful pregnancies on nocturnal home hemodialysis. Clin J Am Soc Nephrol 2008;3:392-6.

10. Gangji AS, Windrim R, Gandhi S, et al. Successful pregnancy with nocturnal hemodialysis. Am J Kidney Dis 2004; 44:912-6.

11. Hou SH. Frequency and outcome of pregnancy in women on dialysis. Am J Kidney Dis 1994;23:60-3.

12. Souqiyyeh $M$, Huraib $O$, Abdul Ghayoum $M$, et al. Pregnancy in chronic hemodialysis patients in the kingdom of Saudi Arabia. Am J kidney dis 1992;19:235-8.

13. Luders C, Castro MC, Titan SM, et al. Obstetric outcome in pregnant women on long-term dialysis: a case series. Am J Kidney Dis 2010;56:77-85.

14. Perl J, Chan CT. Home hemodialysis, daily hemodialysis, and nocturnal hemodialysis: core curriculum 2009. Am J Kidney Dis 2009;54:1171-84.

15. Asamiya $Y$, Otsubo $S$, Matsuda $Y$, et al. The importance of low blood urea nitrogen levels in pregnant patients undergoing hemodialysis to optimize birth weight and gestational age. Kidney Int 2009;75: 1217-22.

16. Okundaye I, Abrinko P, Hou S. Registry of pregnancy in dialysis patients. Am J Kidney Dis 1998:31: 766-73.

17. Shahir AK, Briggs N, Katsoulis J, Levidiotis V. An observational outcomes study from 1966-2008, examining pregnancy and neonatal outcomes from dialyzed women using data from the ANZDATA Registry. Nephrology (Carlton) 2013;18:276-84.

18. World Health Organization: trends in maternal mortality: 1990 to 2010, Geneva, Switzerland, World Health Organization, 2012.

19. Hladunewich M, Hercz AE, Keunen J, Chan C, Pierratos A. Pregnancy in end-stage renal disease. Semin Dial 2011;24:634-9.

20. Toal M, Chan C, Fallah S, et al. Usefulness of a placental profile in high-risk pregnancies. Am J Obstet Gynecol 2007;196:363.e1-7. 


\section{Chapter}

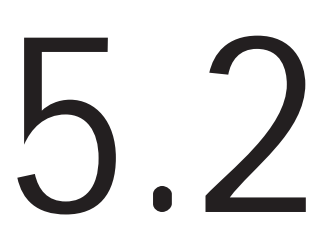

\section{Fertility and obstetrical follow-up in intensive home hemodialysis}

Cornelis T, Hladunewich M A, Hui D, Keating S, Pierratos A, Nesrallah G, Goldstein M, Lipscombe J, Chan CT, Keunen J 


\section{ABSTRACT}

Background: Pregnancy is uncommon in dialysis patients and often complicated by significant materno-fetal morbidity and even mortality. Our recent data from a Canadian and United States cohort comparison indicate that intensive hemodialysis (HD) is associated with higher live birth rate and longer pregnancy duration as compared to conventional HD.

Design, Setting, Participants and Measurements: We prospectively collected obstetrical data including first trimester screen (FTS), maternal serum screen (MSS), level II ultrasound and placental ultrasounds in all pregnancies supported by intensive HD and followed closely by a multidisciplinary, high-risk team from 2000 to 2011 in Toronto.

Results: We included 17 pregnancies with 15 live births (live birth rate 88.2\%) for a pregnancy incidence of $22 \%$. Biochemical markers and estimated fetal growth patterns were largely normal as was placental function and morphology. Median gestational age was 36.4 (IQR 32.4-37.6) weeks and median birth weight was 2076 (IQR 1600-2750) gram. Pregnancy complications were few.

Conclusion: Intensified HD seems to the best option for dialysis patients of childbearing age who want to become pregnant. Clinical benefits of intensive HD on live birth rate and pregnancy duration are corroborated by obstetrical follow-up parameters including FTS, MSS, placental function, placental morphology and estimated fetal weight, comparable to normal pregnancies. 


\section{Introduction}

Historically, fertility rates on conventional hemodialysis (HD) regimens are low, and pregnancy when it occurs is often complicated by significant fetal and maternal morbidity, and even mortality. Our group previously demonstrated that nocturnal HD (NHD), as an intensive dialysis modality, resulted in reduced maternal and fetal complications in pregnant patients requiring dialysis ${ }^{1,2}$. Recently, we demonstrated, in a Canadian and United States comparison, that live birth rate and pregnancy duration are significantly higher in intensive as compared to less intensive $H D^{3}$. In this brief report, we present data of the meticulous obstetrical follow-up in all pregnant patients supported by intensive HD in Toronto from 2000 to 2011. All patients were followed by a high-risk obstetrical team, which offered standardized assessments of serum biomarkers as well as high-resolution ultrasound follow-up of fetal growth and wellbeing along with placental function. Through a multidisciplinary clinic, a nephrologist was able to carefully oversee and adjust the HD prescription.

We hypothesized that intensive HD with meticulous follow-up improves the likelihood of conception, and is associated with normal placental function as well as normal fetal growth and development, thereby markedly decreasing pregnancy complications for both mother and child. The affiliated programs research ethics boards have approved collection and reporting of anonymous patient data.

\section{Methods}

\section{Included patients}

Female end-stage renal disease (ESRD) patients on NHD at the time of conception or who were started on NHD during pregnancy at the University Health Network, Humber River Regional Hospital, St Michael's Hospital or Credit Valley Hospital in Toronto between January 2001 and December 2011 were included.

\section{Intensive HD prescription}

This dialysis modality was delivered as extensively described in previous publications about the effects of home NHD in pregnancy ${ }^{1-3}$. In short, the dialysis intensity was increased to 6 to 8 hours per night for 6 to 7 nights per week either prior to or immediately after diagnosis of pregnancy in stable HD patients. Patients not on dialysis yet prior to pregnancy were started on the same intensified dialysis treatment. 


\section{Routine obstetrical follow-up}

Our obstetrical follow-up was also described recently ${ }^{3}$. The first trimester screen (FTS) including nuchal translucency (NT), pregnancy-associated plasma protein-A (PAPP-A) and free beta human chorionic gonadotropin (hCG) was performed between 11 and 14 weeks of gestation to detect fetal aneuploidy. However, free beta hCG values was not included in the assessment of aneuploidy risk as renal failure increases free beta hCG, which may result in false positive FTS and an incorrect suspicion of gestational trophoblastic disease ${ }^{2}$. The maternal serum screen (MSS) or the quadruple (Quad) test, which included alpha fetoprotein (AFP), total hCG, inhibin A (DIA) and unconjugated estriol (uE3), was done between 15 and 20 weeks of gestation. Increased values of AFP, DIA and total hCG and decreased levels of first trimester PAPP-A are associated with adverse pregnancy outcomes commonly encountered in renal patients such as preterm labor, preeclampsia and intra-uterine growth restriction (IUGR) 4 .

Between 18 and 20 weeks of gestation, a level II ultrasound was performed to detect fetal anomalies, but more importantly, to measure cervical length, a predictor of preterm birth. Between 22-24 weeks of gestation, a placental ultrasound was done to assess again cervical length and placental dimensions along with uterine and umbilical artery Doppler wave forms to detect early signs of impending utero- and/or fetoplacental insufficiency ${ }^{4}$. From week 26 of gestation, ultrasounds were arranged every 2 weeks to follow fetal well-being, biometry, amniotic fluid index (AFI) and umbilical artery pulsatility indices (PI). The frequency of these assessments was increased to weekly as the patient approached term or when pregnancy complications occurred. Routinely, induction of labor was planned prior to 39 weeks of gestation mainly for logistical reasons to coordinate in-centre dialysis and nephrology care. In all cases, antenatal care was delivered in the PreKid (Pregnancy and Kidney Disease) Clinic by a high-risk obstetrician (Dr. J. Keunen or Dr. D. Hui) and by a dedicated nephrologist (Dr. M. Hladunewich).

\section{Results}

\section{Clinical cases}

Thirteen patients had a total of 17 pregnancies resulting in 15 live births (live birth rate 88.2\%), a single first trimester termination and a single pre-viable fetal loss (Table 5.2.1). Eleven pregnancies occurred while the women were stable on NHD. Till December 2011, 50 women of childbearing age ( $\leq 45$ years) had been trained through the Toronto NHD programs resulting in a conception rate of $22 \%$. The median age at 
the time of conception was 34 (IQR 30.8-35.5) years. Patients 2 and 13 (twin pregnancy) were on conventional HD when they conceived, but were converted to the intensified regimen 3 and 7 weeks after conception, respectively. Patients 1, 5 and 12 were not on any renal replacement treatment yet when they conceived, and were initiated on NHD because of deterioration of renal function at a gestational age of 15, 20 and 8 weeks, respectively. For the patients who were on NHD at the time of conception, the median NHD vintage was 55 (IQR 22-71) months.

Table 5.2.1 Pregnancy outcomes.

\begin{tabular}{lccccl}
\hline Patient & Gestation & Delivery & Weight $(\mathrm{g})$ & APGAR & Complications \\
\hline Pt 1* & 26w1d & SVD & 980 & $3 / 7$ & Short cervix; Preterm delivery; NICU \\
Pt 2* & 37w2d & Vacuum & 2015 & $8 / 8$ & Transient polyhydramnios; SGA \\
Pt 3: pregnancy 1 & 37w4d & SVD & 2930 & $9 / 9$ & None \\
Pt 3: pregnancy 2 & 38w3d & SVD & 2520 & $9 / 9$ & None \\
Pt 4: pregnancy 1 & 36w & C/S & 2020 & $9 / 9$ & Short Cervix \\
Pt 4: pregnancy 2 & 22w2d & SVD & 460 & NA & PPROM, Neonatal Death \\
Pt 5* & 32w3d & C/S & 1120 & $7 / 9$ & Preeclampsia \\
Pt 6 & 36w1d & SVD & 2415 & $9 / 9$ & None \\
Pt 7: pregnancy 1 & 38w & SVD & 3000 & $5 / 8$ & None \\
Pt 7: pregnancy 2 & 37w4d & SVD & 2785 & $9 / 9$ & None \\
Pt 8 & 38w5d & C/S & 2750 & $8 / 9$ & None \\
Pt 9 & 36w5d & VaCuum & 2690 & $6 / 9$ & None \\
Pt 10 & 30w & SVD & 1260 & $5 / 7$ & NICU \\
Pt 11 & 32w1d & C/S & 1850 & $4 / 7$ & Rescue cerclage (22w), PPROM \\
Pt 12* & 36w6d & SVD & 2900 & $9 / 9$ & None \\
Pt 13* & 34w & SVD & 2000 & $6 / 9$ & Short cervix, PPROM \\
& & & 1600 & $9 / 9$ & \\
\hline
\end{tabular}

* Patients who started intensive HD after conception; APGAR: appearance pulse grimace activity respiration; after 1 and 5 minutes. SVD: spontaneous vaginal delivery; C/S: cesarean section; NA: not applicable. SGA: small for gestational age; NICU: neonatal intensive care unit; PPROM: preterm premature rupture of membranes

\section{Pregnancy outcomes}

Pregnancy outcomes are summarized in Table 5.2.1. The 15 live births had a median gestational age of 36.4 (IQR 32.4-37.6) weeks and a mean birth weight of 2076 (IQR 1600-2750) grams. Four patients were documented to have short cervices, 1 patient had transient polyhydramnios, 1 patient presumably had preeclampsia, and patient 10 was admitted for preterm labor at 30 weeks of gestation ${ }^{3}$.

\section{Obstetrical parameters: FTS, M SS, placental ultrasound and pathology, estimated fetal weight}

The mean systolic and diastolic blood pressure (BP) was within normal physiological ranges during the full period of gestation. However, 3 patients required 1, 2 and 3 
antihypertensive agents respectively for the whole pregnancy, patient 3 required labetalol from week 22 of gestation in her second pregnancy, patient 7 was treated with methyldopa during the last trimester of both her pregnancies, patient 10 required labetalol beginning in the second trimester and patient 12 required one antihypertensive during the first 2 months of the pregnancy.

Table 5.2.2 describes the results of the obstetrical follow-up of the pregnancies. It shows that the median results of individual FTS and MSS parameters, placental length and thickness as well as median uterine and umbilical artery PI and median cervical length were largely within the normal ranges in these pregnancies with the exception of the elevated free beta hCG serum values due to impaired renal excretion. Figure 5.2.1 illustrates that serial fetal growth assessments progressed on average along the $50^{\text {th }}$ centile except for 1 pregnancy complicated by IUGR (EFW below $10^{\text {th }}$ centile). Placental pathology was available in 8 cases and the vast majority revealed no salient findings with the exception of advanced villous maturation for gestational age (Patient 1), chorioamnionitis (Patient 11) and a placenta weighing less than the $3^{\text {rd }}$ percentile with distal villous hypoplasia (Patient 5).

Table 5.2.2 Obstetrical parameters.

\begin{tabular}{llccrc}
\hline Laboratory Test & & Median & IQR & N & Normal Values \\
\hline First Trimester Screen & NT & 1.08 & $(0.94-1.2)$ & 8 & $<1.5$ \\
& PAPP & 0.84 & $(0.53-1.27)$ & 10 & $>0.35$ \\
& BHCG & 7.81 & $(6.14-19.58)$ & 9 & $>2.0$ \\
Maternal Serum Screen & AFP & 0.93 & $(0.86-1.18)$ & 13 & $<2.0$ \\
& HCG & 2.42 & $(1.84-2.58)$ & 10 & $<4.0$ \\
& DIA & 0.98 & $(0.81-1.48)$ & 7 & $<3.0$ \\
Placental Ultrasound & Length (cm) & 13.1 & $(12.1-14.6)$ & 9 & $>10$ \\
& Thickness (cm) & 3.2 & $(2.5-3.9)$ & 8 & $<4$ \\
& UtA PI left & 1.01 & $(1.00-1.10)$ & 10 & $<1.45$ \\
& UtA PI right & 0.99 & $(0.83-1.00)$ & 10 & $<1.45$ \\
& UmA PI & 1.3 & $(1.2-1.4)$ & 9 & $<1.5$ \\
Level II Ultrasound & Cervix length (cm) & 3.6 & $(3.3-3.7)$ & 15 & $>2.5$ \\
& Anomalies & & None & & NA \\
\hline
\end{tabular}

First trimester screen and maternal serum screen values in MoM (multiples of mean). NT: nuchal translucency; PAPP: pregnancy associated plasma protein; BHCG: free beta human chorionic gonadotropin; AFP: alpha fetoprotein; HCG: total human chorionic gonadotropin; DIA: inhibin A. UtA: uterine artery; UmA: umbilical artery; PI: pulsatility index; NA: not applicable. 


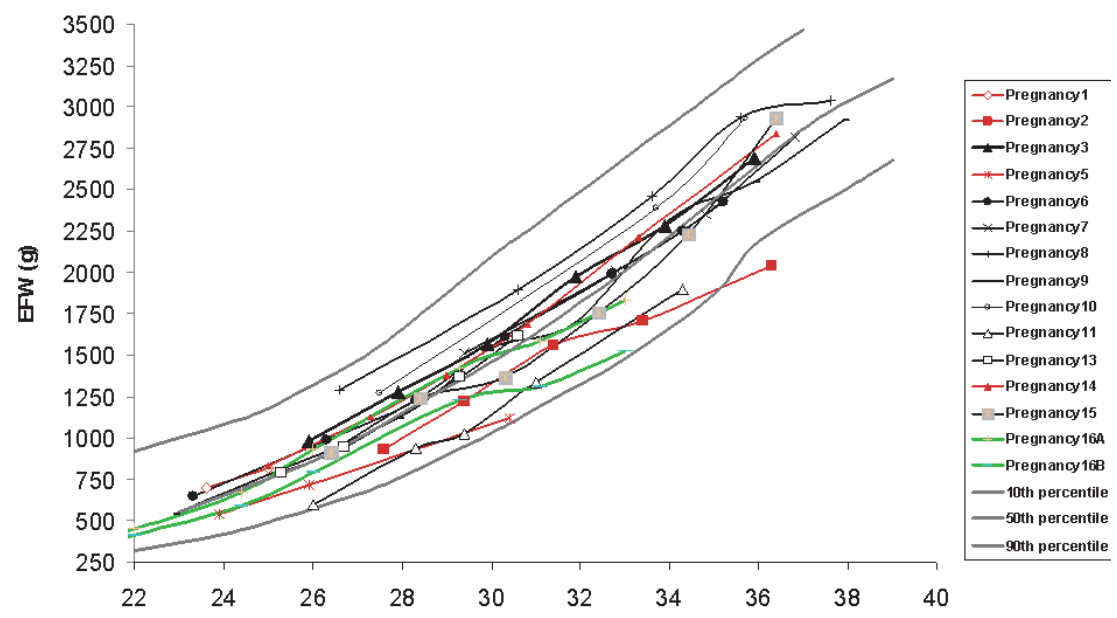

Gestational Age (weeks)

Figure 5.2.1 Serial Estimated Fetal Weights (EFW) for all pregnancies.

\section{Discussion}

Our series demonstrates that intensified delivery of dialysis improves the rate of conception, and supports, by means of normal obstetrical follow-up parameters, our recent analysis showing higher live birth rates and longer pregnancy duration with intensive $H D$ as compared to conventional $H D^{3}$.

Women with ESRD are known to have gonadal dysfunction manifested as anovulation, irregular menses, sexual dysfunction and earlier onset of menopause primarily due to multiple abnormalities in the hypothalamic-pituitary-ovarian axis. Pregnancy, therefore, is uncommon in women on dialysis with conception rates in the literature ranging from $<1 \%$ to $7.9 \%^{5-10}$. Even the most complete registry data collected from all hemodialysis units in Belgium in $1996^{11}$, including all 32 dialysis centres, representing 4135 patients of which 1472 were women of childbearing age, noted an incidence rate of pregnancy progressing beyond the first trimester to be only 0.3 per 100 patient-years ( 15 cases in 1472 females of childbearing age treated, for a total of 4545 patient-years). In the most recent analysis of this topic, from the Australian and New Zealand Dialysis and Transplant (ANZDATA) Registry, the pregnancy rate in dialyzed women in the era 19962008 was 3.3 per 1000 person-years ${ }^{12}$. Thus, our data also represents the highest 
conception rates reported in the literature to date with 11 pregnancies in 50 established NHD patients (22\%). Further, most of these women were previously on conventional HD for prolonged periods, but none conceived. Thus, more intensive clearance normalizes the female menstrual cycle ${ }^{13}$ and fertility can be restored.

In this analysis, results of FTS and MSS, placental length and thickness as well as median uterine and umbilical artery PI and median cervical length were largely comparable to pregnancies in patients without ESRD. Serial fetal growth assessments progressed on average along the $50^{\text {th }}$ centile, which is most uncommon in patients with advanced renal failure (Figure 5.2.1). We confirm that the intensified dialysis dose is critical in providing a healthy maternal environment for normal placental development, a prerequisite for normal fetal growth and decreased pregnancy complications.

Improved endothelial function may assist with healthy placental implantation and prevent preeclampsia. NHD has a proven vascular benefit. Significant decreases in peripheral vascular resistance have been noted along with improvements in markers of endothelial function including baroreceptor sensitivity, restoration of endothelial progenitor cells and endothelium-dependent vasodilatation ${ }^{14-16}$. We have previously demonstrated that endothelium-dependent vasodilatation cannot be elicited in patients on conventional HD, but was restored shortly (2 months) after initiation of a more intensive NHD regimen highlighting the importance of establishing adequate dialysis prior to conception to assist with adequate placental implantation ${ }^{17}$. Recently, we illustrated the protective effects of intensive HD on endothelial function and BP, in a patient started on intensive HD at week 26 of gestation, by the stable results of the weekly measurements of 24-hour BP as well as hemodynamic and arterial stiffness parameters, in combination with comparable serial results of the angiogenic balance of soluble fms-like tyrosine kinase (sFlt-1) / Placental Growth Factor (PIGF) to normal pregnancies $^{18}$. In our series, median placental length and thickness as well as median uterine and umbilical artery PI were within the normal ranges demonstrating overall adequate placental growth and perfusion. Further, complications reflective of inadequate placentation occurred only in a single patient not already well established on NHD.

In conclusion, we consider intensified HD as the best option for dialysis patients of childbearing age who want to become pregnant or who are pregnant. We also found comparable results of meticulous obstetrical follow-up of pregnancies in patients with ESRD on intensive HD as in patients without ESRD. This finding is in line with recent data showing improved pregnancy outcomes in terms of live birth rate and pregnancy duration with intensive HD. 


\section{References}

1. Gangji AS, Windrim R, Gandhi S, Silverman JA, Chan CT. Successful pregnancy with nocturnal hemodialysis. Am J Kidney Dis 2004;44:912-6.

2. Barua M, Hladunewich M, Keunen J, Pierratos A, M cFarlane P, Sood M, Chan CT. Successful pregnancies on nocturnal home hemodialysis. Clin J Am Soc Nephrol 2008;3:392-6.

3. Hladunewich M, Hou S, Odutayo A, Cornelis T, Pierratos A, Goldstein M, Tennankore K, Keunen J, Hui D, Chan CT. Intensive hemodialysis is associated with improved pregnancy outcomes: a Canadian and United States cohort comparison. J Am Soc Nephrology 2014;25:1103-9.

4. Toal M, Chan C, Fallah S, Alkazaleh F, Chaddha V, Windrim RC, Kingdom JC. Usefulness of a placental profile in high-risk pregnancies. Am J Obstet Gynecol 2007;196:363.e1-7.

5. Successful pregnancies in women treated by dialysis and kidney transplantation. Report from the Registration Committee of the European Dialysis and Transplant Association. Br J Obstet Gynaecol 1980;87:839-45.

6. Toma H, Tanabe K, Tokumoto T, Kobayashi C, Yagisawa T. Pregnancy in women receiving renal dialysis or transplantation in Japan: a nationwide survey. Nephrol Dial Transplant 1999;14:1511-6.

7. Okundaye I, Abrinko P, Hou S. Registry of pregnancy in dialysis patients. Am J Kidney Dis 1998:31: 766-73.

8. Hou SH. Frequency and outcome of pregnancy in women on dialysis. Am J Kidney Dis 1994;23:60-63.

9. Malik GH, Al-Harbi A, Al-Mohaya S, Dohaimi H, Kechrid M, Shetaia MS, Al-Hassan AO, Quiapos LS. Pregnancy in patients on dialysis--experience at a referral center. J Assoc Physicians India 2005;53: 937-41.

10. Bahloul H, Kammoun K, Kharrat M, Jarraya F, Charffedine K, Hamida MB, Hachicha J. Pregnancy in chronic hemodialysis women: outcome of multicentric study. Saudi J Kidney Dis Transpl 2003;14:530-1.

11. Bagon JA, Vernaeve H, De M uylder X, Lafontaine JJ, M artens J, Van Roost G. Pregnancy and dialysis. Am J Kidney Dis 1998;31:756-65.

12. Shahir AK, Briggs N, Katsoulis J, Levidiotis V. An observational outcomes study from 1966-2008, examining pregnancy and neonatal outcomes from dialysed women using data from the ANZDATA registry. Nephrology 2013;18:276-84.

13. van Eps C, Hawley C, Jeffries J, Johnson DW, Campbell S, Isbel N, M udge DW, Prins J. Changes in Serum Prolactin, Sex Hormones and Thyroid Function with Alternate Nightly Nocturnal Home Haemodialysis. Nephrology (Carlton) 2012;17:42-7.

14. Chan CT, Jain V, Picton P, Pierratos A, Floras JS. Nocturnal hemodialysis increases arterial baroreflex sensitivity and compliance and normalizes blood pressure of hypertensive patients with end-stage renal disease. Kidney Int 2005;68:338-44.

15. Chan $\mathrm{CT}$, Shen XS, Picton P, Floras J. Nocturnal home hemodialysis improves baroreflex effectiveness index of end-stage renal disease patients. J Hypertens 2008;26:1795-800.

16. Yuen DA, Kuliszewski MA, Liao C, Rudenko D, Leong-Poi H, Chan CT. Nocturnal hemodialysis is associated with restoration of early-outgrowth endothelial progenitor-like cell function. Clin J Am Soc Nephrol 2011;6:1345-53.

17. Chan CT, Harvey PJ, Picton P, Pierratos A, M iller JA, Floras JS. Short-term blood pressure, noradrenergic, and vascular effects of nocturnal home hemodialysis. Hypertension 2003;42:925-31.

18. Cornelis T, Spaanderman M, Beerenhout C, Perschel FH, Verlohren S, Schalkwijk CG, van der Sande FM, Kooman JP, Hladunewich M. Antiangiogenic factors and maternal hemodynamics during intensive hemodialysis in pregnancy. Hemodial Int 2013;17:639-43. 



\section{Chapter}

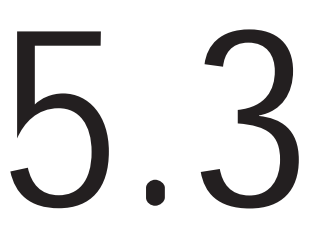

\section{Antiangiogenic factors and maternal hemodynamics during intensive hemodialysis in}

pregnancy

Cornelis T, Spaanderman M, Beerenhout C, Perschel FH, Verlohren S, Schalkwijk CG, van der Sande FM, Kooman JP, Hladunewich M 


\section{ABSTRACT}

We report on a 21-year old pregnant patient with IgA nephropathy who was initiated on intensive hemodialysis (8 hours of hemodialysis three times a week) at a gestational age of 26 weeks on the basis of worsening kidney function resulting in rapidly progressive fatigue and difficulties in metabolic control. Throughout the pregnancy, and while on intensive hemodialysis, 24-hour ambulatory blood pressure control was within the target, and results of weekly 24-hour measurement of central hemodynamics and pulse wave velocity, and of serial levels of circulating (anti-) angiogenic factors were comparable to normal pregnancies. Estimated fetal growth evolved along the 50th percentile, and no polyhydramnios was detected. After induction for a sudden, unexplained increase in blood pressure, she delivered a healthy boy of $2480 \mathrm{~g}$ at a gestational age of 36 weeks. This case adds to the expanding literature which supports the use of intensive hemodialysis in pregnant patients with end-stage renal disease, and illustrates, for the first time, the potential use of serial (anti-) angiogenic factors and 24-hour measurements of blood pressure and hemodynamic indices in order to facilitate monitoring of these complicated patients. 


\section{Background}

Pregnancy in patients with end-stage renal disease (ESRD) is uncommon. If it occurs, there is a high likelihood of fetal and maternal complications ${ }^{1}$. Historically, the degree of residual renal function in these patients was noted to be important to improve the outcomes of pregnancy. M ore recently, intensive hemodialysis (HD) [i.e. longer and/or more frequent HD than in conventional (4 hours HD 3 times a week) schedules] has been put forward as the optimal strategy to improve outcomes in these patients ${ }^{2-4}$. To predict preeclampsia, serial measurement of circulating antiangiogenic factors may be helpful $\left.\right|^{5-7}$. Additionally, regular 24-hour measurement of blood pressure (BP) and hemodynamic parameters may give extra information on hemodynamic control [central $\mathrm{BP}$ and cardiac output (CO)] and arterial wall properties [peripheral vascular resistance (PVR) and pulse wave velocity (PWV)] during pregnancy, and hence may predict adverse pregnancy events ${ }^{8,9}$. We performed, for the first time, serial monitoring of antiangiogenic factors with weekly 24-hour BP as well as hemodynamic parameter control in a patient who was successfully initiated on intensive HD during pregnancy.

\section{Case report}

A 21-year old primigravida was referred at 21 weeks gestation for further pregnancy management. Two years before, she was diagnosed with IgA nephropathy. Despite treatment with lisinopril and steroids according to the Pozzi protocol ${ }^{10}$, her kidney function deteriorated to creatinine values between 200 and $250 \mu \mathrm{mol} / \mathrm{l}$, corresponding to measured creatinine clearances between 20 and $25 \mathrm{ml} / \mathrm{min}$. At 20 weeks gestation, methyldopa and labetalol were initiated for BP control, and at 22 weeks gestation, oral thyroid and iron supplementation as well as erythropoietin (EPO) were started.

During pregnancy, her kidney function progressively decreased with a creatinine of $393 \mu \mathrm{mol} / \mathrm{l}$ by week 26 of gestation (corresponding to a measured creatinine clearance of $13 \mathrm{ml} / \mathrm{min}$ ), resulting in rapidly progressive fatigue and difficulties in metabolic control (hyperphosphatemia and metabolic acidosis), prompting us to initiate intensive HD (8 hours 3 days a week) via a tunneled dialysis catheter. Based on a measured endogenous creatinine clearance of almost $15 \mathrm{ml} / \mathrm{min}$ in our patient and an estimated equivalent renal urea clearance (EKR) of 20-25 ml/min resulting from the long-hour HD sessions 3 times a week, we assessed that the combination of residual renal function and intensive HD in our patient would correspond to an estimated EKR of $35-40 \mathrm{ml} / \mathrm{min}$ delivered by nightly noctural HD (NHD) (7 to 8 hours of HD 7 nights a week) as is 
performed routinely in Toronto in pregnant dialysis patients with successful outcomes ${ }^{2,3}$.

Blood and dialysate flow were 250 and $500 \mathrm{ml} / \mathrm{min}$ respectively. Nadroparin was given for anticoagulation. Potassium and phosphate were supplemented during HD. Dialysate calcium and bicarbonate concentration were 1.5 and $34 \mathrm{mmol} / /$ respectively. No ultrafiltration was necessary because of residual urine production. EPO and iron were given intravenously during dialysis.

General labs were done weekly, showing hemoglobin levels between 110 and $120 \mathrm{~g} / \mathrm{l}$, normal acid-base status, stable uric acid levels and liver function tests as well as steady residual renal function (pre-dialysis serum creatinines of $300 \mu \mathrm{mol} / \mathrm{I}$ and measured creatinine clearances of $15 \mathrm{ml} / \mathrm{min}$ ), and constant proteinuria of 5-6 g/day. Serum albumin remained at $22 \mathrm{~g} / \mathrm{l}$. Pre-dialysis serum samples were sent for determination of angiogenic and antiangiogenic factors. Single measurements were performed for soluble fms-like tyrosine kinase (sFlt-1) and placental growth factor (PIGF) on the fully automated Cobas system (Cobas/Elecsys human PIGF and Cobas/Elecsys sFIt-1, Roche Diagnostics $\mathrm{GmbH}$, M annheim, Germany) ${ }^{11}$. Serum factor levels were within the ranges as expected in normal pregnancy (Table 5.3.1) ${ }^{12}$. Obstetrical assessments including cardiotocography (CTG) and fetal ultrasounds were performed weekly. Serial estimated fetal weight (EFW) evolved along the $50^{\text {th }}$ percentile. No polyhydramnios was detected.

Table 5.3.1 Serial angiogenic and antiangiogenic factors.

\begin{tabular}{ccccccc}
\hline GA & $\begin{array}{c}\text { sFlt-1 } \\
\text { (patient) }\end{array}$ & $\begin{array}{c}\text { sFlt-1 } \\
\text { (normal) }\end{array}$ & $\begin{array}{c}\text { PIGF } \\
\text { (patient) }\end{array}$ & $\begin{array}{c}\text { PIGF } \\
\text { (normal) }\end{array}$ & $\begin{array}{c}\text { sFlt-1/PIGF } \\
\text { (patient) }\end{array}$ & $\begin{array}{c}\text { sFlt-1/PIGF } \\
\text { (normal) }\end{array}$ \\
\hline 21w & 2968 & $1576(589-3421)$ & 888.3 & $265(109-700)$ & 3.34 & $6.09(2.02-16.2)$ \\
22w4d & 2932 & & 793.6 & & 3.69 & \\
23w2d & 2721 & & 979.4 & & 2.78 & \\
24w & 2867 & $1449(514-4482)$ & 1177 & $412(108-1853)$ & 2.44 & $3.80(0.99-20.8)$ \\
26w4d & 2563 & & 881.5 & & 2.91 & \\
27w1d & 3345 & & 1799 & & 1.86 & \\
28w2d & 2329 & & 1290 & & 1.81 & \\
29w2d & 4215 & $1934(680-8042)$ & 1570 & $439(54-1312)$ & 2.68 & $4.03(0.80-86.4)$ \\
$30 w 2 d$ & 5547 & & 2158 & & 2.57 & \\
21w2d & 5015 & & 2301 & & 2.18 & \\
32w2d & 2268 & & 1545 & & 1.47 & \\
33w2d & 2197 & & 2252 & & 0.98 & \\
34w2d & 2314 & $2972(833-11643)$ & 1907 & $232(43.6-1177)$ & 1.21 & $13.3(1.01-109)$ \\
35w2d & 2374 & & 2105 & & 1.13 & \\
35w4d & 2857 & & 2259 & & 1.26 & \\
d2 pd & 843 & & 43 & & 19.6 & \\
d4 pd & 501 & & 33 & & 15.2 & \\
\hline
\end{tabular}

GA: gestational age) in w(eeks) and d(ays); sFlt-1: soluble fms-like tyrosine kinase in pg/ml; PIGF: placental growth factor in $\mathrm{pg} / \mathrm{ml}$; $\mathrm{d} 2 \mathrm{pd}$ : day 2 post-delivery; $\mathrm{d} 4 \mathrm{pd}$ : day 4 post-delivery; median values and ranges in normal pregnancies for gestational weeks 20-23, 24-28, 29-33 and 34-36, were obtained from reference 12. 
BP, central hemodynamics [Pulse Wave Analysis (PWA) and CO] and arterial stiffness (PVR and PWV) were assessed during 24 hours prior to the first dialysis treatment of every week using the Mobil-0-Graph ${ }^{\circledR}$. This validated device ${ }^{13,14}$ is lighter and smaller than conventional 24 hour BP monitors. The same device can also capture pulse wave analysis with the ARC Solver. This is a novel non-invasive method for the determination of the aortic systolic BP and the augmentation index based on oscillometric BP measurement with a common cuff. The results (Table 5.3.2) show comparable hemodynamic values as in normal pregnancies, although in our patient the $\mathrm{CO}$ values were in the lower and the PVR values in the higher ranges of normal pregnancies ${ }^{15-17}$.

Table 5.3.2 Serial 24-hour blood pressure, central hemodynamics and PWV.

\begin{tabular}{|c|c|c|c|c|c|c|c|c|c|c|}
\hline GA & $\begin{array}{c}\mathrm{SBP} \\
\mathrm{mmHg} \\
\end{array}$ & $\begin{array}{c}\mathrm{DBP} \\
\mathrm{mmHg} \\
\end{array}$ & $\begin{array}{c}\mathrm{CSBP} \\
\mathrm{mmHg}\end{array}$ & $\begin{array}{c}\text { cDBP } \\
\mathrm{mmHg}\end{array}$ & $\begin{array}{c}\mathrm{HR} \\
\mathrm{bpm}\end{array}$ & $\begin{array}{c}\text { Alx } \\
\% \\
\end{array}$ & $\begin{array}{c}\text { Alx@75 } \\
\% \\
\end{array}$ & $\begin{array}{c}\mathrm{CO} \\
1 / \min \end{array}$ & $\begin{array}{c}\text { PVR } \\
s^{*} \mathrm{mmHg} / \mathrm{ml} \\
\end{array}$ & $\begin{array}{r}\mathrm{PWV} \\
\mathrm{m} / \mathrm{s} \\
\end{array}$ \\
\hline $23 w$ & $\begin{array}{c}137.5 \\
( \pm 10.9)\end{array}$ & $\begin{array}{c}79.6 \\
( \pm 10.0)\end{array}$ & $\begin{array}{c}130.0 \\
( \pm 15.0)\end{array}$ & $\begin{array}{c}82.2 \\
( \pm 9.3)\end{array}$ & $\begin{array}{c}77.2 \\
(+10.5)\end{array}$ & $\begin{array}{c}39.9 \\
(+19.5)\end{array}$ & $\begin{array}{c}40.5 \\
(+17.7)\end{array}$ & $\begin{array}{c}4.3 \\
( \pm 0.5)\end{array}$ & $\begin{array}{c}1.4 \\
( \pm 0.2)\end{array}$ & $\begin{array}{c}5.6 \\
( \pm 0.5)\end{array}$ \\
\hline $26 w 4 d$ & $\begin{array}{r}130.9 \\
( \pm 10.2)\end{array}$ & $\begin{array}{c}78.5 \\
( \pm 7.7)\end{array}$ & $\begin{array}{l}125.3 \\
( \pm 8.9)\end{array}$ & $\begin{array}{c}82.0 \\
( \pm 7.1)\end{array}$ & $\begin{array}{c}78.3 \\
( \pm 9.0)\end{array}$ & $\begin{array}{c}34.8 \\
( \pm 11.5)\end{array}$ & $\begin{array}{l}35.1 \\
( \pm 9)\end{array}$ & $\begin{array}{c}4.4 \\
( \pm 0.5)\end{array}$ & $\begin{array}{c}1.4 \\
( \pm 0.2)\end{array}$ & $\begin{array}{c}5.5 \\
( \pm 0.3)\end{array}$ \\
\hline $29 w 1 d$ & $\begin{array}{r}125.0 \\
( \pm 15.5)\end{array}$ & $\begin{array}{l}75.6 \\
( \pm 8.2)\end{array}$ & $\begin{array}{c}114.4 \\
( \pm 17.6)\end{array}$ & $\begin{array}{c}77.9 \\
( \pm 8.9)\end{array}$ & $\begin{array}{c}90.7 \\
( \pm 13.6)\end{array}$ & $\begin{array}{c}21.3 \\
( \pm 13.7)\end{array}$ & $\begin{array}{c}30.8 \\
( \pm 11.1)\end{array}$ & $\begin{array}{c}4.5 \\
( \pm 0.6)\end{array}$ & $\begin{array}{c}1.2 \\
( \pm 0.2)\end{array}$ & $\begin{array}{c}5.3 \\
( \pm 0.4)\end{array}$ \\
\hline $30 w 1 d$ & $\begin{array}{c}137.4 \\
( \pm 15.1)\end{array}$ & $\begin{array}{c}76.7 \\
( \pm 9.8)\end{array}$ & $\begin{array}{c}126.3 \\
(+15.5)\end{array}$ & $\begin{array}{c}79.6 \\
( \pm 9.5)\end{array}$ & $\begin{array}{c}82.6 \\
( \pm 9.1)\end{array}$ & $\begin{array}{c}33.9 \\
( \pm 12.7)\end{array}$ & $\begin{array}{c}38.0 \\
( \pm 11.7)\end{array}$ & $\begin{array}{c}4.5 \\
( \pm 0.5)\end{array}$ & $\begin{array}{c}1.3 \\
( \pm 0.2)\end{array}$ & $\begin{array}{c}5.5 \\
( \pm 0.5)\end{array}$ \\
\hline $32 \mathrm{w} 1 \mathrm{~d}$ & $\begin{array}{l}127.0 \\
( \pm 14)\end{array}$ & $\begin{array}{c}75.8 \\
( \pm 9.5)\end{array}$ & $\begin{array}{l}118.6 \\
( \pm 14)\end{array}$ & $\begin{array}{c}77.9 \\
( \pm 9.5)\end{array}$ & $\begin{array}{c}86.1 \\
(+12.7)\end{array}$ & $\begin{array}{c}25.4 \\
( \pm 15.7)\end{array}$ & $\begin{array}{c}31.1 \\
(+14.1)\end{array}$ & $\begin{array}{c}4.6 \\
( \pm 0.6)\end{array}$ & $\begin{array}{c}1.2 \\
( \pm 0.2)\end{array}$ & $\begin{array}{c}5.3 \\
( \pm 0.4)\end{array}$ \\
\hline $33 w 1 d$ & $\begin{array}{c}131.3 \\
( \pm 14.4)\end{array}$ & $\begin{array}{c}79.4 \\
( \pm 11.5)\end{array}$ & $\begin{array}{c}121.1 \\
(+13.6)\end{array}$ & $\begin{array}{c}81.6 \\
( \pm 11.6)\end{array}$ & $\begin{array}{c}86.0 \\
(+10.1)\end{array}$ & $\begin{array}{c}29.1 \\
( \pm 13.6)\end{array}$ & $\begin{array}{c}35.0 \\
( \pm 10.7)\end{array}$ & $\begin{array}{c}4.6 \\
( \pm 0.5)\end{array}$ & $\begin{array}{c}1.3 \\
( \pm 0.2)\end{array}$ & $\begin{array}{c}5.4 \\
( \pm 0.4)\end{array}$ \\
\hline $34 w 1 d$ & $\begin{array}{c}131.7 \\
( \pm 11.2)\end{array}$ & $\begin{array}{c}78.7 \\
( \pm 9.3)\end{array}$ & $\begin{array}{c}117.7 \\
(+10.8)\end{array}$ & $\begin{array}{c}81.0 \\
( \pm 9.4)\end{array}$ & $\begin{array}{c}88.9 \\
(+12.7)\end{array}$ & $\begin{array}{c}25.9 \\
( \pm 15.3)\end{array}$ & $\begin{array}{c}34.3 \\
( \pm 13.0)\end{array}$ & $\begin{array}{c}4.4 \\
( \pm 0.4)\end{array}$ & $\begin{array}{c}1.3 \\
( \pm 0.2)\end{array}$ & $\begin{array}{c}5.3 \\
( \pm 0.3)\end{array}$ \\
\hline $35 w 1 d$ & $\begin{array}{r}137.0 \\
( \pm 12.5) \\
\end{array}$ & $\begin{array}{c}81.2 \\
(+12.5)\end{array}$ & $\begin{array}{r}130.3 \\
(+13.3)\end{array}$ & $\begin{array}{c}84.1 \\
( \pm 12.5)\end{array}$ & $\begin{array}{c}84.9 \\
(+10.7)\end{array}$ & $\begin{array}{c}36.2 \\
( \pm 18.1)\end{array}$ & $\begin{array}{c}41.8 \\
(+15.2)\end{array}$ & $\begin{array}{c}4.7 \\
( \pm 0.5)\end{array}$ & $\begin{array}{c}1.3 \\
( \pm 0.1)\end{array}$ & $\begin{array}{c}5.6 \\
( \pm 0.4)\end{array}$ \\
\hline
\end{tabular}

Values in mean \pm SD; GA: gestational age; SBP: systolic blood pressure; DBP: diastolic blood pressure; c: central; HR: heart rate; bpm: beats per minute; Alx: augmentation index; Alx@ 75: Alx corrected for HR of 75 bpm; CO: cardiac output; PVR: peripheral vascular resistance; PWV: pulse wave velocity.

At 35 weeks and 2 days, she was admitted for closer follow-up as we were approaching the 37-38 week range which we had set as the time to deliver and eventual need for induction. Daily CTG's were performed. At 35 weeks and 5 days, at the end of a scheduled HD session, she developed sudden, unexplained hypertension and was therefore induced. She delivered a $2480 \mathrm{~g}$ weighing boy (vaginal instrumental birth) at 36 weeks. Apgar scores were 9 and 10 after 1 and 5 minutes respectively. The boy required ICU admission for non-invasive ventilatory support for 1 day because of wet lung syndrome. He was discharged home 8 days after delivery. 
Our patient's creatinine increased to over $400 \mu \mathrm{mol} / \mathrm{l}$ in the days after delivery, and then exceeded $600 \mu \mathrm{mol} / \mathrm{l}$ the second week after delivery when we decided to restart her HD treatments. One year later, she successfully received a living-donor kidney transplant.

\section{Discussion}

We describe a young woman with IgA nephropathy, who was successfully initiated on intensive HD during pregnancy. The pregnancy evolved uneventfully from a maternal (serial levels of antiangiogenic factors comparable to normal pregnancies ${ }^{12}$ and incompatible with preeclampsia ${ }^{18}$, and 24 hour BP, PWA, CO, PVR and PWV comparable to normal pregnancies ${ }^{15-17}$ ) and fetal-neonatal (normal serial EFW, absence of polyhydramnios, normal birth weight and no prematurity) perspective, re-illustrating the benefits of intensive HD in pregnancy ${ }^{2,3}$.

Especially in the anuric pregnant dialysis population, the clinical diagnosis of preeclampsia may be extremely challenging. The same difficulty goes for patients with nephrotic syndrome who already have severe proteinuria (as our patient) and hypertension. In these patients, monitoring (anti-)angiogenic factor levels may therefore have a role. These factors could not be detected in dialysate specimens of our patient, meaning that the stable levels are not an effect of augmented removal, but rather of normal production. Shan et al. reported on a pregnant dialysis patient with uncontrollable hypertension at 29 weeks gestation ${ }^{19}$. A caesarean section was performed. However, placenta pathology did not reveal abnormalities suggestive of preeclampsia, and retrospective analysis of antepartum sFlt-1 and soluble endoglin levels showed values comparable to normal pregnancies. Volume overload rather than preeclampsia was the cause of hypertension in that patient. Two other studies confirmed the use of antiangiogenic factors as a reliable tool in the assessment of preeclampsia ${ }^{18,20}$. Furthermore, it was recently elegantly demonstrated that (anti-) angiogenic factor levels may be very useful to discriminate between chronic kidney disease (CKD) and preeclampsia ${ }^{21}$. The levels of (anti-) angiogenic factors in our patient were normal, except for higher PIGF levels from week 29 of gestation. Also, the ratio of sFIt-1/PIGF was on the lower side of the range in normal pregnancies. We cannot really explain these findings, but at least it is not compatible with very low PIGF levels or very high ratios of sFIt-1/PIGF as is found in pregnancies complicated by preeclampsia ${ }^{18}$. Thus in our patient, it is unlikely that preeclampsia was the cause of the sudden rise in $\mathrm{BP}$ at a gestational age of 35 weeks and 6 days because of normal levels 2 days prior to the BP rise and the rapid decline of sFlt-1 levels 2 and 4 days post-delivery (Table 5.3.1). 
Therefore, we suggest that circulating antiangiogenic factors, if readily available at the bedside, may be used to differentiate other hypertensive disorders from preeclampsia in pregnant dialysis patients. The protective effects of intensive HD on BP, cardiac and endothelial function have been well described ${ }^{22-25}$, and are elegantly demonstrated in our patient by the stable results of the weekly measurements of 24-hour BP as well as hemodynamic and arterial stiffness parameters. The serial use of these measurements, in combination with serial follow-up of the angiogenic balance of sFIt-1/PIGF, may therefore be valuable additions to the arsenal of clinical and technical tools which are currently used in the meticulous follow-up of these complicated patients. Rising BP and/or increasing values of PVR and PWV on 24-hour measurements, together with subtle alterations in the angiogenic balance, may indeed prompt the treating team to increase surveillance for the development of preeclampsia or other pregnancy-related complications $s^{8,9,18,20}$. However, we must indeed recognize that the sudden increase in $\mathrm{BP}$ at the end of the last dialysis session prior to induction and delivery, was by no means foreseen by the $24 \mathrm{~h} \mathrm{BP}$ results obtained from the measurement performed 5 days prior to the BP rise. Continuous clinical vigilance will therefore always remain essential in the management of these complicated patients. On the other hand, the sudden BP elevation may have been attributable to stress, merely since there were no clinical arguments for volume overload nor were the angiogenic factor levels compatible with the diagnosis of preeclampsia.

Of course, the limitations of this report are the retrospective analysis of the circulating antiangiogenic factors in our patient, as well as the absence of validation of the MobilO-Graph/ARC Solver ${ }^{\circledR}$ system in young and pregnant patients. Furthermore, large prospective studies are required to investigate the potential additional benefit of serial measurement of antiangiogenic factors as well as 24-hour BP and central hemodynamics in the management of pregnant dialysis patients.

In conclusion, we show, for the first time, serial antiangiogenic factors and 24-hour measurements of BP and hemodynamic parameters comparable to normal pregnancies in a patient successfully initiated on intensive HD during pregnancy. Also, this case adds to the expanding literature supporting the use of intensive HD in pregnant ESRD patients. Last, this case demonstrates that early start of dialysis may not be harmful in pregnancy. 


\section{References}

1. Bagon JA, Vernaeve H, De M uylder X, Lafontaine JJ, Martens J, Van Roost G. Pregnancy and dialysis. Am J Kidney Dis 1998;31:756-65.

2. Gangji AS, Windrim R, Gandhi S, Silverman JA, Chan CT. Successful pregnancy with nocturnal hemodialysis. Am J Kidney Dis 2004;44:912-6.

3. Barua M, Hladunewich M, Keunen J, Pierratos A, M CFarlane P, Sood M, Chan CT. Successful pregnancies in nocturnal hemodialysis. Clin J Am Soc Nephrol 2008;3:392-6.

4. Piccoli GB, Conijn A, Consiglio V, Vasario E, Attini R, Deagostini MC, Bontempo S, Todros T. Pregnancy in dialysis patients: is the evidence strong enough to lead us to change our counseling policy? Clin J Am Soc Nephrol 2010;5:62-71.

5. Maynard SE, M in JY, M erchan J, Lim KH, Li J, M endal S, Libermann TA, M organ JP, Sellke FW, Stillman IE, Epstein FH, Sukhatme VP, Karumanchi SA. Excess placental soluble fms-like tyrosine kinase1 (sFlt1) may contribute to endothelial dysfunction, hypertension, and proteinuria in preeclampsia. J Clin Invest 2003;111:649-58.

6. Levine RJ, M aynard SE, Qian C, Lim KH, England LJ, Yu KF, Schisterman EF, Thadhani R, Sachs BP, Epstein FH, Sibai BM, Sukhatme VP, Karumanchi SA. Circulating angiogenic factors and the risk of preeclampsia. N Engl J Med 2004;350:672-83.

7. Salahuddin S, Lee Y, Vadnais M, Sachs BP, Karumanchi SA, Lim KH. Diagnostic utility of soluble fms-like tyrosine kinase 1 and soluble endoglin in hypertensive diseases of pregnancy. Am J Obstet Gynecol 2007;197:e1-e6.

8. Hausvater A, Giannone T, Gomez Sandoval Y-H, Doonan RJ, Antonopoulos CN, Matsoukis IL, Petridou ET, Daskalopoulou SS. The association between preeclampsia and arterial stiffness. J Hypertens 2012;30:17-33.

9. Vasapollo B, Novelli GP, Valensise H. Total vascular resistance and left ventricular morphology as screening tools for complications in pregnancy. Hypertension 2008;51:1020-6.

10. Pozzi C, Andrulli S, Del Vecchio L, M elis P, Fogazzi GB, Altieri P, Ponticelli C, Locatelli F. Corticosteroid effectiveness in IgA nephropathy: long-term results of a randomized, controlled trial. J Am Soc Nephrol 2004;15:157-63.

11. Schneider E, Gleixner A, Hänel R, Leyhe Y, Kleinschmidt C, Beck G, Steinberg M, Denk B, Gassner D. Technical performance of the first fully automated assays for soluble fms-like tyrosine kinase 1 and human placental growth factor. ZGeburtshilfe Neonatol 2009;213:A8.

12. Verlohren S, Galindo A, Zeisler H, Herraiz I, M oertl M G, Pape J, Dudenhausen JW, Denk B, Stepan H. An automated method for the determination of the sFIt-1/PIGF ratio in the assessment of preeclampsia. Am J Obstet Gynecol 2010;202:161.e1-161.

13. Wassertheurer S, Kropf J, Weber T, van der Giet M, Baulmann J, Ammer M, Hametner B, Mayer CC, Eber B, Magometschnigg D. A new oscillometric method for pulse wave analysis: comparison with a common tonometric method. J Hum Hypertens 2010;24:498-504.

14. Wassertheurer S, Mayer C, Breitenecker F. Modeling arterial and left ventricular coupling for noninvasive measurements. Simulation modelling practice and theory 2008;16:988-97.

15. van Oppen AC, van der Tweel I, Alsbach GP, Heethaar RM, Bruinse HW. A longitudinal study of maternal hemodynamics during normal pregnancy. Obstet Gynecol 1996;88:40-6.

16. van Oppen AC, Stigter RH, Bruinse HW. Cardiac output in normal pregnancy: a critical review. Obstet Gynecol 1996;87:310-8.

17. Edouard DA, Pannier BM, London GM, Cuche JL, Safar ME. Venous and arterial behavior during normal pregnancy. Am J Physiol 1998;274:1605-12.

18. Verlohren S, Herraiz I, Lapaire O, Schlembach D, M oertl M, Zeisler H, Calda P, Holzgreve W, Galindo A, Engels T, Denk B, Stepan H. The sFIt-1/PIGF ratio in different types of hypertensive pregnancy disorders and its prognostic potential in preeclamptic patients. Am J Obstet Gynecol 2012;206:58.e1-8.

19. Shan HY, Rana S, Epstein FH, Stillman IE, Karumanchi SA, Williams ME. Use of circulating antiangiogenic factors to differentiate other hypertensive disorders from preeclampsia in a pregnant woman on dialysis. Am J Kidney Dis 2008;51:1029-32. 
20. Rana S, Powe CE, Salahuddin S, Verlohren S, Perschel FH, Levine RJ, Lim KH, Wenger JB, Thadhani R, Karumanchi SA. Angiogenic factors and the risk of adverse outcomes in women with suspected preeclampsia. Circulation 2012;125:911-9.

21. Rolfo A, Attini R, Nuzzo AM, Piazzese A, Parisi S, Ferraresi M, Todros T, Piccoli GB. Chronic kidney disease may be differentially diagnosed from preeclampsia by serum biomerkers. Kidney Int 2013;83:177-81.

22. Chan CT, Harvey PJ, Picton P, Pierratos A, Miller JA, Floras JS. Short-term blood pressure, noradrenergic, and vascular effects of nocturnal home hemodialysis. Hypertension 2003; 42: 925-31.

23. Chan CT, Li SH, Verma S. Nocturnal hemodialysis is associated with restoration of impaired endothelial progenitor cell biology in end-stage renal disease. Am J Physiol Renal Physiol 2005; 289: F679-84.

24. Yuen DA, Kuliszewski MA, Liao C, Rudenko D, Leong-Poi H, Chan CT. Nocturnal hemodialysis is associated with restoration of early-outgrowth endothelial progenitor-like cell function. Clin J Am Soc Nephrol 2011;6:1345-53.

25. Perl J, Chan CT. Home hemodialysis, daily hemodialysis, and nocturnal hemodialysis: core curriculum 2009. Am J Kidney Dis 2009;54:1171-84. 



\section{Chapter $\mathbf{0}$}

The role of intensive and home hemodialysis

in geriatric ESRD 



\section{Chapter 6.1}

\section{Can intensive hemodialysis prevent loss of functionality in the elderly ESRD patient?}

Cornelis T, Kotanko P, Goffin E, Kooman JP, van der Sande FM , Chan CT 


\section{ABSTRACT}

Initiation of dialysis may be accompanied by decline of physical and cognitive function and independence, especially in the elderly end-stage renal disease patient. Here, we postulate the underlying factors which may contribute to this observation in the elderly dialysis population, such as increased risk of dialysis-induced hypotension and associated cerebral and cardiac events, as well as malnutrition, infections, sleep abnormalities and psychological complications of dialysis initiation. We describe an elderly dialysis patient who did well on nocturnal home hemodialysis, and we hypothesize how intensive hemodialysis (i.e. nocturnal hemodialysis and/or short daily hemodialysis) may reduce the incidence of these dialysis complications and may therefore be considered as an option to attempt to preserve functional status and quality of life, especially early after the transition from pre-dialysis to dialysis. Before general adoption of this strategy, further studies on the etiology of functional loss at the time of dialysis initiation as well as on the potential advantageous effects of intensive hemodialysis in the elderly end-stage renal disease patient as compared to conventional hemodialysis, peritoneal dialysis and kidney transplantation, are required. 


\section{Introduction}

The number of elderly patients with end-stage renal disease (ESRD) requiring initiation of renal replacement therapy (RRT) is steadily increasing. In 1985 elderly patients (75 years or older) represented 22\% of incident patients with ESRD, whereas in 1999 they were $48 \%$ in the European Dialysis and Transplant Association (EDTA) Registry ${ }^{1}$. Recently Santoro et al. even reported $41.5 \%$ of incident dialysis patients being older than 75 years according to data of their registry ${ }^{2}$.

ESRD and dialysis initiation in elderly are often accompanied by loss of independence ${ }^{3,4}$. Recently Jassal et al. reported a negative effect of dialysis initiation on independent living by patients 80 years of age or older ${ }^{4}$. Within the first 6 months after dialysis [hemodialysis (HD) or peritoneal dialysis (PD)] onset, more than $30 \%$ of patients lost functionality requiring caregiver support or transfer to a nursing home. This suggests that elderly patients are less likely to overcome events occurring around the time of dialysis initiation as compared to younger patients. The events leading to functional decline may include dialysis-related hypotension, cerebral and cardiac events, as well as malnutrition and increased infection risk. Sleep abnormalities and psychological disturbances may also play a role.

These complications may be related to the often dramatic changes in the internal milieu associated with thrice weekly HD treatments in patients less likely to tolerate these changes in homeostasis because of their age and concomitant frailty ${ }^{5}$. More frequent and/or longer HD sessions may reduce the severity of internal environment disturbance and hence be of particular benefit in the vulnerable elderly ESRD patient. Here we speculate on the potential complications of dialysis initiation in the elderly and their etiology. We also postulate the mechanisms by which intensive HD [i.e. nocturnal hemodialysis (NHD: nightly or alternate night 8 hours of HD) and/or short daily hemodialysis (SDHD: 6 days per week 3 hours of HD)] may be able to ameliorate these complications.

\section{Case study}

An 88-year old woman with ESRD secondary to type 2 diabetes and hypertension was initiated on RRT in April of 2010. Her past medical history was significant for over 30 years of type 2 diabetes complicated with coronary artery disease, peripheral vascular disease, stroke, retinopathy and renal failure. Concomitantly, she has had difficult to control hypertension during the same time period. Her past surgical history included a remote hysterectomy and a hernia repair. 
Our patient was originally initiated on home assisted PD. Unfortunately, PD was complicated by mechanical malfunction of the PD catheter. As a result, she was receiving suboptimal clearances which required additional once a week in-centre HD treatment. Her quality of life was poor while undergoing combined PD and in-centre HD. Moreover, she had a substantial amount of intra-dialytic morbidities especially during her in-centre HD therapies including supra-ventricular tachycardia, extremes of blood pressure (BP) and tremendous fatigue.

Given that our patient has a dedicated family and was willing to train for home HD, we offered intensive nocturnal home HD as a salvage therapeutic option. Our patient's daughter was the designated care provider and undertook extended home HD training with our patient over a 16 weeks period. Our patient was transitioned to home assisted NHD (4 sessions per week, 8 hours per session) during the late summer of 2010.

Six months after conversion to home HD, sustained biochemical improvements were noted (hemoglobin increased from 74 to $114 \mathrm{~g} / \mathrm{l}$, phosphorus decreased from 2.12 to $1.7 \mathrm{mmol} / \mathrm{l}$, albumin increased from 25 to $32 \mathrm{~g} / \mathrm{l}$ ). Intra-dialytic extremes of BP became less frequent and there was subjective improvement in our patient and her family's quality of life. Our patient continues to be maintained on home assisted nocturnal home HD.

\section{Potential complications of ESRD and dialysis (initiation) in the elderly contributing to geriatric syndromes}

As opposed to non-ESRD patients, elderly ESRD patients suffer from an increased risk to develop geriatric syndromes. Much of the functional decline occurs early after dialysis initiation ${ }^{3,4}$. The geriatric syndromes include frailty (unintentional weight loss, exhaustion, slow gait speed, weakness, and/or low physical activity $)^{6-8}$, increased incidence of falls ${ }^{9}$, cognitive impairment ${ }^{10}$, disability and dependence ${ }^{11}$. Here we postulate and unravel potential ESRD- and dialysis-related mechanisms which may contribute to the development of these geriatric syndromes. However, most of the described effects have not yet been studied specifically in the elderly dialysis population and therefore further investigation in this population is absolutely necessary.

\section{Dialysis-related hypotension}

Elderly patients are particularly susceptible of dialysis-related hypotension ${ }^{12}$. This may be due to underlying ischemic and valvular heart disease as well as to left ventricular hypertrophy (LVH) and diastolic dysfunction ${ }^{13}$. Autonomic nervous system and baroreceptor sensitivity impairment may also play a role in dialysis-related hypotension 
in the elderly ${ }^{14}$. Furthermore, vascular refilling from the interstitial compartment may be impaired due to arterial stiffness ${ }^{15}$ and hypoalbuminemia. This can ultimately lead to hypovolemia and hypotension during ultrafiltration. Also, the reduced neuro-vegetative reactivity blunts the peripheral venous constriction and hence lowers the amount of venous blood returning to the heart ${ }^{16}$, and it also blunts the heart rate response to acute hypotension and bradycardia may develop as hypovolemia ensues (Bezold-Jarisch reflex) $)^{17}$.

Dialysis-related hypotension is an independent risk factor for morbidity and mortality ${ }^{18}$. This certainly applies to older patients who often already have reduced blood flow to vital organs such as brain, heart, and intestine. Further deterioration of cognitive function and progressive functional decline at the time of dialysis initiation may therefore be related to repetitive dialysis-related hypotension leading to recurrent episodes of brain hypoperfusion and ischemic damage (as described below). Stefanidis et al. observed a significant continuous decrease of the mean blood flow velocity in the middle cerebral artery during HD as measured by transcranial Doppler ultrasonography ${ }^{19}$. Reduced coronary flow results in myocardial stunning (for which presence age is also an independent determinant) which is associated with increased morbidity and mortality in dialysis patients ${ }^{20}$ (as discussed below). Next, gut hypoperfusion has been associated with translocation of endotoxins which is linked with inflammation, malnutrition and wasting ${ }^{21,22}$. Last, dialysis-related hypotension compromises residual renal function which in itself is an important determinant of patient survival ${ }^{23}$. Residual urine output also helps to keep the ultrafiltration rate low, thereby minimizing the risk of dialysis-related hypotension.

\section{Cerebral disturbances}

Multiple adverse effects of dialysis on the brain have been described, ranging from silent cerebral infarcts, generalized cerebral atrophy and leukoaraiosis. Leukoaraiosis is a form of subcortical injury which occurs in the watershed perfusion area of the brain where episodic reduced perfusion expectedly has the highest impact. Indeed, dialysis patients mainly lose primarily subcortical functions (relating to decision making and executive functioning) and have relative preservation of cortical functions such as memory and vocabulary ${ }^{24}$. Even more interesting is the recent finding that subclinical subcortical ischemic white matter changes are associated with the disruption of cortical-subcortical circuits mediating mood ${ }^{25,26}$. This may be one of the biological bases for depression and it may play a role in loss of independence in elderly patients initiating dialysis.

Also, older patients may be more prone to developing dialysis disequilibrium syndrome (DDS) due to malnutrition and smaller distribution volumes for urea in elderly. 
Malnutrition may limit the exchangeability and redistribution of uremic solutes between compartments if serum solute levels drop during dialysis treatment. Brain edema results in a variety of neurological disturbances ranging from unspecific behavioural changes to convulsions and altered levels of consciousness ${ }^{27}$.

\section{Cardiac events}

The predisposition of the uremic heart to demand ischemia is caused by low coronary flow reserve resulting from a high prevalence of coronary heart disease in the elderly dialysis population. Recurrent HD-related myocardial injury induces myocardial hypoperfusion and contractile dysfunction ${ }^{28}$. This may lead to long-term loss of segmental and global contractile performance which may further precipitate dialysisrelated hypotension and hence recurrent myocardial stunning, thereby closing the vicious circle.

Also, older people are at higher risk for arrhythmias secondary to hypertension, coronary heart disease and changes in the autonomic innervation of the heart ${ }^{29}$. These patients may therefore be more likely to develop arrhythmias during dialysis as electrolyte shifts and/or demand ischemia occur.

\section{Malnutrition}

Elderly patients are at increased risk for malnutrition due to polypharmacy, dental problems, dysgeusia, low socio-economic status, limited access to food of choice as a result of reduced mobility, as well as an increased frequency of gastro-intestinal problems, such as gastroparesis and constipation. Post-dialysis fatigue and intercurrent illnesses may reduce appetite and induce food avoidance, whereas translocation of endotoxins due to gut hypoperfusion may contribute to the malnutrition-inflammation syndrome ${ }^{21,22}$. Also, anorexia due to persistent uremic syndrome may contribute to malnutrition even though dialysis has been initiated ${ }^{2}$.

\section{Infections}

The uremic syndrome is typically accompanied by a predisposition to infections. The burden of infections in older patients on dialysis is considerable ${ }^{30}$. In patients with ESRD septicaemia and pulmonary infection account for $9.7 \%$ and $2.5 \%$ of all deaths, respectively ${ }^{31}$. The immunodeficient state in uremia is caused by a variety of immunological changes such as defective costimulatory function of antigen-presenting cells, inflammatory activation of monocytes and high levels of interleukin-12, leading to a reduced $\mathrm{CD}^{+} / \mathrm{CD} 8^{+}$T-lymphocyte ratio as well as increased rates of apoptosis and smaller populations of naive and central memory $T$ lymphocytes ${ }^{32,33}$. Dialysis patients 
may also have an increased risk of infection due to the frequent use of central venous dialysis catheters and the reduced response to vaccinations, especially pneumococcal and hepatitis vaccinations. Furthermore, elderly patients may be at higher risk for infection due to malnutrition, muscle weakness, impaired cough reflex, overhydration, altered microbial flora and age-related changes of the gastro-intestinal tract such as achlorhydria and diverticula ${ }^{2}$. Last, infections may be the trigger for cardiovascular events in older patients on dialysis, in particular in the first 30 days after an infectionrelated hospitalisation, which may further enhance loss of functionality in these patients ${ }^{34}$.

\section{Sleep problems}

Sleep disorders are common in elderly and ESRD patients and are associated with daytime sleepiness, heightened cardiovascular morbidity, and mortality. Unruh et al. found that $14 \%$ of incident dialysis patients had a decline in sleep quality in the first year of dialysis (HD or PD) treatment ${ }^{35}$. Post-dialysis fatigue may lead to daytime sleepiness and subsequent insomnia, although age was not a determinant for postdialysis fatigue in a study by Sklar et al. ${ }^{36}$. Furthermore, volume overload may cause pharyngeal edema and sleep apnea syndrome ${ }^{37}$. Also, sleep problems contribute to the increased use of benzodiazepines leading to a higher risk of falls.

\section{Psychological complications}

Depression soon after the onset of dialysis is common and significant ${ }^{38}$. Many patients struggle to accept the need for dialysis and its accompanying restrictive impact on their daily lives and autonomy. These psychological problems are detrimental to quality of life, and are also related to adverse clinical outcomes. If the patient loses functionality and the family members cannot cope adequately, then often he or she is transferred to a chronic care facility enforcing the feelings of isolation and desperation of the elderly dialysis patient.

How may intensive HD deal with these potential complications and prevent loss of independence at the time of dialysis initiation in the elderly ESRD patient?

Many well studied advantages of intensive HD may play a role in the protection of the elderly ESRD patient against functional deterioration at the time of dialysis initiation. Here we hypothesize how especially the elderly ESRD group may benefit from these protective mechanisms of intensive HD (Table 6.1.1). Most of the described effects 
have not yet been studied specifically in the elderly dialysis population and require further investigation.

\section{Reduction of dialysis-related hypotension}

SDHD and NHD result in fewer dialysis-related hypotensive episodes, mainly due to lower ultrafiltration rates and better preservation of plasma volume ${ }^{39,40}$. Also, intensive $\mathrm{HD}$ reduces $\mathrm{LVH}^{40-42}$ and NHD restores endothelial progenitor cell number and function as well as endothelial function with improvements in endothelial-dependent (postischemic vasodilatation) and endothelial-independent (response to nitroglycerin) vasodilatation ${ }^{43-45}$. Furthermore, intensive HD may improve autonomic nervous system function; NHD partially restores heart rate variability during sleep and improves baroreceptor sensitivity, and SDHD results in decreased sympathetic activity ${ }^{45,46}$.

\section{Cerebral protection}

Improved hemodynamic stability resulting from reduction of dialysis-related hypotension episodes may minimize the occurrence of cerebrovascular events and hence reduce cerebral damage from the time of initiation of dialysis. Restorative effects on the endothelium as well as reduction of hypertension in intensive $H D^{40-45}$ may further contribute to cerebrovascular protection. Also, optimization of nutritional status together with slower urea clearance may reduce the risk of DDS. In this context, Jassal et al. showed better cognitive functioning with improvement in psychomotor efficiency, processing speed, attention and working memory in patients converting from conventional HD to $\mathrm{NHD}^{47}$. However, the recent Frequent Hemodialysis Network (FHN) trial did not show a statistically significant effect on cognitive performance of frequent $H D^{42}$. 


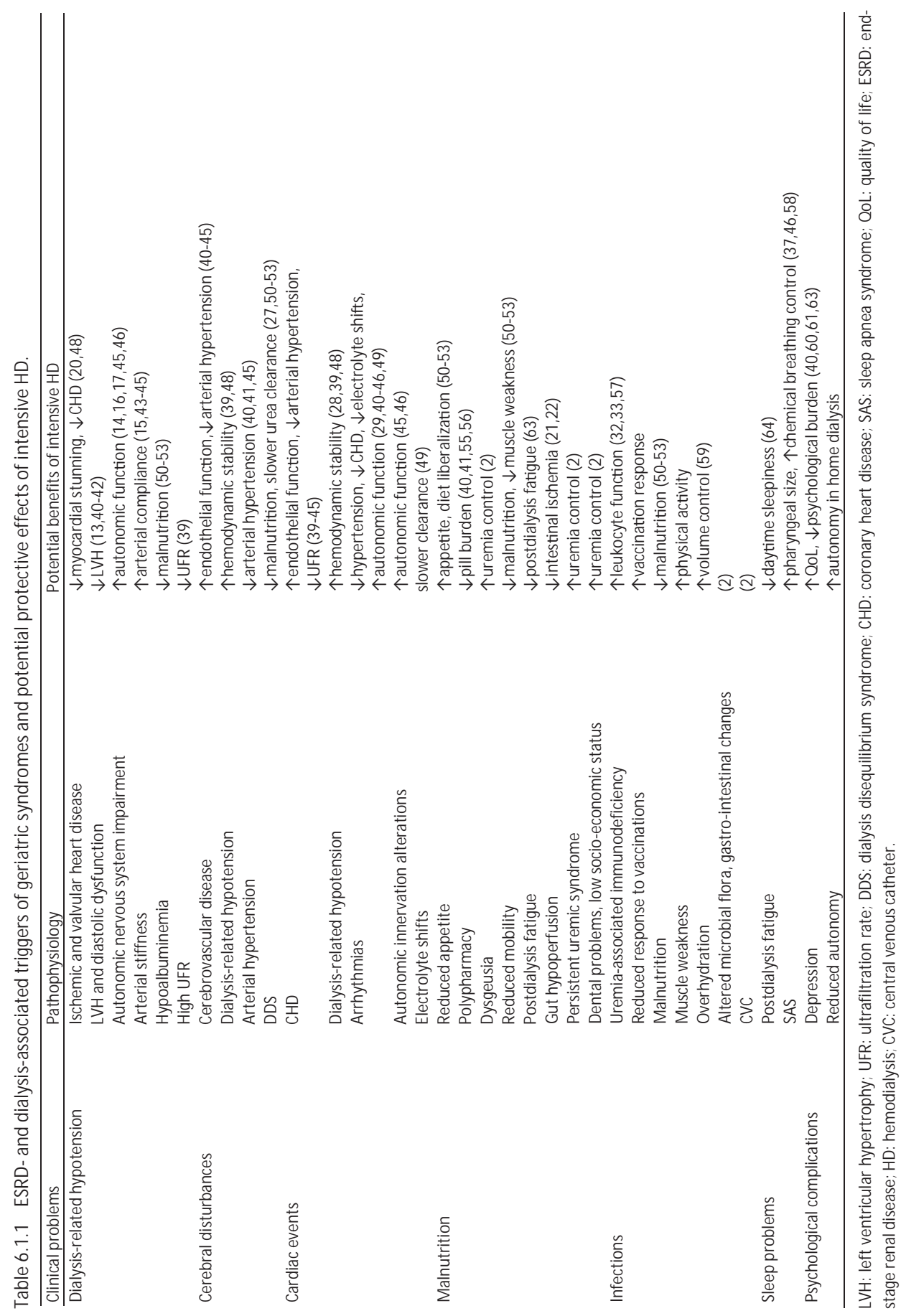




\section{Cardiac protection}

Lower UF rates may be the main reason why especially NHD but also SDHD (with 3-hour sessions) is associated with significantly reduced levels of dialysis-induced acute cardiac injury. This was recently demonstrated by Jefferies et al. in cross-sectional studies with NHD and SDHD patients as compared to conventional HD patients after careful matching of patients for age, dialysis vintage and coronary artery disease ${ }^{48}$. As already mentioned, intensive $\mathrm{HD}$ protects against $\mathrm{LVH}^{40-42}$ and furthermore, because of reduced incidence of hypertension ${ }^{40-42,45}$, restoration of autonomic control and less dramatic electrolyte changes ${ }^{49}$, the heart may be less prone to arrhythmias intensive HD patients.

\section{Improved nutritional status}

Improved appetite is experienced by patients converted to daily HD treatment and results in weight gain and increased muscle mass and strength ${ }^{50-54}$. The positive effect of intensive HD on appetite may be explained by liberalization of the diet due to optimized removal of e.g. sodium, potassium and phosphate with intensive $\mathrm{HD}^{55,56}$. Also, superior control of the uremic syndrome may play a role. Fewer episodes of intestinal ischemia and translocation of endotoxins may also result in reduction of malnutrition, systemic inflammation and wasting. Furthermore, the decreased burden of pills such as antihypertensive drugs $s^{40-42}$ as well as phosphate binders ${ }^{55,56}$ may help to preserve the appetite in intensive HD patients.

\section{Reduction of infections}

Uremic toxins have a profound impact on leukocyte function ${ }^{57}$ and intensive HD may therefore at least partially correct the immunodeficient state as a result of improved clearance of these uremic toxins, although the immunological effects of intensive HD have never been studied. intensive HD may reduce the risk of infections and also stimulate the response to e.g. Pneumococcus vaccinations. Furthermore, increased muscle strength and better control of volume status may further protect the intensive HD patient against pulmonary infections.

\section{Sleep restoration}

Conversion from conventional HD to NHD is associated with improvements in sleep apnea syndrome ${ }^{58}$. This has been attributed to a decrease in ventilatory sensitivity (possibly due to optimized uremic toxin clearance) thereby stabilizing the chemical control of breathing ${ }^{58}$ and to an increase in pharyngeal size (possibly due to optimized 
fluid homeostasis $\left.{ }^{59}\right)^{37}$. Also, reduction of post-dialysis fatigue may reduce daytime sleepiness and subsequent insomnia.

\section{Psychological stability}

Intensive HD may, due to its beneficial effects helping to maintain functionality, independence and quality of life, alleviate the psychological burden for patients starting dialysis ${ }^{38,60-62}$. Also, the FHN trial showed a statistically significant improvement in the self-reported physical-health score ${ }^{42}$. However, previous studies did not show statistically significantly lower depression scores in intensive HD patients as compared to conventional HD or PD patients ${ }^{40,42,63}$, although there was a trend to a lower beck Depression Inventory score in the SDHD group in the FHN trial ${ }^{42}$. Intensive HD may be an option to prevent psychological deterioration at the time of dialysis initiation in the elderly ESRD patient, certainly when it can be performed at night at home, thereby not dramatically interrupting with their daily life activities. In this context, Jaber et al. recently demonstrated that daily NxStage HD resulted in significant decrease in postdialysis recovery time and fatigue, and in long-term improvement in depressive symptoms ${ }^{64}$.

\section{Further considerations and potential barriers regarding the adoption of intensive HD in the elderly}

First, it should be clear that non-dialysis renal care is also an important therapeutic option that should be communicated with all patients and their families ${ }^{65,66}$. In centres that have well-developed programs, a substantial amount of patients chose not to undergo dialysis if they had been well informed about non-dialysis care as an alternative treatment ${ }^{67-71}$. Symptoms can be minimized by specific interventions and medications in order to promote quality of life rather than lengthy living. If conventional dialysis modalities offer a modest patient survival, this often happens at the expense of increased hospitalization rate and reduced likelihood of dying at home with family or friends ${ }^{68,69}$. Therefore, especially in elderly patients with multiple comorbidities, dialysis may not improve quality of life and, also at the background of increasing costs of dialysis for society, suggestions of non-dialysis care in this ESRD population should be considered seriously ${ }^{72}$.

Secondly, the decision to start dialysis should be taken on the basis of meticulous observation of various clinical parameters and should therefore not be based on the glomerular filtration rate (GFR) alone. This was recently made clear in a large randomized controlled trial which compared early versus late start of dialysis ${ }^{73,74}$. No improvement in survival could be demonstrated in the early start group and quality of 
life was higher in the late start group. By postponing dialysis until clinical parameters necessitate RRT, loss of function and independence caused by dialysis initiation may be avoided.

Third, the role of PD and kidney transplantation in the elderly ESRD patient should not be disregarded. In a cross-sectional multicentre study, Brown et al. recently suggested higher quality of life due to its potentially lower illness intrusion in older patients doing $\mathrm{PD}$ as compared to $\mathrm{HD}^{75}$. Oliver et al. showed that over $50 \%$ of an elderly population deemed suitable for PD chose for PD if appropriate multidisciplinary team support and education was provided ${ }^{76}$. Also, PD in elderly patients in a nursing home showed excellent patient and technique survival and a low peritonitis rate with good training of the nursing home nursing staff ${ }^{77}$. Nevertheless, although all these studies provide evidence for the feasibility of PD in the elderly ESRD population, still Jassal et al. showed that loss of function at the time of dialysis initiation in the elderly was not dependent on whether the patient did conventional HD or PD suggesting that PD may also not be able to avoid function loss 4 .

Kidney transplantation may also be an option in the elderly. Recent studies highlight the improved survival in elderly patients after kidney transplantation as compared to continuing dialysis ${ }^{78,79}$. However, whether elderly patients receiving a kidney transplant are more capable of maintaining functionality as compared to dialysis patients, has not been demonstrated yet.

The final choice of the dialysis modality should therefore be taken by the well-informed elderly ESRD patient. Also, providing patients with a choice of dialysis modality in itself has been shown to ameliorate quality of life ${ }^{80}$. Piccoli recently formulated the idea of interchangeability between different dialysis regimes ${ }^{81}$. This may indeed further increase quality of life by promoting patient autonomy. The benefits of this strategy of interchangeability may be optimal when the patient alternates between one of the intensive HD regimes, whether it is alternate night NHD, nightly NHD or SDHD ${ }^{82}$.

Fourth, if the decision has been made to start intensive HD in the elderly ESRD patient, ideally this treatment should be delivered to the patient at home. Elderly patients may not always agree to come 6 times a week to the hospital for their SDHD treatment or to sleep 3 nights a week in the hospital for their NHD treatment. Indeed, outcomes associated with an in-centre NHD program indicate that older patients are often not willing to enter a nightly dialysis program ${ }^{83}$. Home HD may be the best option for elderly patients since it affords considerable patient autonomy regarding treatment scheduling and individualization of therapy and it also eliminates transport time to and from the dialysis unit. This may further prevent loss of function and it may increase quality of life. Assistance by a home dialysis nurse may significantly facilitate the adoption of intensive $\mathrm{HD}$ at home in the elderly ESRD population. A recent study from 
New Zealand revealed that home HD was possible in older patients with levels of comorbidity and disease severity similar to the in-centre dialysis population and that it resulted in high patient satisfaction ${ }^{84}$. However, age is a significant predictor of technique failure (defined as physical or cognitive inability to perform nocturnal home HD either independently or with assistance) as was well demonstrated in a Canadian multicentre nocturnal home HD cohort ${ }^{85}$. Therefore, the feasibility of home intensive HD needs to be assessed in a multidisciplinary way for each individual elderly ESRD patient.

Fifth, the FHN trial revealed an increased need of vascular access procedures in SDHD patients as compared to conventional HD patients ${ }^{42}$. In this trial the average age of the patients was 50.4 years. The increased need for access procedures may certainly apply to the elderly dialysis population in which the "failure to mature" rate is higher than in younger dialysis patients ${ }^{86}$. Hence, it is possible that frequent HD may induce a higher graft and catheter rate with associated increased morbidity and mortality. However, the exact etiology why SDHD patients in the FHN trial required more vascular access interventions still needs to be elucidated and it may well have been that it was simply due to more frequent visits and evaluations in the HD unit.

Last, active inpatient rehabilitation with integrated dialysis care should be considered in elderly patients starting dialysis, certainly when intensive HD (whether it is delivered at home or in a dialysis unit) fails to prevent functional decline and loss of independence. The RightStart disease management program strategy (a model of delivering services by focusing on the unique needs of incident dialysis patients through a comprehensive approach including patient evaluation, team collaboration and time devoted to teaching self-management strategies) should be part of this integrated dialysis care and may further reduce morbidity and mortality in the first year after dialysis initiation ${ }^{87,88}$. In Toronto over $70 \%$ of older HD patients return back to their private homes after completion of a rehabilitation program ${ }^{89}$.

If this program however, because of persistent functional dependence, is not able to send seniors back to their private homes, which then necessitates permanent nursing home admission, patients with high functional and symptom burdens could also be advised to discontinue dialysis treatment and prefer palliative care with pain relief and symptom management. Geriatric renal palliative care implements geriatric principles of the interdisciplinary team through a holistic approach. Active treatment of renal and dialysis complications (e.g. management of anemia, bone disease, fluid balance, acidosis and BP) may be continued but the focus is on evaluation and treatment of geriatric syndromes and symptoms (e.g. pain, depression, constipation, pruritus, fatigue, insomnia) in order to optimize quality of life, avoid hospitalizations and finally allow a dignified death ${ }^{65,66}$. 


\section{Conclusions}

Elderly ESRD patients are frail and are at higher risk for loss of independence after initiation of dialysis as compared to younger ESRD patients. Further elucidation of the underlying pathophysiology of functional decline at the time of dialysis initiation in the elderly ESRD population is required. If the well-informed elderly ESRD patient has decided to initiate dialysis instead of adopting non-dialysis renal care, the patient may also be informed about the possibility of intensive HD. It may be considered as an option to overcome potential complications associated with the start of dialysis, since it may reduce dialysis-related hypotension and because it may be protective against cerebral and cardiac events and lower the incidence of malnutrition, infections, sleep disturbances and psychological complications at the time of dialysis onset. This may enable elderly ESRD patients to tolerate the transition from pre-dialysis to dialysis in a biologically better way, which may then lead to fewer cognitive and functional disturbances and hence better preservation of both independence and quality of life. Home intensive HD may in this be the ideal treatment in the ideal system by stimulating autonomy and permitting individualization of therapy and because it eliminates transport time.

However, no evidence is available yet to substantiate the suggested option of the adoption of intensive HD in the elderly ESRD population. Also, studies should look at potential differences between SDHD and NHD in maintaining functionality in elderly ESRD patients. Furthermore, limiting factor to widely adopt this strategy is the possible unwillingness of elderly people to undergo frequent transport to the hospital/dialysis unit (for SDHD) or to sleep in the hospital (NHD). The possibility of intensive HD in nursing homes should also be investigated. Awaiting further studies, integrated dialysis care is crucial for the elderly dialysis patients. Finally, kidney transplantation, especially in the old-for-old program, may also be a valuable RRT modality in the elderly ESRD population. 


\section{References}

1. Stengel B, Billon S, Van Dijk PC, Jager KJ, Dekker FW, Simpson K, Briggs JD. Trends in the incidence of renal replacement therapy for end-stage renal disease in Europe, 1990-1999. Nephrol Dial Transplant 2003;18:1824-33.

2. Santoro A and Mancini E. Hemodialysis and the elderly patient: complications and concerns. J Nephrol 2010;23:80-9.

3. Kurella Tamura M, Covinsky KE, Chertow GM, Yaffe K, Landefeld CS, M cCulloch CE. Functional status of elderly adults before and after initiation of dialysis. N Engl J M ed 2009;361:1539-47.

4. Jassal SV, Chiu E, Hladunewich M. Loss of independence in patients starting dialysis at 80 years of age or older. N Engl J Med 2009;361:1612-3.

5. Shlipak MG, Stehman-Breen C, Fried LF, Song X, Siscovick D, Fried LP, Psaty BM, Newman AB. The presence of frailty in elderly persons with chronic renal insufficiency. Am J Kidney Dis 2004;43:861-7.

6. Johansen KL, Chertow GM, Jin C, Kutner NG. Significance of frailty among dialysis patients. J Am SoC Nephrol 2007;18:2960-7.

7. Johansen KL, Chertow GM, Kutner NG, Dalrymple LS, Grimes BA, Kaysen GA. Low level of self-reported physical activity in ambulatory patients new to dialysis. Kidney Int 2010;78:1164-70.

8. Cupisti AA, Capitanini A, Betti G, D'Alessandro C, Barsotti G. Assessment of habitual physical activity and energy expenditure in dialysis patients and relationships to nutritional parameters. Clin Nephrol 2011;75:218-25.

9. Cook WL, Tomlinson G, Donaldson M, Markowitz SN, Naglie G, Sobolev B. Falls and fall-related injuries in older dialysis patients. Clin J Am Soc Nephrol 2006;1:1197-204.

10. Murray AM, Tupper DE, Knopman DS, Gilbertson DT, Pederson SL, Li S, Smith GE, Hochhalter AK, Collins AJ, Kane RL. Cognitive impairment in hemodialysis patients is common. Neurology 2006;67:216-23.

11. Tawney KW, Tawney PJ, Kovach J. Disablement and rehabilitation in end-stage renal disease. Semin Dial 2003;16:447-52.

12. Tisler A, Akocsi K, Harshegyi I, Varga G, Ferenczi S, Grosz M, Kulcsar I, Löcsey L, Samik J, Solt I, Szegedi J, Toth E, Wagner G, Kiss I. Comparison of dialysis and clinical characteristics of patients with frequent and occasional hemodialysis-associated hypotension. Kidney Blood Press Res 2002;25:97-102.

13. van der Sande FM, Mulder AW, Hoorntje SJ, Peels KH, van Kuijk WH, Kooman JP, Leunissen KM. The hemodynamic effect of different ultrafiltration rates in patients with cardiac failure and patients without cardiac failure: comparison between isolated ultrafiltration and ultrafiltration with dialysis. Clin Nephrol 1998;50:301-8.

14. Di Leo R, Vita G, Messina C, Savica V. Autonomic function in elderly uremics studied by spectral analysis of heart rate. Kidney Int 2005;67:1521-5.

15. Schneditz D, Roob J, Oswald M, Pogglitsch H, Moser M, Kenner T, Binswanger U. Nature and rate of vascular refilling during dialysis. Kidney Int 1992;42:1425-33.

16. Kooman JP, Gladziwa U, Bocker G, van Bortel LM, van Hooff JP, Leunissen KM. Role of the venous system in hemodynamics during ultrafiltration and bicarbonate dialysis. Kidney Int 1992;42:718-26.

17. Santoro A, Mancini E, Spongano M, Rossi M, Paolini F, Zucchelli P. A haemodynamic study of hypotension during hemodialysis using electrical bioimpedance cardiography. Nephrol Dial Transplant 1990; Suppl 1:147-51.

18. Shoji T, Tsubakihara Y, Fuji M, Imai E. Hemodialysis-associated hypotension as an independent risk factor for two-year mortality in hemodialysis patients. Kidney Int 2004;66:1212-20.

19. Stefanidis I, Bach R, M ertens PR, Liakopoulos V, Liapi G, Mann H, Heintz B. Influence of hemodialysis on the mean blood flow velocity in the middle cerebral artery. Clin Nephrol 2005;64:129-37.

20. Burton JO, Jefferies HJ, Selby NM , M cIntyre CW. Hemodialysis-induced cardiac injury: determinants and associated outcomes. Clin J Am Soc Nephrol 2009;4:914-20.

21. Kotanko P, Carter M, Levin NW. Intestinal bacterial microflora-a potential source of chronic inflammation in patients with chronic kidney disease. Nephrol Dial Transplant 2006;21:2057-60. 
22. M cIntyre CW, Harrison LEA, Eldehni MT, Jefferies HJ, Szeto CC, John SG, Sigrist MK, Burton JO, Hothi D, Korsheed S, Owen PJ, Lai KB, Li PK. Circulating endotoxaemia: a previously unrecognised factor in the pathophysiology of systemic inflammation and cardiovascular disease in chronic kidney disease patients. Clin J Am Soc Nephrol 2011;6:133-41.

23. Termorshuizen F, Dekker FW, van Manen JG, Korevaar JC, Boeschoten EW, Krediet RT. Relative contribution of residual renal function and different measures of adequacy to survival in hemodialysis patients: an analysis of the Netherlands Cooperative Study on the Adequacy of Dialysis (NECOSAD)-2. J Am Soc Nephrol 2004;15:1061-70.

24. Pereira AA, Weiner DE, Scott T, Chandra P, Bluestein R, Griffith J, Sarnak MJ. Subcortical cognitive impairment in dialysis patients. Hemodial Int 2007;11:309-14.

25. Lamar M, Charlton RA, M orris RG, M arkus HS. The impact of subcortical white matter disease on mood in euthymic older adults: a diffusion tensor imaging study. Am J Geriatr psychiatry 2010;18:634-42.

26. Alexopoulos GS, Kiosses DN, Klimstra S, Kalayam B, Bruce M L. Clinical presentation of the "depressionexecutive dysfunction syndrome" of late life. Am J Geriatr Psychiatry 2002;10:98-106.

27. Arieff Al. Dialysis disequilibrium syndrome: current concepts on pathogenesis and prevention. Kidney Int 1994;45:629-35.

28. Burton JO, Jefferies HJ, Selby NM, M cIntyre CW. Hemodialysis-induced repetitive myocardial injury results in global and segmental reduction in systolic cardiac function. Clin J Am Soc Nephrol 2009;4: 1925-31.

29. Gupta AK, Maheshwari A, Tresch DD, Thakur RK. Cardiac arrhythmias in the elderly. Card Electrophysiol Rev 2002;6:20-8.

30. Dalrymple LS, Johansen KL, Chertow GM, Cheng SC, Grimes B, Gold EB, Kaysen GA. Infection-related hospitalizations in older patients with ESRD. Am J Kidney Dis 2010;56:522-30.

31. United States Renal Data System. USRDS 2006 Annual Data Report: Atlas of End-Stage Renal Disease in the United States. National Institutes of Health, National Institute of Diabetes and Digestive and Kidney Diseases, Bethesda, MD; 2006.

32. Girndt M, Sester U, Sester M, Kaul H, Köhler H. Impaired cellular immune function in patients with endstage renal failure. Nephrol Dial Transplant 1999;14:2807-10.

33. Sallusto $F$, Lenig $D$, Förster $R$, Lipp $M$, Lanzavecchia A. Two subsets of memory $T$ lymphocytes with distinct homing potentials and effector functions. Nature 1999;401:708-12.

34. Dalrymple LS, M ohammed SM, M u Y, Johansen KL, Chertow GM , Grimes B, Kaysen GA, Nguyen DV. Risk of cardiovascular events after infection-related hospitalizations in older patients on dialysis. Clin J Am Soc Nephrol 2011;6:1708-13.

35. Unruh ML, Buysse DJ, Dew MA, Evans IV, Wu AW, Fink NE. Sleep quality and its correlates in the first year of dialysis. Clin J Am Soc Nephrol 2006;1:802-10.

36. Sklar AH, Riesenberg LA, Silber AK, Ahmed W, Ali A. Postdialysis fatigue. Am J Kidney Dis 1996;28:732-6.

37. Beecroft JM, Hoffstein V, Pierratos A, Chan CT, M cFarlane PA, Hanly PJ. Pharyngeal narrowing in endstage renal disease: implications for obstructive sleep apnoea. Eur Respir J 2007;30:965-71.

38. Watnick S, Kirwin P, Mahnensmith R, Concato J. The prevalence and treatment of depression among patients starting dialysis. Am J Kidney Dis 2003;41:105-10.

39. Basile C, Libutti P, DiTuro AL, Tundo S, Maselli P, Casucci F, Losurdo N, Teutonico A, Vernaglione L, Lomonte C. Haemodynamic stability in standard bicarbonate haemodialysis and long-hour slow-flow bicarbonate haemodialysis. Nephrol Dial Transplant 2011;26:252-8.

40. Culleton BF, Walsh M, Klarenbach SW, Mortis G, Scott-Douglas N, Quinn RR, Tonelli M, Donnelly S, Friedrich MG, Kumar A, Mahalatti H, Hemmelgarn BR, Manns BJ. Effect of frequent nocturnal hemodialysis versus conventional hemodialysis on left ventricular mass and quality of life: a randomized controlled trial. JAM A 2007;298:1291-9.

41. Fagugli RM, Reboldi G, Quintaliani G, Pasini P, Ciao G, Cicconi B, Pasticci F, Kaufman JM, Buoncristiani U. Short daily hemodialysis: blood pressure control and left ventricular mass reduction in hypertensive hemodialysis patients. Am J Kidney Dis 2001;38:371-6. 
42. Chertow GM, Levin NW, Beck GJ, Depner TA, Eggers PW, Gassman JJ, Gorodetskaya I, Greene T, James S, Larive B, Lindsay RM, M ehta RL, Miller B, Ornt DB, Rajagopalan S, Rastogi A, Rocco MV, Schiller B, Sergeyeva O, Schulman G, Ting GO, Unruh M L, Star RA, Kliger AS. In-center haemodialysis six times per week versus three times per week. N Engl J M ed 2010;363:2287-300.

43. Chan CT, Li SH, Verma S. Nocturnal hemodialysis is associated with restoration of impaired endothelial progenitor cell biology in end-stage renal disease. Am J Physiol Renal Physiol 2005;289:F679-84.

44. Yuen DA, Kuliszewski MA, Liao C, Rudenko D, Leong-Poi H, Chan CT. Nocturnal hemodialysis is associated with restoration of early-outgrowth endothelial progenitor-like cell function. Clin J Am Soc Nephrol 2011;6:1345-53.

45. Chan CT, Harvey PJ, Picton P, Pierratos A, Miller JA, Floras JS. Short-term blood pressure, noradrenergic, and vascular effects of nocturnal home hemodialysis. Hypertension 2003;42:925-31.

46. Chan CT, Hanly P, Gabor J, Picton P, Pierratos A, Floras JS. Impact of nocturnal hemodialysis on the variability of heart rate and duration of hypoxemia during sleep. Kidney Int 2004;65:661-5.

47. Jassal SV, Devins GM, Chan CT, Bozanovic R, Rourke S. Improvements in cognition in patients converting from thrice weekly hemodialysis to nocturnal hemodialysis: a longitudinal pilot study. Kidney Int 2006;70:956-62.

48. Jefferies HJ, Virk B, Schiller B, M oran J, M cIntyre CW. Frequent hemodialysis schedules are associated with reduced levels of dialysis-induced cardiac injury (myocardial stunning). Clin J Am Soc Nephrol 2011;6:1326-32.

49. King RS and Glickman JD. Electrolyte management in frequent home hemodialysis. Semin Dial 2010;23:571-4.

50. M CPhatter LL, Lockridge RS Jr, Albert J, Anderson H, Craft V, Jennings FM, Spencer M, Swafford A, Barger T, Coffey L. Nightly home hemodialysis: improvement in nutrition and quality of life. Adv Ren Replace Ther 1999;6:358-65.

51. Spanner E, Suri R, Heidenheim AP, Lindsay RM . The impact of quotidian hemodialysis on nutrition. Am J Kidney Dis 2003;42(1 Suppl):30-5.

52. Galland R, Traeger J, Arkouche W, Cleaud C, Delawari E, Fouque D. Short daily hemodialysis rapidly improves nutritional status in hemodialysis patients. Kidney Int 2001;60:1555-60.

53. Galland R, Traeger J, Arkouche W, Delawari E, Fouque D. Short daily hemodialysis and nutritional status. Am J Kidney Dis 2001;37(1 Suppl 2):S95-8.

54. van den Ham EC, Kooman JP, Schols AM, Nieman FH, Does JD, Franssen FM, Akkermans M A, Janssen PP, van Hooff JP. Similarities in skeletal muscle strength and exercise capacity between renal transplant and hemodialysis patients. Am J Transplant 2005;5:1957-65.

55. M ucsi I, Hercz G, Uldall R, Ouwendyk M, Francoeur R, Pierratos A. Control of serum phosphate without any phosphate binders in patients treated with nocturnal hemodialysis. Kidney Int 1998:53:1399-404.

56. Yuen D, Richardson RM, Chan CT. Improvements in phosphate control with short daily in-center hemodialysis. Clin Nephrol 2005;64:364-70.

57. Vanholder R, Baurmeister U, Brunet P, Cohen G, Glorieux G, Jankowski J. A bench to bedside view of uremic toxins. J Am Soc Nephrol 2008;19:863-70.

58. Beecroft JM, Duffin J, Pierratos A, Chan CT, McFarlane P, Hanly PJ. Decreased chemosensitivity and improvement of sleep apnea by nocturnal hemodialysis. Sleep M ed 2009;10:47-54.

59. Fagugli RM, Pasini P, Pasticci F, Ciao G, Cicconi B, Buoncristiani U. Effects of short daily hemodialysis and extended standard hemodialysis on blood pressure and cardiac hypertrophy: a comparative study. J Nephrol 2006;9:77-83.

60. Mohr PE, Neumann PJ, Franco SJ, Marainen J, Lockridge R, Ting G. The case for daily dialysis: its impact on costs and quality of life. Am J Kidney Dis 2001;37:777-89.

61. McFarlane PA, Bayoumi AM, Pierratos A, Redelmeier DA. The quality of life and cost utility of home nocturnal and conventional in-center hemodialysis. Kidney Int 2003;64:1004-11.

62. Heidenheim AP, M uirhead N, M oist L, Lindsay RM. Patient quality of life on quotidian hemodialysis. Am J Kidney Dis 2003;42(1 Suppl):36-41.

63. Fong E, Bargman JM, Chan CT. Cross-sectional comparison of quality of life and illness intrusiveness in patients who are treated with nocturnal home hemodialysis versus peritoneal dialysis. Clin J Am Soc Nephrol 2007;2:1195-200. 
64. Jaber BL, Lee Y, Collins AJ, Hull AR, Kraus MA, M cCarthy J, Miller BW, Spry L, Finkelstein FO. Effect of daily hemodialysis on depressive symptoms and postdialysis recovery time: interim report from the FREEDOM (Following Rehabilitation, Economics and Everyday-Dialysis Outcome Measurements) Study. Am J Kidney Dis 2010;56:531-9.

65. Arnold RM and Zeidel ML. Dialysis in frail elders: a role for palliative care. N Engl J Med 2009;361: 1597-8.

66. Jassal SV, Watson D. Doc, don't procrastinate...rehabilitate, palliate and advocate. Am J Kidney Dis 2010;55:209-12.

67. Smith C, Silva-Gane M, Chandna S, Warwicker P, Greenwood R, Farrington K. Choosing not to dialyse: evaluation of planned non-dialytic management in a cohort of patients with end-stage renal failure. Nephron Clin Pract 2003;95:c40-6.

68. Murtagh FE, Marsh JE, Donohoe P, Ekbal NJ, Sheerin NS, Harris FE. Dialysis or not? A comparative survival study of patients over 75 years with chronic kidney disease stage 5. Nephrol Dial Transplant 2007;22:1955-62.

69. Carson RC, Juszczak M, Davenport A, Burns A. Is maximum conservative management an equivalent treatment option to dialysis for elderly patients with significant comorbid disease? Clin J Am Soc Nephrol 2009;4:1611-9.

70. Joly D, Anglicheau D, Alberti C, Nguyen AT, Touam M, Grünfeld JP, Jungers P. Octogenarians reaching end-stage renal disease: cohort study of decision-making and clinical outcomes. J Am Soc Nephrol 2003;14:1012-21.

71. De Biase V, Tobaldini O, Boaretti C, Abaterusso C, Pertica N, Loschiavo C, Trabucco G, Lupo A, Gambaro G. Prolonged conservative treatment for frail elderly patients with end-stage renal disease: the Verona experience. Nephrol Dial Transplant 2008;23:1313-7.

72. Rettig RA. Special treatment - the story of M edicare's ESRD entitlement. N Engl J M ed 2011;364: 596-8

73. Cooper BA, Branley P, Bulfone L, Collins JF, Craig JC, Fraenkel MB, Harris A, Johnson DW, Kesselhut J, Li JJ, Luxton G, Pilmore A, Tiller DJ, Harris DC, Pollock CA. A Randomized, Controlled Trial of Early versus Late Initiation of Dialysis. N Engl J M ed 2010;363:609-19.

74. Cornelis T, Kooman JP, van der Sande FM. Just-in-time initiation of optimal dialysis. Ned Tijdschr Geneeskd 2010;154:A2549.

75. Brown EA, Johansson L, Farrington K, Gallagher H, Sensky T, Gordon F, Da Silva-Gane M, Beckett N, Hickson M. Broadening options for long-term dialysis in the elderly (BOLDE): differences in quality of life on peritoneal dialysis compared to haemodialysis for older patients. Nephrol Dial Transplant 2010:25:3755-63.

76. Oliver MJ, Quinn R, Richardson EP, Kiss AJ, Lamping DL, Manns BJ. Home care assistance and the utilization of peritoneal dialysis. Kidney Int 2007;71:673-8.

77. Taskapan H, Tam P, Leblanc D, Ting RH, Nagai GR, Chow SS, Fung J, Ng PS, Sikaneta T, Roscoe J, Oreopoulos DG. Peritoneal dialysis in the nursing home. Int Urol Nephrol 2010;42:545-51.

78. Macrae J, Friedman AL, Friedman EA, Eggers P. Live and deceased donor kidney transplantation in patients aged 75 years and older in the United States. Int Urol Nephrol 2005;37:641-8.

79. Heldal K, Hartmann A, Grootendorst DC, de Jager DJ, Leivestad T, Foss A, M idtvedt K. Benefit of kidney transplantation beyond 70 years of age. Nephrol Dial Transplant 2010;25:1680-7.

80. Szabo E, Moody H, Hamilton T, Ang C, Kovithavongs C, Kjellstrand C. Choice of treatment improves quality of life: a study on patients undergoing dialysis. Arch Intern M ed 1997;157:1352-6.

81. Piccoli GB. The never-ending search for the perfect dialysis. Should we move from the best treatment to the best system? Nephrol Dial Transplant 2011;26:1128-31.

82. Cornelis T, Kooman JP, van der Sande FM. Intensive home hemodialysis: the best treatment in the best system. Nephrol Dial Transplant 2011;26:3067-8.

83. Lacson E Jr, Wong W, Lester K, Ofsthun N, Lazarus JM, Hakim RM. Outcomes associated with in-center nocturnal hemodialysis from a large multicenter program. Clin J Am Soc Nephrol 2010;5:220-6.

84. Derrett S, Darmody M, Williams S, Rutherford M, Schollum J, Walker R. Older peoples' satisfaction with home-based dialysis. Nephrology 2010;15:464-70. 
85. Pauly RP, Maximova K, Coppens J, Asad RA, Pierratos A, Komenda P, Copland M, Nesrallah GE, Levin A, Chery A, Chan CT. Patient and technique survival among a Canadian multicenter nocturnal home hemodialysis cohort. Clin J Am Soc Nephrol 2010;5:1815-20.

86. Lok CE, Oliver MJ, Su J, Bhola C, Hannigan N, Jassal SV. Arteriovenous fistula outcomes in the era of the elderly dialysis population. Kidney Int 2005;67:2462-9.

87. Wingard RL, Pupin LB, Krishnan M, Shintani A, Ikizler TA, Hakim RM. Early intervention improves hospitalization rates in incident hemodialysis patients: RightStart program. Clin J Am Soc Nephrol 2007;2:1170-5.

88. Wingard RL, Chan KE, Lazarus M, Hakim RM. The "Right" of passage: surviving the first year of dialysis. Clin J Am Soc Nephrol 2009;4:S114-20.

89. Li M, Porter E, Lam R, Jassal SV. Quality improvement through the introduction of interdisciplinary geriatric hemodialysis rehabilitation care. Am J Kidney Dis 2007;50:90-7. 



\section{Chapter}

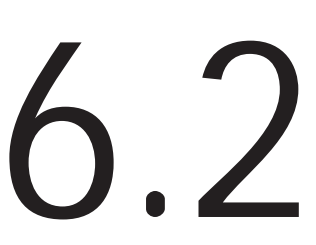

\section{Intensive hemodialysis in the (nursing) home: the bright side of geriatric ESRD care?}

Cornelis T, Kotanko P, Goffin E, van der Sande FM, Kooman JP, Chan CT 


\section{Introduction}

The number of geriatric end-stage renal disease (ESRD) patients requiring renal replacement therapy (RRT) continues to increase ${ }^{1}$. Dialysis is nowadays considered routine care for these patients whereas 25 years ago, 45\% of UK nephrologists responding to a survey would not offer dialysis to a 50-year old ESRD patient with ischemic heart disease ${ }^{2}$. Also, from the geriatric patient perspective, only $12.5 \%$ of those older than 80 years would not recommend dialysis to patients of the same age ${ }^{3}$. Initiation of dialysis in geriatric ESRD patients is often complicated by deterioration of functional status with loss of independence and admission in nursing homes ${ }^{4}$. In particular, the geriatric syndromes may include frailty (unintentional weight loss, exhaustion, slow gait speed, weakness, and/or low physical activity), increased incidence of falls, cognitive impairment, disability and dependence. We previously speculated that the geriatric syndromes in elderly dialysis patients may associate with the occurrence of intra-dialytic hypotension, cardiac and cerebral events, malnutrition and infections as well as sleep abnormalities and psychological complications ${ }^{5}$. We also have put intensive hemodialysis (HD) forward as the optimal dialysis modality to prevent the development of the geriatric syndromes including frailty at the time of dialysis initiation since it may reduce the above described complications. However, the typical choice offered to elderly ESRD patients is currently between in-centre HD and, sometimes, home-based peritoneal dialysis (PD) treatment. Further studies are required to investigate the underlying etiology of the geriatric syndromes in geriatric ESRD as well as to objectify the speculated beneficial effects of intensive HD. In this opinion article, we shortly repeat the potential advantageous effects of intensive HD in elderly ESRD patients, we describe the feasibility of geriatric home HD, elaborate on assisted home and nursing home intensive HD, discuss the barriers of this modality and finish with perspectives towards the future.

\section{Advantages of intensive HD in elderly ESRD}

The potential protective effects of intensive HD in geriatric ESRD patients have been extensively described before by this group of authors ${ }^{5}$. Possible complications of ESRD and dialysis (initiation) in the elderly contributing to geriatric syndromes may be dialysis-related hypotension, cerebral disturbances including cerebrovascular events and dialysis disequilibrium syndrome (DDS), cardiac events including acute coronary syndromes and arrhythmias, malnutrition and infections. Sleep problems such as sleep apnea and post-dialysis fatigue, as well as psychological complications may also play an important role. In our previous publication on the potential role of intensive HD in 
geriatric ESRD, we speculated how intensive HD may protect the elderly ESRD patient against functional deterioration at the time of dialysis initiation (summarized in Table 6.2.1). This may be by facilitating reduction of dialysis-related hypotension, cerebral and cardiac protection, improvement of nutritional status, reduction in infections, sleep restoration as well as providing psychological stability.

Table 6.2.1 ESRD- and dialysis-associated triggers of geriatric syndromes and potential protective effects of intensive HD. (Adapted from reference 5)

\begin{tabular}{|c|c|c|}
\hline \multirow{2}{*}{$\frac{\text { Clinical problems }}{\text { Dialysis-related hypotension }}$} & Pathophysiology & Potential benefits of intensive HD \\
\hline & $\begin{array}{l}\text { Ischemic and valvular heart disease } \\
\text { LVH and diastolic dysfunction } \\
\text { Autonomic nervous system dysfunction } \\
\text { Arterial stiffness } \\
\text { Hypoalbuminemia } \\
\text { High UFR }\end{array}$ & $\begin{array}{l}\downarrow \text { myocardial stunning, } \downarrow \text { CHD } \\
\downarrow \text { LVH } \\
\uparrow \text { autonomic function } \\
\text { 个arterial compliance } \\
\downarrow \text { malnutrition } \\
\downarrow \text { UFR }\end{array}$ \\
\hline \multirow[t]{2}{*}{ Cerebral disturbances } & Cerebrovascular disease & $\begin{array}{l}\uparrow \text { endothelial function, } \\
\downarrow \text { arterial hypertension }\end{array}$ \\
\hline & $\begin{array}{l}\text { Arterial hypertension } \\
\text { DDS }\end{array}$ & $\begin{array}{l}\uparrow \text { blood pressure control } \\
\downarrow \text { malnutrition, slower urea clearance }\end{array}$ \\
\hline \multirow[t]{3}{*}{ Cardiac events } & CHD & $\begin{array}{l}\text { 个endothelial function, } \\
\downarrow \text { arterial hypertension, } \\
\downarrow \text { UFR }\end{array}$ \\
\hline & $\begin{array}{l}\text { Dialysis-related hypotension } \\
\text { Arrhythmias }\end{array}$ & $\begin{array}{l}\text { } \text { hemodynamic stability } \\
\downarrow \text { hypertension, } \\
\downarrow \text { CHD, } \\
\downarrow \text { electrolyte shifts, } \\
\text { 个autonomic function }\end{array}$ \\
\hline & $\begin{array}{l}\text { Autonomic innervation alterations } \\
\text { Electrolyte shifts }\end{array}$ & $\begin{array}{l}\text { 个autonomic function } \\
\text { slower clearance }\end{array}$ \\
\hline \multirow[t]{4}{*}{ Malnutrition } & $\begin{array}{l}\text { Reduced appetite } \\
\text { Polypharmacy } \\
\text { Dysgeusia } \\
\text { Reduced mobility }\end{array}$ & $\begin{array}{l}\text { better clearance, diet liberalization } \\
\downarrow \text { pill burden } \\
\uparrow \text { uremia control } \\
\downarrow \text { malnutrition, } \\
\downarrow \text { muscle weakness }\end{array}$ \\
\hline & Postdialysis fatigue & $\downarrow$ postdialysis fatigue \\
\hline & Gut hypoperfusion & $\downarrow$ intestinal ischemia \\
\hline & Persistent uremic syndrome & 个uremia control \\
\hline Infections & $\begin{array}{l}\text { Uremia-associated immunodeficiency } \\
\text { Reduced response to vaccinations } \\
\text { Malnutrition } \\
\text { M uscle weakness } \\
\text { Overhydration }\end{array}$ & $\begin{array}{l}\text { 个leukocyte function } \\
\uparrow \text { vaccination response } \\
\downarrow \text { malnutrition } \\
\uparrow \text { physical activity } \\
\uparrow \text { volume control }\end{array}$ \\
\hline Sleep problems & $\begin{array}{l}\text { Postdialysis fatigue } \\
\text { Restless legs } \\
\text { SAS }\end{array}$ & $\begin{array}{l}\downarrow \text { daytime sleepiness } \\
\downarrow \text { restless legs } \\
\uparrow \text { pharyngeal size, } \\
\uparrow \text { chemical breathing control }\end{array}$ \\
\hline Psychological complications & Reduced autonomy & $\begin{array}{l}\uparrow Q \text { QL, } \\
\downarrow \text { psychological burden } \\
\uparrow \text { autonomy in home dialysis }\end{array}$ \\
\hline
\end{tabular}

HD: hemodialysis; LVH: left ventricular hypertrophy; UFR: ultrafiltration rate; DDS: dialysis disequilibrium syndrome; CHD: coronary heart disease; SAS: sleep apnea syndrome; QoL: quality of life. 
Recently, 2 observational studies have again demonstrated that intensive HD associates with a significant survival benefit in the general population and this may also be applicable to the elderly ESRD population ${ }^{6,7}$. Another recent study by Foley et al. showed that the longest interdialytic interval was linked to the highest mortality thereby illustrating the importance of shortening the interdialytic interval and potentially at least partly explaining the improved patient survival with intensive $H D^{8}$. Ideally, intensive HD should be delivered at home. The elimination of transport time as well as considerable patient autonomy regarding treatment scheduling and individualization of therapy are potential pivotal advantages of home dialysis.

Last, the economic advantages of (nursing) home dialysis should be emphasized. The lowered costs of home HD have been confirmed by many groups ${ }^{9}$. Decreased frequency of hospitalization, decreased need for erythropoietin, antihypertensives and phosphate binders, reduced transport costs and decreased need for dialysis nurses, may explain why (nursing) home dialysis is cheaper than in-centre dialysis. The average age of the prevalent dialysis population is further increasing which makes the economic aspects of this treatment very important considerations especially in the current tough economic times.

\section{Feasibility of geriatric home HD}

It is often perceived that elderly ESRD patients have a lower propensity for self-care dialysis treatments because of a higher number of co-morbidities, a higher risk of cognitive dysfunction, increased levels of frailty and potential sensorial disturbances ${ }^{10}$. Survival of elderly patients on home dialysis has been especially studied in PD. The North Thames Dialysis Study did not find 1-year survival differences between PD and incentre HD in a sample of 123 incident patients older than 70 years ${ }^{11}$. Other studies also have demonstrated decent survival rates in older patients on both dialysis modalities $^{12,13}$ In a small study from New Zealand, 25 self-care home dialysis (PD and HD) patients were prospectively followed up and had survival rates comparable with national averages at 1 and 2 years ${ }^{14}$. Therefore, it seems reasonable to assume that (intensive) home HD in elderly ESRD patients will have at least similar survival rates than PD and in-centre HD.

Quality of life is definitely a better outcome to assess the feasibility of geriatric home HD. Recent studies have elucidated that in elderly the illness and treatment intrusion levels are lower in home dialysis (especially PD) than in in-centre HD treatments ${ }^{11,15}$. Particularly in settings where sufficient home assistance can be delivered, half of elderly ESRD patients opt to do home dialysis enabling them to remain at home for 
their dialysis treatments and continue their daily lives and social activities instead of being dependent on hospital stays for 3 half days per week, thereby also wasting time for transport to the dialysis centre and back home ${ }^{16}$.

The feasibility of home dialysis in older dialysis patients is demonstrated by relatively high numbers of home treatments in Australia and New Zealand where 24\% (4 and $20 \%$ ) and $47 \%$ (8 and 39\%) of older patients are on home dialysis (home HD and PD) respectively ${ }^{17}$. These numbers are in great contrast to the numbers from the US and UK where 94 and $86 \%$ of elderly dialysis patients are doing in-centre HD treatments respectively ${ }^{1,18}$. These data suggest that home dialysis is currently underused in many parts of the world and that higher proportions of elderly ESRD patients qualify for home therapy than current numbers suggest.

In the study from New Zealand involving 25 self-care home dialysis patients, few complications were seen with home HD treatments and most hospital admissions were because of clotted arteriovenous fistulas. Dialysis therapy was well tolerated and technique survival rates were comparable to in-centre treatments. In another recent pilot study from New Zealand, it was suggested that older patients are satisfied with home dialysis, PD or home HD, even when living remote from the dialysis unit ${ }^{19}$. The authors concluded that home-based dialysis is possible in older patients with levels of co-morbidity and disease severity similar to in-centre HD patients.

\section{Assisted intensive home HD}

Attempts to involve the elderly patient in the self-care dialysis should be made in order to increase participation in the dialysis treatments. This may help to maintain independence of the geriatric dialysis patient, which is an important determinant in technique survival of home HD especially if caregiver support is not available. Still, age is a significant predictor of technique failure (defined as physical or cognitive inability to perform nocturnal home HD either independently or with assistance) as was nicely illustrated in a Canadian multicentre nocturnal home HD cohort ${ }^{20}$.

However, as we know from studies from Toronto, the possibility of assistance at home increases the eligibility of dialysis patients to dialyze at home ${ }^{16}$. Also in France, assisted $\mathrm{PD}$, provided by community nurses, has been standard treatment for older dialysis patients since many years with similar survival to in-centre HD and possibly better quality of life results ${ }^{21}$. This recent report from the French PD Registry illustrated the feasibility of assisted home dialysis in 1613 patients older than 75 years where $76 \%$ of patients required assistance by community private nurses to do the exchanges. These patients had a median survival of 27.1 months, which is at least equal to the $50 \%$ 
survival of 24 months for incident patients on RRT older than 75 years in the UK renal registry ${ }^{18}$.

Different methods of delivering assisted PD have been developed. As far as home HD treatments concerns, community nurses may need more specialized training as compared to PD training in order to develop the required technical skills to perform HD treatments.

When considering home treatments in elderly people, it is extremely important to also consider the caregiver of the dialysis patient. Caregivers often experience emotional stress, anxiety, depression and worsening health, and they also report feelings of isolation and exhaustion ${ }^{22}$. In a recent study from Toronto, a cross-sectional study was performed among 36 prevalent nocturnal home HD patients and 31 caregivers $^{23}$. Depression criteria were present in $25 \%$ of caregivers. However, total global burden perceived by the caregivers was rather low. Since the study population in this report was relatively young (mean age was 52 years for patients and 51 years for caregivers), we could expect that the depression numbers may be significantly higher in an older and hence potentially frailer home HD caregiver population.

Therefore, pre-dialysis assessment by the social worker of the home situation is crucial to evaluate the resilience of both the ESRD patient and the caregiver, to avoid unnecessary ordeals, and to involve professional caregivers instead. Assistance for home HD therapies can be delivered by dialysis nurses, community nurses or healthcare assistants. If the partner or other family member is deemed qualified to function as a caregiver, the opportunities of respite care should not be disregarded and may facilitate the long-term continuation of the home dialysis therapy with the help of the caregiver ${ }^{22}$. Indeed, healthcare professionals should be aware of the caregivers' experiences when caring for elderly ESRD patients and need to develop practices that are sensitive to the patients' but also the families' needs.

\section{Nursing home intensive HD}

Many elderly ESRD patients reside in an extended care facility. Already in 1999, 4.8\% of the dialysis population in the US lived in a nursing home, with an estimated 2000-3000 HD patients entering a nursing home on a yearly basis ${ }^{24}$. These numbers have since then only increased. The biggest experience with nursing home dialysis is with PD. There are indeed several reports available in the literature of successful PD for nursing home residents $\mathrm{s}^{25,26}$.

Alternatively to PD, HD treatments may also take place in the nursing home. Dialysis patients from the same area could then be admitted to one single nursing home where 
the dialysis expertise is present. Nursing home HD may alleviate the transportation burden, which has an enormous impact on the quality of life of these patients by interfering with valuable rehabilitation needs, social interaction and meals. Furthermore, it may lower the costs of HD treatments dramatically, since specialized vans for wheelchair transport or ambulances are often necessary for the nursing home patients. Also, nocturnal HD (NHD) may allow a minimum amount of dialysis nurses to support the dialysis treatments in these patients.

The feasibility of nursing home HD was demonstrated in a large cohort in the US ${ }^{27}$. The success of their program was shown by a high rate $(40 \%)$ of rehabilitation and eventual discharge home. In their setting, the dialysis treatments were performed by dialysis technicians who had at least 3 years of experience and a registered nurse on-staff was available for emergencies. Nephrologists came to the nursing homes to see the patients within one week of entry into the program and thereafter at least twice a month. Jassal et al. described a similar experience with elderly dialysis patients admitted to a rehabilitation centre ${ }^{28}$. The mean age of these patients was 67 years and $85 \%$ of patients had at least 2 co-morbidities. Eighty percent of the patients were on HD. Of the 185 patients followed, 34\% were discharged home. The most common medical problem was vascular access related, and a total of 4.7 transfers to an acute nephrology transfer were recorded for each patient-year of follow-up. The authors concluded that admission from a high care facility to a chronic care facility makes practical and economic sense and may improve health care planning and provide more stability for the patient, family and caregivers.

In one study, nursing home HD patients were more likely to have intradialytic hypotension requiring intervention than other patients ( 36 vs. $13 \%, P \varangle 0.05)^{29}$. In this context, intensive HD may help to reduce the occurrence of dialysis-related hypotension by reducing the ultrafiltration rate, by protecting against myocardial stunning, by reducing left ventricular hypertrophy (LVH) and improving nutritional status, autonomic function as well as arterial compliance ${ }^{5}$. Furthermore, in the study by Reddy et al. ${ }^{27}$, new nursing home dialysis patients had more myocardial infarctions, infections and lower serum albumin and hemoglobin levels as compared with established patients. Again here, intensive HD may be the ideal strategy to counteract these potential ESRD and dialysis complications via similar mechanisms as described above ${ }^{5}$. 


\section{How to remove the bias against home HD treatment for elderly ESRD patients?}

\section{Patient-based barriers}

Hearing and visual impairment, frailty, physical and cognitive dysfunction, and social isolation can be managed by the introduction of assisted home HD. As shown by Oliver et al., a multidisciplinary approach to identifying barriers to home dialysis (medical, psychological, or social) may help to overcome these potential barriers ${ }^{16}$. With such an approach, they estimated up to $80 \%$ of their patients eligible for PD. In France, the use of assisted PD has been the standard treatment for older patients since many years; $54 \%$ of men and $59 \%$ of women were on PD in January 2006 being over 70 years of $\operatorname{age}^{21}$.

\section{Modality education}

Pre-dialysis education of elderly people is a challenge. Often they tend to leave the decision of the dialysis modality choice in the hands of the family and the renal care team ${ }^{30}$. Furthermore, age older than 75 years is a predictor of starting dialysis treatment with HD even when these patients had opted for PD in the pre-dialysis setting $^{31}$. The exact underlying mechanism for this observation remains unclear, but influence from family members, peer, and the treating physician team as well as social and disease-related (such as superimposed acute kidney injury) barriers may explain some of the discrepancy ${ }^{31}$. Also, elderly patients may have cognitive dysfunction and uremic symptoms, making it difficult for them to appreciate all the implications of the given information.

The starting point for a successful home-based dialysis program is therefore timely and appropriate education to enable the patient and his family to comprehend benefits and pitfalls of the respective dialysis modalities, and to offer adequate home support for home dialysis. It is also essential that the nephrologists and renal nurses become more convinced of the potential benefits of home-based dialysis therapies, especially intensive home $\mathrm{HD}^{32}$.

\section{Incentives from government and health insurance companies}

Incentives for the hospitals and for the patients to do home-based therapies should be implemented, but need to include incentives for assisted home HD in elderly dialysis patients ${ }^{32,33}$. 


\section{Combination with rehabilitation}

In all elderly ESRD patients, active rehabilitation should be considered as part of integrated dialysis care to prevent decline in functionality and further progression of the frailty syndrome. Active rehabilitation may be performed at home, in a dedicated rehabilitation centre, or in the nursing home. The RightStart program has indeed shown that a comprehensive approach including patient evaluation, team collaboration, and teaching of self-management strategies may reduce morbidity and mortality in dialysis patients $^{35,36}$. An integrated and multidisciplinary approach involving nephrologists, (renal) nurses, dieticians, physiotherapists, social workers, and psychologists is crucial to benefit optimally form the potential advantages of intensive HD as described above.

\section{Don't forget the "conservative ESRD care" option}

It cannot be overemphasized that non-dialysis renal care is also an important therapeutic option in the management of ESRD in elderly patients ${ }^{37,38}$. Especially, if elderly patients are mentally disabled, have multiple co-morbidities, are not unable to ambulate anymore, have a poor overall quality of life, and/or have an untreatable disease, physicians should consider being conservative in the treatment of ESRD patients, because the start of dialysis can be considered as an external stressor of which benefits may not necessarily outweigh risks, especially in already frail elderly patients. Indeed, conventional dialysis modalities may modestly increase patient survival, but often this is at the expense of increased hospitalization rates and a reduced likelihood to die at home surrounded by family and friends ${ }^{39}$. Patients and their family should be educated in the pre-dialysis clinics about the option of conservative care. In that setting, symptoms can be alleviated with specific interventions and medications to improve quality of life.

To guide the assessment of this group of patients in the pre-dialysis setting, frailty scores may aid the renal care team to decide whether or not a patient is eligible for dialysis and whether an elderly patient with ESRD will benefit from intensive HD. These frailty scores may include assessment of weight loss, gait speed, muscle strength, cognitive functioning, as well as laboratory parameters such as serum albumin and inflammatory markers. Also, the "surprise" question and predictive models may help to decide whether an elderly patient qualifies for (intensive) dialysis treatments or rather should receive priority for palliative care interventions ${ }^{40,41}$. 


\section{Future perspectives}

Further research, observational, and, ideally, prospective randomized trials are necessary to convince nephrologists that intensive home HD may offer an excellent treatment for elderly dialysis patient $5^{5,33,34}$.

Once the renal care team is convinced by facts, pre-dialysis education should focus on the "Intensive HD first" principle and aim to encourage ESRD patients to consider home $\mathrm{HD}^{42}$. To be sure, support by governments, medical administration, insurances, and industry is indispensable for further development of this strategy. Also, adequate intraand extramural infrastructure for home HD training, support, and education, and facilities for respite care are necessary. Last but not least, support of the patient and his or her family by enthusiastic social workers and, if necessary, psychological guidance in combination with rehabilitation opportunities is crucial to the holistic approach toward the elderly ESRD patient in need for dialysis treatment.

\section{Conclusion}

An increasing number of elderly ESRD patients start dialysis. Because of underlying frailty, they often lose functionality following dialysis initiation. We believe that intensive HD may prevent elderly ESRD patients from these ESRD and dialysis complications, and hence help them to preserve autonomy and quality of life. Further studies are required to test this hypothesis and to elucidate the mechanisms underlying frailty and other geriatric syndromes in this highly vulnerable patient population. Once the well-informed elderly ESRD patient has opted for intensive HD, ideally dialysis should then be delivered at home because this approach is likely to optimize autonomy and permits individualization of therapy. An interesting suggestion in the home setting is to switch between intensive HD modalities, such as to alternate between short-daily HD and nocturnal HD to further improve quality of life ${ }^{33,34}$. To support patient and caregiver and prevent burn-out, assisted home HD may be the preferred modality. In patients living in nursing homes, nursing home HD may be an attractive option. 


\section{References}

1. United States Renal Data System: US Renal Data System, USRDS 2010 Annual Data Report: Atlas of EndStage Renal Disease in the United States. Bethesda, National Institutes of Health, National Institute of Diabetes and Digestive and Kidney Diseases, 2010.

2. Challah S, Wing AJ, Bauer R, M orris RW, Schroeder SA. Negative selection of patients for dialysis and transplantation in the United Kingdom. Br M ed J (Clin Red Ed) 1984;288:1119-22.

3. Schaefer K, von Herrath D, Faust J, Röhrich B. The very elderly dialysis patient: indication and discontinuation of dialysis. Int Urol Nephrol 2002;34:573-6.

4. Kurella Tamura M, Covinsky KE, Chertow GM, Yaffe K, Landefeld CS, M cCulloch CE. Functional status of elderly adults before and after initiation of dialysis. N Engl J Med 2009;361:1612-3.

5. Cornelis T, Kotanko P, Goffin E, Kooman JP, van der Sande FM, Chan CT. Can intensive hemodialysis prevent loss of functionality in the elderly ESRD patient? Semin Dial 2011;24:645-52.

6. Nesrallah GE, Lindsay RM, Cuerden MS, Garg AX, Port F, Austin PC, M oist LM, Pierratos A, Chan CT, Zimmerman D, Lockridge RS, Couchoud C, Chazot C, Ofsthun N, Levin A, Copland M, Courtney M, Steele A, McFarlane PA, Geary DF, Pauly RP, Komenda P, Suri RS. Intensive hemodialysis associates with improved survival compared with conventional hemodialysis. J Am Soc Nephrol. 2012;23:696-705.

7. Lacson E Jr, Xu J, Suri RS, Nesrallah G, Lindsay R, Garg AX, Lester K, Ofsthun N, Lazarus M, Hakim RM. Survival with three-times weekly in-center nocturnal versus conventional hemodialysis. J Am Soc Nephrol. 2012;23:687-95.

8. Foley RN, Gilbertson DT, Murray T, Collins AJ. Long interdialytic interval and mortality among patients receiving hemodialysis. N Engl J Med. 2011;365:1099-107.

9. McFarlane P, Komenda P. Economic considerations in frequent home hemodialysis. Semin Dial 2011;24:678-83.

10. Brown EA, Johansson L. Dialysis options for end-stage renal disease in older people. Nephron Clin Pract 2011;119:c10-3.

11. Lamping DL, Constantinovici N, Roderick P, Normand C, Henderson L, Harris S, Brown E, Gruen R, Victor C. Clinical outcomes, quality of life, and costs in the North Thames Dialysis Study of elderly people on dialysis: a prospective cohort study. Lancet 2000;356:1543-50.

12. Kurella M, Convinsky KE, Collins AJ, Chertow GM. Octogenarians and nonagenarians starting dialysis in the United States. Ann Intern Med 2007;146:177-83.

13. Castrale C, Evans D, Verger C, Fabre E, Aguilera D, Ryckelyck JP, Lobbedez T. Peritoneal dialysis in elderly patients: report from the French Peritoneal Dialysis Registry (RDPLF). Nephrol Dial Transplant 2010;25:255-62.

14. McDonald M, M cPhee PD, Walker RJ. Successful self-care home dialysis in the elderly: a single center's experience. Perit Dial Int 1995;15:33-6.

15. Brown EA, Johansson L, Farrington K, Gallagher H, Sensky T, Gordon F, Da Silva-Gane M, Beckett N, Hickson M. Broadening Options for Long-term Dialysis in the Elderly (BOLDE): differences in quality of life on peritoneal dialysis compared to haemodialysis for older patients. Nephrol Dial Transplant 2010;25:3755-63.

16. Oliver MJ, Quinn R, Richardson EP, Kiss AJ, Lamping DL, Manns BJ. Home care assistance and the utilization of peritoneal dialysis. Kidney Int 2007; 71:673-8.

17. MacDonald S, Excell L, Livingston BE. ANZDATA Registry 2009. Adelaide, Australia and New Zealand Dialysis and Transplant Registry, 2009.

18. Ansell D, Castledine C, Feehally J, Fogarty D, Ford D, Inward C, Tomson C, Warwick G, Webb L, Williams AE. UK Renal Registry Report 2009. Bristol, UK Renal Registry, 2010.

19. Derrett S, Darmody M, Williams S, Rutherford M, Schollum J, Walker R. Older peoples' satisfaction with home-based dialysis. Nephrology 2010;15:464-70.

20. Pauly RP, M aximova K, Coppens J, Asad RA, Pierratos A, Komenda P, Copland M, Nesrallah GE, Levin A, Chery A, Chan CT. Patient and technique survival among a Canadian multicenter nocturnal home hemodialysis cohort. Clin J Am Soc Nephrol 2010;5:1815-20. 
21. Verger C, Ryckelynck JP, Duman M, Veniez G, Lobbedez T, Boulanger E, M oranne O. French Peritoneal Dialysis Registry (RDPLF): outline and main results. Kidney Int Suppl 2006;103:S12-20.

22. Qyinan P. Home hemodialysis and the caregivers' experience: a critical analysis. CANNT J 2005;15:2532.

23. Rioux JP, Narayanan R, Chan CT. Caregiver burden among nocturnal home hemodialysis patients. Hemodial Int 2012;16:214-9.

24. Anderson JE, Kraus J, Sturgeon D. Incidence, prevalence, and outcomes of end-stage renal disease patients placed in nursing homes. Am J Kidney Dis 1993;21:619-27.

25. Anderson JE. Ten years' experience with CAPD in a nursing home setting. Perit Dial Int 1997;17:255-61.

26. Taskapan H, Tam P, LeBlanc D, Ting RH, Nagai GR, Chow SS, Fung J, Ng PS, Sikaneta T, Roscoe J, Oreopoulos DG. Peritoneal dialysis in the nursing home. Int Urol Nephrol 2010;42:545-51.

27. Reddy NC, Korbet SM, Wozniak JA, Floramo SL, Lewis EJ. Staff-assisted nursing home hemodialysis: patient characteristics and outcomes. Nephrol Dial Transplant 2007;22:1399-406.

28. Jassal SV, Brissenden JE, Roscoe JM. Specialized chronic care for dialysis patients - a five-year study. Clin Nephrol 1998;50:84-9.

29. Sankarasubbaiyan S, Holley JL. An analysis of the increased demands placed on dialysis health care team members by functionally dependent hemodialysis patients. Am J Kidney Dis 2000;35:1061-7.

30. Bastiaens H, Van Royen P, Pavlic DR, Raposo V, Baker R. Older peoples' preferences for involvement in their own care: a qualitative study in primary health care in 11 European countries. Patient Educ Couns 2007;68:33-42.

31. Liebman SE, Bushinsky DA, Dolan JG, Veazie P: Differences between dialysis modality selection and initiation. Am J Kidney Dis 2012;59:550-7.

32. Ludlow MJ, George CRP, Hawley CM, Mathew TH, Agar JWM, Kerr PG, Lauder LA. How Australian nephrologists view home dialysis: results of a national survey. Nephrology 2011;16:446-52.

33. Piccoli GB. The never-ending search for the perfect dialysis. Should we move from the best treatment to the best system? Nephrol Dial Transplant 2011;26:1128-31.

34. Cornelis T, Kooman JP, van der Sande FM. Intensive home hemodialysis: the best treatment in the best system. Nephrol Dial Transplant 2011;26:3067-8.

35. Wingard RL, Pupin LB, Krishnan M, Shintani A, Ikizler TA, Hakim RM. Early intervention improves hospitalization rates in incident hemodialysis patients: RightStart program. Clin J Am Soc Nephrol 2007;2:1170-5.

36. Wingard RL, Chan KE, Lazarus M, Hakim RM. The "Right" of passage: surviving the first year of dialysis. Clin J Am Soc Nephrol 2009;4:S114-20.

37. Arnold RM, Zeidel M L. Dialysis in frail elders: a role for palliative care. N Engl J M ed 2009;361:1597-8.

38. Jassal SV, Watson D. Doc, don't procrastinate...rehabilitate, palliate and advocate. Am J Kidney Dis 2010;55:209-12.

39. Carson RC, Juszczak M, Davenport A, Burns A. Is maximum conservative management an equivalent treatment option to dialysis for elderly patients with significant comorbid disease? Clin J Am Soc Nephrol 2009;4:1611-9.

40. Moss AH, Ganjoo J, Sharma S, Gansor J, Senft S, Weaner B, Dalton C, MacKay K, Pellegrino B, Anantharaman P, Schmidt R. Utility of the "surprise" question to identify dialysis patients with high mortality. Clin J Am Soc Nephrol 2008;3:1379-84.

41. Thijssen S, Usvyat L, Kotanko P. Prediction of mortality in the first two years of hemodialysis: results from a validation study. Blood Purif 2012;33:165-7.

42. Cornelis T, Kooistra MP, Kooman JP, Leunissen KM, Chan CT, van der Sande FM. Education of ESRD patients on dialysis modality selection: "Intensive HD first". Nephrol Dial Transplant 2010;25:129-30. 


\section{Chapter}

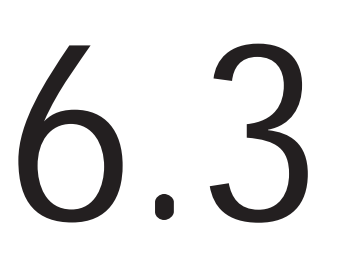

\section{An international feasibility study of home hemodialysis in older patients}

Cornelis T, Tennankore KT, Goffin E, Rauta V, Honkanen E, Őzyilmaz A, Thanaraj V, Jayanti A, M itra S, van der Sande FM, Kooman JP, Chan CT 


\section{Abstract}

Background: Home hemodialysis (HD) is undergoing a significant revival. There is a global demographic shift with a rising mean age of dialysis patients. We postulated that intensive home HD may also benefit the older dialysis population. However, there is a lack of literature on the feasibility of home HD in older patients with end-stage renal disease (ESRD). The purpose of this study was to ascertain the feasibility of delivering home HD to older patients.

Methods: We conducted a multi-centre multinational retrospective cohort study of home HD patients $\geq 65$ years of age at the time of home HD initiation; 79 patients were included. Baseline demographic data included age at start of dialysis, race and sex. Dialysis characteristics including total weekly treatment hours, need for assistance, training time, dialysis access, modality and dialysis vintage were captured, as well as cause of ESRD and medical co-morbidities. The primary outcome was time to technique failure or death. Rates of hospitalization, cardiovascular events, non-infectious vascular access events and infections were collected.

Results: Median age at start was 68 (interquartile range 66-71) years. An arteriovenous fistula was the predominant access, and most patients were receiving $<16$ hours of total weekly dialysis treatment. Family or nurse assistance for dialysis was required in $54 \%$ of patients. There were 17 (22\%) deaths and 20 (26\%) technique failures. The cumulative time at risk was 188 years. Eventfree survival at 1, 2 and 5 years was $85 \%, 77 \%$ and $24 \%$, respectively, and technique survival was $92 \%, 83 \%$ and $56 \%$, respectively. Advancing age (categorized into quartiles) was an unadjusted risk factor for death and technique failure.

Conclusions: This analysis confirms feasibility of home HD in patients 65 years or older at the start of this modality, and should foster further research on the potential benefits of (intensive) home HD in older ESRD patients. 


\section{Introduction}

The number of older patients requiring dialysis is increasing ${ }^{1}$. Although there is a secular shift in societal attitudes towards renal replacement therapy (RRT) in the elderly, options to preserve autonomy and enhance quality of life are limited in this patient population. Futhermore, kidney transplantation is in many cases not an option in geriatric end-stage renal disease (ESRD) patients because of co-morbidities and contraindications to surgery and immunosuppression. It is intriguing to note that a large majority of dialysis patients older than 80 years would recommend dialysis to patients of the same age ${ }^{2}$. Taken together, there is an important unmet need facing the fastest growing segment of all patients requiring RRT.

The typical pre-dialysis education in older ESRD patients includes in-centre hemodialysis (HD) and, sometimes, home-based peritoneal dialysis (PD). We speculated before that home HD treatment, especially when delivered as intensive HD, may be an alternative modality in this patient population ${ }^{3,4}$. We hypothesized that home HD may help to prevent the development of the geriatric syndromes, including frailty, at the time of dialysis initiation, as it may reduce dialysis-related complications such as intradialytic hypotension, cerebral disturbances, cardiac events, malnutrition, infections, sleep disorders and psychological problems ${ }^{5}$. Even if conventional HD (3 times a week for 4 hours) is performed in a home setting, beneficial effects such as increased autonomy, individualization of therapy and elimination of transport time may significantly contribute to increased well-being of the elderly ESRD patient.

The purpose of the present study was to examine the feasibility of delivering home HD to an older cohort of ESRD patients. We hypothesized that age and medical comorbidities could be important determinants of technique and patient survival in older individuals receiving home $\mathrm{HD}$.

\section{Methods}

We conducted a multicentre international cohort study of home HD patients between 1 January 1970 and 31 December 2012 that were $\geq 65$ years of age at the time of home HD initiation. The cohort included patients from six centres in five countries (Brussels, Belgium; Groningen, Netherlands; Helsinki, Finland; Maastricht, Netherlands; M anchester, United Kingdom; Toronto, Canada). Baseline demographic data of interest included age at start of home HD, race and sex. We captured dialysis characteristics including total weekly treatment hours, need for assistance (either by a dialysis nurse or a family member), training time (defined as the number of days between first 
training day and last training day), dialysis access [including type of needling for those with arteriovenous fistulas (AVF)], modality and time on an alternative form of RRT prior to starting home HD (dialysis vintage). Cause of ESRD (diabetes, ischemic renal disease, polycystic kidney disease or glomerulonephritis) and medical co-morbidities were also collected. Co-morbidities of interest included diabetes, hypertension, cardiac disease, peripheral vascular disease and malignancy. The primary outcome of the study was time to technique failure (inability to continue with home HD) or death during home HD from the date of initiation of the modality. Acknowledging that the cohort extended over a long period of time, a sensitivity analysis for the primary outcome was performed among those patients who initiated home HD between 1999-2012. Secondary outcomes included time to technique failure and unadjusted rates of cardiovascular events, hospitalizations and infections. We also examined proportions of non-infectious vascular access interventions and need for respite care (treatment backup in training-centre and in-centre). For both time to event analyses, patients were censored at the date of renal transplantation.

Baseline characteristics were described as medians and interquartile range (IQR) for continuous variables, and number and percentage for categorical variables. Age was transformed into quartiles assuming there would be a non-linear relationship between age and outcome. Time to event was analyzed with the Kaplan Meier Product Limit method. Potential associations between baseline characteristics and the primary outcome were explored using a Cox survival analysis. We included clinically important variables (including gender, need for dialysis assistance, vascular access, comorbidity and hours of dialysis) in the multivariable model. Unadjusted rates of vascular access interventions, hospitalizations, infectious events and cardiac events were described as number/time on home HD. All statistical analyses were performed with Stata IC, version 12 (StataCorp, College Station, Tex., USA). A two-sided $P$ value $\varangle 0.05$ was considered statistically significant.

Approval for the study was initially received from the research ethics board at the Maastricht University Medical Centre (Maastricht, Netherlands) under number METC 13-4-032, and subsequently from the other $R \& D$ centres. All patient data were anonymised prior to analysis. 


\section{Results}

\section{Baseline characteristics}

The cohort consisted of 79 patients that were $\geq 65$ years of age at the time of home HD start. Sixteen patients were included from the home HD centre in Brussels, 11 in Groningen, 24 in Helsinki, 4 in Maastricht, 11 in Manchester, and 13 patients were recruited in Toronto. Baseline characteristics of the study cohort are noted in Table 6.3.1. Of note, the median age at start was 68 (IQR 66-71) years, and the majority of patients were Caucasian males. With respect to dialysis characteristics, an AVF was the predominant type of access (in $75 \%$ of the cohort), and most (67\%) patients were receiving $<16$ hours of total weekly dialysis treatment. Family or nurse assistance for dialysis was required in $54 \%$ of patients.

\section{Primary outcome}

There were a total of 17 deaths (22\%) and 20 technique failures (26\%). Reasons for death were: cardiovascular events (8), co-morbidities (4), withdrawal/age (2), line sepsis (1), suicide (1), and unknown (1). Reasons for technique failure were: comorbidities (7), burn-out or health problem of the partner (6), memory problems (2), psychological burden (1), access problems (1), frailty (1), patient preference for PD (1), and because the patient moved to another city (1). The cumulative time at risk was 188 years. Median follow-up time was 2.0 (IQR 1.0-3.6) years. Nineteen patients (24\%) underwent kidney transplantation, and the median age of transplanted patients at the start of home HD was 67 (IQR 65-68) years. Time to death or technique failure is graphically displayed in Figure 6.3.1; event-free survival at 1, 2 and 5 years after home HD initiation was $85 \%, 77 \%$ and $24 \%$, respectively. Figure 6.3 .2 demonstrates the primary outcome stratified by age quartile (logrank $P=0.006$ ). Only age (quartile 3 and 4) and male sex (only adjused) had an association with the composite event (Table 6.3.2). The association between age and time to death or technique failure remained after multivariable adjustment, and restriction to the most recent era (1999-2012) of the cohort (Table 6.3.2). Time to death and technique failure for the most recent era of the cohort is displayed in Figure 6.3.3. 
Table 6.3.1 Baseline characteristics of study cohort $(n=79)$

\begin{tabular}{|c|c|}
\hline Variable & Value \\
\hline \multicolumn{2}{|l|}{ Demographics } \\
\hline Age, median (IQR), min, max & $68(66-71), 65,88$ \\
\hline Caucasian race, n (\%) & $76(96)$ \\
\hline Male sex, n (\%) & $57(72)$ \\
\hline Era $1970-1979, n(\%)$ & $1(1)$ \\
\hline 1980-1989, n (\%) & $5(6)$ \\
\hline 1990-1998, n (\%) & $7(9)$ \\
\hline 1999-2012, n (\%) & $66(84)$ \\
\hline \multicolumn{2}{|l|}{ Dialysis characteristics } \\
\hline Total weekly hours, median (IQR) & $15(12-16.5)$ \\
\hline Proportion receiving $\geq 16$ hours/week, n (\%) & $26(33)$ \\
\hline Assisted by family member ( $n=78), n(\%)$ & $27(35)$ \\
\hline Assisted by dialysis nurse (n=78), n (\%) & $15(19)$ \\
\hline Training time in days & $75(49-107)$ \\
\hline \multicolumn{2}{|l|}{ Dialysis access, n (\%) } \\
\hline Arteriovenous fistula & $61(77)$ \\
\hline Buttonhole cannulation & $35(58)$ \\
\hline Rope ladder cannulation & $16(26)$ \\
\hline Both types used & $2(3)$ \\
\hline Unknown & $8(13)$ \\
\hline Arteriovenous graft & $2(3)$ \\
\hline Central venous catheter & $13(16)$ \\
\hline Arteriovenous fistula and central venous catheter & $3(4)$ \\
\hline \multicolumn{2}{|l|}{ Dialysis modality prior to starting home HD } \\
\hline None & $35(44)$ \\
\hline Peritoneal dialysis & $5(6)$ \\
\hline In-centre hemodialysis & $33(42)$ \\
\hline Transplant & $6(8)$ \\
\hline Renal replacement therapy vintage $(n=66)$, median years (IQR) & $0(0-0.39)$ \\
\hline \multicolumn{2}{|l|}{ Cause of ESRD } \\
\hline Polycystic kidney disease & $8(10)$ \\
\hline Diabetes & $12(15)$ \\
\hline Glomerulonephritis & $16(20)$ \\
\hline Hypertension/ischemic renal disease & $21(27)$ \\
\hline Other & $22(28)$ \\
\hline \multicolumn{2}{|l|}{ Comorbidities, n (\%) } \\
\hline Diabetes & $13(16)$ \\
\hline Hypertension & $27(34)$ \\
\hline Coronary artery disease & $17(22)$ \\
\hline Malignancy & $20(25)$ \\
\hline Congestive heart failure & $7(9)$ \\
\hline Atrial fibrillation ( $n=59)$ & $9(15)$ \\
\hline Valvular heart disease & $7(9)$ \\
\hline Peripheral vascular disease & $12(15)$ \\
\hline History of failed renal transplant & $7(9)$ \\
\hline
\end{tabular}

* Percentages may not add to 100 due to rounding 


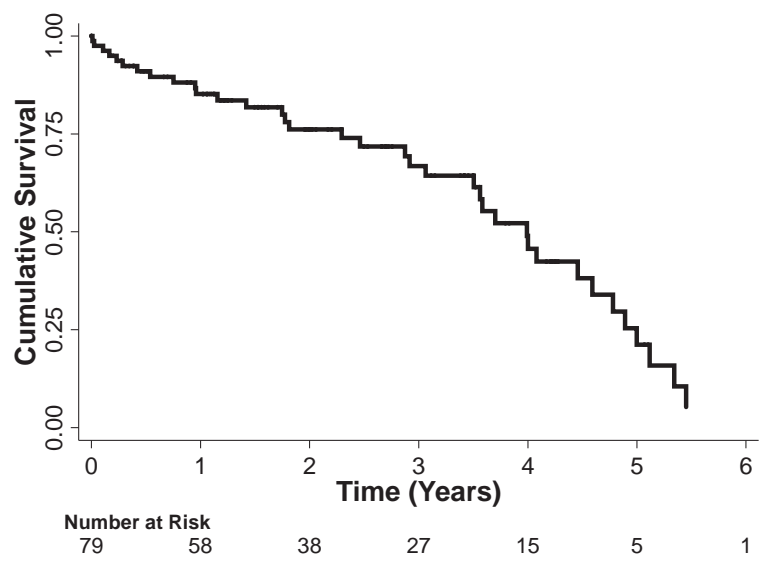

Figure 6.3.1 Time to death or technique failure for home hemodialysis cohort.
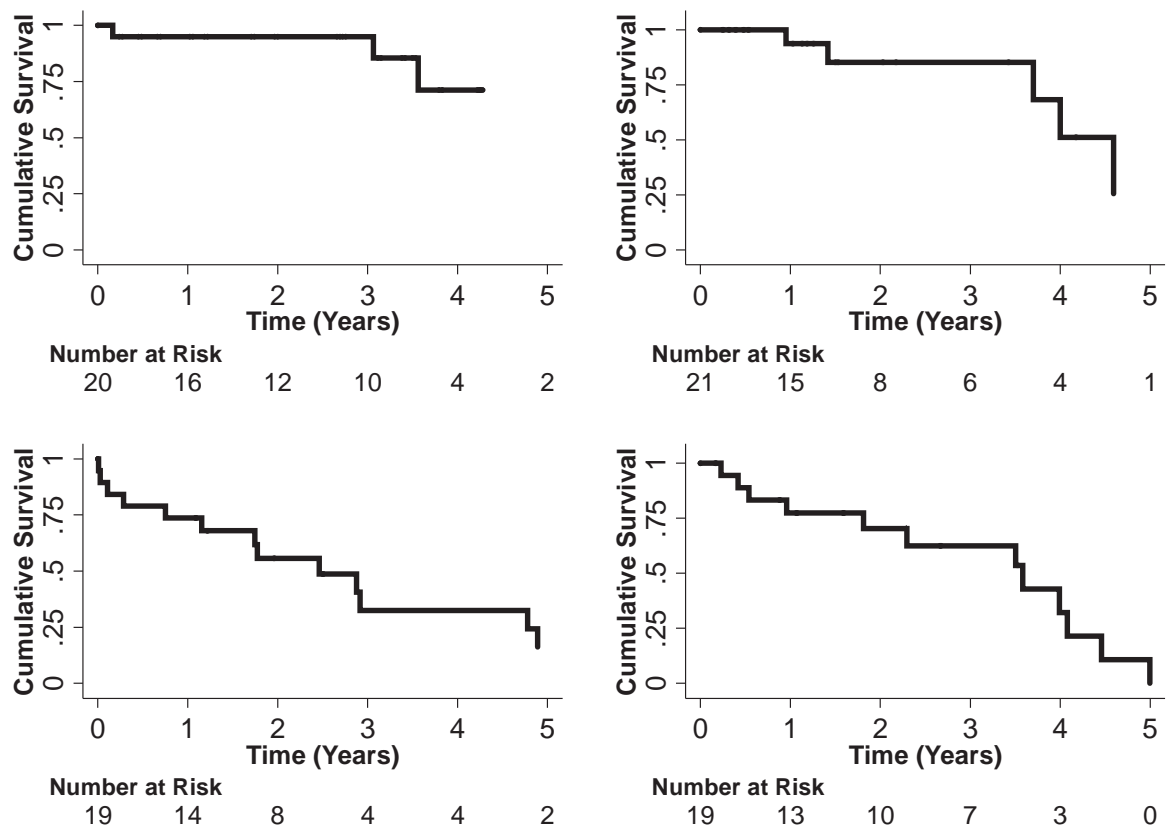

Figure 6.3.2 Time to death or technique failure, stratified by age quartile (upper left: quartile 1, upper right: quartile 2 , below left: quartile 3 , below right: quartile 4) (logrank $P=0.006$ ). 
Table 6.3.2 Unadjusted and adjusted associations with death or technique failure.

\begin{tabular}{|c|c|c|c|c|}
\hline Variable & Unadjusted $\mathrm{HR}(95 \% \mathrm{Cl})$ & $\mathrm{P}$ & Adjusted HR* $(95 \% \mathrm{Cl})$ & $\mathrm{P}$ \\
\hline \multicolumn{5}{|l|}{ Entire cohort $(n=79)$} \\
\hline \multicolumn{5}{|l|}{ Age quartile } \\
\hline $65-66$ & 1 & & 1 & \\
\hline $67-68$ & $2.38(0.59-9.55)$ & 0.221 & $1.65(0.35-7.78)$ & 0.530 \\
\hline $68-71$ & $6.06(1.71-21.43)$ & 0.005 & $7.06(1.88-26.47)$ & 0.004 \\
\hline $71-88$ & $5.79(1.60-20.95)$ & 0.007 & $5.15(1.30-20.41)$ & 0.020 \\
\hline Male sex & $0.83(0.39-1.75)$ & 0.621 & $0.37(0.14-0.98)$ & 0.045 \\
\hline Central venous catheter access & $1.08(0.41-2.82)$ & 0.881 & $0.32(0.07-1.42)$ & 0.133 \\
\hline >16 hours of dialysis/week & $1.59(0.74-3.40)$ & 0.231 & $1.67(0.60-4.67)$ & 0.331 \\
\hline Ischemic heart disease & $1.84(0.90-3.82)$ & 0.100 & $1.59(0.53-4.77)$ & 0.411 \\
\hline Hypertension & $1.66(0.80-3.44)$ & 0.171 & $1.59(0.62-4.09)$ & 0.333 \\
\hline Diabetes & $1.60(0.68-3.75)$ & 0.281 & $1.63(0.47-5.63)$ & 0.442 \\
\hline Congestive heart failure & $0.96(0.36-2.52)$ & 0.929 & $1.16(0.35-3.90)$ & 0.806 \\
\hline Assisted with dialysis & $1.15(0.57-2.33)$ & 0.696 & $0.80(0.31-2.06)$ & 0.642 \\
\hline \multicolumn{5}{|l|}{ Cohort era 1999-2012 $(n=66)$} \\
\hline \multicolumn{5}{|l|}{ Age quartile } \\
\hline $65-66$ & 1 & & 1 & \\
\hline $67-68$ & $4.98(0.55-44.99)$ & 0.153 & $2.45(0.23-25.58)$ & 0.455 \\
\hline $68-71$ & $17.33(2.14-140.54)$ & 0.008 & $18.14(2.08-157.97)$ & 0.009 \\
\hline $71-88$ & $10.67(1.39-82.14)$ & 0.023 & $11.37(1.22-106.21)$ & 0.033 \\
\hline Male sex & $1.41(0.59-3.42)$ & 0.442 & $0.47(0.14-1.58)$ & 0.223 \\
\hline Central venous catheter access & $0.62(0.23-1.68)$ & 0.349 & $0.22(0.03-1.42)$ & 0.112 \\
\hline >16 hours of dialysis/week & $1.46(0.64-3.32)$ & 0.363 & $2.17(0.65-7.16)$ & 0.205 \\
\hline Ischemic heart disease & $1.22(0.51-2.89)$ & 0.108 & $0.70(0.14-3.37)$ & 0.652 \\
\hline Hypertension & $1.76(0.77-4.04)$ & 0.182 & $1.80(0.63-5.12)$ & 0.272 \\
\hline Diabetes & $1.45(0.57-3.71)$ & 0.440 & $2.31(0.58-9.26)$ & 0.238 \\
\hline Congestive heart failure & $1.91(0.63-5.82)$ & 0.254 & $3.19(0.65-15.71)$ & 0.154 \\
\hline Assisted with dialysis & $1.08(0.48-2.41]$ & 0.859 & $0.40(0.10-1.68)$ & 0.211 \\
\hline
\end{tabular}

* Includes all variables in unadjusted model

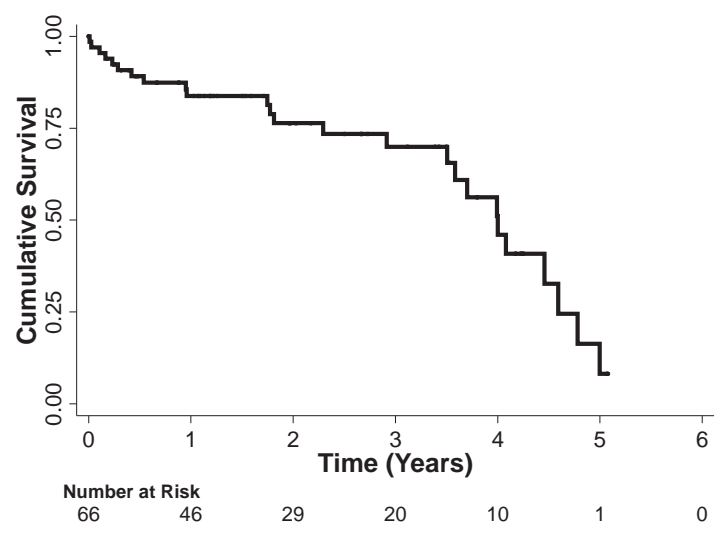

Figure 6.3.3 Time to death or technique failure for home hemodialysis cohort (era 1999-2012). 


\section{Secondary outcomes}

Time to technique failure is displayed in Figure 6.3.4; technique survival at 1, 2 and 5 years after home HD initiation was $92 \%, 83 \%$ and $56 \%$, respectively. Time to technique failure for the most recent era of the cohort is displayed in Figure 6.3.5. Time to death for the entire cohort is shown in Figure 6.3.6. Proportions and/or rates of infections, cardiac events, need for respite care, hospitalizations, and non-infectious vascular access events are noted in Table 6.3.3. Among those with available data, 49\% (31/63 patients) required at least one respite in-centre/training facility dialysis treatment during the follow-up time. The overall hospitalization rate was 0.55 admissions/year of home HD. The majority of hospitalizations were due to other causes (e.g. elective admissions for lower limb angiography, hernia surgery, nephrectomy, epilepsy), and not the result of infections, cardiovascular events, dialysis access or dialysis treatment.

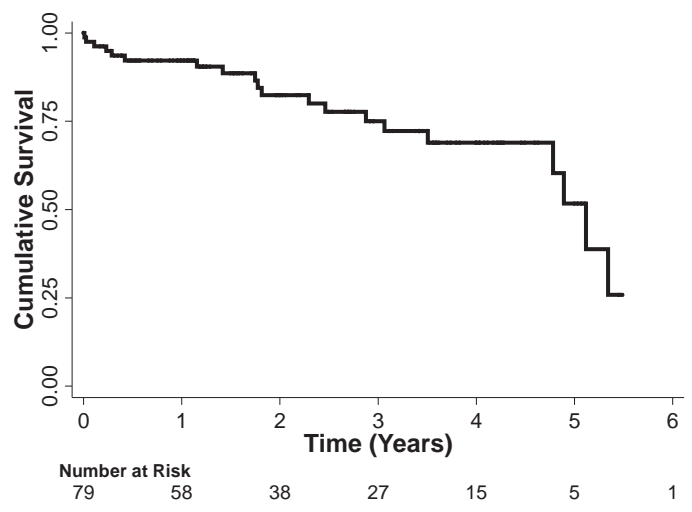

Figure 6.3.4 Time tn technique failure for home hemodialysis cohort.

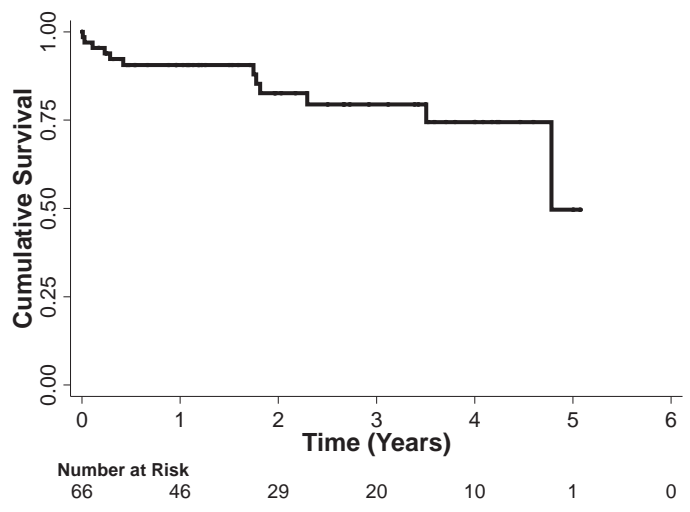

Figure 6.3.5 Time to technique failure for home hemodialysis cohort (era 1999-2012). 


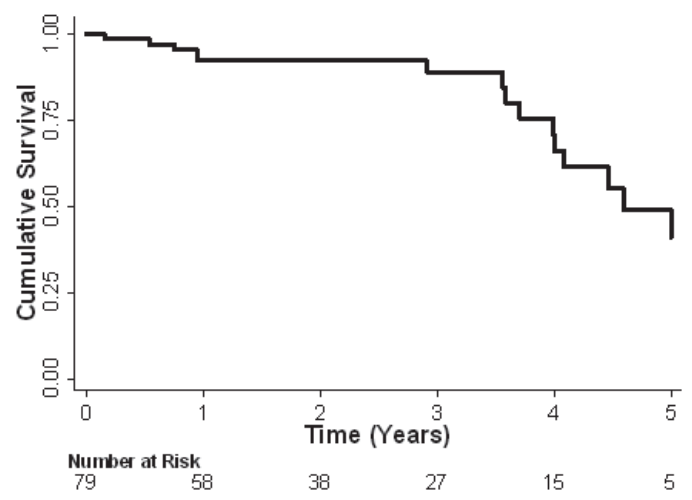

Figure 6.3.6 TIme to death for home hemodialysis cohort

Table 6.3 .3

Adverse events.

\begin{tabular}{ll}
\hline Variable & Value \\
\hline Infections* & 16 \\
Total episodes & 0.09 \\
Total rate (episode/ patient-year of home HD) & 0.03 \\
Rate of access-related infection episodes & 103 \\
Hospitalizations & 0.55 \\
Total episodes & 19 \\
Total rate (episode/ patient-year of home HD) & 8 \\
Reason for hospitalization & 23 \\
$\quad$ Cardiovascular events & 8 \\
$\quad$ Volume overload & \\
Infections & 17 \\
Access-related & 0.09 \\
Cardiovascular events* & \\
Total episodes & 3 \\
Total rate (episode/patient-year of home HD) & 1 \\
Types of cardiovascular events & 8 \\
M yocardial infarction & 6 \\
$\quad$ Stroke & \\
Volume overload & 130 \\
Arrhythmia & 108 \\
Non-infectious vascular access events** & 12 \\
Total episodes & 10 \\
Angioplasty/declot & $31 / 63(49 \%)$ \\
Permanent vascular access loss & \\
Other (bleeding, surgery) & \\
Need for respite care &
\end{tabular}

* Data unavailable for Toronto, Canada. ** Rates were not calculated due to lack of accurate time-at-risk for patients with failed fistulas 


\section{Discussion}

This international multi-centre study represents the largest cohort of ESRD patients older than 65 years starting home HD. Seventy-nine home HD patients had, at a cumulative time risk of 188 years, an event-free survival at 1,2 and 5 years after initiation of home HD of 85,77 and $24 \%$, respectively, and a technique survival of 92 , 83 and $56 \%$, respectively. In an unadjusted analysis, only age was associated with the composite event of death or technique failure.

Our data document the feasibility of home HD in an older ESRD population. Event-free and technique survival in this older ESRD cohort is lower than in younger home HD populations such as in the Canadian nocturnal home HD cohort (mean age 45.7 years) with 1- and 5-year adverse event-free survival of 95.2 and $80.1 \%$, and 1- and 5 -year technique survival of 97.9 and $95.2 \%$, respectively ${ }^{6}$. On the other hand, the results in our cohort seem comparable to the New Zealand elderly home dialysis cohort which reported a 1-, 2- and 3-year patient survival of 90, 84 and 56\% (combined for PD and home HD), and a 1, 2- and 3-year technique survival of 83,73 and $36 \%$ (for home HD alone), respectively ${ }^{7}$. These self-care home dialysis patients in New Zealand had survival rates comparable with national averages, and technique survival rates comparable to in-centre HD treatments. Dialysis therapies were well tolerated and few complications were seen with home HD treatments. Hospital admissions were mainly for vascular access issues, whereas in our study most hospitalizations were due to non-dialysis related causes. The study cohort survival rates are superior to the survival rates of incident dialysis (PD, in-centre HD and home HD) patients reported in the 2001-2005 ERA EDTA Registry, showing adjusted 1-, 2- and 5-year survival of $81.2,67.0$, and $35.8 \%$ for patients $65-74$ years of age, respectively, and $72.8,53.8$, and $19.9 \%$ for patients 75 years of age or older, respectively ${ }^{8}$.

The outcome data in our home HD cohort seem also to be in line with those of the other home dialysis modality, PD, in elderly ESRD cohorts. Yang et al. reported overall survival rates at 1,3 and 5 years of 84,56 , and $38 \%$ among patients $65-74$ years of age; and those among $\geq 75$ years of age were 85,67 , and $42 \%$, respectively ${ }^{9}$. Two-year technique survival was $88 \%$ in patients 65 years of age or older. De Vecchi et al. similarly found $86 \%$ two-year technique survival in PD patients older than 70 years ${ }^{10}$. The Canadian Organ Replacement Register (CORR) reported unadjusted one-year, three-year, and five-year patient survival rates among patients 65-74 years of age of $83.9,52.6$, and $32.2 \%$, whilst those for the $\geq 75$ years group were $76.6,36.7$, and $17.8 \%$, respectively ${ }^{11}$. Of note, the BOLDE (Broadening Options for Long-Term Dialysis in the Elderly) study elucidated that elderly patients on PD potentially have a higher quality of life (lower depression and illness intrusion scores) than elderly patients on $H D^{12}$. 
While home HD is feasible in older ESRD patients, they are also highly selected. Nineteen of the 79 (24\%) patients starting home HD at an age older than 65 years, received a renal transplant while on home $H D$, illustrating the relatively well preserved general condition of the patients in this cohort. Kidney transplantation is indeed an option also in elderly, although higher age and multiple co-comorbities often urge the treating nephrologist to withhold the possibility of renal transplantation from these frail patients. The high transplant rate in our cohort indeed suggests that our patients may not be wholly representative of the general elderly ESRD population. Next, most patients in this international cohort had an AVF as their dialysis access illustrating the possibility of fistula maturation in the elderly ESRD patient but also the feasibility of cannulation at home in these patients. Again, the high AVF prevalence in this study may be a reflection of optimal pre-dialysis preparation and case selection. Also, only few patients in our study were octogenarians. Recent studies and editorials recommend greater thought in the decision making process and choice of vascular access in patients older than 80 years of age, including the consideration of AVG or perhaps central venous catheter as first choice access ${ }^{13,14}$.

The results presented in this work also unveil some potential caveats to increased adoption and implementation of home HD in older ESRD patients, such as caregiver burden and need for increased training time. More than half of the patients in our cohort required home assistance either by the partner or by a dialysis assistant. This number is not unexpected given the fact that age is a predictor of technique failure, which can potentially be overcome by timely assistance by a dialysis nurse $e^{6,15,16}$. Indeeed, prior studies from Toronto have illustrated the possibility of assistance at home increasing the eligibility of ESRD patients to be dialyzed in the home setting ${ }^{17}$. Similarly, in France, assisted PD provided by community nurses has been the standard treatment for many years. Patients receiving assisted PD have survival rates similar to those on in-centre HD and quality of life scores that may be higher than in in-centre $H D^{18}$. The potential of expanding home HD to include nurse-assisted intensive home HD will require considerable investment in infrastructure that needs to be balanced against the perceived benefits.

Interestingly, $35 \%$ of our patients was assisted by a family member. In this context, we know that the caregiver has to be taken care of as much as the patient. In a recent cross-sectional study from Toronto among 36 prevalent nocturnal home HD patients and 31 caregivers, $25 \%$ of caregivers fulfilled depression criteria ${ }^{19}$. The mean age in this Toronto cohort was 52 years for patients and 51 years for caregivers, and hence we could expect the depression prevalence in older patients and their caregivers to be substantially higher, illustrating again the need for adequate physician, nursing, psychological and social worker support for this vulnerable patient and caregiver 
population. A recent analysis of caregiver needs and concerns found that respite services and interventions to manage the emotional responses to caregiving are particularly important ${ }^{20}$.

Median training time for home HD patients in this study was 75 (49-107) days. The Frequent Hemodialysis Network (FHN) Nocturnal Trial showed a mean number of home HD training sessions of $27.7 \pm 10.4$ (range $11-59$ days) ${ }^{21}$. Training time in the FHN study indeed correlated with older patient age. In the New Zealand home HD cohort, the average training time was 5.1 months $^{7}$. Hence, the potential need for extended training time will be an important consideration for planning greater adoption or utilization of home HD in older ESRD patients.

Many aspects of the adoption of home HD in older ESRD patients remain unknown. More research is necessary to ascertain the impact of home HD in elderly on survival, quality of life, hospitalization, vascular access and cost issues. Future studies will also have to address the specific needs in infrastructure of home HD units to support elderly patients undergoing home HD, e.g. training time, availability of backup dialysis, fall back rate and development of user-friendly home HD machines.

Limitations of this study have to be recognized. Firstly, this study is retrospective with a relatively small sample size and few outcomes (therefore our multivariable model may have been an overfit). Outcome data such as patient reported outcomes, quality of life and burden of disease was lacking. We acknowledge that no markers of frailty were available for this analysis. Also, differences in practice patterns among the different centres as well as the extensive period of inclusion (although $84 \%$ of the patients were included after 1999) make uniform interpretation of the results complicated. Since the inclusion of participating centres was based on non-systematic criteria, potentially important information from other home HD centres in the world may be lacking ${ }^{22-25}$. Disparities in outcome among different modalities of home HD could not be investigated due to the relatively small numbers as compared with other studies. Rates of infections that did not require hospitalization may have been underestimated due to lack of consistent documentation. Furthermore, our cohort appeared to be a "young old" group with few patients older than 80 years making generalization of our results to octogenarian ESRD patients difficult. Finally, we lacked a comparator group of PD and in-centre HD patients in this study.

Despite some of the limitations, the study has several strengths and represents the largest cohort in the literature of older ESRD patients on home HD. Since it combines data from several home HD centres from different countries, it confirms the widespread applicability of home HD in older ESRD patients in real-life clinical practice and its settings. So far, experiences of home HD in older ESRD patients have been reported in small patient populations from single centres. Also, we systematically 
examined parameters of home HD feasibility and outcomes, including need for assistance, training time, dialysis access, time to technique failure or death, and adverse events provide valuable insight into these patients on home HD modality.

In conclusion, home HD is feasible and safe in older ESRD patients. Further prospective studies are essential to elucidate the potential beneficial effects of this modality on quality of life and preservation of autonomy and independence in the older dialysis population. More research is needed to verify the potential impact of intensive home $\mathrm{HD}$ on the development of the geriatric syndromes. Finally, the possibility of assistance at home by caregiver and/or dialysis nurse should be evaluated alongside issues such as patient and caregiver burn-out. Further research is necessary to support innovation and long-term sustainablity of the practice of home HD in older patients. 


\section{References}

1. United States Renal Data System: US Renal Data System, USRDS 2010 Annual Data Report: Atlas of EndStage Renal Disease in the United States. Bethesda, National Institutes of Health, National Institute of Diabetes and Digestive and Kidney Diseases, 2010.

2. Schaefer K, von Herrath $D$, Faust J, Röhrich B. The very elderly dialysis patient: indication and discontinuation of dialysis. Int Urol Nephrol 2002;34:573-6.

3. Cornelis T, Kotanko P, Goffin E, van der Sande FM, Kooman JP, Chan CT. Intensive hemodialysis in the (nursing) home: the bright side of geriatric ESRD care? Semin Dial 2012;25:605-10.

4. Cornelis T, Kotanko P, Goffin E, Kooman JP, van der Sande FM, Chan CT. Can intensive hemodialysis prevent loss of functionality in the elderly ESRD patient? Semin Dial 2011; 24:645-52.

5. Cornelis T, van der Sande FM, Kooman JP. Balancing transition to dialysis: the urgent need for more intensive hemodialysis. Kidney Int 2013;83:967-8.

6. Pauly RP, Maximova K, Coppens J, et al. Patient and technique survival among a Canadian multicenter nocturnal home hemodialysis cohort. Clin J Am Soc Nephrol 2010;5:1815-20.

7. M Monald M, M cPhee PD, Walker RJ. Successful self-care home dialysis in the elderly: a single center's experience. Perit Dial Int 1995;15:33-6.

8. ERA-EDTA Registry: ERA-EDTA Registry Annual Report 2011. Academic M edical Center, Department of Medical Informatics, Amsterdam, The Netherlands, 2013.

9. Yang $X$, Fang W, Kothari J, et al. Clinical outcomes of elderly patients undergoing chronic peritoneal dialysis: experiences from one center and a review of the literature. Int urol nephrol 2007;39:1295-302.

10. De Vecchi AF, Maccario M, Braga M, Scalamagna A, Castelnovo C, Ponticelli C. Peritoneal dialysis in nondiabetic patients older than 70 years: comparison with patients aged 40 to 60 years. Am J Kidney Dis 1998;31:479-90.

11. Canadian Organ Replacement Register (CORR) annual report: treatment of end-stage organ failure in Canada, 1995 and 2004. Canadian Institute for Health Information, Don M ills, ON, Canada.

12. Broadening options for long-term dialysis in the elderly (BOLDE): differences in quality of life on peritoneal dialysis compared to hemodialysis for odler patients. Nephrol Dial Transplant 2010;25:375563.

13. Moist LM, Lok CE, Vachharajani TJ, et al. Optimal hemodialysis vascular access in the elderly patient. Semin Dial 2012;25:640-8.

14. DeSilva RN, Patibandla BK, Vin Y, Chawla V, Brown RS, Goldfarb-Rumyantzev AS. Fistula first is not always the best strategy for the elderly. J Am Soc Nephrol 2013;24:1297-304.

15. Jayanti A, Nikam M, Ebah L, Dutton G, Morris J, Mitra S. Technique survival in home haemodialysis: a composite success rate and its risk predictors in a prospective longitudinal cohort from a tertiary renal network programme. Nephrol Dial Transplant 2013;28:2612-20.

16. Schachter ME, Tennankore $\mathrm{KK}$, Chan $\mathrm{CT}$. Determinants of training and technique failure in home hemodialysis. Hemodial Int 2013;17:421-6.

17. Oliver MJ, Quinn R, Richardson EP, Kiss AJ, Lamping DL, Manns BJ. Home care assistance and the utilization of peritoneal dialysis. Kidney Int 2007;71:673-8.

18. Verger C, Ryckelynck JP, Duman M, et al. French Peritoneal Dialysis Registry (RDPLF): outline and main results. Kidney Int Suppl 2006;103:S12-20.

19. Rioux JP, Narayanan R, Chan CT. Caregiver burden among nocturnal home hemodialysis patients. Hemodial Int 2012;16:214-9.

20. Welch JL, Thomas-Hawkins C, Bakas T, et al. Needs, concerns, strategies, and advice of daily home hemodialysis caregivers. Clin Nurs Res 2014;23:644-63.

21. Pipkin M, Eggers PW, Larive B, et al. Recruitment and training for home hemodialysis: experience and lessons from the Nocturnal Dialysis Trail. Clin J Am Soc Nephrol 2010;5:1614-20.

22. Kjellstrand C, Buoncristiani U, Ting G, et al. Survival with short-daily hemodialysis: association of time, site, and dose of dialysis. Hemodial Int 2010;14:464-70.

23. Kjellstrand CM, Buoncristiani U, Ting G, et al. Short daily hemodialysis: survival in 415 patients treated for 1006 patient-years. Nephrol Dial Transplant 2008;23:3283-329. 
24. Walker R, Marshall M, Morton RL, M CFarlane P, Howard K. The cost effectiveness of contemporary home haemodialysis modalities compared to facility haemodialysis: a systematic review of full economic evaluations. Nephrology (Carlton) 2014;19:459-70.

25. Piccoli GB, Ferraresi M, Consiglio V, et al. Why home hemodialysis? A systematic "marketing" analysis. J Nephrol 2012;25:159-69. 


\section{Chapter 7}

Vascular access vulnerability in intensive hemodialysis: a significant Achilles' heel?

Cornelis T, Usvyat LA, Tordoir JH, Wang Y, Wong M, Leunissen KM, van der Sande FM, Kotanko P, Kooman JP 


\section{Abstract}

Background: Frequent hemodialysis may be associated with an increased risk of vascular access complications. Studies addressing vascular access outcomes in frequent hemodialysis show conflicting results.

Methods: We searched Medline for trials looking at vascular access outcomes in frequent hemodialysis.

Results: Nineteen studies met the inclusion criteria; only studies with a control group were included for analysis (15 studies). The vascular access event rate was higher in intensive hemodialysis as compared to conventional hemodialysis (difference of 6.7 events per 100 patient years, $\mathrm{P}=0.009$ ). Overall event rates were not significantly different between conventional and intensive hemodialysis when stratified for access type, but were notably higher in the arteriovenous graft (AVG) and catheter group as compared to the arteriovenous fistula (AVF) group.

Conclusion: Intensive hemodialysis is associated with an increased risk of vascular access complications. Overall reported event rates were lower in the AVF group. Further controlled studies should investigate whether a Fistula First strategy may be recommended also for intensive hemodialysis. 


\section{Introduction}

Hemodialysis (HD) was performed routinely at home in the Seventies of the previous century. Thereafter, for logistic and economic reasons, in-centre conventional HD became the standard of care. In the Nineties, home HD underwent a significant revival under the impulse of Uldall and Pierratos from Toronto, who re-introduced home programs especially because of ample clinical benefits and reduced costs ${ }^{1}$. Initially, home HD was performed with a dialysis catheter as vascular access. The question arose whether the use of arteriovenous fistulas (AVF) would be a potential barrier for home $H D$, especially in frequent $H D$.

Compared with conventional dialysis modalities, intensive HD [i.e. extended and/or frequent $H D$, either as short daily HD (SDHD) or nocturnal HD (NHD)] is associated with multiple clinical benefits, including improved survival, quality of life, blood pressure control, left ventricular hypertrophy, better phosphate control, less sleep abnormalities, and improved fertility and pregnancy outcomes ${ }^{2}$. For these reasons intensive HD has been put forward as the optimal dialysis modality for patients with end-stage renal disease (ESRD). In that vein, we previously recommended that the concept of "intensive HD first" should be an obligatory part of pre-dialysis patients education ${ }^{3}$. However, multiple barriers impede and even prevent the implementation of this strategy. One of the barriers is the creation and maintenance of proper vascular access. If intensive HD would lead to more frequent access events, it might result in increased morbidity, reduced quality of life, and increased resource utilization. In one of the early studies of that topic, Woods et al. reported in 1999 that the number of access events decreased after conversion from conventional $H D$ to daily $\mathrm{HD}^{4}$. This finding was corroborated one year later by Quintaliani et al. ${ }^{5}$. In fact, these 2 studies were anticipated 30 years earlier by DePalma who stated in 1969 that previous shunt failures should be an indication for daily HD; this statement was made in the context of lower ultrafiltration rates and thus reduced rates of intra-dialytic hypotension and shunt thrombosis ${ }^{6}$. However, more recent studies, including the Frequent Hemodialysis Network (FHN) trials, casted doubt on this optimistic view. In the daily FHN trial, patients randomized to intensive HD experienced significantly more arteriovenous access repairs than the patients randomized to conventional HD. Albeit non-significant, comparable trends were observed in the nocturnal FHN trial $^{7}$.

This somewhat ambiguous situation motivated us to review existing trials reporting vascular access outcomes in patients on intensive HD. Recently, a meta-analysis was performed and published by the Canadian Society of Nephrology to inform clinical practice guidelines for the provision of intensive $H D^{8}$. In our review and analysis, we 
focused on access-related hospital admissions, access dysfunction, permanent access failure, and access infections in intensive and conventional HD patients.

\section{Materials and methods}

\section{Research questions}

The primary questions addressed in this review were: (1) what is the published experience with vascular access in intensive HD (SDHD and/or NHD); (2) is there sufficient evidence to conclude that intensive HD is associated with an increased risk of vascular access complications; and (3) do vascular access complications differ between intensive and conventional HD with respect to access type [AVF; arteriovenous grafts (AVG); catheters]?

\section{Included studies}

We included published full-text case series, cohort studies, and randomized controlled trials whenever two investigators independently agreed that the articles reported demographics and access events during a follow-up of 1 month or more in 5 or more adult patients (at least 18 years of age) receiving SDHD or NHD. We included both home and in-centre intensive HD studies. Only studies with a control group (parallel and/or pre-post) were included for the analysis. Reports published in abstract form only were excluded.

\section{Finding relevant studies}

An independent review of citations from MEDLINE (OVID 1966 to April 1, 2013) bibliographic database was conducted by 2 investigators. The search strategy made use of multiple synonyms for the terms dialysis, daily, frequent, intensive, vascular access, dysfunction, infections, hospitalizations, and outcomes.

\section{Statistical analysis}

Studies were analyzed in a combined fashion by computing total number of events and number of access years per study. Separate analyses were performed by access type. Log-linear mixed effects models for Poisson data with the offset of access years and study specific random effects were used to determine differences in event rates between intensive and conventional HD. Log-linear mixed effects models with study specific random effects were also used to assess the association between access 
events, access types, and kind of access dysfunction. Analyses were performed in SAS 9.3 (Cary, NC).

\section{Results}

\section{Description of studies}

Nineteen studies met the inclusion criteria ${ }^{4,5,7,9-25}$. Three studies were excluded because vascular access event rates were not reported ${ }^{26,27}$ or because of missing demographic data $^{28}$. Three studies were randomized controlled trials, 11 were prospective cohort studies and 5 were retrospective cohort studies. Four studies had no control group ${ }^{9-11,18}$ and were not included in the analysis. Table 7.1 summarizes the demographic and treatment characteristics, including weekly dialysis frequency, treatment duration, location (home; in-centre), mean or median time on intensive HD and access type. M ean patient ages ranged from 35.6 to 59.9 years, and the majority of patients were male (range 39.4 to $94 \%$ ). M ean conventional HD vintages ranged from 2.0 to 9.6 years.

\section{Vascular access complications in intensive versus conventional HD}

Table 7.2 summarizes vascular access event rates in intensive and conventional HD programs. Definitions and outcomes varied considerably between studies. To facilitate description of the results, we defined "access dysfunction" as any intervention intended to salvage the access, and "permanent access failure" as any event necessitating placement of a new vascular access. The access type "Access unknown" refers to studies where access type was not specified, whereas the access types "AVF", "AVG" and "Catheter" show results for studies looking at AVF, AVG or catheter only, respectively. Table 7.2 shows the event rates of access-related hospital admissions, access dysfunction, permanent access failure, and access infections by access types. Differences in vascular access event rates between intensive and conventional HD and the respective $p$-values are reported. 


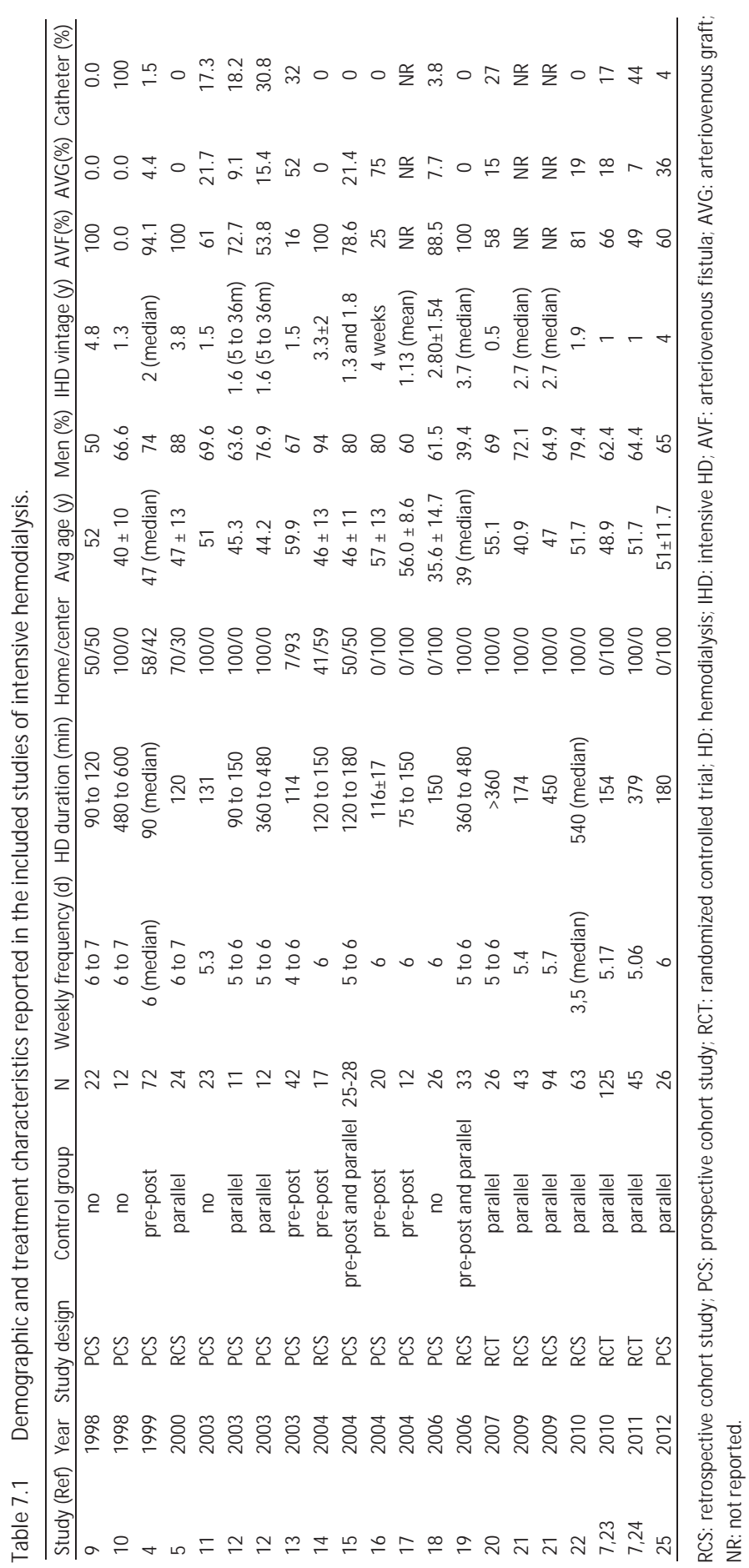




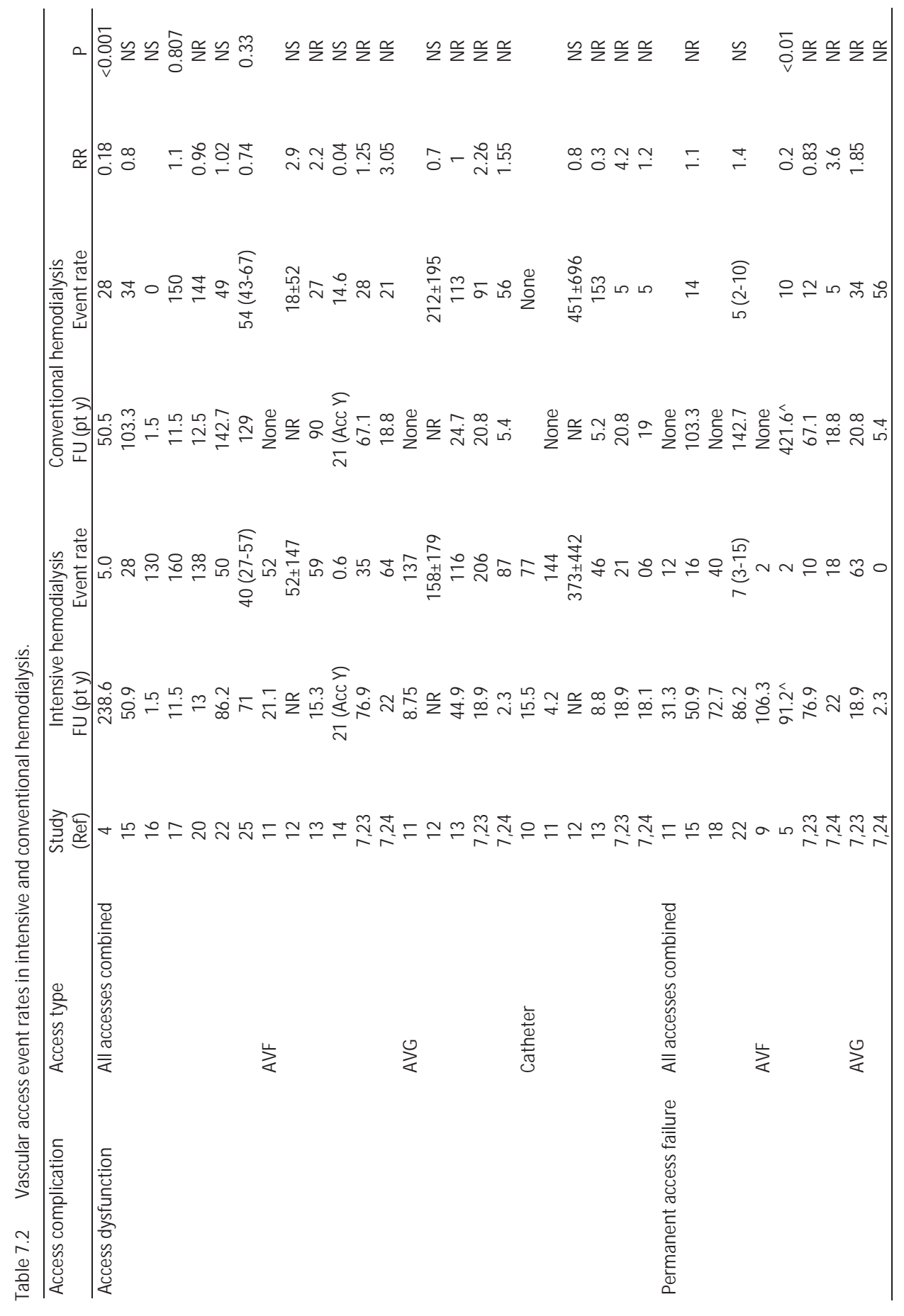




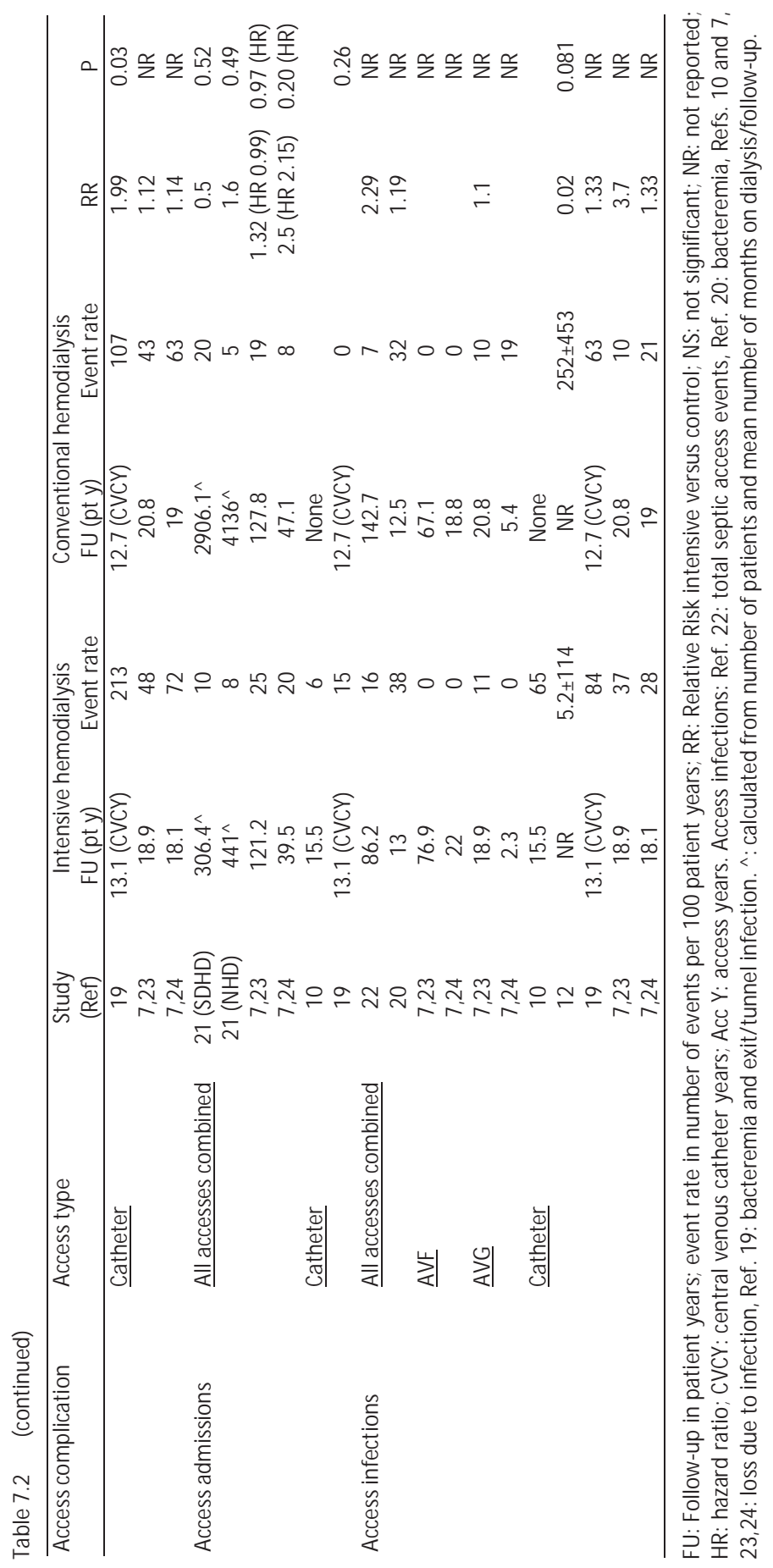


Our analysis, consolidating a total number of 1540 access years for intensive HD and a total number of 2284 access years for conventional HD, indicates that across all access groups and access complications, intensive HD is associated with a higher vascular access event rate as compared with conventional HD (difference $=6.7$ events per 100 patient years, $P=0.009$ for all included studies) (Figure 7.1). Overall event rates in the AVG group (61.0 events per 100 patient years in conventional HD and 98.6 events per 100 patient years in intensive HD) and catheter group (36.0 events per 100 patient years in conventional $H D$ and 52.9 events per 100 patient years in intensive $H D$ ) were higher than in the AVF group. Also, vascular access event rates were higher, although not significant, in patients undergoing intensive HD compared to conventional HD for both the AVG group (difference $=37.6$ events per 100 patient years, $P=0.139$ ) and catheter group (difference $=16.9$ events per 100 patient years, $P=0.133$ ); difference in the AVF group was smaller (difference 2.7, $\mathrm{P}=0.162$ ).

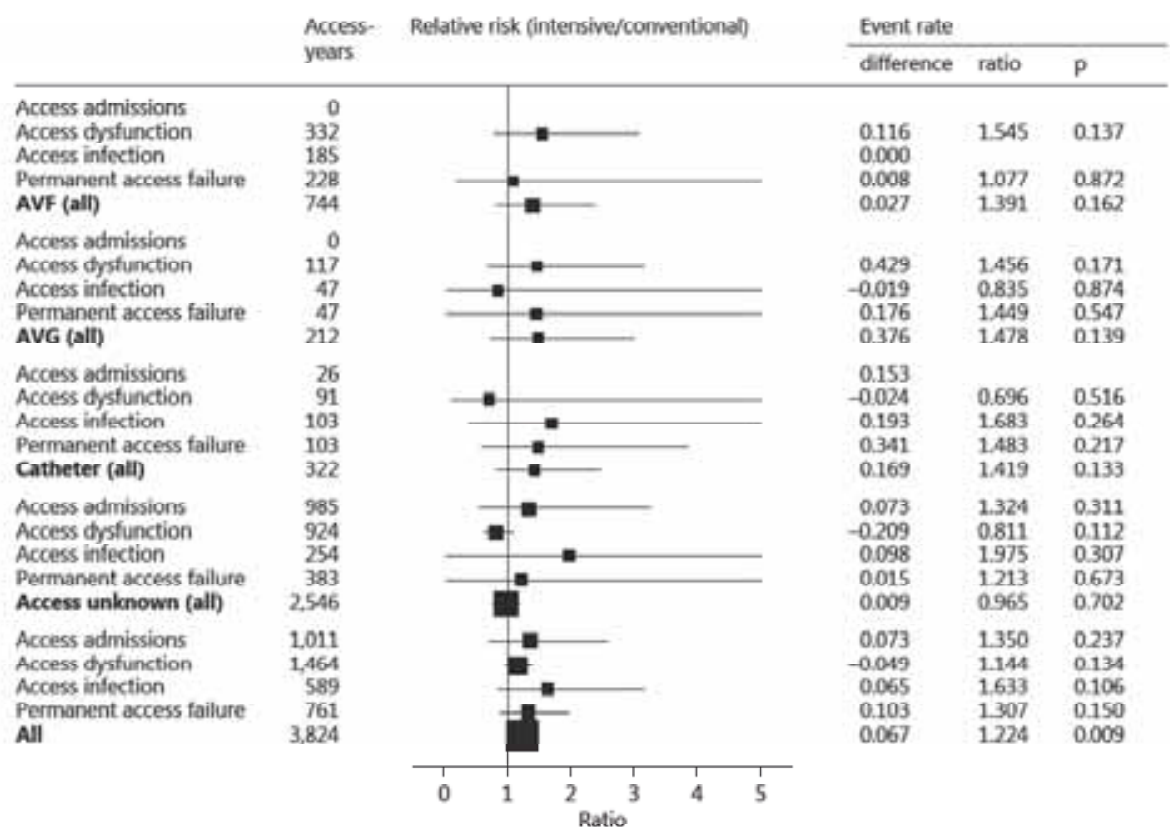

Figure 7.1 Forest plot of vascular access event rates for all accesses in intensive as compared to conventional HD; analysis of studies with a control group only $(n=15)$. There was a significantly higher vascular access event rate in intensive HD as compared to conventional HD looking at all sorts of access complications in all access types together (difference of 0.067 events per patient year, relative risk $=1.224, P=0.009$ ). No difference in vascular access complications between intensive and conventional HD in the different access types could be demonstrated. 


\section{Discussion}

Our review, which comprehensively summarizes the currently published literature on vascular access in intensive HD, suggests an increased risk of vascular access complications in intensive HD as compared to conventional HD. Although the difference in vascular access complications between intensive and conventional HD in our analysis is rather small from a clinical point of view, this finding may have important implications for the adoption of intensive HD, such as an increased need for vascular access vigilance and interventions.

No significant difference in overall vascular access complications was found between intensive and conventional HD looking at patients with AVF, AVG or catheter separately. However, a trend toward more pronounced differences between intensive and conventional HD was observed in the AVG and catheter group as compared to the AVF group. In addition, the reported vascular access event rates in the AVG and catheter group were fare higher as compared to native AVF's, a finding well established in many previous studies and reflected in international and national guidelines ${ }^{29}$. AVG may be especially susceptible to early failure in intensive HD, because more frequent cannulation may promote weakening of the graft. On the other hand in patients treated with intensive HD and catheters as vascular access, the need for more frequent manipulation may increase the risk of catheter-related infections. In line with current recommendations for conventional $H D$, one may be tempted to interpret these results as support for the Fistula First Strategy advocating that AVF should be the vascular access of first choice, also in patients treated with intensive HD, although it should be acknowledged that in no study a randomized head-on comparison between different access types was performed ${ }^{30}$.

Despite the repeated cannulation-induced fistula trauma, the multifactorial pathobiology of access failure may offer an explanation for the relatively low vascular access event rate of AVF in intensive HD. Venous outflow obstruction plays an important role in vascular access failure, and neointimal hyperplasia by vascular smooth muscle and hyperplastic myofibroblasts is central in the genesis of venous outflow stenosis ${ }^{31-35}$. Repeated cannulation of the access triggers the local release of local cytokines which have been implicated in neointimal hyperplasia ${ }^{36}$. However, also poor nutrition, inflammation, atherosclerosis, hemodynamic instability, and uremic toxin levels play a role in vascular access failure ${ }^{37-39}$. Intensive HD may be the best currently available HD modality to protect the vascular access against these potentially damaging factors ${ }^{2}$. Furthermore, hyperhomocysteinemia is associated with vascular access thrombosis in dialysis patients ${ }^{40}$; it was also demonstrated that homocysteine levels are significantly reduced in NHD patients, compared to conventional HD 
patients ${ }^{41}$. These potential protective effects of intensive HD on vascular access seem to be outweighed in patients with AVG and catheters by the increased frequency of cannulation and disconnection resulting in recurrent graft trauma and weakening and access infections, respectively.

Limitations of this review should be appreciated. We were not able to research the patient-specific data. Also, only few studies were randomized controlled trials, as most studies were observational. Furthermore, the included studies varied considerably with respect to patient population; dialysis time, frequency, and location; definition of outcomes; methods of outcome assessment; follow-up times; and methodological design. This heterogeneity is likely one factor contributing to the inconsistency of results observed. Thus, in the absence of randomized trials, several aspects of vascular access in intensive HD remain uncertain and deserve further study in future trials. The ideal vascular access type in intensive HD has yet to be defined, and may depend upon individual clinical parameters such as age, co-morbidities, immunosuppressive medications, and personal preference.

In conclusion, our analysis shows an overall higher rate of vascular access complications in patients treated with intensive HD as compared to conventional HD. However, in patients with AVF, the event rates were relatively low both in conventional and intensive HD. Further studies are required to investigate whether AVF may be the vascular access of first choice, also for intensive HD. 


\section{References}

1. Uldall R, Ouwendyk M, Francoeur R, Wallace L, Sit W, Vas S, Pierratos A. Slow nocturnal home hemodialysis at the Wellesley Hospital. Adv Ren Replace Ther 1996;3:133-6.

2. Perl J, Chan CT. Home hemodialysis, daily hemodialysis, and nocturnal hemodialysis: core curriculum 2009. Am J Kidney Dis 2009;54:1171-84.

3. Cornelis T, Kooistra MP, Kooman JP, Leunissen KM, Chan CT, van der Sande FM. Education of ESRD patients on dialysis modality selection: "Intensive HD first". Nephrol Dial Transplant 2010;25:129-30.

4. Woods JD, Port FK, Orzol S, Buoncristiani U, Young E, Wolfe RA, Held PJ. Clinical and biochemical correlates of starting "daily" hemodialysis. Kidney Int 1999;55:2467-76.

5. Quintaliani G, Buoncristiani U, Fagugli R, Kulurianu H, Ciao G, Rondini L, Lowenthal DT, Reboldi G. Survival of vascular access during daily and three times a week hemodialysis. Clin Nephrol 2000;5:3727.

6. DePalma JR, Pecker EA, Maxwell MH. A new automatic coil dialyzer system for "daily" dialysis. Proc Eur Dial Transplant Assoc 1969;6:26-34.

7. Suri RS, Larive B, Sherer S, Eggers P, Gassman J, James SH, Lindsay RM, Lockridge RS, Ornt DB, Rocco MV, Ting GO, Kliger AS, and the Frequent Hemodialysis Network Trial Group. Risk of vascular access complications with frequent hemodialysis. J Am Soc Nephrol 2013;24:498-505.

8. Mustafa RA, Zimmerman D, Rioux J-P, Suri RS, Gangji A, Steele A, MacRae J, Pauly RP, Perkins DN, Chan CT, Copland M, Komenda P, M cFarlane PA, Lindsay R, Pierratos A, Nesrallah GE. Vascular access for intensive maintenance hemodialysis: a systematic review for the Canadian Society of Nephrology Clincial Practice Guideline. Am J Kidney Dis 2013;62:112-31.

9. Pinciaroli A. Results of daily hemodialysis in Catanzaro: a 12-year experience with 22 patients treated for more than 1 year. Home Hemodial Int 1998;2:12-7.

10. Pierratos A, Ouwendyk M, Francoeur R, Vas S, Rai DSC, Ecclestone A-M, Langos V, Uldall R. Nocturnal hemodialysis: three-year experience. J Am Soc Nephrol 1998;9:859-68.

11. Kjellstrand CM, Blagg CR, Twardowski Z), Bower J. Blood access and daily hemodialysis: clinical experience and review of the literature. ASAIO Journal 2003;49:645-9.

12. Lindsay $R$, Leitch $R$, Heidenheim $P$, Kortas $C$. The London daily/nocturnal hemodialysis study-study design, morbidity, and mortality results. Am J Kidney Dis 2003;42(S1):S5-12.

13. Ting GO, Kjellstrand C, Freitas T, Carrie BJ, Zarghamee S. Long-term study of high-comorbidity ESRD patients converted from conventional to short daily hemodialysis. Am J Kidney Dis 2003;42:1020-35.

14. Traeger J, Galland R, Delawari E, Arkouche W, Hadden R. Six years' experience with short daily hemodialysis: do the early improvements persist in the mid and long term? Hemodial Int 2004;8:151-8.

15. Piccoli GB, Bermond F, Mezza E, Burdese M, Fop F, Mangiarotti G, Pacitti A, Maffei S, et al. Vascular access survival and morbidity on daily dialysis: a comparative analysis of home and limited care hemodialysis. Nephrol Dial Transplant 2004;19:2084-94.

16. Williams AW, Chebrolu SB, Ing TS, Ting G, Blagg CR, Twardowski Z), Woredekal Y, Delano B, Gandhi VC, Kjellstrand CM . Early clinical, quality-of-life, and biochemical changes of "daily hemodialysis" (6 dialyses per week). Am J Kidney Dis 2004;43:90-102.

17. Reynolds JT, Homel P, Cantey L, Evans E, Harding P, Gotch F, Wuerth D, Finkelstein S, Levin N, Kliger A, Simon DB, Finkelstein FO. A one-year trial of in-center daily hemodialysis with an emphasis on quality of life. Blood Purif 2004;22:320-8.

18. Martins Castro MC, Luders C, Elias RM, Abensur H, Romao Junior JE. High-efficiency short daily haemodialysis-morbidity and mortality rate in a long-term study. Nephrol Dial Transplant 2006;21:2232-8.

19. Perl J, Lok CE, Chan CT. Central venous catheter outcomes in nocturnal hemodialysis. Kidney Int 2006;70:1348-54.

20. Culleton BF, Walsh M, Klarenbach SW, Mortis G, Scott-Douglas N, Quinn RR, Tonelli M, Donnelly S et al. Effect of frequent nocturnal hemodialysis versus conventional hemodialysis on left ventricular mass and quality of life: a randomized controlled trial. JAM A 2007;298:1291-9. 
21. Johansen KL, Zhang R, Huang Y, Chen S-C, Blagg CR, Goldfarb-Rumyantzev AS, Hoy CD, Lockridge RS, Miller BW, et al. Survival and hospitalization among patients using nocturnal and short daily compared to conventional hemodialysis: a USRDS study. Kidney Int 2009;76:984-90.

22. van Eps C, Jones M, Ng T, Johnson DW, Campbell SB, Isbel NM, Mudge DW, Beller E, Hawley CM. The impact of extended-hours home hemodialysis and buttonhole cannulation technique on hospitalization rates for septic events related to dialysis access. Hemodial Int 2010;14:451-63.

23. Chertow GM, Levin NW, Depner TA, Eggers PW, Gassman JJ, Gorodetskaya I, Greene T, James S et al. Incenter hemodialysis six times per week versus three times per week. N Engl J M ed 2010;363:2287-300.

24. Rocco MV, Lockridge RS, Beck GJ, Eggers PW, Gassman JJ, Greene T, Larive B, Chan CT, Chertow GM et al. The effects of frequent nocturnal home hemodialysis: the Frequent Hemodialysis Network Nocturnal Trial. Kidney Int 2011;80:1080-91.

25. Achinger S, Ikizler TA, Bian A, Shintani A, Ayus JC. Long-term effects of daily hemodialysis on vascular access outcomes; a prospective controlled study. Hemodial Int 2013;17:208-15.

26. Goldfarb-Rumyantzev AS, Leypoldt JK, Nelson N, Kutner NG, Cheung AK. A cross-over study of short daily hemodialysis. Nephrol Dial Transplant 2006;21:166-75.

27. Jun M, Jardine M J, Gray N, M asterson R, Kerr PG, Agar JW, Hawley CM, van Eps C, Cass A, Gallagher M, Perkovic V. Outcomes of extended-hours hemodialysis performed predominantly at home. Am J Kidney Dis 2013;61:247-53.

28. Pipkin M, Craft V, Spencer M, Lockridge RJ Jr. Six years of experience with nightly home hemodialysis access. Hemodial Int 2004;8:249-353.

29. NKF-K/DOQI Clinical Practice Guidelines For Vascular Access: Update 2006. Guideline 8: Clinical outcome goals, 8.1 goals for access placement, 8.1.2 prevalent functional AVF placement rate.

30. Allon M, Robbin M L. Increasing arteriovenous fistulas in hemodialysis patients: problems and solutions. Kidney Int 2002; 62:1109-24.

31. Roy-Chaudhury P, Sukhatme VP, Cheung AK. Hemodialysis vascular access dysfunction: a cellular and molecular viewpoint. J Am Soc Nephrol 2006;17:1112-27.

32. Weiss MF, Scivittaro V, Anderson JM. Oxidative stress and increased expression of growth factors in lesions of failed hemodialysis access. Am J Kidney Dis 2001;37:970-80.

33. Roy-Chaudhury P, Kelly BS, Miller M A, Reaves A, Armstrong J, Nanayakkara N, Heffelfinger SC. Venous neointimal hyperplasia in polytetrafluoroethylene dialysis grafts. Kidney Int 2001;59:2325-34.

34. Stracke S, Konner K, Köstlin I, Friedl R, Jehle PM, Hombach V, Keller F, Waltenberger J. Increased expression of TGF-betal and IGF-I in inflammatory stenotic lesions of hemodialysis fistulas. Kidney Int 2002;61:1011-9.

35. Swedberg SH, Brown BG, Sigley R, Wight TN, Gordon D, Nicholls SC. Intimal fibromuscular hyperplasia at the venous anastomosis of PTFE grafts in hemodialysis patients. Clinical, immunocytochemical, light and electron microscopic assessment. Circulation 1989;80:1726-36.

36. Albers FJ. Causes of hemodialysis access failure. Adv Ren Replace Ther 1994;1:107-18.

37. Chen HY, Chiu YL, Chuang YF, et al. Association of low serum fetuin A levels with poor arteriovenous access patency in patients undergoing maintenance hemodialysis. Am J Kidney Dis 2010;56:720-7.

38. Gagliardi GM, Rossi S, Condino F, et al. Malnutrition, infection and arteriovenous fistula failure: is there a link? J Vasc Access 2010;12:57-62.

39. Chou CY, Liu JH, Kuo HL, et al. The association between pulse pressure and vascular access thrombosis in chronic hemodialysis patients. Hypertens Res 2009;32:712-5.

40. Mallamaci F, Bonanno G, Seminara G, Rapisarda F, Fatuzzo P, Candela V, Scudo P, Spoto B, Testa A, Tripepi G, Tech S, Zoccali C. Hyperhomocysteinemia and arteriovenous fistula thrombosis in hemodialysis patients. Am J Kidney Dis 2005;45:702-7.

41. Friedman AN, Bostom AG, Levey AS, Rosenberg IH, Selhub J, Pierratos A. Plasma total homocysteine levels among patients undergoing nocturnal versus standard hemodialysis. J Am Soc Nephrol 2002;13:265-8. 


\section{Chapter 8}

Summary, conclusions and future perspectives 



\section{Summary}

Hemodialysis (HD) was performed routinely at home in the seventies of the twentieth century. Thereafter, for logistic and economic reasons, in-centre conventional HD became the standard of care for patients with end-stage renal disease (ESRD). In the nineties, home HD underwent a significant revival under the impulse of Uldall and Pierratos from Toronto, who re-introduced home (nocturnal) programs especially because of ample clinical benefits and reduced costs ${ }^{1,2}$. Home HD facilitates intensive (increased frequency and/or duration of HD session) HD since it eliminates the need for transport to the dialysis centre. The benefits of intensive HD range from improved blood pressure (BP) and phosphate control and reduction of left ventricular hypertrophy (LVH) to improved sleep quality, higher kidney-related quality of life and potentially better survival rates compared to conventional HD, as discussed in CHAPTER 1. On the other hand, intensive HD may also put the patient at an increased risk of adverse events. These may include vascular access complications (because of frequent cannulation and/or long needle dwell times) and expedited loss of residual kidney function [as was recently suggested by the Nocturnal arm of the Frequent Hemodialysis Network (FHN) trial] $]^{3,4}$. Both clinical benefits and risks-barriers of intensive (home) HD represent an opportunity for continuous research and quality optimization initiatives to further encourage the adoption of intensive home HD in the general dialysis population as well as in specific patient groups. In this setting, we opted to study both acute effects and long-term outcomes of intensive (home) HD.

In the FIRST PART of the thesis, we studied the acute effects of intensive HD in prevalent conventional HD patients in the Acute INTHEM O (INTensive HEM Odialysis) Study. In this randomized crossover trial, 13 prevalent conventional HD patients underwent, in random order, a single session of 4 hour $\mathrm{HD}$, a single session of 4 hour hemodiafiltration (HDF), a single session of 8 hour HD, and a single session of 8 hour HDF with a 2-week interval in between the study sessions in which they received their routine conventional HD treatments. In chapter 2 , the acute effects on hemodynamics and on uremic toxins [small solutes and middle molecules beta2-microglobulin (B2M) and Fibroblast Growth Factor-23 (FGF-23)] of the respective four sessions were compared. In chapter 3 , the acute effects on non-traditional uremic toxins [proteinbound uremic toxins (PBUT), dicarbonyl stress compounds, and advanced glycation endproducts (AGES)] of the four modalities were assessed.

In CHAPTER 2, we found that extended dialysis (8 hour HD and 8 hour HDF) associated with improved intra-dialytic stability of peripheral and central BP. No differences 
between HD and HDF on hemodynamic control were observed. Improved hemodynamic control was likely related to better cardiac output (CO) preservation in long-hour dialysis, which seemed to result from slower relative blood volume (RBV) decline due to increased capillary refill. This latter finding is in line with the study from Basile et al. showing better plasma volume preservation with long-hour $\mathrm{HD}^{5}$. This was not yet linked to CO stability, and no study before has analyzed the effects of long-hour HDF on RBV and CO preservation and on intra-dialytic BP stability. Some previous studies suggested that conventional hemofiltration and HDF allow improved cardiovascular stability, resulting in a reduction of intradialytic hypotension compared to $H D^{6,7}$. Other studies demonstrated that in low temperature $H D$ the same hemodynamic stability can be obtained as in hemofiltration and HDF probably due to improved vascular reactivity ${ }^{8,9}$. Donauer and colleagues showed that online HDF had a more pronounced cooling effect due to additional energy loss through the infusion line $^{9}$. We found no difference in energy transfer rate between the different treatments, including both HDF prescriptions. The lack of difference in our study between HD and HDF is most likely due to the usage of lower dialysate temperatures as compared to previous studies, in which the effect of additional energy loss through the infusion line may have been less pronounced.

Also in chapter 2, we studied the clearance of small and middle molecules in the 4 different modalities. No differences in total solute removal (TSR) for urea, creatinine, uric acid and phosphate were found between HD and HDF, but longer treatments resulted in the highest values. The absence of difference in phosphate removal between HD and HDF in our report, as opposed to previous reports ${ }^{10-12}$, could be explained by the usage of high-flux membranes, and also by the use of relatively low convective volumes during HDF. As expected because of the additional effect of convection on the clearance of middle molecules, reduction ratios (RRs) of B2M and FGF-23 were higher in HDF than in HD and superior for extended HDF ${ }^{13,14}$. Total removal of B2M was superior in the extended HDF sessions.

In CHAPTER 3, we studied RR and TSR of PBUT, dicarbonyl stress compounds and AGES in the acute INTHEMO Study. These non-traditional uremic toxins are associated with inflammation, oxidative stress and cardiovascular morbidity and mortality in patients with chronic kidney disease (CKD). We demonstrated, for the first time, increased reduction and removal of the non-traditional uremic toxins by extending dialysis session time, if blood and dialysate flow are kept at 300 and $500 \mathrm{ml} / \mathrm{min}$ respectively. This finding is in contrast with data from Basile et al. who observed no increased removal of indole-3 acetic acid (IAA), indoxyl sulfate (IS), hippuric acid (HA) and homocysteine during 8 hours of slow-flow dialysis with the Genius device and high-flux 
membranes, however while using blood and dialysate flows of $190 \mathrm{ml} / \mathrm{min}^{15}$. The clearance of hippuric, indolic and phenolic PBUT is mainly diffusive, and thus depends on blood and dialysate flows ${ }^{16,17}$. Increasing dialysis time while maintaining blood flow will progressively lower free PBUT levels, facilitating dissociation of bound toxins from albumin resulting in continued availability of these toxins for diffusion to the dialysate. Whereas in chapter 2 a large increase in RR and/or TSR of the middle molecules FGF23 and B2M with the addition of convection by HDF compared to HD was shown, both during long and short treatment times, the additive effect of convection on PBUT was smaller. This could be explained by the fact that HDF especially contributes to optimized removal of middle molecules whereas the additional effect on small molecules (such as the free fraction of PBUT) is limited. RR and TSR of dicarbonyl products and free AGEs were also significantly enhanced by increasing treatment time. Convection had an additional effect on RR of free $\mathrm{N}$-carboxymethyl-lysine $(\mathrm{CM} \mathrm{L})$ and $\mathrm{N}$-carboxyethyl-lysine (CEL). A recent meta-analysis showed a significant reduction in pre-dialytic plasma levels of pentosidine, but not in the RR of pentosidine and AGES with high-flux HD or HDF as compared to low-flux $H D^{13}$, suggesting that other mechanisms (e.g. a decrease in inflammation) may be involved in the beneficial effects of these treatments on AGE levels. The long-term effects of extended HD and HDF on levels of these non-traditional toxins and their potential association with better cardiovascular protection and lower survival rates in intensive dialysis require further prospective investigation.

In the SECOND PART of this thesis, we evaluated the long-term effects of intensive HD. Because most previous studies on benefits and barriers-risks of intensive HD were performed in the general dialysis population, we chose to evaluate the long-term effects of intensive HD in three specific vulnerable patient populations.

The first group of vulnerable patients studied in this thesis, were patients who developed ESRD after non-renal solid organ transplantation (NRSOT). These patients often have multiple co-morbidities including diabetes mellitus, hypertension and arterial hypertension. The impact of the choice of the dialysis modality in NRSOT patients with ESRD is unknown. Renal registry data suggest that home dialysis including peritoneal dialysis (PD) is underused in the setting of NRSOT, potentially because of perceptions of infectious complications and poor technique survival ${ }^{18-20}$. Heterogeneous results favoring both PD or HD provide no uniform recommendation for this vulnerable patient population, and no study had evaluated the possibility of home HD in patients who develop ESRD after NRSOT. The second group of vulnerable dialysis patients analyzed in this thesis, are women with ESRD who want to become pregnant or who are pregnant. The first successful pregnancy reported in a patient on chronic HD 
occurred in $1970^{21}$. Initial enthusiasm was tempered with subsequent studies indicating pregnancy in women with ESRD to be uncommon due to decreased fertility, and often associated with poor outcomes such as reduced live birth rate, low birth weight and preeclampsia ${ }^{22-28}$. However, recent data showed that frequent nocturnal HD (NHD), as an intensive dialysis modality, resulted in reduced maternal and fetal complications in pregnant ESRD patients ${ }^{29}$. The third and last group of vulnerable ESRD patients studied in this thesis, are older patients on dialysis. The number of elderly patients with ESRD requiring dialysis initiation is steadily increasing ${ }^{30,31}$. ESRD and dialysis initiation in elderly are often accompanied by loss of independence ${ }^{32,33}$. This suggests that elderly patients are less likely to overcome events occurring around the time of dialysis initiation as compared to younger patients. The events leading to functional decline may include dialysis-related hypotension, cerebral and cardiac events, as well as malnutrition and increased infection risk. We speculate that more frequent and/or longer HD sessions may reduce the severity of internal environment dysregulation, and hence be of particular benefit in the elderly ESRD patient.

In CHAPTER 4, we described our experience with home dialysis (intensive home HD and PD) for patients who developed ESRD after NRSOT. This study provided the longest follow-up (median 24 months) of home dialysis in NRSOT recipients. The data showed that home dialysis is a feasible and sustainable modality in patients who develop ESRD after NRSOT, and also that home dialysis might provide specific benefits for this particular patient population. Nocturnal home HD is indeed associated with several potential benefits including improved BP control ${ }^{34}$, regression of LVH and improved left ventricular ejection fraction ${ }^{35,36}$, optimization of phosphate control ${ }^{37}$, and improved survival compared to conventional $H D^{38}$. Our home dialysis cohort had $\mathrm{BP}$ and laboratory parameters within the K/DOQI targets for the first two years of follow-up ${ }^{39-}$ ${ }^{41}$. These benefits of home dialysis are pivotal in the management of NRSOT patients who might benefit from optimized hemodynamic stability and from improved metabolic control which is essential in the context of the metabolic side effects of calcineurin inhibitors. Based on our results, home dialysis should be considered as a first line therapy for NRSOT patients developing ESRD. Patients should be educated about home dialysis to provide the renal replacement therapy (RRT) best suited to their lifestyle and medical conditions ${ }^{42,43}$. The promotion of home dialysis in this vulnerable population may help to preserve their quality of life, which should be examined in future studies. 
In CHAPTER 5, the effects of intensive HD on fertility and pregnancy were studied. In CHAPTER 5.1, improved pregnancy outcomes were observed in intensive HD compared to conventional HD. The live birth rate in the intensive HD cohort (86.4\%) was significantly higher than in the conventional cohort (61.4\%; $P=0.03)$. Furthermore, among women with established ESRD, the duration of pregnancy was longer in the intensive home HD cohort at 36 weeks (IQR, 32-37) compared with 27 weeks (IQR, 21$35)$ in the conventional $H D$ cohort $(P=0.002)$. Maternal and neonatal complications were few and manageable in the intensive home HD cohort. Also, a dose response between dialysis intensity and pregnancy outcomes emerged, with highest live birth rates in women dialyzed more than 36 hours per week and with longer gestational age and greater infant birth weight for women dialyzed more intensively. We speculate that an intensified dialysis dose may play an important role by providing a healthy maternal environment for normal placental development. In women with established ESRD, it would appear that more intensive HD is necessary to optimize outcome, because women receiving the highest amounts of HD had significantly better live birth rates, longer gestational ages, and thus bigger babies. There are a number of other potential mechanisms wherein intensive dialysis regimens might improve pregnancy outcome. Studies in NHD patients have demonstrated advantageous effects, including clinical (BP, $\mathrm{LVH}$ ), biochemical (uremic toxin clearance, anemia) and biological parameters (endothelial function, inflammation) ${ }^{44}$, which may all contribute to improved pregnancy outcomes. The success of intensified regimens seems directly related to the removal of low MW uremic toxins such as urea, althought this does not preclude the effects of larger toxins. In a series of 28 pregnant women receiving HD with 18 surviving infants, a significant negative relationship was noted between blood urea nitrogen (BUN) and birth weight $(r=0.53, P=0.02)$ as well as gestational age $(r=0.50, P=0.02)^{45}$. A birth weight of at least $1500 \mathrm{~g}$ was achieved at a BUN $<49 \mathrm{mg} / \mathrm{dl}$ (urea $17.9 \mathrm{mmol} / \mathrm{l}$ ) and a gestational age of at least 32 weeks was achieved at a BUN $<48 \mathrm{mg} / \mathrm{dl}$ (urea $17.1 \mathrm{mmol} / \mathrm{l}$ ). Furthermore, residual renal function has been demonstrated to improve pregnancy outcomes, with significant discrepancies in live birth rates that favored women who conceived before the initiation of dialysis compared with established dialysis patients ${ }^{28,46}$. Our study confirmed the importance of enhanced clearance with improved live birth rates among women with residual renal function and intensified dialysis regimens. Dialysis dose should be titrated to maintain optimal metabolic control, with women with more residual kidney function requiring less intensive dialysis.

In CHAPTER 5.2, we demonstrated that intensified delivery of dialysis appears to improve the rate of conception compared to conventional dialysis strategies. Eleven 
pregnancies occurred while the women were stable on NHD. Till December 2011, 50 women of childbearing age ( $\leq 45$ years) had been trained through the Toronto NHD programs resulting in a conception rate of $22 \%$. Women with ESRD have gonadal dysfunction manifested as anovulation, irregular menses, sexual dysfunction and earlier onset of menopause. Pregnancy, therefore, is uncommon in women on dialysis with

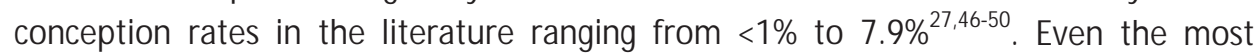
complete registry data collected from all HD units in Belgium in $1996^{28}$, including all 32 dialysis centres, representing 4135 patients of which 1472 were women of childbearing age, noted an incidence rate of pregnancy progressing beyond the first trimester to be only 0.3 per 100 patient years. In the most recent analysis of this topic, from the Australian and New Zealand Dialysis and Transplant (ANZDATA) Registry, the pregnancy rate in dialyzed women in the era 1996-2008 was 3.3 per 1000 person-years ${ }^{51}$. Thus, our data also represents the highest conception rates reported in the literature to date. Further, most of these women were previously on conventional HD for prolonged periods, but none conceived. Thus, more intensive clearance normalizes the female menstrual cycle $e^{52}$ and fertility can be restored.

Also in chapter 5.2, we described the results of the obstetrical follow-up of the pregnancies. We showed that the median results of individual first trimester screen (FTS) and maternal serum screen (MSS) parameters, placental length and thickness as well as median uterine and umbilical artery pulsatility indices and median cervical length were largely within the normal ranges in these pregnancies, demonstrating overall adequate placental growth and perfusion. Also, serial fetal growth assessments progressed on average along the $50^{\text {th }}$ centile except for 1 pregnancy complicated by intra-uterine growth retardation. Placental pathology was available in 8 cases and the vast majority revealed no salient findings. These normal results of obstetrical parameters during pregnancy follow-up are in line with the improved pregnancy outcomes during intensive home HD as demonstrated in chapter 5.1.

Improved endothelial function may assist with healthy placental implantation and prevent preeclampsia. NHD has a proven vascular benefit. Significant decreases in peripheral vascular resistance have been noted along with improvements in markers of endothelial function including baroreceptor sensitivity, restoration of endothelial progenitor cells and endothelium-dependent vasodilatation ${ }^{53-55}$. It was previously demonstrated that endothelium-dependent vasodilatation cannot be elicited in patients on conventional HD, but was restored shortly (2 months) after initiation of a more intensive NHD regimen highlighting the importance of establishing adequate dialysis prior to conception to assist with adequate placental implantation ${ }^{34}$. In CHAPTER 5.3, we illustrated the protective effects of intensive HD on endothelial 
function and $\mathrm{BP}$, in a patient started on intensive $\mathrm{HD}$ at week 26 of gestation, by the stable results of the weekly measurements of 24 -hour BP as well as hemodynamic and arterial stiffness parameters, in combination with comparable serial results of the angiogenic balance of soluble fms-like tyrosine kinase (sFlt-1) / Placental Growth Factor (PIGF) to normal pregnancies. Especially in the anuric pregnant dialysis population, the clinical diagnosis of preeclampsia may be extremely challenging. In these patients, monitoring (anti-) angiogenic factor levels may therefore have a role. Shan et al. reported on a pregnant dialysis patient with uncontrollable hypertension at 29 weeks gestation ${ }^{56}$. A caesarean section was performed. However, placenta pathology did not reveal abnormalities suggestive of preeclampsia, and retrospective analysis of antepartum sFlt-1 and soluble endoglin levels showed values comparable to normal pregnancies. Volume overload rather than preeclampsia was the cause of hypertension in that patient. Two other studies confirmed the use of antiangiogenic factors as a reliable tool in the assessment of preeclampsia ${ }^{57,58}$. Furthermore, it was recently elegantly demonstrated that (anti-) angiogenic factor levels may be very useful to discriminate between chronic kidney disease (CKD) and preeclampsia ${ }^{59}$. The serial use of the described cardiovascular measurements, in combination with serial follow-up of the angiogenic balance of sFIt-1/PIGF, may be valuable additions to the arsenal of clinical and technical tools which are currently used in the meticulous follow-up of these complicated patients $5^{57,58,60,61}$. Large prospective studies are necessary to investigate the potential additional benefit of serial measurement of antiangiogenic factors as well as 24-hour BP and central hemodynamics in the management of pregnant dialysis patients.

In CHAPTER 6, we dicussed the potential role of intensive HD for older ESRD patients. In CHAPTER 6.1, we speculated on the potential underlying mechanisms of the development of geriatric syndromes including frailty in elderly after the start of dialysis. These mechanisms may include intra-dialytic hemodynamic instability, cardiac events and cerebral disturbances. Also malnutrition, inflammation, sleep disorders and psychological complications of dialysis initiation may contribute to loss of functionality in this vulnerable patient population. We also hypothesized that intensive HD may potentially protect older ESRD patients against these geriatric syndromes by reducing the incidence of the aforementioned dialysis complications based on the established benefits of intensive HD. These advantages of intensive HD resulting in protection against the geriatric syndromes may include lower ultrafiltration rates, reduction of arterial BP and LVH, improvement of endothelial and autonomous nervous system function, protection against myocardial stunning, and reduction of sleep apnea ${ }^{5,34,36,37,55,62-72}$. 
In CHAPTER 6.2, we discussed practical aspects and future perspectives of intensive home HD in elderly. It is often perceived that elderly ESRD patients have a lower propensity for self-care dialysis treatments because of a higher number of comorbidities, a higher risk of cognitive dysfunction, increased levels of frailty and potential sensorial disturbances ${ }^{73}$. Survival of elderly patients on home dialysis has been especially studied in PD. In a small study from New Zealand, 25 self-care home dialysis (PD and HD) patients had survival rates comparable with national averages ${ }^{74}$. Recent studies have elucidated that in elderly the illness and treatment intrusion levels are lower in home dialysis (especially PD) than in in-centre HD treatments ${ }^{75,76}$. The feasibility of home dialysis in older dialysis patients is demonstrated by relatively high numbers of home treatments in Australia and New Zealand where $24 \%$ ( 4 and $20 \%$ ) and $47 \%$ ( 8 and $39 \%$ ) of older patients are on home dialysis (home HD and PD) respectively ${ }^{77}$. Attempts to involve the elderly patient in the self-care dialysis should be made in order to increase participation in the dialysis treatments. However, the possibility of assistance at home increases the eligibility of dialysis patients to dialyze at home ${ }^{78}$. When considering home treatments in elderly people, it is extremely important to also consider the caregiver of the dialysis patient. Caregivers often experience emotional stress, anxiety, depression and worsening health, and they also report feelings of isolation and exhaustion ${ }^{79}$. Therefore, pre-dialysis assessment by the social worker of the home situation is crucial to evaluate the resilience of the patient but also the caregiver of the ESRD patient in order to avoid unnecessary ordeals and to involve professional caregivers instead. Many elderly ESRD patients reside in an extended care facility. HD treatments may also take place in the nursing home. Dialysis patients from the same area could then be admitted to one single nursing home where the dialysis expertise is present. Nursing home HD may alleviate the transportation burden, which has an enormous impact on the quality of life of these patients by interfering with valuable rehabilitation needs, social interaction and meals. Furthermore, it may lower the costs of HD treatments dramatically, since specialized vans for wheelchair transport or ambulances are often necessary for the nursing home patients. Also, NHD may allow a minimum amount of dialysis nurses to support the dialysis treatments in these patients. The feasibility of nursing home HD was demonstrated in a large cohort in the $U S^{80}$. The success of their program was shown by a high rate $(40 \%)$ of rehabilitation and eventual discharge home. In their setting, the dialysis treatments were performed by dialysis technicians who had at least 3 years of experience and a registered nurse on-staff was available for emergencies. Nephrologists came to the nursing homes to see the patients. In one study, nursing home HD patients were more likely to have intra-dialytic hypotension requiring intervention than other patients ( 36 vs. $13 \%, P<0.05)^{81}$. In this context, intensive HD 
may help to reduce the occurrence of dialysis-related hypotension by reducing the ultrafiltration rate, by protecting against myocardial stunning, by reducing LVH and improving nutritional status, autonomic function as well as arterial compliance. Furthermore, in the study by Reddy et al. ${ }^{80}$, new nursing home dialysis patients had more myocardial infarctions, infections and lower serum albumin and hemoglobin levels as compared to established patients. Again here, intensive HD may be the ideal strategy to counteract these potential ESRD and dialysis complications via similar mechanisms as described above. Assistance of elderly patients and their partners in combination with opportunities for rehabilitation seem necessary assets in order to facilitate the adoption of this modality in elderly ESRD patients. Also, the possibility of nursing home HD deserves further evaluation.

In CHAPTER 6.3, we studied the feasibility of delivering home HD to older patients. We conducted an international multi-centre retrospective study of home HD patients between 1 January 1970 and 31 December 2012 that were $\geq 65$ years of age at the time of home HD initiation. The primary outcome of the study was time to technique failure (inability to continue with home HD) or death during home HD from the date of initiation of the modality. Ninety-seven patients 65 years of age or older were included. Event-free survival at 1, 2 and 5 years was $85 \%, 77 \%$ and $24 \%$, respectively, and technique survival was $92 \%, 83 \%$ and $56 \%$, respectively. Advancing age was an unadjusted risk factor for death and technique failure. Our data document the feasibility of home HD in an older ESRD population. Event-free and technique survival in this older ESRD cohort is lower than in younger home HD populations, but seem comparable to the New Zealand elderly home dialysis cohort which reported a 1-, 2and 3-year patient survival of 90\%, 84\% and 56\% (combined for PD and home HD), and a 1,2- and 3-year technique survival of $83 \%, 73 \%$ and $36 \%$ (for home HD alone), respectively ${ }^{82,83}$. These self-care home dialysis patients in New Zealand had survival rates comparable with national averages, and technique survival rates comparable to in-centre HD treatments. The study cohort survival rates are superior to the survival rates of incident dialysis (PD, in-centre HD and home HD) patients reported in the 20012005 ERA EDTA Registry ${ }^{84}$. The outcome data in our home HD cohort seem also to be in line with those of the other home dialysis modality, PD, in elderly ESRD cohorts. Yang et al. reported overall survival rates at 1,3 and 5 years of $84 \%, 56 \%$, and $38 \%$ among patients 65-74 years of age ${ }^{85}$. Two-year technique survival was $88 \%$ in patients 65 years of age or older. The Canadian Organ Replacement Register (CORR) reported unadjusted one-year, three-year, and five-year patient survival rates among patients 65-74 years of age of $83.9 \%, 52.6 \%$, and $32.2 \%{ }^{86}$. While home HD is feasible in older ESRD patients, they are also highly selected. Nineteen of the 79 (24\%) patients starting home HD at an 
age older than 65 years, received a renal transplant while on home HD, illustrating the relatively well preserved general condition of the patients in this cohort. Next, most patients in this international cohort had an arteriovenous fistula (AVF) as their dialysis access which may be a reflection of optimal pre-dialysis preparation and case selection. The results from our analysis also unveil some potential caveats to increased adoption and implementation of home HD in older ESRD patients, such as caregiver burden and need for increased training time. More than half of the patients in our cohort required home assistance either by the partner or by a dialysis assistant. The potential of expanding home $H D$ to include nurse assisted intensive home $H D$ will require considerable investment in infrastructure that needs to be balanced against the perceived benefits. Interestingly, $35 \%$ of our patients was assisted by a family member. In this context, we know that the caregiver has to be taken care of as much as the patient. In a recent cross-sectional study from Toronto among 36 prevalent nocturnal home HD patients and 31 caregivers, $25 \%$ of caregivers fulfilled depression criteria ${ }^{87}$. The mean age in this Toronto cohort was 52 years for patients and 51 years for caregivers, and hence we could expect the depression prevalence in older patients and their caregivers to be substantially higher, illustrating again the need for adequate physician, nursing, psychological and social worker support for this vulnerable patient and caregiver population. More research is necessary to ascertain the impact of home HD in elderly on survival, quality of life, hospitalization, vascular access and cost issues. Future studies will also have to address the specific needs in infrastructure of home HD units to support elderly patients undergoing home HD, e.g. training time, availability of backup dialysis, fall back rate and development of user-friendly home HD machines.

Finally in CHAPTER 7, we performed an in-depth review of available studies in the literature looking at vascular outcomes in patients doing frequent HD compared to conventional HD. One of the barriers of intensive home HD is indeed the creation and maintenance of proper vascular access. If intensive HD would lead to more frequent access events, it might result in increased morbidity, reduced quality of life, and increased resource utilization. In one of the early studies of that topic, Woods et al. reported in 1999 that the number of access events decreased after conversion from conventional $H D$ to daily $H D^{88}$. This finding was corroborated one year later by Quintaliani et al. ${ }^{89}$. However, more recent studies, including the FHN trials, casted doubt on this optimistic view. In the daily FHN trial, patients randomized to intensive HD experienced significantly more arteriovenous access repairs than the patients randomized to conventional HD. Albeit non-significant, comparable trends were observed in the nocturnal FHN trial ${ }^{3}$. This somewhat ambiguous situation motivated us to review existing trials reporting vascular access outcomes in patients on intensive HD. 
Our analysis, consolidating a total number of 1540 access years for intensive HD and a total number of 2284 access years for conventional HD, indicated that across all access groups and access complications, intensive HD is associated with a higher vascular access event rate as compared with conventional HD (difference $=6.7$ events per 100 patient years, $P=0.009$ for all included studies). Overall event rates in the arteriovenous graft (AVG) group ( 61.0 events per 100 patient years in conventional HD and 98.6 events per 100 patient years in intensive HD) and catheter group (36.0 events per 100 patient years in conventional HD and 52.9 events per 100 patient years in intensive HD) were higher than in the AVF group. Also, vascular access event rates were higher, although not significant, in patients undergoing intensive HD compared to conventional HD for both the AVG group (difference=37.6 events per 100 patient years, $P=0.139$ ) and catheter group (difference $=16.9$ events per 100 patient years, $P=0.133$ ); the difference in the AVF group was smaller (difference 2.7, $P=0.162$ ). AVG may be especially susceptible to early failure in intensive $H D$, because more frequent cannulation may promote weakening of the graft. On the other hand in patients treated with intensive HD and catheters as vascular access, the need for more frequent manipulation may increase the risk of catheter-related infections. In line with current recommendations for conventional $\mathrm{HD}$, one may be tempted to interpret these results as support for the Fistula First Strategy advocating that AVF should be the vascular access of first choice, also in patients treated with intensive HD, although it should be acknowledged that in no study a randomized head-on comparison between different access types was performed ${ }^{90}$.

\section{Revised target populations for intensive home HD based on this thesis}

Patients with severe hypertension and/or LVH as well as patients with persistent extracellular volume overload are established target patients for intensive home $\mathrm{HD}^{91}$. Chapter 2 in part I of this thesis confirmed the beneficial effects of extended dialysis on cardiovascular stability. Also in chapter 2, increased RR of FGF-23 (a middle molecule associated with cardiovascular morbidity and mortality in the dialysis population) by extended dialysis was demonstrated, with a significant additional benefit of convection in HDF on RR of FGF-23. In chapter 3, we observed improved RR and TSR of most PBUT, dicarbonyl stress compounds and free AGEs by prolonging dialysis treatment time. Because these non-traditional uremic toxins are also associated with cardiovascular morbidity and mortality in dialysis patients, lowering baseline levels of these toxins by means of intensive HD may contribute to the observed cardiovascular protective effects 
of this modality. However, the long-term results of intensive HD on the levels of these substances need to be addressed in prospective trials.

Previously, intensive HD was suggested for pregnant prevalent dialysis patients or women of childbearing age who want to become pregnant ${ }^{91}$. In chapter 5 , we compared pregnancy outcomes of pregnant patients on intensive home HD with pregnancy outcomes of patients on more conventional dialysis schedules. We found significantly better outcomes in terms of live birth rate and gestational age and a trend towards higher babies in intensive home HD compared to conventional HD. In line with the finding of improved clinical pregnancy outcomes, we also observed comparable results of routine obstetrical assessment parameters in these patients as in normal controls with preserved renal function. Finally, our series demonstrates that intensified delivery of dialysis improves the rate of conception compared to conventional dialysis. We therefore conclude from this thesis that intensive home HD should be upgraded from a suggested to an established indication in pregnant prevalent dialysis patients and in women on dialysis who wish to conceive.

Also patients with persistent uremic symptoms and low quality of life are a suggested target population for intensive home $H D^{91}$. We demonstrated increased RR and TSR of middle molecules and PBUT, dicarbonyl stress and AGEs by prolongation of dialysis session time. All these uremic toxins are associated with inflammation and oxidative stress, which are two underlying mechanisms of uremic symptoms and low quality of life. The potential long-term effects of intensive home HD on baseline levels of these toxins as well as on their association with inflammation, oxidative stress, uremic symptoms and quality of life are the subject of prospective trials such as the Chronic INTHEM O Study as will be discussed in the Future Perspectives section.

As emerging indications for intensive home HD, caregiver-dependent, obese, employed and transplant/PD failure patients have been mentioned ${ }^{91}$. As a result of this thesis, we would like to suggest ESRD patients after NRSOT as another potential emerging population. Further prospective long-term studies are required to assess the potential benefits of intensive home HD in this patient population especially at the level of cardiovascular protection, metabolic control, quality of life and survival. Furthermore, elderly patients appear as another category of patients who may be potential candidates for intensive home HD. We hypothesized in this thesis on the underlying mechanisms of the geriatric syndromes and frailty in elderly ESRD patients. We also speculated on how the beneficial effects of this modality may protect these patients against these geriatric syndromes and frailty. To start off, we performed an international feasibility study on home HD in patients 65 years of age or older at the start of the modality, and we ascertained the feasibility of home HD in patients 65 years 
or older at the start of this modality, which should foster further research on the potential benefits of (intensive) home HD in older ESRD patients.

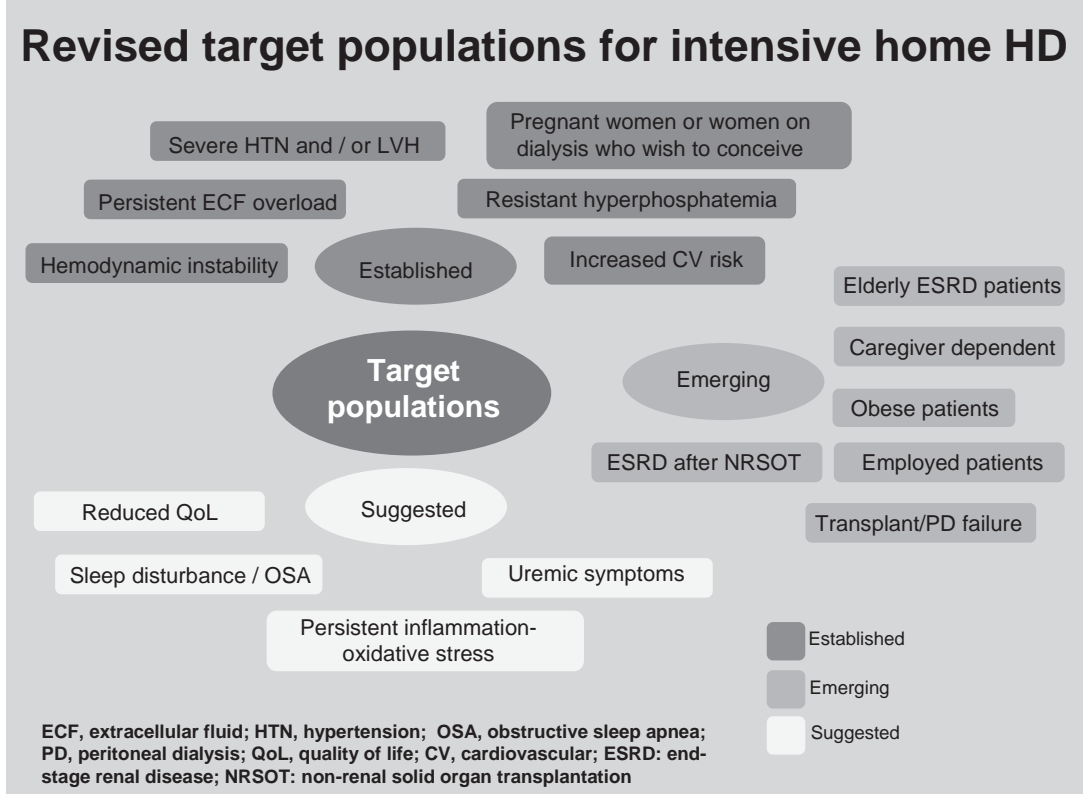

Figure 8.1 Revised target populations for intensive home HD based on this thesis (adapted from ref. 91). 


\section{Conclusions of the thesis}

\section{Part I: Acute effects of intensive hemodialysis}

1. Extension of dialysis time improves intra-dialytic stability of peripheral and central systolic and diastolic blood pressure as well as of cardiac output and relative blood volume. No differences in hemodynamic stability are present between HD and HDF if cool dialysate is used.

2. Extension of dialysis time increases reduction ratio and total solute removal of small and middle molecules including beta2-microglobulin and FGF-23 compared to conventional HD. HDF has a significant additional benefit compared to HD on reduction and removal of middle molecules.

3. Extension of dialysis time results in augmentation of reduction ratio and total solute removal of most protein-bound uremic toxins, dicarbonyl stress compounds and free AGEs compared to conventional duration HD if similar blood and dialysate flows are used. HDF has limited additional benefits compared to HD for the reduction and removal of these non-traditional uremic toxins.

\section{Part II: Long-term outcomes of intensive and home hemodialysis}

1. Home dialysis is feasible in patients who developed ESRD after a non-renal solid organ transplantation. In addition, home dialysis may have particular benefits in this patient population at the level of hemodynamic and metabolic control compared to in-centre HD.

2. Intensive home HD is associated with improved pregnancy outcomes including gestational age and birth weight compared with conventional dialysis settings. This is in line with comparable results of obstetrical and hemodynamic monitoring in pregnant patients performing intensive HD as in pregnant patients without ESRD. Finally, intensive HD also results in improved conception rates compared to more conventional HD.

3. Intensive home HD may have particular benefits in elderly patients with ESRD. We speculated how this modality may protect elderly patients against frailty and the development of geriatric syndromes. Furthermore, we demonstrated, in an international analysis, the feasibility of home HD in ESRD patients 65 years of age or older at the start of this modality. These results should foster further research on the advantages of home HD in elderly also at the level of quality of life, functionality, survival, vascular access and costs. 
4. Frequent $\mathrm{HD}$ is associated with an increased risk of vascular access complications compared to conventional HD. Future studies are required to assess whether arteriovenous fistulas may be the vascular access of choice also for intensive HD. 


\section{Future perspectives}

Further research and observational data are necessary to convince as many nephrologists all over the world that intensive and home HD may offer a very good alternative to many ESRD patients. In addition to the studies we performed to assess the long-term outcomes of intensive and home HD, we designed the Chronic INTHEMO Study which is now underway. This is a prospective multi-centre trial aiming to include 60 patients on intensive HD [short daily HD (SDHD), NHD and frequent NHD] and compare their outcomes with 40 patients on conventional HD and 20 patients on PD. The study originates in Maastricht, and will be carried out in collaboration with the dialysis centres in Hasselt and Brussels (Belgium), Heerlen (Netherlands), Manchester (United Kingdom), as well as in Lyon and Caen (France). The primary objective of this study is to compare vascular biology (vascular markers) and cardiovascular effects (volume status with bio-impedance, 24 hour BP, pulse wave velocity and microcirculation) in the different dialysis modalities. The secondary objectives of this study are to compare the kinetics and levels of uremic toxins (small solutes, middle molecules, PBUT, dicarbonyl stress compounds and AGEs) as well as the degree of physical activity in patients treated with these different dialysis modalities. For the purpose of the study, incident and prevalent intensive HD, conventional HD and PD patients will be prospectively followed up over a period of 2 years with measurements at the start of the study, and subsequently every 6 months till the end of the study.

Also, studies should assess the balance between benefits and risks of intensive and home HD. However, we are convinced that clinical dialysis practice should focus on the opportunities of home-based dialysis therapies rather than on barriers. Bringing therapies to patients' homes will also allow them to incorporate health and disease in their daily lives, a strategy which may support them to continue daily life activities including employment rather than putting the emphasis on medicalization of diseaserelated issues.

Convincing patients of medical strategies starts with the health care team. A different attitude towards home-based dialysis should therefore be strived for. By making home dialysis a basic theoretical and practical part of nephrology training for medical trainees and nurses, a better perception and appreciation of its ins and outs may be achieved. Once the renal care team is convinced, pre-dialysis education should focus on the "home dialysis first" principle ${ }^{92-94}$. Experience indicates that patients should start directly onto home dialysis, as starting with in-centre HD stimulates the development of "learned helplessness" ${ }^{95}$. For sure, support from governments, medical administration and health care companies is indispensable for the development of this strategy. Also, 
adequate infrastructure with a separate building, in or outside the hospital, for home HD training, support, education and clinics, as well as facilities for respite care, are necessary. Last, support of the patient and his/her family by an enthusiastic social worker and, if necessary, psychological evaluation in combination with rehabilitation, are crucial elements in the holistic approach of the ESRD patient who requires dialysis treatment.

The question remains how patients should be initiated on dialysis at the time of transition from pre-dialysis to dialysis, if he or she opts for home HD after proper predialysis education. We previously speculated that intensive home HD may be the strategy of excellence in order to prevent loss of functionality in the first year after dialysis initiation by reducing dialysis-related complications ${ }^{96,97}$. However, given the recent results of the FHN trial showing expedited loss of residual renal function in the nocturnal arm as well as potential detrimental effects of intensive HD on vascular access and cognition, perhaps incremental home HD may be the way to go ${ }^{3,4,98-100}$. Hereby, HD is initiated three times a week for four hours, and thereafter dialysis duration and/or frequency may be augmented on the basis of a variety of clinical and subclinical parameters. Clinical parameters to assess the required dialysis dose may include the amount of residual renal function, metabolic control (acidosis, hyperkalemia, hyperphosphatemia, secondary hyperparathyroidism), BP regulation and volume status. Subclinical parameters to evaluate whether an increase in dialysis dose may be required, may include body composition and hydration status (bio-impedance), myocardial stunning (echocardiography or positron electron tomography), assessment of physical activity (questionnaires, grip strengths, walking speed, Sensewear ${ }_{\text {device), }}$ levels of non-traditional toxins (FGF-23, PBUT, dicarbonyl stress and AGEs), as well as polysomnography and quality of life questionnaires. Recently, Kalantar-Zadeh et al. suggested a similar strategy of incremental HD. In their vision, HD should be initiated twice-weekly instead of thrice-weekly ${ }^{101}$. This approach is based on HD-associated loss of residual renal function which they hope to preserve by reducing the frequency of HD at the time of dialysis initiation. The clinical factors on which they base the concept of incremental HD and eventual increase of dialysis frequency, include: residual kidney function, volume status, cardiovascular symptoms, body size, potassium and phosphorus levels, comorbid conditions, hospitalizations, and health-related quality of life. In their view, transition from twice-weekly HD to thrice-weekly HD should be considered if urine output drops below $0.5 \mathrm{l} /$ day or if the nutritional status or general health condition of the patient shows a deteriorating trend over time. However, we suggest that the minimum dialysis frequency should be thrice-weekly for the following reasons: association of long interdialytic interval with cardiovascular morbidity and 
mortality, already high mortality rates with current thrice-weekly HD regimes, and difficulties to convince the patient to increase dialysis frequency to thrice-weekly if it turns out to be necessary according to the concept of incremental HD of KalantarZadeh et al. ${ }^{102,103}$. Moreover, almost all patients starting dialysis based on clinical grounds in line with the IDEAL trial will fail the suggested criteria for twice-weekly $\mathrm{HD}^{104,105}$. This idea of a minimum of thrice-weekly dialysis was recently supported in a review on dialysis frequency versus dialysis time by Hakim and Saha ${ }^{106}$. These authors also suggest a minimum dialysis duration of 4 hours per session which may be increased to 6 or even 8 hours if clinical and/or subclinical parameters are getting out of control. Further studies are required to determine the optimal dialysis dosing at the time of transition from pre-dialysis to dialysis and also at the long-term. A series of randomized controlled trials of incremental versus thrice-weekly HD that characterizes the relation between dialysis dosing and frequency, residual kidney function, and patient-related outcomes, are envisioned by Kalantar-Zadeh et al. ${ }^{101}$.

Another item which deserves further study, is the potential role of nocturnal hemodiafiltration. Maduell et al. demonstrated excellent outcomes when thriceweekly conventional online HDF patients were converted to alternate-night online nocturnal $\mathrm{HDF}^{14}$. They found lower uremic toxin and phosphate levels and higher RR of urea and B2M, better BP control, a reduction in phosphate binders and in antihypertensive drugs, as well as improved LVH. Thumfart et al. also described good results (reduction in antihypertensive medication, higher albumin levels and increased and protein catabolic rate) in a pediatric nocturnal HDF program after conversion from conventional $\mathrm{HD}^{107}$. In the acute INTHEM $\mathrm{O}$ study, as discussed in chapter 2, acute hemodynamic effects did not differ between HD and HDF, most likely because of the usage of relative cool dialysate ${ }^{108}$. However, HDF significantly increased RR and removal of the middle molecules B2M and FGF-23, to such an extent that 4-hour HDF yielded similar results as 8-hour HD. These results were obtained with suboptimal substitution volumes because both the short and long HDF prescriptions were consistent with what is considered low-efficiency HDF. In an editorial on our acute INTHEM O study, Canaud and Bowry speculated that with more optimal convective dose prescription (i.e. increasing convective volume by $30 \%$ ), one could foresee an increase in solute removal by $20-30 \%{ }^{109,110}$. This would result in a phosphate removal of $1200 \mathrm{mg}$ in 4-hour HDF and $2000 \mathrm{mg}$ in 8-hour HDF, and in B2M removal of $200 \mathrm{mg}$ in 4-hour HDF and $260 \mathrm{mg}$ in 8-hour $\mathrm{HDF}^{108}$. Canaud and Bowry therefore concluded that long HDF with adequate convective volume may provide the optimal platform for developing nocturnal treatment schedules, and that long-term use of HDF could achieve a quasinormalization of phosphate without using phosphate binders, a decrease in serum B2M 
levels to $20 \mathrm{mg} / \mathrm{l}$, and a reduction in circulating FGF-23 levels of about $30 \%{ }^{109}$. For the PBUT, dicarbonyl stress compounds and AGEs, convection had only a small additional effect on RR and TSR, whereas dialysis time extension (HD8 and HDF8) significantly optimized TSR and RR of PBUT, dicarbonyl stress and AGEs compared to conventional dialysis sessions ${ }^{111}$. Long-term studies are necessary to assess the potential benefits of nocturnal HDF on levels of traditional and non-traditional uremic toxins as well as on quality of life, hospitalization, and survival. Also, the potential advantageous effects of HDF should be outweighed against increased costs for higher hygienic needs and maintenance issues related to HDF use.

Even though optimized clinical outcomes may be realized by increasing the dialysis intensity as in intensive home HD, this modality does not integrally mimic a normal kidney function. M oreover, if the patient has decided to dialyze at home, infrastructural changes have to be performed in the house setting before home therapy can be initiated. Also, home based-therapies may place a significant burden on the caregivers of the patient, in terms of adopting responsibility for the treatment and maintaining vigilance for treatment complications. This motivated the search for a wearable dialysis device that would allow patients to receive continuous treatment while going on with the normal daily life activities ${ }^{112}$. Despite many attempts to develop such a wearable artificial kidney, it is only recently, with the help of micro-technologies, that it has been possible to construct. We believe that, awaiting the widespread applicability of this wearable artificial kidney, alternate-night nocturnal home HD currently represents the best available dialysis modality. Moreover, the artificial kidney still has to prove adequate ultrafiltration for volume regulation as well as comparable removal of small solutes, middle molecules and PBUT as in intensive home HD. Hopefully in the future, an implantable artificial kidney may be the best solution for patients with ESRD, not only to avoid housing requirements necessary for successful home HD but also to reduce complications from an extracorporeal blood loop ${ }^{112}$.

It should be emphasized that the role of peritoneal dialysis in the treatment of ESRD patients remains very useful ${ }^{113}$. Especially at the time of transition from pre-dialysis to dialysis, PD may be an excellent alternative to home HD, also given consistent data demonstrating an association between preservation of residual kidney function and PD therapy ${ }^{114}$. However, once residual kidney function deteriorates, timely measures (such as education to patient and partner about home HD, and home HD installation), should be taken to allow an uncomplicated switch from PD to home HD. This should be the final goal of pre-dialysis and dialysis education and care: provide a continuum of home based ESRD care to our patients. Finally, the individualized choice of transition to renal 
replacement treatment versus conservative ESRD care and palliative treatment options should also be discussed for certain patients especially those with terminal conditions $^{115,116}$. 


\section{References}

1. Uldall R, Ouwendyk M, Francoeur R, Wallace L, Sit W, Vas S, Pierratos A. Slow nocturnal home hemodialysis at the Wellesley Hospital. Adv Ren Replace Ther 1996;3:133-6.

2. Perl J, Chan CT. Home hemodialysis, daily hemodialysis, and nocturnal hemodialysis: core curriculum 2009. Am J Kidney Dis 2009;54:1171-84.

3. Suri RS, Larive B, Sherer S, Eggers P, Gassman J, James SH, Lindsay RM, Lockridge RS, Ornt DB, Rocco MV, Ting GO, Kliger AS, and the Frequent Hemodialysis Network Trial Group. Risk of vascular access complications with frequent hemodialysis. J Am Soc Nephrol 2013;24:498-505.

4. Daugirdas JT, Greene T, Rocco MV, Kaysen GA, Depner TA, Levin NW, Chertow GM, Ornt DB, Raimann JG, Larive B, Kliger AS; FHN Trial Group. Effect of frequent hemodialysis on residual renal function. Kidney Int 2013;83:949-58.

5. Basile C, Libutti P, Di Turo AL, Tundo S, Maselli P, Casucci F, Losurdo F, Teutonico A, Vernaglione L, Lomonte C. Haemodynamic stability in standard bicarbonate haemodialysis and long-hour slow-flow bicarbonate haemodialysis. Nephrol Dial Transplant 2011;26:252-8.

6. Locatelli F, Altieri P, Andrulli S, Bolasco P, Sau G, Pedrini LA, Basile C, David S, Feriani M, M ontagna G, Di Iorio BR, Memoli B, Cravero R, Battaglia G, Zoccali C. Hemofiltration and hemodiafiltration reduce intradialytic hypotension in ESRD. J Am Soc Nephrol 2010;21:1798-807.

7. Maduell F, Moreso F, Pons M, Ramos R, Mora-Macià J, Carreras J, Soler J, Torres F, Campistol JM, Martinez-Castelao A; ESHOL study group. High-efficiency postdilution online hemodiafiltration reduced all-cause mortality in hemodialysis patients. J Am Soc Nephrol 2013;24:487-97.

8. van der Sande FM, Kooman JP, Konings C), Leunissen KM. Thermal effects and blood pressure response during postdilution hemodiafiltration and hemodialysis: the effect of amount of replacement fluid and dialysate temperature. J Am Soc Nephrol 2001;12:1916-20.

9. Donauer J, Schweiger C, Rumberger B, Krumme B, Böhler J. Reduction of hypotensive side effects during online-haemodiafiltration and low temperature haemodialysis. Nephrol Dial Transplant 2003;18:1616-22.

10. Minutolo R, Bellizzi V, Cioffi M, Iodice C, Giannattasio P, Andreucci M, Terracciano V, Di lorio BR, Conte G, De Nicola L. Postdialytic rebound of serum phosphorus: pathogenetic and clinical insights. J Am Soc Nephrol 2002;13:1046-54.

11. Penne EL, van der Weerd NC, van den Dorpel MA, Grooteman MP, Lévesque R, Nubé MJ, Bots ML, Blankestijn PJ, ter Wee PM; CONTRAST Investigators. Short-term effects of online hemodiafiltration on phosphate control: a result from the randomized controlled Convective Transport Study (CONTRAST). Am J Kidney Dis 2010;55:77-87.

12. Pedrini LA, De Cristofaro V, Comelli M, Casino FG, Prencipe M, Baroni A, Campolo G, Manzoni C, Colì L, Ruggiero P, Acquistapace I, Auriemma L. Long-term effects of high-efficiency on-line haemodiafiltration on uraemic toxicity. A multicenter prospective randomized study. Nephrol Dial Transplant 2011;26:2617-24.

13. Susantitaphong P, Siribamrungwong M, Jaber BL. Convective therapies versus low-flux hemodialysis for chronic kidney failure: a meta-analysis of randomized controlled trials. Nephrol Dial Transplant 2013;28:2859-74.

14. Maduell $F$, Arias $M$, Duran $C E$, Vera $M$, Fontseré $N$, Azqueta $M$, Rico N, Pérez $N$, Sentis $A$, Elena $M$, Rodriguez N, Arcal C, Bergadá E, Cases A, Bedini JL, Campistol JM. Nocturnal, every-other-day, online haemodiafiltration: an effective therapeutic alternative. Nephrol Dial Transplant 2012;27:1619-31.

15. Basile C, Libutti P, Di Turo AL, Casino FG, Vernaglione L, Tundo S, Maselli P, De Nicolò EV, Ceci E, Teutonico A, Lomonte C. Removal of uraemic retention solutes in standard bicarbonate haemodialysis and long-hour slow-flow bicarbonate haemodialysis. Nephrol Dial Transplant 2011;26:1296-303.

16. Sirich TL, Luo FJ, Plummer NS, Hostetter TH, Meyer TW. Selectively increasing the clearance of proteinbound uremic solutes. Nephrol Dial Transplant 2012;27:1574-9.

17. Luo FJ, Patel KP, Marquez IO, Plummer NS, Hostetter TH, M eyer TW: Effect of increasing dialyzer mass transfer area coefficient and dialysate flow on clearance of protein bound solutes: a pilot crossover trial. Am J Kidney Dis 2009;43: 1042-9. 
18. Alam A, Badovinac K, Ivis F, Trpeski L, Cantarovich M. The outcome of heart transplant recipients following the development of end-stage renal disease: analysis of the Canadian Organ Replacement Register (CORR). Am J Transplant 2007; 7: 461-5.

19. Al Riyami D, Alam A, Badovinac K, Ivis F, Trpeski L, Cantarovich M. Decreased survival in liver transplant patients requiring chronic dialysis: a Canadian experience. Transplantation 2008; 85: 1277-80.

20. Gill JS, Abichandani R, Khan S, Kausz AT, Kausz AT, Pereira BJ. Opportunities to improve the care of patients with kidney transplant failure. Kidney Int 2002; 61: 2193-200.

21. Confortini P, Galanti G, Ancona G, Giongo A, Bruschi E, Lorenzini E. Full term pregnancy and successful delivery in a patient on chronic hemodialysis. Proc Eur Dial Transplant Assoc 1971;8: 74-80.

22. Holley JL, Schmidt RJ, Bender FH, Dumler F, Schiff M. Gynecologic and reproductive issues in women on dialysis. Am J Kidney Dis 1997; 29: 685-90.

23. Lim VS, Henriquez C, Sievertsen G, Frohman LA. Ovarian function in chronic renal failure: evidence suggesting hypothalamic anovulation. Ann Intern Med 1980; 93:21-7.

24. Mantouvalos H, Metallinos C, Makrygiannakis A, Gouskos A. Sex hormones in women on hemodialysis. Int J Gynaecol Obstet 1984; 22: 367-70.

25. Gomez F, de la Cueva R, Wauters JP, Lemarchand-Béraud T. Endocrine abnormalities in patients undergoing long-term hemodialysis. The role of prolactin. Am J Med 1980; 68: 522-30.

26. Hou SH, Grossman S, Molitch ME. Hyperprolactinemia in patients with renal insufficiency and chronic renal failure requiring hemodialysis or chronic ambulatory peritoneal dialysis. Am J Kidney Dis 1985; 6: 245-9.

27. Report from the Registration Committee of the European Dialysis and Transplant Association: Successful pregnancies in women treated by dialysis and kidney transplantation. Br J Obstet Gynaecol 1980;87:839-45.

28. Bagon JA, Vernaeve H, De M uylder X, Lafontaine JJ, Martens J, Van Roost G. Pregnancy and dialysis. Am J Kidney Dis 1998; 31: 756-65.

29. Barua M, Hladunewich M, Keunen J, Pierratos A, M cFarlane P, Sood M, Chan CT. Successful pregnancies on nocturnal home hemodialysis. Clin J Am Soc Nephrol 2008; 3: 392-6.

30. Stengel B, Billon S, Van Dijk PC, Jager KJ, Dekker FW, Simpson K, Briggs JD. Trends in the incidence of renal replacement therapy for end-stage renal disease in Europe, 1990-1999. Nephrol Dial Transplant 2003;18:1824-33.

31. Santoro A and Mancini E. Hemodialysis and the elderly patient: complications and concerns. J Nephrol 2010;23:80-9.

32. Kurella Tamura M, Covinsky KE, Chertow GM, Yaffe K, Landefeld CS, M cCulloch CE. Functional status of elderly adults before and after initiation of dialysis. N Engl J M ed 2009;361:1539-47.

33. Jassal SV, Chiu E, Hladunewich M. Loss of independence in patients starting dialysis at 80 years of age or older. N Engl J M ed 2009;361:1612-3.

34. Chan CT, Harvey PJ, Picton P, Pierratos A, M iller JA, Floras JS. Short-term blood pressure, noradrenergic, and vascular effects of nocturnal home hemodialysis. Hypertension 2003; 42: 925-31.

35. Chan C, Floras JS, M iller JA, Pierratos A. Improvement in ejection fraction by nocturnal haemodialysis in end-stage renal failure patients with coexisting heart failure. Nephrol Dial Transplant 2002; 17: 151821.

36. Culleton BF, Walsh M, Klarenbach SW, Mortis G, Scott-Douglas N, Quinn RR, Tonelli M, Donnelly S, Friedrich MG, Kumar A, Mahallati H, Hemmelgarn BR, Manns BJ. Effect of frequent nocturnal hemodialysis vs conventional hemodialysis on left ventricular mass and quality of life: a randomized controlled trial. JAM A 2007; 298: 1291-9.

37. M ucsi I, Hercz G, Uldall R, Ouwendyk M, Francoeur R, Pierratos A. Control of serum phosphate without any phosphate binders in patients treated with nocturnal hemodialysis. Kidney Int 1998; 53: 1399-404.

38. Johansen KL, Zhang R, Huang Y, Chen SC, Blagg CR, Goldfarb-Rumyantzev AS, Hoy CD, Lockridge RS Jr, Miller BW, Eggers PW, Kutner NG. Survival and hospitalization among patients using nocturnal and short daily compared to conventional hemodialysis: a USRDS study. Kidney Int 2009; 76: 984-90.

39. KDOQI Clinical Practice Guideline and Clinical Practice Recommendations for anemia in chronic kidney disease: 2007 update of hemoglobin target. Am J Kidney Dis 2007; 50: 471-530. 
40. K/DOQI clinical practice guidelines for bone metabolism and disease in chronic kidney disease. Am J Kidney Dis 2003; 42: S1-201.

41. K/DOQI clinical practice guidelines for cardiovascular disease in dialysis patients. Am J Kidney Dis 2005; 45: S1-153.

42. Manns BJ, Taub K, Vanderstraeten $\mathrm{C}$, Jones H, et al. The impact of education on chronic kidney disease patients' plans to initiate dialysis with self-care dialysis: a randomized trial. Kidney Int 2005; 68: 177783.

43. M cLaughlin $\mathrm{K}$, Jones $\mathrm{H}$, VanderStraeten $\mathrm{C}$, Mills $\mathrm{C}$, Mills $\mathrm{C}$, Visser M, M cLaughlin $\mathrm{K}$. Why do patients choose self-care dialysis? Nephrol Dial Transplant 2008; 23: 3972-3976.

44. Perl J, Chan CT. Home hemodialysis, daily hemodialysis, and nocturnal hemodialysis: core curriculum 2009. Am J Kidney Dis 2009;54:1171-1184.

45. Asamiya Y, Otsubo S, M atsuda Y, Kimata N, Kikuchi K, M iwa N, Uchida K, M ineshima M, Mitani M, Ohta $\mathrm{H}$, Nitta K, Akiba T. The importance of low blood urea nitrogen levels in pregnant patients undergoing hemodialysis to optimize birth weight and gestational age. Kidney Int 2009; 75: 1217-1222.

46. Okundaye I, Abrinko P, Hou S. Registry of pregnancy in dialysis patients. Am J Kidney Dis 1998:31:76673.

47. Toma H, Tanabe $\mathrm{K}$, Tokumoto $\mathrm{T}$, Kobayashi C, Yagisawa T. Pregnancy in women receiving renal dialysis or transplantation in Japan: a nationwide survey. Nephrol Dial Transplant 1999;14:1511-6.

48. Hou SH. Frequency and outcome of pregnancy in women on dialysis. Am J Kidney Dis 1994;23:60-3.

49. Malik GH, Al-Harbi A, Al-Mohaya S, Dohaimi H, Kechrid M, Shetaia MS, Al-Hassan AO, Quiapos LS. Pregnancy in patients on dialysis--experience at a referral center. J Assoc Physicians India 2005;53:93741.

50. Bahloul H, Kammoun K, Kharrat M, Jarraya F, Charffedine K, Hamida MB, Hachicha J. Pregnancy in chronic hemodialysis women: outcome of multicentric study. Saudi J Kidney Dis Transpl 2003;14:530-1.

51. Shahir AK, Briggs N, Katsoulis J, Levidiotis V. An observational outcomes study from 1966-2008, examining pregnancy and neonatal outcomes from dialysed women using data from the ANZDATA registry. Nephrology 2013;18:276-84.

52. van Eps C, Hawley C, Jeffries J, Johnson DW, Campbell S, Isbel N, M udge DW, Prins J. Changes in Serum Prolactin, Sex Hormones and Thyroid Function with Alternate Nightly Nocturnal Home Haemodialysis. Nephrology (Carlton) 2012;17:42-7.

53. Chan CT, Jain V, Picton P, Pierratos A, Floras JS. Nocturnal hemodialysis increases arterial baroreflex sensitivity and compliance and normalizes blood pressure of hypertensive patients with end-stage renal disease. Kidney Int 2005;68:338-44.

54. Chan CT, Shen XS, Picton P, Floras J. Nocturnal home hemodialysis improves baroreflex effectiveness index of end-stage renal disease patients. J Hypertens 2008;26:1795-800.

55. Yuen DA, Kuliszewski MA, Liao C, Rudenko D, Leong-Poi H, Chan CT. Nocturnal hemodialysis is associated with restoration of early-outgrowth endothelial progenitor-like cell function. Clin J Am Soc Nephrol 2011;6:1345-53.

56. Shan HY, Rana S, Epstein FH, Stillman IE, Karumanchi SA, Williams ME. Use of circulating antiangiogenic factors to differentiate other hypertensive disorders from preeclampsia in a pregnant woman on dialysis. Am J Kidney Dis 2008;51:1029-32.

57. Verlohren S, Herraiz I, Lapaire O, Schlembach D, M oertl M, Zeisler H, Calda P, Holzgreve W, Galindo A, Engels T, Denk B, Stepan $\mathrm{H}$. The sFIt-1/PIGF ratio in different types of hypertensive pregnancy disorders and its prognostic potential in preeclamptic patients. Am J Obstet Gynecol 2012;206:58. e1-8.

58. Rana S, Powe CE, Salahuddin S, Verlohren S, Perschel FH, Levine RJ, Lim KH, Wenger JB, Thadhani R, Karumanchi SA. Angiogenic factors and the risk of adverse outcomes in women with suspected preeclampsia. Circulation 2012;125:911-9.

59. Rolfo A, Attini R, Nuzzo AM, Piazzese A, Parisi S, Ferraresi M, Todros T, Piccoli GB. Chronic kidney disease may be differentially diagnosed from preeclampsia by serum biomerkers. Kidney Int 2013;83:177-81.

60. Hausvater A, Giannone T, Gomez Sandoval Y-H, Doonan RJ, Antonopoulos CN, Matsoukis IL, Petridou ET, Daskalopoulou SS. The association between preeclampsia and arterial stiffness. J Hypertens 2012;30:17-33. 
61. Vasapollo B, Novelli GP, Valensise H. Total vascular resistance and left ventricular morphology as screening tools for complications in pregnancy. Hypertension 2008;51:1020-6.

62. Fagugli RM, Reboldi G, Quintaliani G, Pasini P, Ciao G, Cicconi B, Pasticci F, Kaufman JM, Buoncristiani U. Short daily hemodialysis: blood pressure control and left ventricular mass reduction in hypertensive hemodialysis patients. Am J Kidney Dis 2001; 38: 371-6.

63. Chertow GM, Levin NW, Beck GJ, Depner TA, Eggers PW, Gassman JJ, Gorodetskaya I, Greene T, James S, Larive B, Lindsay RM, Mehta RL, Miller B, Ornt DB, Rajagopalan S, Rastogi A, Rocco MV, Schiller B, Sergeyeva O, Schulman G, Ting GO, Unruh M L, Star RA, Kliger AS. In-center haemodialysis six times per week versus three times per week. N Engl J M ed 2010;363:2287-300.

64. Chan CT, Li SH, Verma S. Nocturnal hemodialysis is associated with restoration of impaired endothelial progenitor cell biology in end-stage renal disease. Am J Physiol Renal Physiol 2005;289:F679-84.

65. Chan CT, Hanly P, Gabor J, Picton P, Pierratos A, Floras JS. Impact of nocturnal hemodialysis on the variability of heart rate and duration of hypoxemia during sleep. Kidney Int 2004;65:661-5.

66. Jassal SV, Devins GM, Chan CT, Bozanovic R, Rourke S. Improvements in cognition in patients converting from thrice weekly hemodialysis to nocturnal hemodialysis: a longitudinal pilot study. Kidney Int 2006;70:956-62.

67. Jefferies HJ, Virk B, Schiller B, M oran J, M cIntyre CW. Frequent hemodialysis schedules are associated with reduced levels of dialysis-induced cardiac injury (myocardial stunning). Clin J Am Soc Nephrol 2011;6:1326-32.

68. Yuen D, Richardson RM, Chan CT. Improvements in phosphate control with short daily in-center hemodialysis. Clin Nephrol 2005;64:364-70.

69. Beecroft JM, Duffin J, Pierratos A, Chan CT, M cFarlane P, Hanly PJ. Decreased chemosensitivity and improvement of sleep apnea by nocturnal hemodialysis. Sleep M ed 2009;10:47-54.

70. M cFarlane PA, Bayoumi AM, Pierratos A, Redelmeier DA. The quality of life and cost utility of home nocturnal and conventional in-center hemodialysis. Kidney Int 2003;64:1004-11.

71. Fong E, Bargman JM, Chan CT. Cross-sectional comparison of quality of life and illness intrusiveness in patients who are treated with nocturnal home hemodialysis versus peritoneal dialysis. Clin J Am Soc Nephrol 2007;2: 1195-200.

72. Jaber BL, Lee Y, Collins AJ, Hull AR, Kraus MA, M cCarthy J, Miller BW, Spry L, Finkelstein FO. Effect of daily hemodialysis on depressive symptoms and postdialysis recovery time: interim report from the FREEDOM (Following Rehabilitation, Economics and Everyday-Dialysis Outcome Measurements) Study. Am J Kidney Dis 2010;56:531-9.

73. Brown EA, Johansson L. Dialysis options for end-stage renal disease in older people. Nephron Clin Pract 2011;119:c10-c313.

74. M CDonald M, M CPhee PD, Walker RJ. Successful self-care home dialysis in the elderly: a single center's experience. Perit Dial Int 1995;15:33-6.

75. Lamping DL, Constantinovici N, Roderick P, Normand C, Henderson L, Harris S, Brown E, Gruen R, Victor C. Clinical outcomes, quality of life, and costs in the North Thames Dialysis Study of elderly people on dialysis: a prospective cohort study. Lancet 2000;356:1543-50.

76. Brown EA, Johansson L, Farrington K, Gallagher H, Sensky T, Gordon F, Da Silva-Gane M, Beckett N, Hickson M. Broadening Options for Long-term Dialysis in the Elderly (BOLDE): differences in quality of life on peritoneal dialysis compared to haemodialysis for older patients. Nephrol Dial Transplant 2010;25:3755-63.

77. MacDonald S, Excell L, Livingston BE. ANZDATA Registry 2009. Adelaide, Australia and New Zealand Dialysis and Transplant Registry, 2009.

78. Oliver MJ, Quinn R, Richardson EP, Kiss AJ, Lamping DL, Manns BJ. Home care assistance and the utilization of peritoneal dialysis. Kidney Int 2007; 71:673-678.

79. Qyinan P. Home hemodialysis and the caregivers' experience: a critical analysis. CANNT J 2005;15:2532.

80. Reddy NC, Korbet SM, Wozniak JA, Floramo SL, Lewis EJ. Staff-assisted nursing home hemodialysis: patient characteristics and outcomes. Nephrol Dial Transplant 2007;22:1399-1406.

81. Sankarasubbaiyan S, Holley JL. An analysis of the increased demands placed on dialysis health care team members by functionally dependent hemodialysis patients. Am J Kidney Dis 2000;35:1061-7. 
82. Pauly RP, Maximova K, Coppens J, Asad RA, Pierratos A, Komenda P, Copland M, Nesrallah GE, Levin A, Chery A, Chan CT; CAN-SLEEP Collaborative Group. Patient and technique survival among a Canadian multicenter nocturnal home hemodialysis cohort. Clin J Am Soc Nephrol 2010;5:1815-20.

83. M cDonald M, M CPhee PD, Walker RJ. Successful self-care home dialysis in the elderly: a single center's experience. Perit Dial Int 1995;15:33-6.

84. ERA-EDTA Registry: ERA-EDTA Registry Annual Report 2011. Academic Medical Center, Department of Medical Informatics, Amsterdam, The Netherlands, 2013.

85. Yang X, Fang W, Kothari J, Khandelwal M, Naimark D, Jassal SV, Bargman JM, Oreopoulos DG. Clinical outcomes of elderly patients undergoing chronic peritoneal dialysis: experiences from one center and a review of the literature. Int urol nephrol 2007;39:1295-302.

86. Canadian Organ Replacement Register (CORR) annual report: treatment of end-stage organ failure in Canada, 1995 and 2004. Canadian Institute for Health Information, Don M ills, ON, Canada.

87. Rioux JP, Narayanan R, Chan CT. Caregiver burden among nocturnal home hemodialysis patients. Hemodial Int 2012;16:214-9.

88. Woods JD, Port FK, Orzol S, Buoncristiani U, Young E, Wolfe RA, Held PJ. Clinical and biochemical correlates of starting "daily" hemodialysis. Kidney Int 1999;55:2467-76.

89. Quintaliani G, Buoncristiani U, Fagugli R, Kulurianu H, Ciao G, Rondini L, Lowenthal DT, Reboldi G. Survival of vascular access during daily and three times a week hemodialysis. Clin Nephrol 2000;5:3727.

90. Allon M, Robbin M L. Increasing arteriovenous fistulas in hemodialysis patients: problems and solutions. Kidney Int 2002; 62:1109-24.

91. Tennankore K, Nadeau-Fredette AC, Chan CT. Intensified home hemodialysis: clinical benefits, risks and target populations. Nephrol Dial Transplant 2014;29:1342-9.

92. Cornelis T, Kooistra M P, Kooman J, Leunissen KM, Chan CT, van der Sande F. Education of ESRD patients on dialysis modality selection: 'intensive hemodialysis first'. Nephrology Dialysis Transplantation 2010;25:3129-30.

93. Goovaerts T, Jadoul M, Goffin E. Influence of a pre-dialysis education programme (PDEP) on the mode of renal replacement therapy. Nephrol Dial Transplant. 2005;20:1842-7.

94. Goovaerts T, Jadoul M, Goffin E. Influence of a predialysis education program on the choice of renal replacement therapy. Am J Kidney Dis. 2012;60:499; author reply 499-500.

95. Seligman ME, Weiss J, Weinraub M, Schulman A. Coping behaviour: learned helplessness, physiological change and learned inactivity. Behav Res Ther 1980;18:459-512.

96. Cornelis T, Kooman J, van der Sande F. Just-in-time initiation of optimal dialysis. Nederlands Tijdschrift voor Geneeskunde 2010;154:A2549.

97. Cornelis T, van der Sande FM, Kooman JP. Balancing transition to dialysis: the urgent need for more intensive hemodialysis. Kidney Int 2013;83:967-8.

98. Kurella Tamura M, Unruh ML, Nissenson AR, Larive B, Eggers PW, Gassman J, Mehta RL, Kliger AS, Stokes JB; Frequent Hemodialysis Network (FHN) Trial Group. Effect of more frequent hemodialysis on cognitive function in the frequent hemodialysis network trials. Am J Kidney Dis 2013;61:228-37.

99. Berns JS, Dember LM. Can frequent hemodialysis be too frequent? J Am Soc Nephrol 2013;24:334-6.

100. Farrington K. Commentary for "Effect of frequent hemodialysis on residual kidney function": Frequent Hemodialysis Network (FHN) Trials. Kidney Int 2013;83:787-9.

101. Kalantar-Zadeh K, Unruh M, Zager PG, Kovesdy CP, Bargman JM, Chen J, Sankarasubbaiyan S, Shah G, Golper T, Sherman RA, Goldfarb DS. Twice-Weekly and Incremental Hemodialysis Treatment for Initiation of Kidney Replacement Therapy. Am J Kidney Dis. 2014;64:181-6.

102. Foley RN, Gilbertson DT, Murray T, Collins AJ. Long interdialytic interval and mortality among patients receiving hemodialysis. N Engl J M ed. 2011;365:1099-107.

103. Collins AJ, Foley RN, Chavers B, Gilbertson D, Herzog C, Ishani A, Johansen K, Kasiske BL, Kutner N, Liu J, St Peter W, Guo H, Hu Y, Kats A, Li S, Li S, Maloney J, Roberts T, Skeans M, Snyder J, Solid C, Thompson $B$, Weinhandl $E$, Xiong H, Yusuf A, Zaun D, Arko C, Chen SC, Daniels F, Ebben J, Frazier E, Johnson R, Sheets D, Wang X, Forrest B, Berrini D, Constantini E, Everson S, Eggers P, Agodoa L. US Renal Data System 2013 Annual Data Report. Am J Kidney Dis. 2014;63(1 Suppl):A7. 
104. Vanholder R, Van Biesen W, Lameire N. Is starting hemodialysis on a twice-weekly regimen a valid option? Am J Kidney Dis 2014;64:165-7.

105. Cooper BA, Branley P, Bulfone L, Collins JF, Craig JC, Fraenkel MB, Harris A, Johnson DW, Kesselhut J, Li JJ, Luxton G, Pilmore A, Tiller DJ, Harris DC, Pollock CA; IDEAL Study. A randomized, controlled trial of early versus late initiation of dialysis. N Engl J Med. 2010;363:609-19.

106. Hakim RM, Saha S. Dialysis frequency versus dialysis time, that is the question. Kidney Int 2014;85:1024-9.

107. Thumfart J, Puttkamer CV, Wagner S, Querfeld U, M üller D. Hemodiafiltration in a pediatric nocturnal dialysis program. Pediatr Nephrol. 2014;29:1411-6.

108. Cornelis T, van der Sande FM, Eloot S, Cardinaels E, Bekers O, Damoiseaux J, Leunissen KM, Kooman JP. Acute hemodynamic response and uremic toxin removal in conventional and extended hemodialysis and hemodiafiltration: a randomized crossover study. Am J Kidney Dis 2014;64:247-56.

109. Canaud B, Bowry SK. Revisiting frontiers and tolerability and efficacy in renal replacement therapy. Am J Kidney Dis 2014;64:171-3.

110. M ostovaya IM, Blankestijn PJ, Bots ML, Covic A, Davenport A, Grooteman M P, Hegbrant J, Locatelli F, Vanholder R, Nubé MJ; EUDIAL1 - an official ERA-EDTA Working Group. Clinical evidence on hemodiafiltration: a systematic review and a meta-analysis. Semin Dial 2014;27:119-27.

111. Cornelis T, Eloot S, Vanholder R, Glorieux G, van der Sande FM, Scheijen JL, Leunissen KM, Kooman JP, Schalkwijk CG. Protein-bound Uremic Toxins, Dicarbonyl Stress and Advanced Glycation Endproducts in Conventional and Extended Hemodialysis and Hemodiafiltration. Nephrol Dial Transpl 2015 April 9. [Epub ahead of print].

112. Fissell WH, Roy S, Davenport A. Achieving more frequent and longer dialysis for the majority: wearable dialysis and implantable artificial kidney devices. Kidney Int 2013;84:256-64.

113. Bargman JM. Advances in peritoneal dialysis: a review. Semin Dial 2012;25:545-9.

114. Van Biesen W, Vanholder RC, Veys N, Dhondt A, Lameire NH. An evaluation of an integrative care approach for end-stage renal disease patients. J Am Soc Nephrol. 2000;11:116-25.

115. Rhee CM, Kalantar-Zadeh K. Transition to dialysis: controversies in its timing and modality. Introduction. Semin Dial 2013;26:641-3.

116. Jassal SV, Watson D. Doc, don't procrastinate...Rehabilitate, palliate, and advocate. Am J Kidney Dis. 2010;55:209-12. 


\section{Samenvatting}





\section{Samenvatting}

Hemodialyse (HD) werd routinematig in de thuissituatie uitgevoerd in de jaren zeventig van de twintigste eeuw. Daarna werd, om logistieke en economische redenen, incentrum conventionele HD de standaardzorg voor patiënten met eindstadium nierfalen (ESRD). In de jaren negentig van de vorige eeuw onderging thuis HD een aanzienlijke revival onder impuls van Uldall en Pierratos uit Toronto, die thuis (nachtelijke) HD programma's herintroduceerden vooral vanwege klinische voordelen en lagere kosten. Thuis HD faciliteert intensieve (verhoogde frequentie en/ of duur van de HD-sessie) HD, omdat het de noodzaak voor het vervoer naar het dialysecentrum wegneemt. De voordelen van intensieve $H D$ variëren van verbeterde bloeddruk- en fosfaatcontrole en vermindering van linker ventrikel hypertrofie (LVH) tot een betere slaapkwaliteit, hogere levenskwaliteit en potentieel betere overleving in vergelijking met conventionele HD, zoals besproken in HOOFDSTUK 1. Anderzijds kan intensieve HD ook geassocieerd zijn met een aantal risico's zoals vaattoegangscomplicaties (vanwege veelvuldig aanprikken) en versneld verlies van restnierfunctie [zoals onlangs aangetoond in de nachtelijke arm van de Frequent Hemodialysis Network (FHN) trial]. Zowel klinische voordelen als risico's-barrières van intensieve (thuis) HD bieden een platform voor initiatieven rondom research en kwaliteitsverbeteringsprojecten om de toepassing van intensieve thuis HD uit te breiden zowel in de algemene dialyse bevolking als in specifieke patiëntengroepen. In deze optiek hebben we in dit proefschrift gekozen om zowel acute effecten als lange termijn resultaten van intensieve en thuis HD te bestuderen.

In het MRSTE D田 van het proefschrift hebben we de acute effecten van intensieve HD bestudeerd in prevalente conventionele HD patiënten in de acute INTHEMO (INTensieve HEMOdialyse) studie. In deze gerandomiseerde cross-over studie, ondergingen 13 prevalente conventionele HD patiënten in willekeurige volgorde een enkele sessie van 4 uur HD, een enkele sessie van 4 uur hemodiafiltratie (HDF), een enkele sessie van 8 uur HD, en een enkele sessie van 8 uur HDF met een 2-weken interval tussen de studiesessies waarin ze hun routine conventionele HD behandelingen ontvingen. In HOOFDSTUK 2 werden de acute effecten op de hemodynamiek en op uremische toxines [kleine opgeloste stoffen en middelgrote molecules zoals bèta-2microglobuline (B2M) en FGF-23] van de betreffende vier sessies vergeleken. In HOOFDSTUK 3 werden de acute effecten op niet-traditionele uremische toxines [eiwitgebonden uremische toxines, dicarbonyl stress-verbindingen, en advanced glycation endproducts (AGE's)] van de vier modaliteiten geëvalueerd. 
In HOOFDSTUK 2 vonden we dat langere dialyse (8 uur HD en 8 uur HDF) geassocieerd was met een verbeterde intra-dialytische stabiliteit van perifere en centrale bloeddruk. Er werden geen verschillen in hemodynamische stabiliteit waargenomen tussen HD en HDF. Verbeterde hemodynamische controle was waarschijnlijk gerelateerd aan een beter behoud van cardiac output (CO) in langere dialyse, hetgeen leek te berusten op een langzamere daling van relatief bloedvolume (RBV) veroorzaakt door een betere capillaire refill. Deze laatste bevinding is in overeenstemming met het onderzoek van Basile et al. die beter behoud van plasmavolume heeft aangetoond met lange HD. Dit was niet eerder gekoppeld aan de stabiliteit van $\mathrm{CO}$ en geen enkele studie heeft voordien de effecten van lange HDF op RBV en CO behoud en op intra-dialytische bloeddruk-stabiliteit geanalyseerd. Sommige eerdere studies suggereerden dat conventionele hemofiltratie en HDF tot een verbeterde cardiovasculaire stabiliteit leiden, terwijl andere studies hebben aangetoond dat bij lage temperatuur HD dezelfde hemodynamische stabiliteit kan worden verkregen zoals in hemofiltratie en HDF. Donauer en collega's toonden aan dat online HDF een meer uitgesproken koeleffect op het lichaam heeft door extra energieverlies via het extracorporeel systeem (dialyselijnen en kunstnier). Wij vonden geen verschil in snelheid van energieoverdracht tussen de verschillende behandelingen, met inbegrip van korte en lange HDF. Het gebrek aan verschil tussen HD en HDF in onze studie is waarschijnlijk te wijten aan het gebruik van koel dialysaat in vergelijking met eerdere studies, waarin het effect van extra energieverlies via het extracorporeel systeem allicht minder uitgesproken is geweest.

In HOOFDSTUK 2 hebben we ook de klaring van kleine en middelgrote moleculen in de 4 verschillende dialysemodaliteiten bestudeerd. We vonden geen verschillen in total solute removal (TSR) (totale verwijdering) van ureum, creatinine, urinezuur en fosfaat tussen HD en HDF, maar langere behandelingen resulteerden wel in de hoogste waarden. Het gebrek aan verschil in fosfaatverwijdering tussen HD en HDF in onze studie, in tegenstelling tot eerdere analyses, kan worden verklaard door het gebruik van high-flux membranen, en door het gebruik van relatief lage convectievolumes in HDF. Gebaseerd op de bijdrage van convectie aan klaring van middelgrote moleculen, waren de reductie ratio's (RR) van B2M en FGF-23 hoger in HDF dan in HD en superieur voor lange HDF. Total solute removal van B2M was superieur in de lange HDF sessies.

In HOOFDSTUK 3 onderzochten we RR en TSR van eiwitgebonden uremische toxines, dicarbonyl stress-verbindingen en AGE's in de acute INTHEMO Study. Deze niettraditionele uremische toxines zijn geassocieerd met inflammatie (ontsteking), oxidatieve stress en cardiovasculaire morbiditeit en mortaliteit bij patiënten met chronische nierziekte (CKD). Wij toonden voor het eerst verhoogde RR en TSR aan van 
deze niet-traditionele uremische toxines door verlengen van de dialyseduur, tenminste als bloed- en dialysaatflow behouden blijven zoals bij conventionele HD. Deze bevinding is in tegenstelling met de gegevens van Basile et al., die bij slow flow lange HD geen verhoogde verwijdering van indool-3 azijnzuur (IAA), indoxyl sulfaat (IS), hippuurzuur (HA) en homocysteïne zagen. De klaring van hippuurzuur, indolische en fenolische eiwitgebonden uremische toxines berust voornamelijk op diffusie en is dus afhankelijk van bloed- en dialysaatflow. Verlengen van de dialyseduur samen met behoud van bloedflow zal resulteren in lagere spiegels van eiwitgebonden uremische toxines hetgeen de dissociatie van gebonden toxines van albumine faciliteert. Dit leidt tot voortdurende beschikbaarheid van deze toxines voor diffusie naar het dialysaat. Terwijl in hoofdstuk 2 een grote toename van RR en / of TSR van de middelgrote moleculen FGF23 en B2M door toevoeging van convectie in HDF ten opzichte van HD werd aangetoond, zowel voor korte als lange behandelingstijden, was het additieve effect van convectie voor de reductie en klaring van eiwitgebonden uremische toxines kleiner. Dit kan worden verklaard door het feit dat HDF in het bijzonder bijdraagt tot optimalisatie van verwijdering van middelgrote moleculen terwijl het extra effect op kleine moleculen (zoals de vrije fractie van eiwitgebonden uremische toxines) beperkt is. RR en TSR van dicarbonyl producten en vrije AGE's werden ook aanzienlijk verbeterd door het verlengen van de behandelingstijd. Convectie had een extra effect op de RR van de vrije dicarbonyl stress-verbindingen $C M L$ [ $\mathrm{N}^{\epsilon}$-(Carboxymethyl)lysine] en CEL [ $\mathrm{N}^{\epsilon}$ (Carboxyethyl)lysine]. Een recente meta-analyse toonde een significante vermindering van pre-dialytische plasmaspiegels van pentosidine aan bij high-flux HD of HDF in vergelijking met low-flux HD, maar geen verhoogde RR van pentosidine en AGE's, wat suggereert dat andere mechanismen (zoals een afname van inflammatie) betrokken zijn bij de gunstige effecten van deze behandelingen op AGE spiegels. De lange-termijn effecten van lange HD en HDF op het vlak van deze niet-traditionele uremische toxines en hun mogelijke associatie met betere cardiovasculaire bescherming en hogere overlevingskansen in intensieve HD vergen nader prospectief onderzoek.

In het TWت⿴囗十 D田 van dit proefschrift hebben we de lange termijn effecten van intensieve HD geëvalueerd. Omdat de meeste eerdere studies over de voordelen en barrière-risico's van intensieve HD werden uitgevoerd in de algemene dialysebevolking, hebben we gekozen om de lange termijn effecten van intensieve HD te evalueren in drie specifieke kwetsbare patiëntengroepen.

De eerste groep van kwetsbare patiënten bestudeerd in dit proefschrift, waren patiënten die ESRD ontwikkelden na niet-renale soliede orgaantransplantatie (NRSOT). Deze patiënten hebben vaak meerdere co-morbiditeiten zoals diabetes mellitus, hypertensie en arteriële hypertensie. De impact van de keuze van de dialysemodaliteit 
bij NRSOT patiënten met ESRD is onbekend. Renale registratiegegevens suggereren dat de optie van thuisdialyse inclusief peritoneale dialyse (PD) onvoldoende benut is in de setting van ESRD na NRSOT, mogelijk als gevolg van percepties van infectieuze complicaties en een slechte techniekoverleving. Heterogene resultaten ten gunste van PD en HD bieden geen uniforme aanbeveling voor deze kwetsbare patiëntenpopulatie, en tot voordien had geen enkele studie de mogelijkheid van thuis HD bij patiënten met ESRD na NRSOT geëvalueerd. De tweede groep van kwetsbare dialysepatiënten bestudeerd in dit proefschrift, zijn vrouwen met ESRD die zwanger willen worden of die zwanger zijn. De eerste succesvolle zwangerschap gerapporteerd bij een chronische HD patiënt dateert van 1970. Het aanvankelijke enthousiasme werd getemperd door latere studies die erop wezen dat zwangerschap bij vrouwen met ESRD ongewoon is als gevolg van verminderde vruchtbaarheid, en vaak geassocieerd is met slechte resultaten zoals lager levende geboortecijfer, een laag geboortegewicht en pre-eclampsie. Uit recente gegevens blijkt dat frequente nachtelijke HD resulteert in verminderde maternale en foetale complicaties bij zwangere ESRD patiënten. De derde en laatste groep van kwetsbare ESRD patiënten bestudeerd in dit proefschrift, zijn oudere dialysepatiënten. Het aantal oudere patiënten met terminale nierinsufficiëntie dat dialyse start, neemt gestaag toe. ESRD en dialyse initiatie bij ouderen gaan vaak gepaard met het verlies van onafhankelijkheid. Dit suggereert dat oudere patiënten minder goed veranderingen rondom de start van dialyse verdragen in vergelijking met jongere patiënten. De gebeurtenissen die tot functieverlies kunnen leiden, zijn dialysegerelateerde hypotensie, cerebrale en cardiale gebeurtenissen, evenals ondervoeding en een verhoogd infectierisico. Wij speculeerden in dit proefschrift dat frequentere en / of langere HD-sessies de ontregeling van het intern milieu kunnen verzachten, en om die reden vooral ook bij oudere ESRD patiënten van nut kunnen zijn, zeker ook als deze behandelingen in de thuissituatie kunnen plaatsvinden.

In HOOFDSTUK 4 beschreven we onze ervaring met thuisdialyse (intensieve thuis HD en PD) bij patiënten die ESRD ontwikkelden na NRSOT. Dit onderzoek leverde de langste follow-up (mediaan 24 maanden) van thuisdialyse in NRSOT ontvangers. De gegevens toonden aan dat thuisdialyse een haalbare en duurzame modaliteit is bij patiënten die ESRD ontwikkelen na NRSOT, en ook dat thuisdialyse potentieel specifieke voordelen voor deze patiëntenpopulatie biedt. Nachtelijke thuis HD is inderdaad geassocieerd met een aantal voordelen, waaronder verbeterde bloeddrukcontrole, regressie van LVH en verbeterde linker ventrikel ejectiefractie, optimalisering van fosfaatcontrole, en een verbeterde overleving in vergelijking met conventionele HD. Onze thuisdialyse cohort had bloeddruk- en laboratoriumparameters binnen de K / DOQI streefwaarden gedurende de eerste twee jaar van follow-up. Deze voordelen van thuisdialyse zijn 
cruciaal voor de behandeling van NRSOT patiënten die baat hebben bij hemodynamische stabiliteit en metabole controle (hetgeen essentieel is in het kader van de metabole bijwerkingen van calcineurineremmers). Op basis van onze resultaten, dient thuisdialyse te worden overwogen als een eerste lijn therapie voor NRSOT patiënten die ESRD ontwikkelen. Patiënten dienen te worden voorgelicht over de mogelijkheid van thuisdialyse zodat ze de nierfunctie vervangende therapie kunnen kiezen die het best beantwoordt aan hun levensstijl en medische problematiek. De bevordering van thuisdialyse in deze kwetsbare populatie kan ook helpen om hun levenskwaliteit te verbeteren.

In HOOFDSTUK 5 werden de effecten van intensieve HD op vruchtbaarheid en zwangerschap onderzocht. In HOOFDSTUK $\mathbf{5 . 1}$ werden verbeterde zwangerschapsresultaten waargenomen bij intensieve HD in vergelijking met conventionele HD. Het percentage levende geboorten in de intensieve HD cohort (86.4\%) was significant hoger dan in de conventionele HD cohort $(61.4 \% ; P=0,03)$. Bovendien was de zwangerschapsduur in de intensieve huis $\mathrm{HD}$ cohort 36 weken (IQR, 32-37) tegenover 27 weken (IQR, 21-35) in de conventionele HD cohort $(P=0.002)$. Maternale en neonatale complicaties waren zeldzaam en controleerbaar in de intensieve thuis HD cohort. Ook werd een dosis-respons relatie tussen dialyse intensiteit en zwangerschapsuitkomsten (percentage levend geboren kinderen, zwangerschapsduur en geboortegewicht) vastgelegd. We speculeren dat verhoging van de dialysedosis een beschermende rol kan spelen bij de ontwikkeling van een normale placenta. e voordelige effecten van intensieve HD op het vlak van klinische (bloeddruk, LVH), biochemische (uremische toxines, anemie) en biologische parameters (endotheelfunctie, ontsteking), kunnen hierbij een rol spelen. Het succes van intensieve HD lijkt rechtstreeks verband te houden met het verwijderen van kleine uremische toxines zoals ureum, hoewel dit de effecten van grotere toxines niet uitsluit. In een reeks van 28 zwangere HD patiënten, werd een significante negatieve relatie waargenomen tussen ureum enerzijds en geboortegewicht $(r=0,53, P=0,02)$ en zwangerschapsduur $(r=0,50, P=0,02)$ anderzijds. Bovendien kan de resterende nierfunctie zwangerschapsuitkomsten verbeteren. Onze studie bevestigt het belang van optimalisatie van klaring van uremische toxines met verbeterde levende geboortecijfers onder vrouwen met resterende nierfunctie en intensieve HD regimes. De dialysedosis dient aldus te worden getitreerd om een optimale metabole controle te realiseren, waarbij vrouwen met meer residuele nierfunctie allicht minder intensief hoeven te dialyseren in vergelijking met vrouwen die anuur zijn. 
In HOOFDSTUK 5.2 hebben we aangetoond dat intensieve HD de kans op conceptie verhoogt in vergelijking met conventionele $\mathrm{HD}$. We beschreven elf zwangerschappen bij vrouwen die stabiel waren op nachtelijke HD. Tot en met december 2011 werden 50 vrouwen in de vruchtbare leeftijd ( $\leq 45$ jaar) in Toronto, Canada behandeld in het nachtelijk HD programma resulterend in $22 \%$ kans op bevruchting. Vrouwen met ESRD hebben gonadale dysfunctie dewelke zich manifesteert als anovulatie, onregelmatige menstruatie en vroege menopauze. Zwangerschap is derhalve ongebruikelijk bij vrouwen aan dialyse met conceptie ratio's in de literatuur variërend van $<1 \%$ tot $7.9 \%$. De meest complete gegevens verzameld van alle HD eenheden in België in 1996, met inbegrip van alle 32 dialysecentra (totaal van 4135 patiënten waarvan 1472 in de vruchtbare periode), toonde een zwangerschapsincidentie na het eerste trimester van slechts 0.3 per 100 patiëntjaren. In de meest recente analyse uit Australië en NieuwZeeland, was de kans op zwangerschap in gedialyseerde vrouwen in het tijdperk 199620083.3 per 1000 patiëntjaren. Op deze manier tonen onze data de hoogste concepties in de literatuur tot op heden. Ook in hoofdstuk 5.2 worden de resultaten beschreven van de verloskundige follow-up van de zwangerschappen tijdens nachtelijke thuis HD. We toonden hierbij aan dat de volgende parameters grotendeels binnen de normale waarden van normale zwangerschappen vielen: mediane resultaten van individuele first trimester screen (FTS) en van maternal serum screen (MSS) parameters, de lengte en dikte van de placenta evenals mediane uteriene en umbilicale pulsatiliteitsindices en mediane cervixlengte. Hieruit blijkt dat er bij deze bestudeerde zwangerschappen een adequate groei en perfusie van de placenta was. Ook seriële bepalingen van foetale groei toonde waarden rondom de $50^{\text {ste }}$ percentiel, behalve voor 1 zwangerschap gecompliceerd door intra-uteriene groeivertraging. Placentapathologie was beschikbaar in 8 gevallen, en de overgrote meerderheid liet geen opvallende afwijkingen zien. Deze normale resultaten van verloskundige parameters tijdens de zwangerschap follow-up passen bij de verbeterde resultaten van de zwangerschap tijdens intensieve thuis HD zoals aangetoond in hoofdstuk 5.1.

Verbeterde endotheelfunctie kan helpen bij gezonde placenta-implantatie en bij preventie van pre-eclampsie. Nachtelijke HD heeft een bewezen vasculair voordeel, waaronder significante vermindering van perifere vasculaire weerstand, samen met verbeteringen in de markers van endotheelfunctie zoals baroreceptor gevoeligheid, herstel van endotheliale voorlopercellen en endotheel-afhankelijke vaatverwijding. Endotheel-afhankelijke vasodilatatie kan niet worden uitgelokt bij patiënten tijdens conventionele $\mathrm{HD}$, maar wel kort (2 maanden) na de initiatie van intensieve nachtelijke $\mathrm{HD}$; dit illustreert het belang van adequate dialyse vóór de conceptie om de kans op normale placenta-implantatie te vergroten. In HOOFDSTUK $\mathbf{5 . 3}$ illustreerden we de 
beschermende effecten van intensieve HD op endotheelfunctie en bloeddrukcontrole in een patiënt die met intensieve HD begon in week 26 van de zwangerschap. Deze patiënt had stabiele resultaten van de wekelijkse 24-uurs bloeddrukmetingen en hemodynamische en arteriële stijfheid parameters, in combinatie met vergelijkbare seriële resultaten van de angiogene factoren soluble fms-like tyrosine kinase (sFlt-1) en placental growth factor (PIGF) als bij normale zwangerschappen. Vooral in de anure zwangere dialysepatiënt, kan de klinische diagnose van pre-eclampsie zeer uitdagend zijn. Bij deze patiënten kan het bepalen van (anti-) angiogene factoren dus een rol hebben. Shan et al. rapporteerde een zwangere dialysepatiënt met oncontroleerbare hypertensie bij 29 weken zwangerschap. Er werd een keizersnede uitgevoerd. Verrassend genoeg liet de placenta pathologie geen afwijkingen compatibel met preeclampsie zien, en retrospectieve analyse van antepartum sFlt-1 en oplosbare endoglinespiegels toonde waarden vergelijkbaar met normale zwangerschappen. Er werd geconcludeerd dat volume overbelasting en dus niet pre-eclampsie aan de grondslag lag van hypertensie bij deze patiënt. Twee andere studies bevestigden het gebruik van anti-angiogene factoren als een betrouwbaar hulpmiddel bij de beoordeling van pre-eclampsie. Bovendien werd onlangs op elegante wijze aangetoond dat (anti-) angiogene factoren zeer nuttig kunnen zijn om het onderscheid te maken tussen CKD en pre-eclampsie. Het serieel gebruik van de beschreven cardiovasculaire metingen in combinatie met een seriële follow-up van (anti-) angiogene factoren kan een waardevolle toevoeging zijn aan het arsenaal van klinische en technische middelen die momenteel worden gebruikt in de zorgvuldige opvolging van deze gecompliceerde patiënten. Grote prospectieve studies zijn weliswaar nodig om het potentieel extra voordeel van seriële meting van anti-angiogene factoren, evenals van 24-uurs bloeddruk en centrale hemodynamiek in het beleid van zwangere dialysepatiënten te onderzoeken.

In HOOFDSTUK 6 werd de mogelijke rol van intensieve en thuis HD voor oudere patiënten met terminale nierinsufficiëntie besproken. In HOOFDSTUK 6.1 speculeerden wij over de mogelijke onderliggende mechanismen van de ontwikkeling van geriatrische syndromen waaronder zwakheid bij ouderen na de start van de dialyse. Deze mechanismen kunnen onder meer intra-dialytische hemodynamische instabiliteit, cardiale gebeurtenissen en cerebrale stoornissen betreffen. Ook ondervoeding, infecties, slaapstoornissen en psychische complicaties van het starten van dialyse kunnen bijdragen tot verlies van functionaliteit in deze kwetsbare patiëntenpopulatie. Onze hypothese is dat intensieve HD oudere patiënten met terminale nierinsufficiëntie tegen deze geriatrische syndromen kan beschermen door de vermindering van de incidentie van de hiervoor genoemde dialysecomplicaties op basis van de bestaande 
voordelen van intensieve HD. Deze voordelen van intensieve HD omvatten lagere ultrafiltratie ratio's (snelheid van ontwatering), verlaging van de arteriële bloeddruk en $\mathrm{LVH}$, verbetering van de endotheelfunctie en het autonoom zenuwstelsel, bescherming tegen myocardiale stunning (wandbewegingsstoornissen van het hart door verminderde doorbloeding van de kleine bloedvaten van het hart), alsook vermindering van slaapapnoe.

In HOOFDSTUK 6.2 werden de praktische aspecten en de toekomstperspectieven van intensieve thuis $\mathrm{HD}$ bij ouderen besproken. Oudere ESRD patiënten hebben een lagere tendens tot self-care dialyse vanwege toegenomen co-morbiditeiten, een hoger risico op cognitieve dysfunctie, verhoogde kwetsbaarheid en potentiële sensorische stoornissen. Overleving van oudere patiënten aan thuisdialyse is vooral onderzocht bij PD. In een kleine studie uit Nieuw-Zeeland hadden 25 self-care thuisdialyse (PD en HD) patiënten vergelijkbare overlevingscijfers als de landelijke gemiddelde overleving van dialysepatiënten. Recente studies hebben aan het licht gebracht dat bij ouderen de impact van ziekte en behandeling bij thuisdialyse (vooral PD) lager ligt dan bij incentrum HD behandelingen. De haalbaarheid van thuisdialyse bij oudere dialysepatiënten blijkt uit relatief hoge aantallen thuisbehandelingen in Australië en Nieuw-Zeeland, waar 24\% (respectievelijk 4 en 20\%) en 47\% (respectievelijk 8 en 39\%) van de oudere patiënten thuisdialyse doen (respectievelijk thuis HD en PD). Daar waar oudere patiënten dienen gemotiveerd te worden om meer betrokken te zijn bij hun behandeling, verhoogt de mogelijkheid van thuishulp het in aanmerking komen voor thuisdialyse. Bij het overwegen van thuisbehandelingen bij ouderen, is het uiterst belangrijk om ook rekening houden met de mantelzorger van de dialysepatiënt. $M$ antelzorgers ervaren vaak emotionele stress, angst, depressie en een verslechtering van de gezondheid, en ze melden ook gevoelens van isolatie en uitputting. Om die reden is pre-dialyse beoordeling van de thuissituatie door de maatschappelijk werker van cruciaal belang om de veerkracht van de patiënt, maar ook van de mantelzorger van de ESRD patiënt in te schatten om aldus onnodige beproevingen te voorkomen en in plaats daarvan professionele zorgverleners in te schakelen. Veel oudere ESRD patiënten verblijven in een zorginstelling. Dialysepatiënten uit eenzelfde regio kunnen bijvoorbeeld worden opgenomen in hetzelfde verpleeghuis waar dialysedeskundigheid aanwezig is. HD in het verpleeghuis kan de last voor de patiënt van transport naar en van het dialysecentrum wegnemen. Dit transport verlaagt overigens drastisch de levenskwaliteit van deze patiënten door interferentie met waardevolle revalidatie, sociale interactie en maaltijden. Bovendien kan HD in het verpleeghuis de kosten van de HD-behandelingen drastisch verlagen, gezien gespecialiseerde busjes voor rolstoelvervoer of ambulances vaak nodig zijn voor de verpleeghuispatiënten. Ook laat 
nachtelijke HD een minimum aantal dialyseverpleegkundigen toe om deze behandeling uit te voeren. De haalbaarheid van HD in verpleeghuizen werd aangetoond in een groot cohort in de VS. Het succes van hun programma werd aangetoond door een hoog percentage (40\%) van patiënten in het revalidatieprogramma alsook evolutie richting ontslag naar de thuissituatie. De dialysebehandelingen werden er uitgevoerd door dialysetechnologen (medewerkers van de instrumentele dienst) die minstens 3 jaar ervaring hadden met dialyse, en een geregistreerde verpleegkundige was beschikbaar voor noodsituaties. De nefrologen kwamen naar de verpleeghuizen om er de patiënten te zien. In een andere studie hadden HD patiënten die in een verpleeghuis verblijven, meer kans op intra-dialytische hypotensie dan andere patiënten. In dit verband kan intensieve HD bijdragen tot het voorkomen van dialyse-gerelateerde hypotensie door de ultrafiltratiesnelheid te verlagen, door bescherming tegen myocardiale stunning, door reductie van LVH en verbetering van de voedingstoestand, autonome functie en arteriële compliantie. Ook in de studie van Reddy et al hadden nieuwe verpleeghuis dialysepatiënten meer myocardiale infarcten, infecties en een lager serum albumine en hemoglobine in vergelijking met patiënten die er reeds langer verbleven. Ook hier kan intensieve HD de ideale strategie zijn om deze potentiële ESRD en dialyse complicaties tegen te gaan via dezelfde mechanismen als hierboven beschreven. Assistentie van oudere patiënten en hun partners en/of mantelzorgers in combinatie met revalidatie lijken noodzakelijke activa om de implementatie van deze modaliteit bij oudere patiënten met terminale nierinsufficiëntie te faciliteren. Ook de mogelijkheid van verpleeghuis $H D$ verdient verdere evaluatie.

In HOOFDSTUK 6.3 hebben we de haalbaarheid van thuis HD bij oudere patiënten bestudeerd. Hiervoor hebben we een internationale multicentrische retrospectieve studie uitgevoerd van thuis HD patiënten die tussen 1 januari 1970 en 31 december 2012 met thuis HD zijn gestart toen ze 65 jaar of ouder waren. Het primaire eindpunt van de studie was de tijd tot techniek falen (onvermogen om thuis HD te continueren) of tot overlijden tijdens de periode vanaf de start van thuis HD. Negenenzeventig patiënten van 65 jaar of ouder werden geïncludeerd. Event-vrije (zonder techniek falen of overlijden) overleving bij 1,2 en 5 jaar was resp. $85 \%, 77 \%$ en $24 \%$, en techniekoverleving was resp. $92 \%, 83 \%$ en $56 \%$. Gevorderde leeftijd was een nietgecorrigeerde risicofactor voor overlijden en techniek falen. Onze gegevens documenteren de haalbaarheid van thuis HD in een oudere ESRD bevolking. Event-vrije en techniekoverleving in deze oudere ESRD cohort was lager dan bij de jongere thuis HD bevolking, maar lijkt vergelijkbaar met de Nieuw-Zeelandse thuisdialyse ouderencohort die een 1-, 2- en 3-jaars overleving van $90 \%, 84 \%$ en $56 \%$ rapporteerde (gecombineerd voor PD en thuis HD), en een 1-, 2- en 3-jaars techniekoverleving van 
$83 \%, 73 \%$ en $36 \%$ (voor alleen thuis HD). Deze self-care thuisdialysepatiënten in NieuwZeeland hadden overlevingskansen vergelijkbaar met landelijke gemiddelden, en techniekoverlevingskansen vergelijkbaar met in-centrum HD behandelingen. De overlevingscijfers van ons studiecohort waren superieur aan de overlevingskansen van incidente dialyse (PD, in het centrum HD en thuis HD) patiënten uit de 2001-2005 ERA EDTA Registry. De resultaten lijken ook in dezelfde lijn te liggen als die van de andere thuisdialyse modaliteit, PD, bij oudere ESRD cohorten. Yang et al. vermeldden een overleving na 1, 3 en 5 jaar van respectievelijk $84 \%$, 56\% en 38\% bij patiënten van $65-74$ jaar. De techniekoverleving na 2 jaar was $88 \%$ bij patiënten van 65 jaar of ouder. De Canadese Organ Replacement Register (CORR) rapporteerde een ongecorrigeerde 1-jaars, 3-jaars en 5-jaars patiënten overleving van respectievelijk $83.9 \%$, 52.6\% en $32.2 \%$ bij patiënten van 65-74 jaar. Daar waar thuis HD haalbaar is bij oudere patiënten met terminale nierinsufficiëntie (ESRD), zijn ze allicht ook zeer geselecteerd. Negentien van de 79 (24\%) patiënten die thuis HD startten op een leeftijd ouder dan 65 jaar, kregen een niertransplantatie, wat een illustratie is van de relatief goed bewaard gebleven algemene toestand van de patiënten in dit cohort. Verder hadden de meeste patiënten in dit internationale cohort een arterioveneuze fistel als vaattoegang, wat opnieuw een weerspiegeling van optimale pre-dialyse voorbereiding en case selectie kan zijn. De resultaten van onze analyse onthullen ook een aantal potentiële valkuilen voor de verdere implementatie van thuis $\mathrm{HD}$ bij oudere patiënten met terminale nierinsufficiëntie, zoals belasting van de mantelzorger en noodzaak voor verlengde trainingstijden. Meer dan de helft van de patiënten in ons cohort vereiste thuishulp hetzij door de partner of door een dialyse-assistent. Het potentieel van de uitbreiding van thuis HD naar assisted (ondersteuning van een dialyse verpleegkundige of andere medewerker) intensieve thuis HD zal een aanzienlijke investering in infrastructuur vergen die moet worden afgewogen tegen de verwachte voordelen. Interessant is dat $35 \%$ van onze patiënten werd bijgestaan door een familielid. In deze context weten we, zoals eerder vermeld, dat de mantelzorger evenveel aandacht en zorg behoeft als de patiënt. In een recente cross-sectionele studie uit Toronto onder 36 prevalente nachtelijke thuis HD patiënten en 31 zorgverleners, voldeed $25 \%$ van de mantelzorgers aan depressie criteria. De gemiddelde leeftijd in dit Toronto cohort was 52 jaar voor patiënten en 51 jaar voor de zorgverleners, en we kunnen dus verwachten dat de depressie prevalentie bij oudere patiënten en hun verzorgers aanzienlijk hoger zal zijn. Dit benadrukt opnieuw de noodzaak van adequate multidisciplinaire ondersteuning door artsen, verpleegkundig personeel, psychologen en maatschappelijk werkers van deze kwetsbare patiënten en hun zorgverleners. Meer onderzoek is nodig om de impact van thuis HD op de overleving, kwaliteit van leven, hospitalisatie, vasculaire toegang en kostenproblemen bij ouderen vast te stellen. Toekomstig onderzoek zal zich 
ook moeten richten op de specifieke behoeften in de infrastructuur van thuis HD afdelingen om oudere thuis HD patiënten maximaal te ondersteunen, zoals bij voorbeeld op het vlak van trainingstijd, de beschikbaarheid van back-up dialyse, en de ontwikkeling van gebruiksvriendelijke thuis HD toestellen.

In HOOFDSTUK 7 tot slot, voerden we een grondige review uit van de beschikbare studies in de literatuur over vaattoegang bij patiënten die frequente HD doen in vergelijking met conventionele HD. Eén van de barrières van intensieve thuis $H D$ is inderdaad het creëren en onderhouden van een goede toegang tot de bloedbaan. Als intensieve HD gepaard zou gaan met frequentere complicaties van de vaattoegang, kan het leiden tot een verhoogde morbiditeit, verminderde kwaliteit van leven, en toegenomen kosten. In een van de vroege studies van dit onderwerp, meldde Woods et al. in 1999 dat het aantal vaattoegangscomplicaties verminderde na omschakeling van conventionele HD naar dagelijkse HD. Deze bevinding werd een jaar later bevestigd door Quintaliani et al. Echter, meer recente studies, met inbegrip van de FHN studies, hebben deze vaststelling doen wankelen. In de dagelijkse FHN studie ondervonden patiënten gerandomiseerd in de intensieve HD arm significant meer interventies ter hoogte van de arterioveneuze toegang dan de patiënten gerandomiseerd in de conventionele $\mathrm{HD}$ arm. Zij het niet significant, werden vergelijkbare trends waargenomen in de nachtelijke FHN trial. Deze ietwat dubbelzinnige situatie motiveerde ons om de bestaande studies over vaattoegangsuitkomsten bij intensieve HD patiënten op een rijtje te zetten. Onze analyse consolideerde 1540 vaattoegangsjaren voor intensieve HD en 2284 vaattoegangsjaren voor conventionele HD, en toonde aan dat intensieve HD geassocieerd is met een hogere vaattoegangscomplicatierisico in vergelijking met conventionele $\mathrm{HD}$ (verschil=6.7 gevallen per 100 patiëntjaren, $P=0.009$ voor alle opgenomen studies). Globale event ratio's in de arterioveneuze graft (AVG) groep (61.0 gevallen per 100 patiëntjaren in de conventionele HD en 98.6 gevallen per 100 patiëntjaren in de intensieve HD groep) en in de katheter groep (36.0 gevallen per 100 patiëntjaren in de conventionele HD en 52.9 gevallen per 100 patiëntjaren in intensieve HD) waren hoger dan in de arterioveneuze fistel (AVF) groep. Ook waren de vaattoegangsevent ratio's hoger, hoewel niet significant, bij intensieve HD patiënten vergeleken met conventionele HD zowel voor de AVG-groep (verschil =37.6 gevallen per 100 patiëntjaren, $P=0.139$ ) als de kathetergroep (verschil $=16.9$ gebeurtenissen per 100 patiëntjaren, $P=0.133$ ); het verschil in de AVF groep was kleiner (verschil 2.7, $P=0.162$ ). AVG's in het bijzonder vroegtijdig falen in intensieve $H D$, omdat frequentere cannulatie (prikken in de vaattoegang) leidt tot verzwakking van het prothesemateriaal. Aan de andere kant kan de behoefte voor meer frequente manipulatie bij intensieve HD het risico van katheter- 
gerelateerde infecties verhogen. In lijn met de huidige aanbevelingen voor conventionele $\mathrm{HD}$, kan men in de verleiding zijn om deze resultaten te interpreteren als ondersteunende data voor de Fistula First Strategie ook bij intensieve HD patiënten. Echter, tot op heden werd geen enkele gerandomiseerde studie verricht die verschillende vaattoegangsvormen direct met elkaar vergeleek bij intensieve HD patiënten.

\section{Conclusies van dit proefschrift}

\section{Deel I: Acute effecten van intensieve hemodialyse}

1. Verlengen van de dialyseduur verbetert de stabiliteit tijdens de dialyse van de perifere en centrale systolische en diastolische bloeddruk, alsook van cardiac output en relatief bloedvolume. Er werden geen verschillen in hemodynamische stabiliteit gevonden tussen HD en HDF, allicht omdat met koel dialysaat werd gedialyseerd.

2. Verlengen van de dialyseduur verhoogt de reductie en verwijdering van kleine en middelgrote moleculen (zoals beta2-microglobuline en FGF-23) ten opzichte van conventionele (4-uurs) HD. HDF heeft een significant bijkomend voordeel op de reductie en verwijdering van middelgrote moleculen ten opzichte van HD.

3. Verlengen van de dialyseduur verhoogt ook de reductie en verwijdering van de meeste eiwitgebonden uremische toxines, dicarbonyl-stress verbindingen en vrije AGE's ten opzichte van conventionele (4-uurs) HD, tenminste als de bloedflow en de dialysaatflow behouden blijven. HDF heeft slechts beperkte bijkomende winst in vergelijking met $H D$ in de reductie en verwijdering van deze non-traditionele uremische toxines.

\section{Deel II: Lange-termijn resultaten van intensieve en thuis hemodialyse}

1. Thuisdialyse is mogelijk bij patiënten die terminaal nierfalen ontwikkelen na nietrenale soliede orgaantransplantatie. Bovendien zou thuisdialyse aan deze patiëntenpopulatie bepaalde voordelen kunnen bieden ten opzichte van incentrum conventionele HD, vooral op hemodynamisch en metabool vlak.

2. Intensieve thuis $\mathrm{HD}$ is geassocieerd met verbeterde zwangerschapsresultaten zoals zwangerschapsduur en geboortegewicht ten opzichte van conventionele HD. Dit valt ook samen met vergelijkbare resultaten bij zwangere patiënten tijdens intensieve HD van obstetrische en hemodynamische monitoring als bij zwangeren 
met normale nierfunctie. Tot slot resulteert intensieve HD in verbeterde conceptie in vergelijking met conventionele HD.

3. Intensieve thuis HD zou ook bepaalde voordelen kunnen bieden bij oudere patiënten met terminaal nierfalen. Wij speculeerden hoe intensieve thuis HD de oudere dialysepatiënt zou kunnen beschermen tegen frailty en het ontwikkelen van geriatrische syndromen. Verder toonden we in een internationale analyse aan dat thuis HD mogelijk is bij patiënten die 65 jaar of ouder zijn op het moment dat ze thuis HD opstarten. Deze resultaten kunnen gebruikt worden om verder onderzoek naar de voordelen van thuis HD bij ouderen op het vlak van levenskwaliteit, functionaliteit, overleving, vaattoegang en kosten te stimuleren.

4. Frequente HD is geassocieerd met een verhoogde kans op complicaties van de vaattoegang in vergelijking met conventionele HD. Toekomstig onderzoek is noodzakelijk om na te gaan of arterioveneuze fistels ook bij intensieve HD de eerste keuze zijn. 

List of abbreviations 



\section{List of abbreviations}

$\begin{array}{ll}\text { ACE } & \text { Angiotensin Converting Enzyme } \\ \text { AFI } & \text { Amniotic Fluid Index } \\ \text { AFP } & \text { Alpha Fetoprotein } \\ \text { AGES } & \text { Advanced Glycation End products } \\ \text { ANOVA } & \text { Analysis of Variance } \\ \text { APGAR } & \text { Appearance Pulse Grimace Activity Respiration } \\ \text { ARPD } & \text { American Registry for Pregnancy in Dialysis patients } \\ \text { AVF } & \text { Arteriovenous Fistula } \\ \text { AVG } & \text { Arteriovenous Graft } \\ \text { BCM } & \text { Body Composition M onitor } \\ \text { B2M } & \text { Beta2-M icroglobulin } \\ \text { BMI } & \text { Body Mass Index } \\ \text { BP } & \text { Blood Pressure } \\ \text { BTM } & \text { Blood Temperature Monitor } \\ \text { BUN } & \text { Blood Urea Nitrogen } \\ \text { BVM } & \text { Blood Volume M onitor } \\ \text { CAPD } & \text { Continuous Ambulatory Peritoneal Dialysis } \\ \text { CCPD } & \text { Continuous Cycling Peritoneal Dialysis } \\ \text { CEL } & \text { Carboxyethyllysine } \\ \text { CNI } & \text { Calcineurin Inhibitor } \\ \text { C } & \text { pre-dialysis Concentration } \\ \text { Cre } & \text { post-dialysis Concentration } \\ \text { CTG } & \text { Cardiotocography } \\ \text { hCG } & \text { human Chorionic Gonadotropin } \\ \text { CKD } & \text { Chronic Kidney Disease } \\ \text { Cl } & \text { dialytic Clearance } \\ \text { CML } & \text { Carboxymethyllysine } \\ \text { CMPF } & \text { 3-carboxyl-4-methyl-5-propyl-2-furanpropionic acid } \\ \text { CO } & \text { Cardiac Output } \\ \text { DDS } & \text { Dialysis Disequilibrium Syndrome } \\ \text { 3-DG } & \text { 3-Deoxyglucosone } \\ \text { DIA } & \text { Inhibin A } \\ \text { uE3 } & \text { unconjugated Estriol } \\ \text { EFW } & \text { Estimated Fetal Weight } \\ \text { ESRD } & \text { End-Stage Renal Disease } \\ \text { ET } & \text { Energy Transfer } \\ \text { FGF23 } & \text { Fibroblast Growth Factor 23 } \\ \text { FHN } & \text { Frequent Hemodialysis Network } \\ \text { FTS } & \text { First Trimester Screen } \\ \text { GFR } & \text { Glomerular Filtration Rate } \\ \text { GO } & \text { Glyoxal } \\ & \end{array}$




$\begin{array}{ll}\text { HA } & \text { Hippuric Acid } \\ \text { HD } & \text { Hemodialysis } \\ \text { HD4 } & \text { 4-hour Hemodialysis } \\ \text { HD8 } & \text { 8-hour Hemodialysis } \\ \text { HDF } & \text { Hemodiafiltration } \\ \text { HDF4 } & \text { 4-hour Hemodiafiltration } \\ \text { HDF8 } & \text { 8-hour Hemodiafiltration } \\ \text { HPLC } & \text { High-Performance Liquid Chromatography } \\ \text { HR } & \text { Heart Rate } \\ \text { IAA } & \text { Indole-3-Acetic Acid } \\ \text { IQR } & \text { Interquartile Range } \\ \text { IS } & \text { Indoxyl Sulphate } \\ \text { IUGR } & \text { Intra-Uterine Growth Restriction } \\ \text { K/ DOQI } & \text { Kidney Disease Outcomes Quality Initiatives } \\ \text { LSD } & \text { Least Significant Difference } \\ \text { LVH } & \text { Left Ventricular Hypertrophy } \\ \text { MDRD } & \text { Modification of Diet in Renal Diseases } \\ \text { MG } & \text { Methylglyoxal } \\ \text { MG-H1 } & \text { hydromethyl-imidazolon-ornithine } \\ \text { MW } & \text { Molecular Weight } \\ \text { MSS } & \text { Maternal Serum Screen } \\ \text { NHD } & \text { Nocturnal Hemodialysis } \\ \text { NRSOT } & \text { Non-Renal Solid organ Transplantation } \\ \text { NS } & \text { Not Significant } \\ \text { NT } & \text { Nuchal Translucency } \\ \text { PAPP-A } & \text { Pregnancy-Associated Plasma Protein-A } \\ \text { PBUT } & \text { Protein-Bound Uremic Toxins } \\ \text { PCS } & \text { P-Cresyl Sulfate } \\ \text { PCG } & \text { P-Cresyl Glucuronide } \\ \text { PD } & \text { Peritoneal Dialysis } \\ \text { PI } & \text { Pulsatility Index } \\ \text { PIGF } & \text { Placental Growth factor } \\ \text { PreKid } & \text { Pregnancy and Kidney Disease } \\ \text { PVR } & \text { Peripheral Vascular Resistance } \\ \text { PWA } & \text { Pulse Wave Analysis } \\ \text { PWV } & \text { Pulse Wave Velocity } \\ \text { QOL } & \text { Quality of Life } \\ \text { RBC } & \text { Red Blood Cell } \\ \text { RBV } & \text { Relative Blood Volume } \\ \text { RCT } & \text { Randomized Controlled Trial } \\ \text { RP-HPLC } & \text { Reversed Phase-High-Performance Liquid Chromatography } \\ \text { RKF } & \text { Residual Kidney Function } \\ \text { RR } & \text { Reduction Ratio } \\ & \end{array}$


RRT

SD

SDHD

sFlt-1

TP

TSR

UPLC-MS
Renal Replacement Therapy

Standard Deviation

Short Daily Hemodialysis

soluble fms-like kinase

Total Protein

Total Solute Removal

Ultra-Performance Liquid Chromatography-tandem M ass

Spectrometry 



\section{Valorisation}





\section{Valorisation}

In the relevant context of economic crisis and an ageing population, we are nowadays confronted with an increasing economic pressure on healthcare management with concomitantly increasing expectations of quality and accessibility of healthcare. The healthcare sector has indeed to cope with a rising demand for services in the presence of limited budgetary conditions. Innovative and cost-saving approaches in healthcare are required to implement sustained and universal high quality care to our patients. This should be the mainstay of translational and clinical research: searching for innovation in diagnosis and treatment resulting in an excellent balance between quality and cost of healthcare.

The number of prevalent end-stage renal disease (ESRD) and dialysis patients steadily increases by almost $7 \%$ per year allover the world ${ }^{1}$. Also in the Netherlands, a yearly increase of $3 \%$ in prevalent dialysis patients is seen . M ost of these patients are dialyzed in the hospital, and only a small minority of these patients perform home dialysis [peritoneal dialysis (PD) or home hemodialysis (HD)]. Survival and quality of life of this in-centre HD patient population has serious limitations. On the other hand, a significant part of the healthcare budget is spent to dialysis, whereas we are all confronted with increasing restrictions of healthcare resources. Dialysis accounts for at least $1 \%$ of healthcare expenditure in the United States, United Kingdom, Australia, New Zealand, but also in the Netherlands ${ }^{2-5}$.

In this thesis, we studied outcomes of intensive and home HD, a nowadays still underutilized strategy in the management of patients with ESRD. Rates of home HD use vary internationally, representing $1.3 \%$ and $3.4 \%$ of all dialysis patients in the United States and United Kingdom, respectively, and $11 \%$ and $18 \%$ of those in Australia and New Zealand, respectively ${ }^{6,7}$. In the Netherlands, $2.7 \%$ of all dialysis patients perform home $H D^{8}$. Both clinical benefits and risks-barriers of intensive and home HD represent an opportunity for ongoing research and quality improvement initiatives to further stimulate the adoption of intensive and home HD in the general dialysis population as well as in specific patient groups. In the next paragraphs, we will discuss the valorisation of the knowledge gained from this thesis from three different perspectives: the dialysis patient perspective, the healthcare institution perspective, as well as the health economics perspective of ESRD and dialysis. 


\section{The dialysis patient}

Home and intensive HD has the potential to enhance survival and quality of life of patients who require dialysis. In this thesis, we found additional benefits of home and intensive $\mathrm{HD}$ at the level of cardiovascular protection, reduction of traditional and nontraditional uremic toxins, in the setting of development of ESRD after NRSOT, in pregnancy and fertility, and potentially in elderly ESRD patients. These advantages may contribute to increased quality of life and survival of dialysis patients, although this was not directly investigated in this thesis.

\section{The healthcare institution: "Vision on Care" of Maastricht UMC+}

The vision of "home dialysis first", which is already implemented in the pre-dialysis clinic and education in our unit at the Maastricht University M edical Centre, also fits within the vision of our hospital ${ }^{9,10}$. The document "Vision of Care" of the Maastricht University Medical Centre stipulates that patients should strive for autonomy and participate in their healthcare as much as they can. "The patient must rely on expert, high quality and safe care. Conversely, the caregiver can count on a patient who feels responsible and shows an appropriate use of effective care. A patient should also be aware of the rising cost of care. This means: a patient who is willing to exploit the opportunities for self-management, who will also follow-up on diagnostic and therapeutic approach, and who wants to participate in new initiatives of care. In short, a patient who wants to participate in transparency of quality and effectiveness of care (Vision on Care from the medical perspective. 1. The patient is central...the participating patient. M aastricht UMC+) (Figure 11.1) ${ }^{11}$.

Home dialysis, both home HD and PD, stimulates the autonomy of the patient because patients and family are involved in patient care to a larger extent than patients on incentre HD. Currenty, half of the patients in the predialysis clinic of the Maastricht University Medical Centre choose to do home dialysis, either PD or home HD, after proper pre-dialysis educational sessions. In Maastricht, 35\% of the prevalent dialysis population is dialyzing at home, and another $15-20 \%$ of the patients dialyzes in Hotel Juliana in Valkenburg, meaning that half of our dialysis patients dialyzes outside the hospital. This thesis adds clinical evidence to the ample benefits of home dialysis, and supports our strategy to even increase the adoption of home dialysis in the future.

In this context, a recent meta-analysis on patient and caregiver perspectives of home $H D$, revealed the importance of clinician validation of decision in order to create an opportunity to thrive for our patients stimulating their freedom and normality ${ }^{12}$. Medical responsiveness, which may be enhanced by proper home HD training of 
nephrologists as well as by expanding the body of evidence regarding home HD advantages, increased the confidence of patients and caregivers to dialyze independently (Figure 11.2).

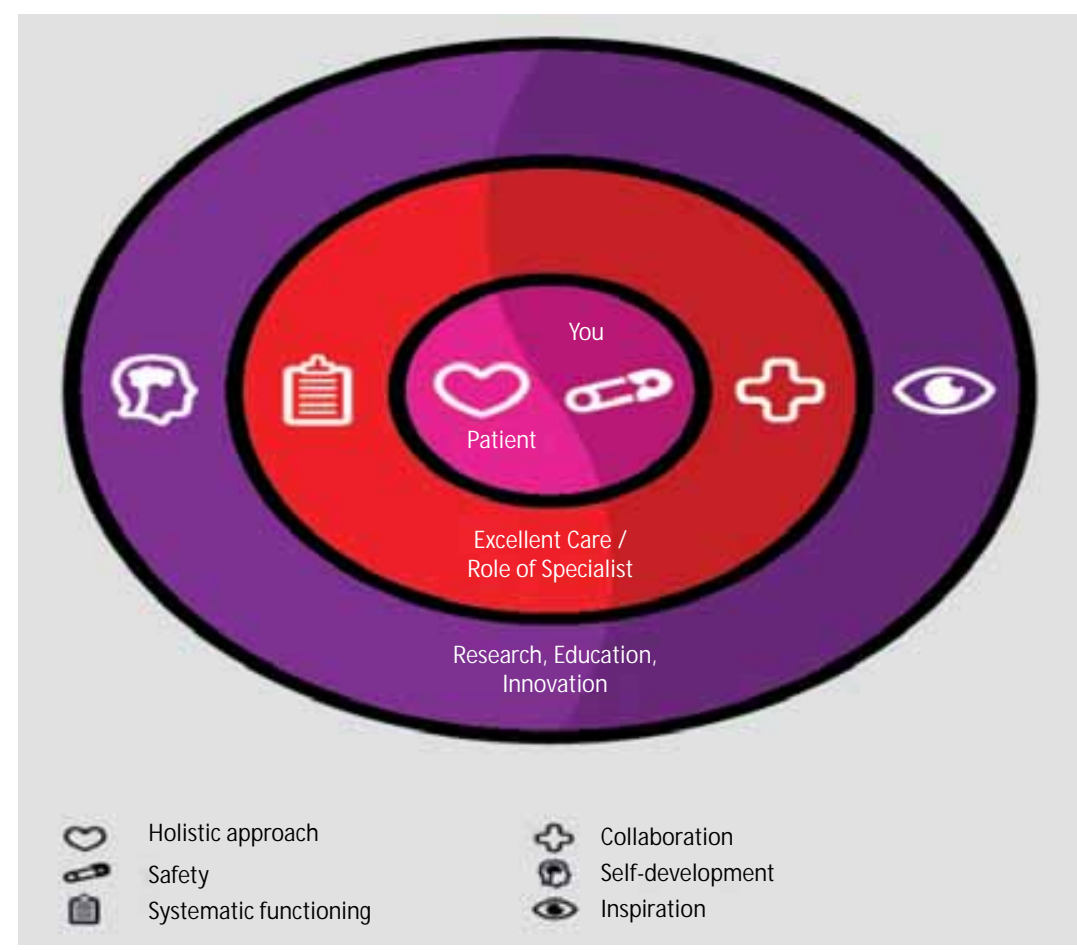

Figure 11.1 Vision on care from the medical perspective. Adapted from Vision on M edical Care 2013-2017 Maastricht UMC+.

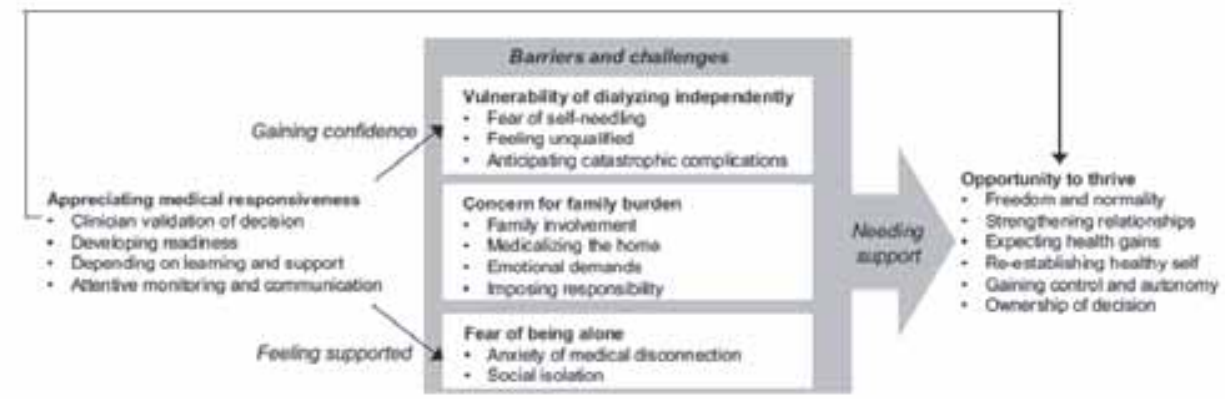

Figure 11.2 Thematic scheme of adult patients' and caregivers' experiences and perspectives of home HD (adopted from ref. 12). 


\section{Health economics of ESRD and dialysis}

In developed nations, home HD is generally cost-effective compared to hospital-based HD. This was recently confirmed by Walker et al in a systematic review of full economic evaluations between 2003 and 2014 in order to analyze the cost-effectiveness of contemporary home HD modalities compared with facility HD ${ }^{13}$. Six studies of economic evaluations that compared home to facility HD were identified ${ }^{14-19}$. Two studies compared home nocturnal HD, one home nocturnal and daily home HD, and three compared conventional home HD to facility HD. The main finding of this review was that contemporary home HD modalities including nocturnal and daily regimens are generally of equivalent cost or are cost-effective compared with conventional facility HD. A variety of reasons explain why home HD modalities are mostly cheaper compared to in-centre HD: reduced need for expensive hospital space, reduced need for dialysis nurses, increased employment by home dialysis, and reduced transport costs to the dialysis centre and back home.

We performed a preliminary economic analysis of HD modalities in the Netherlands ${ }^{20}$. The analysis was based on a Markov model which allows the capturing of all possible treatment options for people with ESRD in so-called transition states, including PD, HD, and kidney transplantation ${ }^{21}$. HD may be performed in-centre or at home, at conventional dose or high dose (intensive HD). This model assumes 28-day cycles as this was used in the economic evaluation by Kirby et al. ${ }^{21}$. Per cycle, each patient can be assigned to only one health state from which they can move to another health state, defined by a transition probability. Only one movement is allowed per cycle, and patients can die in any state of treatment (Figure 11.3).

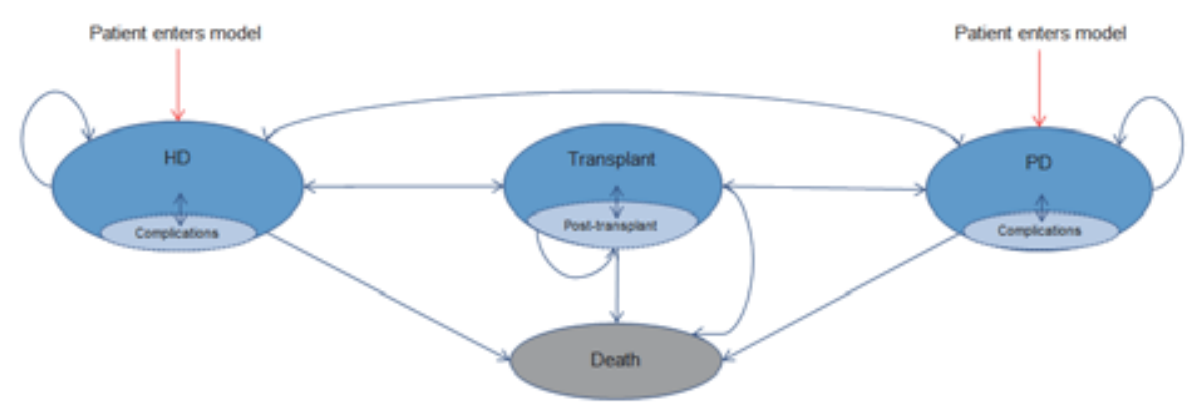

Figure 11.3 The Markov model comprises a number of discrete health states through which patients can transition. HD: hemodialysis; PD: Peritoneal Dialysis. 
As the objective of the analysis was to compare the cost-effectiveness of high dose HD (both in-centre and at home) with conventional in-centre HD, the key parameters of the analysis were quality of life and the survival rates of the studied treatments. The quality of life of a dialysis patient can be determined by health-profile measures which assess health status on a number of domains, such as physical, emotional, or social impairments ${ }^{22}$. They allow the quantification of utilities of dialysis patients on a scale from 0 to 1 , in which 1 corresponds to a perfect health state of the patient. Benefits of high dose HD compared to conventional HD in terms of quality of life were derived from Culleton et al. ${ }^{23}$. Within economic evaluations, the health benefit of a therapy can be expressed in quality adjusted life years (QALYs). QALYs are determined by adjusting the life expectancy (survival) of the patient for the quality of life lived during those years. In this cost-effectiveness analysis, high dose HD therapy (5 sessions of 4 hours HD per week for in-centre high dose HD, and 5 sessions of 7 hours HD per week for high dose home HD) was compared with the current standard-of-care therapy, i.e. in-centre conventional HD (ICHD) (3 sessions of 4 hours HD per week). The differences in cost were weighed against the differences in health benefit ('effect'); this ratio is called the 'incremental cost-effectiveness ratio' (ICER).

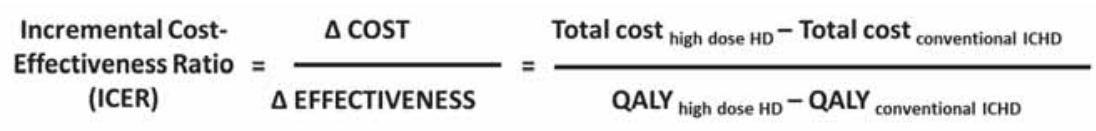

In our model, costs included treatment initiation (dialysis access), treatment (weekly tariffs based on Achmea, including erythropoietin), medication (especially phosphate binders and antihypertensives), complications (hospitalizations), and transportation costs. The willingness to pay (WTP) in the Netherlands lies between $€ 20.000$ and $€ 80.000$ per QALY. In scenario 1 ( $100 \%$ of patients starting on in-centre conventional CHD versus $100 \%$ of patients starting on high dose in-centre HD), the ICER was $€ 279.521$ per QALY, which lies far above the WTP threshold of $€ 80.000$ per QALY. Although high dose HD results in a health benefit increase (+0,267 QALYs) in comparison with conventional in-centre HD, the additional cost (†74.589) for treating the patient with this treatment in-centre is higher than the agreed maximum limit for a treatment. In scenario 2 ( $100 \%$ of patients starting on in-centre conventional HD versus $100 \%$ of patients starting on high dose home HD), the ICER was $€ 16.331$ per QALY, and thus lies below the WTP. High dose HD increased the health benefit of dialysis $(+0,478$ QALYs) for an acceptable cost $(+€ 7.795)$ when the patients were treated at home in comparison with in-centre conventional HD. In scenario 3 ( $100 \%$ of patients starting on in-centre conventional HD versus $100 \%$ of patients starting on conventional home HD), 
the ICER was dominant ( $€ 87.613$ per QALY), signifying that there is an additional health benefit ( $+0,242$ QALYs) when treating patients conventionally at home instead of conventionally in-centre for less costs (-€21.205). In conclusion, also in the Netherlands, home HD is a cost-effective alternative to centre-based HD. These results support our strategy to increase the adoption of home dialysis in our patients with ESRD. 


\section{References}

1. Grassmann A, Gioberge S, Moeller S, Brown G. ESRD patients in 2004: global overview of patient numbers, treatment modalities and associated trends. Nephrol Dial Transplant 2005;20:2587-93.

2. US Renal Data System. Costs of ESRD. In: USRDS 2013 Annual Data Report. www.usrds.org/2013/v2_ch11_13.pdf

3. Ashton T, Marshall MR. The organization and financing of dialysis and kidney transplantation services in New Zealand. Int J Health Care Finance Econ 2007;7:233-52.

4. Cass A, Chadban S, Gallagher M, et al. The economic impact of end-stage kidney disease in Australia: projections to 2020. Sydney, Australia; The George Institute for Global Health; 2010.

5. Manns BJ, Mendelssohn DC, Taub KJ. The economics of end-stage renal disease care in Canada: incentives and impact on delivery of care. Int J Health Care Finance Econ 2007;7:149-69.

6. US Renal Data System. International comparisons. In: USRDS 2013 Annual Data Report. www.usrds.org/2013/v2_ch12_13.pdf

7. M Monald S, Clayton P, Hurst K. The Australia and new Zealand Dialysis and Transplant Registry 35th Annual Report. Adelaide, Australia: ANZDATA; 2012.

8. US Renal Data System. USRDS 2013 Annual Data Report: Atlas of End-Stage Renal Disease in the United States. Vol 2 - Atlas ESRD. International Comparisons. National Institutes of Health, National Institute of Diabetes and Digestive and Kidney Diseases. Bethesda, MD. 2013: 333-344. Available at: www.usrds.org/2013/pdf/v2_ch12_13.pdf. Accessed June 2, 2014.

9. Goovaerts T, Jadoul M, Goffin E. Influence of a pre-dialysis education programme (PDEP) on the mode of renal replacement therapy. Nephrol Dial Transplant 2005;20:1842-7.

10. Goovaerts T, Jadoul M, Goffin E. Influence of a predialysis education program on the choice of renal replacement therapy. Am J Kidney Dis 2012;60:499; author reply 499-500.

11. http://intraspect4.azm.nl/root/diensten_root/projectenENdossiers_root/visieopzorg_root/ visiedocument +medici.pdf. Accessed January 28, 2015.

12. Walker RC, Hanson CS, Palmer SC, et al. Patient and caregiver perspectives on home hemodialysis: a systematic review. Am J Kidney Dis 2015;65:633-48.

13. Walker R, Marshall MR, M orton RL, M cFarlane P, Howard K. The cost-effectiveness of contemporary home haemodialysis modalities compared with facility haemodialysis: a systematic review of full economic evaluations. Nephrology 2014;19:459-470.

14. McFarlane PA, Bayoumi AM, Pierratos A, Redelmeier DA. The quality of life and cost utility of home nocturnal and conventional in-center hemodialysis. Kidney Int 203;64:1004-11.

15. Kroeker A, Clark WF, Heidenheim AP, et al. An operating cost comparison between conventional and home quotidian hemodialysis. Am J Kidney Dis 2003;1:49-55.

16. Gonzalez-Perez JG, Vale L, Stearns SC, Wordsworth S. Hemodialysis for end-stage renal disease: a costeffectiveness analysis of treatment-options. Int J Technol Assess Health Care 2005;21:32-9.

17. Malmstrom RK, Roine RP, Heikkila A, et al. Cost analysis and health-related quality of life of home and self-care satellite haemodialysis. Nephrol Dial Transplant 2008;23:1990-96.

18. Howard K, Salkeld G, White S, et al. The cost-effectiveness of increasing kidney transplantation and home-based dialysis. Nephrology 2009;14:123-32.

19. Klarenbach S, Tonelli M, Pauly R, et al. Economic evaluation of frequent home nocturnal hemodialysis based on a randomized controlled trial. J Am Soc Nephrol 2014;25:587-94.

20. Beby AT, Cornelis T, Zinck R, Culleton B. The cost-effectiveness of high dose hemodialysis in the Netherlands: in-centre and at home. M anuscript in preparation.

21. Kirby L, Vale L. Dialysis for end-stage renal disease. Determining a cost-effective approach. Int J Technol Assess Health Care 2001;17:181-189.

22. Liem YS, Bosch JL, Hunnink MG. Preference-based quality of life of patients on renal replacement therapy: a systematic review and meta-analysis. Value in Health 2008;11:733-741.

23. Culleton $\mathrm{BF}$, Walsh $\mathrm{M}$, Klarenbach $\mathrm{SW}$, et al. Effect of frequent nocturnal hemodialysis vs conventional hemodialysis on left ventricular mass and quality of life: a randomized controlled trial. JAMA 2007; 98:1291-99. 


\section{Dankwoord}




\section{Dankwoord/Acknowledgements}

Het spreekt voor zich dat dit proefschrift nooit tot een einde was gekomen zonder het enthousiasme, de inzet, alsook de sprankelende kwaliteiten en buitengewone talenten van velen. Een dankwoord is dan ook helemaal op zijn plaats aan het einde van dit proefschrift. Indien ik hier toch iemand zou vergeten zijn, zal ik dit achteraf uitgebreid goedmaken. :)

Beste professor Leunissen, beste Karel, ik herinner me levendig onze eerste ontmoeting die plaatsvond tijdens het Amerikaans nefrologiecongres te San Diego in het najaar van 2009. Kort nadien kreeg ik van je te horen dat ik aan de slag kon als nefroloog in de staf nefrologie van het Academisch Ziekenhuis Maastricht. Ik ben je erg dankbaar voor de mogelijkheden die je me hiermee geboden hebt. Het doet deugd op je afdeling te mogen werken samen met de andere stafleden nefrologie en mezelf verder te kunnen ontplooien onder jouw auspiciën.

Beste professor Kooman, beste Jeroen, ik besef maar al te goed welk enorm voordeel het betekent jou als promotor te hebben. Zonder jou had dit werk niet zo een vaart gelopen. Jouw verrassende indrukken en lumineuze ideeën verbazen me steeds opnieuw en werken stimulerend. Ik wil je bedanken voor je inzet, je kritische en snelle evaluaties van onderzoeksideeën en manuscripten, en je positieve supervisie van dit promotietraject.

Dear professor Chan, dear Chris, working in the Torontonian creative and perfectionist academic environment full of highly stimulating nephrologists including yourself, changed me a lot. Your persistent, contagious enthusiasm convinced me of the ample benefits of intensive and home hemodialysis, which was the basic start for this thesis. Having you as a mentor is a great honor, and I cherish our ongoing collaboration and the opportunities you give me. Thank you for being my copromotor!

Beste dokter van der Sande, beste Frank, jou wil ik bedanken voor het faciliteren en het mee-gidsen van het klinisch en onderzoekswerk op onze dialyse-afdeling. Als hoofd van de dialyse-afdeling zorg jij voor een platform waarop jouw medewerkers zich verder kunnen ontwikkelen. Veel dank Frank voor de goede samenwerking en ondersteuning!

Beste leden van de beoordelingscommissie, voorzitter prof. dr. H. ten Cate en leden prof. dr. C.D.A. Stehouwer, prof. dr. W. Van Biesen (Universiteit Gent), prof. dr. J.M.G.A. Schols en dr. C.J. Konings (Catharina Ziekenhuis Eindhoven), dank voor jullie 
bereidwilligheid om dit proefschrift te beoordelen aan de hand van jullie waardevolle commentaren en interessante vraagstellingen.

Beste professor Spaanderman, beste Marc, dank om in de corona te willen plaats nemen, en ook voor de leerrijke besprekingen op klinisch en research vlak en het gezellig tafelen in het ziekenhuisrestaurant.

Dear nephrology mentors (professors B. Bammens, J.M. Bargman, C.T. Chan, E. Goffin, M.A. Hladunewich, D.G. Oreopoulost, and R.S. Parekh), your high-level, idealistic and patient-loving approach of clinical care in combination with high-quality research work is an important stimulus to me. Thank you for your dedicated guidance of my clinical and research work.

Dear national and international collaborators in intensive and home hemodialysis research (Didier Aguilera, Christopher Chan, Tom Dejagere, Tarek Eldehni, Sunny Eloot, Maxence Ficheux, Roula Galland, Eric Goffin, Tony Goovaerts, Michelle Hladunewich, Nicole Heitink-ter Braak, Eero Honkanen, Anu Jayanti, Peter Kotanko, Chris M cIntyre, Sandip M itra, Nicos Mitsides, Akin Özyilmaz, Virpi Rauta, Jean-Philippe Rioux, Karthik Tennankore, Len Usvyat, and Raymond Vanholder), thank you for your great contributions to the research work. Without this inspirational collaborative network, we would never obtain these relevant data in the field of intensive and home hemodialysis. I sincerely hope we can continue to expand our joint research initiatives in the future.

Beste Eveline (Rulkens-Koevoets), Nanda (Diederen) en Natascha (Broers), jullie bijdragen aan het onderzoek op de dialyse-afdeling zijn van onschatbare waarde. Jullie zorgvuldige gedrevenheid, precisie in het bedrijven van onderzoek, en vriendelijke omgang met patiënten en medewerkers is een grote opsteker voor onze afdeling. Veel dank!

Beste Piet (Claessens) en Thijs (de Graaf), een vingerknip of een roep om hulp en jullie staan paraat! Zonder jullie technische en instrumentele expertise, snelle interventie en glimlachende hulpvaardigheid, zouden veel onderzoeken op onze afdeling op een sisser aflopen. Erg bedankt!

Beste collega's van het Centraal Diagnostisch Laboratorium (Otto Bekers, Eline Cardinaels, Jan Damoiseaux, Vincent Kleijnen, Petra Heerings-Rewinkel) en van de Biobank (Berry Soute, Claudia Bosma, Corine Coorens), graag wil ik jullie bedanken voor 
de vlotte samenwerking, de laagdrempelige bereidheid om samen aan onderzoek te doen en ook voor jullie punctuele expertise.

Beste dokter Litjens, beste Elisabeth, jij bent een grote steunpilaar van onze dialyseafdeling. Jouw enorme betrokkenheid en gedrevenheid alsook stipte nauwkeurigheid werken erg geruststellend bij je collega's, het verpleegkundig personeel en de patiënten. Dank voor je grenzeloze inzet!

Beste Maarten (Christiaans), M arielle (Gelens), Elly (van Duijnhoven), Tsz Yeung (Fung), John (Dackus) en Philip (Ulrichts), collega's van de onderafdeling (transplantatie-) nefrologie, ik wil jullie graag bedanken voor de goede samenwerking en de interessante patiëntenbesprekingen. Samen zijn we sterk!

Beste collega's en medewerkers van de afdeling interne geneeskunde, met name ook professor Casper G. Schalkwijk en Jean Scheijen van experimentele geneeskunde, dank voor de goede ondersteuning, de prettige samenwerking op klinisch en research vlak, en ook voor de mooie onderzoeksresultaten.

Beste Jan (Tordoir), Noud (Peppelenbosch), M agda (van Loon) en Rick (de Graaf), mede dankzij onze wekelijkse besprekingen in een aangenaam klimaat en jullie inzet en expertise slagen we er gezamenlijk in om op onze afdeling een gedegen dialysetoegangsbeleid te verzorgen. Dank voor de vruchtbare samenwerking!

Beste verpleegkundigen en andere medewerkers van onze afdeling dialyse en nefrologie, jullie zorgen goed voor de patiënten en daar zijn zij heel blij mee. Dank voor jullie enthousiasme en jullie bereidwillige medewerking aan het onderzoek dat we bedrijven. Beste Gertie (Brepoels), verpleegkundig hoofd van de dialyse-afdeling, dank voor je harde werk en tomeloze inzet voor het functioneren van onze dialyse-afdeling!

Beste (ex-) medewerkers van het secretariaat dialyse en nefrologie, beste Anke, Etienne, Lilian, Marleen en Naomi, dank voor jullie immer vriendelijke en kordate hulpvaardigheid bij de goede gang van zaken op onze afdeling.

Beste patiënten, jullie wil ik in het bijzonder bedanken omdat jullie, ondanks alle lasten die jullie moeten dragen, er toch steeds het beste van willen maken. Ook verdienen jullie een grote pluim omdat jullie steeds bereid zijn onderzoeksvoorstellen te overwegen en indien mogelijk aan onderzoek deel te nemen. 
Beste Nierstichting en partners uit de industrie (Fresenius Medical Care en Baxter Healthcare), dank voor jullie ondersteuning van het onderzoek op onze afdeling. Dear partners from the industry, thank you for your support to our research unit. I especially would like to thank Bruce Culleton, Peter Rutherford, Véronique Chauvet and Markku Asola from Baxter International (Clinical Evidence Council of Home Hemodialysis) for their dedicated support of the chronic INTHEM O study. Beste Anna Trisia (Beby), ook jou wil ik graag bedanken voor je motivatie en deskundigheid bij de health economics analyse van intensieve en thuishemodialyse voor de Nederlandse situatie.

Beste Tiny (Wouters-Lenssen), zonder jouw jarenlange ervaring en gedreven perfectionisme zou dit boekje er niet zo uitzien. Veel dank voor je vakkundigheid en de gedane moeite!

Beste Bert en Geert, dank om mijn paranimfen te willen zijn. Jullie reageerden enigszins verbaasd op de uitnodiging voor deze typisch Nederlandse traditie, maar het doet nu en altijd deugd die noodzakelijke duw in de rug van jullie te mogen voelen. Dank voor jullie heerlijke vriendschap!

Beste vrienden, zonder namen te noemen weten we wat we aan mekaar hebben en wat we aan mekaar kunnen toevertrouwen. Dank voor jullie plagerijen en ook diepgaande gesprekken, de gezellige etentjes, de mooie concerten en fietstochten, alsook de fascinerende weekendjes en vakanties! Het doet me veel deugd ook op jullie te kunnen terugvallen. Dear friends, thanks for your energetic support and ongoing jokes. Let us keep our friendship warm.

Lieve broer, schoonzus, zussen, beste familie, dank voor jullie interesse in mijn werk en de leuke en gezellige momenten die we samen kunnen doorbrengen. Zeker en vast volgt er veel meer. Veel succes en plezier ook in al jullie ondernemingen!

Liefste ouders, dank om me steeds de vrijheid en het vertrouwen te geven om mijn plannen uit te voeren en mijn dromen waar te maken. Aan jullie eindeloos geduld, luisterend oor, wijze raad, interesse en nieuwsgierigheid, en onvoorwaardelijke steun en liefde heb ik veel te danken. Dit proefschrift draag ik dan ook aan jullie op.

Tot slot, liefste Esther en Elin, jullie liefdevolle charme zorgt voor de warme gezelligheid in ons leven. Bij jullie voel ik me thuis. Ik zie jullie graag! (op z'n "Belgisch" ())

\section{Tom Cornelis}

Maastricht, april 2015. 
Curriculum Vitae 


\section{Curriculum Vitae}

Tom Cornelis was born in Ghent, Belgium, on February 27, 1977. He completed primary (Raffelgem) and secondary (Greek-Latin at Klein College) school in Aalst, Belgium. He graduated summa cum laude as Medical Doctor in 2002 at the Katholieke Universiteit Leuven, Belgium. He trained in internal medicine in Brasschaat (Klina), Leuven (University Hospitals), Hasselt (Jessa), Belgium, and Cape Town (Tygerberg Hospital), South-Africa. Subsequently, he finalized his nephrology training in 2008 at the University Hospitals of Leuven, Belgium (professor Vanrenterghemt). In 2009, he did a clinical fellowship in adult nephrology in Toronto, Canada, with focus on home dialysis (hemodialysis and peritoneal dialysis) and pregnancy-related kidney disease under supervision of professor Joanne Bargman (final fellowship evaluation: outstanding overall competence). Since 2010, he is working as staff internist-nephrologist in the department of internal medicine, division of nephrology, of the Maastricht University Medical Centre, Maastricht, Netherlands. He is member of the Global Forum of Home Hemodialysis since 2012, and is volunteer nephrologist for the Renal Disaster Relief Task Force of the International Society of Nephrology. 


\section{LIST OF PUBLICATIONS}

Eloot S, Schneditz D, Cornelis T, Van Biesen W, Kooman J, Vanholder R. Protein-bound uremic toxin profiling as a tool to optimize hemodialysis. Submitted for publication.

Cardinaels E, Cornelis $\mathbf{T}$, van der Sande FM, Leunissen KM, van Dieijen-Visser $M$, Mingels A, Kooman JP, Bekers $\mathrm{O}$. Acute effects of conventional and extended hemodialysis and hemodiafiltration on high-sensitivity cardiac troponins. Clin Chem Lab Med, accepted for publication.

Geerse D, Meynen F, Gelens M, Kooman JP, Cornelis T. Systemic Capillary Leak Syndrome after Influenza Vaccination in a Peritoneal Dialysis Patient. Perit Dial Int, accepted for publication.

Lockridge RS, Cornelis T, van Eps C. Prescriptions for Home Hemodialysis. Hemodial Int, in press.

Cornelis T, Eloot S, Vanholder R, Glorieux G, van der Sande FM, Scheijen JL, Leunissen KM, Kooman JP, Schalkwijk CG. Protein-bound Uremic Toxins, Dicarbonyl Stress and Advanced Glycation Endproducts in Conventional and Extended Hemodialysis and Hemodiafiltration. Nephrol Dial Transplant 2015 April 9. [Epub ahead of print].

Peppelenbosch AG, van Laanen J, Cornelis T, de Graaf R, Mees B, Tordoir J. Revision techniques for failed PD catheters: outcome in a University Hospital. J Vasc Access 2015;16:93-5.

Broers $\mathrm{NJH}$, Martens RJH, Cornelis T, Diederen NMP, Wabel P, van der Sande FM, Leunissen KM, Kooman JP. Body composition in dialysis patients: a functional assessment of bioimpedance using different prediction models. J Renal Nutr 2015;25:121-8.

Cornelis T, Broers N, Titulaer D, Henskens YM, van Oerle R, van der Sande FM, Spronk $H M$, Vink H, Leunissen KM, ten Cate H, Kooman JP. Effects of Ultrapure Hemodialysis and Low Molecular Weight Heparin on the Endothelial Surface Layer. Blood Purif 2014;38:203-10.

Geerse DA, Suijkerbuijk J, van Poppelen KM, Litjens E, Cornelis T. New-onset psoriasis during peritoneal dialysis. Perit Dial Int 2014;34:802-3. 
Cornelis T, Tennankore KT, Goffin E, Rauta V, Honkanen E, Őzyilmaz A, Thanaraj V, Jayanti A, M itra S, van der Sande FM, Kooman JP, Chan CT. An International Feasibility Study of Home Hemodialysis in Older Patients. Nephrol Dial Transplant 2014;29:232733.

Cornelis T, Usvyat LA, Tordoir JH, Wang Y, Wong M, Leunissen KM, van der Sande FM, Kotanko P, Kooman JP. Vascular Access Vulnerability in Intensive Hemodialysis: a Significant Achilles' Heel? Blood Purif 2014;37:222-8.

Cornelis T, van der Sande FM, Eloot S, Cardinaels E, Bekers O, Damoiseaux J, Leunissen $\mathrm{KM}$, Kooman JP. Acute hemodynamic response and uremic toxin removal in conventional and extended hemodialysis and hemodiafiltration: a randomized crossover study. Am J Kidney Dis 2014;64:247-56.

Hladunewich M A, Hou S, Odutayo A, Cornelis T, Pierratos A, Goldstein M, Tennankore $\mathrm{K}$, Keunen J, Hui D, Chan CT. Intensive hemodialysis is associated with improved pregnancy outcomes: a Canadian and United States comparison. J Am Soc Nephrol 2014;25:1103-9.

Krueger T, Schlieper G, Schurgers L, Cornelis T, Cozzolino M , Jacobi J, Jadoul M, Ketteler M, Rump LC, Stenvinkel P, Westenfeld R, Wiecek A, Reinartz S, Hilgers R, Floege J. Vitamin $\mathrm{K} 1$ to slow vascular calcification in haemodialysis patients (VitaVasK trial): rationale and study protocol. Nephrol Dial Transplant 2014;29:1633-8.

Vanhove T, Kuypers D, Claes K, Evenepoel P, Meijers B, Naesens M, Vanrenterghem Y, Cornelis $\mathrm{T}$, Bammens $\mathrm{B}$. Reasons for dose reduction of mycophenolate mofetil during the first year after renal transplantation and its impact on graft outcome. Transpl Int 2013;26:813-21.

Cornelis T, Spaanderman M, Beerenhout C, Perschel FH, Verlohren S, Schalkwijk CG, van der Sande FM, Kooman JP, Hladunewich M. Antiangiogenic Factors and Maternal Hemodynamics during Intensive Hemodialysis in Pregnancy. Hemodial Int 2013;17: $639-43$.

Cornelis T, van der Sande FM, Kooman JP. Balancing transition to dialysis: the urgent need for more intensive hemodialysis. Kidney Int 2013;83:967-8. 
Kooman JP, Broers N, Usvyat L, Thyssen S, van der Sande FM, Cornelis T, Levin NW, Leunissen KM, Kotanko P. Out of control: accelerated aging in uremia. Nephrol Dial Transplant 2013;28:48-54.

Fung TY, Havekes B, Cornelis T. M ilk alkali syndrome sine alkalosis; an elusive cause of intermittent hypercalcemia. Int Urol Nephrol 2013;45:1791-3.

Fung TY, Peppelenbosch AG, Ferdowsbari A, van der Sande FM, Cornelis T. Unusual exit site of a migrated peritoneal dialysis catheter. Perit Dial Int 2013;33:330-1.

Cornelis T, Kotanko P, Goffin E, van der Sande FM, Kooman JP, Chan CT. Intensive hemodialysis in the (nursing) home: the bright side of geriatric ESRD care? Semin Dial 2012;25:605-10.

Cornelis T, van der Sande FM, Winnepenninckx V, Kooman JP, Peppelenbosch AG. Persistent exit site "infection" in a PD patient with CLL. Perit Dial Int 2012;32:671-2.

van der Sande FM, Cnossen TT, Cornelis T, Konings C, Kooman JP, Leunissen KM. Peritoneal dialysis in patients with heart failure. Minerva Urol Nefrol 2012;64:163-72.

Cornelis T, Beckers EA, Driessen AL, van der Sande FM, Koek GH. Bortezomib-associated fatal liver failure in a haemodialysis patient with multiple myeloma. Clin Toxicol (Phila) 2012;50:444-5.

Kooman JP, Cornelis T, van der Sande FM, Leunissen KM . Renal replacement therapy in geriatric end-stage renal disease patients: a clinical approach. Blood Purif. 2012;33: 171-6.

Cornelis T, Kotanko P, Goffin E, Kooman JP, van der Sande FM, Chan CT. Can intensive hemodialysis prevent loss of functionality in the elderly ESRD patient? Semin Dial. 2011;24:645-52.

Cornelis T, Kooman JP, van der Sande FM. Intensive home hemodialysis: the best treatment in the best system. Nephrol Dial Transplant 2011;26:3067-8.

Cornelis T, Odutayo A, Keunen J, Hladunewich M. The kidney in pregnancy and preeclampsia. Semin Nephrol 2011;31:4-14. 
Cornelis T, Oreopoulos DG. Update on potential medical treatments for encapsulating peritoneal sclerosis; human and experimental data. Int Urol Nephrol 2011;43:147-56.

Cornelis T, Bargman JM, Chu M, Oreopoulos A, Khan S, Oreopoulos DG. Discordant PD catheter and effluent culture results. Limited clinical relevance of culturing PD catheters. Perit Dial Int 2011;31:173-8.

Cornelis T, Kooman J, van der Sande F. Just-in-time initiation of optimal dialysis. Ned Tijdschr Geneeskd 2010;154:A2549.

Cornelis T, Kooistra M P, Kooman J, Leunissen KM, Chan CT, van der Sande F. Education of ESRD patients on dialysis modality selection: 'intensive hemodialysis first'. Nephrol Dial Transplant 2010;25:3129-30.

Cornelis T, Rioux JP, Bargman JM, Chan CT. Home dialysis is a successful strategy in non-renal solid organ transplant recipients with end-stage renal disease. Nephrol Dial Transplant 2010;25:3425-9.

Cornelis T, Bargman JM. Sudden increase in 'urine' output in a peritoneal dialysis patient. Perit Dial Int 2010;30:574-6.

Cornelis T, Bammens B, Lerut E, Cosyn L, Goovaerts G, Westhovens R, Vanrenterghem $Y$. AA amyloidosis due to chronic oxalate arthritis and vasculitis in a patient with secondary oxalosis after jejunoileal bypass surgery. Nephrol Dial Transplant 2008; 23:3362-4.

Cornelis T, Hiele M, Vermeire S, Libbrecht L, Verslype C. A unique combination of celiac disease, mesenteric lymph node cavitation, splenic atrophy and necrotizing hepatitis. Acta Gastroenterol Belg 2008;71:267-70.

Cornelis T, Claes K, Gillard P, Nijs E, Roskams T, Lombaerts R, Nevens F, Cassiman D. Cholestatic liver disease in infantile nephropathic cystinosis. J Gastroenterol Hepatol 2008;23:428-31.

Breynaert C, Cornelis T, Stroobants S, Bogaert J, Vanhoof J, Blockmans D. Systemic lupus erythematosus complicated with aortitis. Lupus 2008;17:72-4. 
Cornelis T, Breynaert C, Blockmans D. An abdominal pain syndrome in a lupus patient. Clin Rheumatol 2008;27:257-9.

Cornelis T, Keuleers H, De Moor B, Vanwalleghem J, Stas K. Alcohol and the kidney: deleterious and beneficial effects. Tijdschrift Voor Geneeskunde 2008;64:55-60. 
